UNIVERSIDADE DE SÃO PAULO

INSTITUTO DE QUÍMICA

DETERMINAÇÃO DE NUTRIENTES E CONTAMINANTES

INORGÂNICOS EM CAFÉ SOLÚVEL POR ESPECTROMETRIA DE

EMISSÃO ATÔMICA COM PLASMA DE ARGÔNIO INDUZIDO (ICP-AES)

ÉDER JOSÉ DOS SANTOS

Mestrado: Química Analítica

Orientadora: Profa. Dra. Elisabeth de Oliveira

SÃO PAULO

1999 


\section{"Determinação de Nutrientes e Contaminantes Inorgânicos em café Solúvel por Espectrometria de Emissão Atômica com Plasma de Argônio Induzido (ICP-AES)".}

\section{ÉDER JOSÉ DOS SANTOS}

Dissertação de Mestrado submetida ao Instituto de Química da Universidade de São Paulo como parte dos requisitos necessários à obtenção do grau de Mestre em Ciências - Área: Química Analítica.

Aprovado por:

Profa. Dra. ELISABETH DE OLIVEIRA

IQ - USP

(Orientadora e Presidente)

Profa. Dra. MARIA ENCARNACIÓN VÁZQUEZ SUÁREZ IHA IQ - USP

Prof. Dr. NIVALDO BACCAN

IQ - UNICAMP

SÃo PAULO

07 DE ABRIL DE 1999. 
Algumas pessoas vêem as coisas e perguntam por quê?

Eu sonho com coisas e digo por que não?

(Robert Bernard Shaw) 
À Dariene e a minha familia 
À minha irmã Tánia que tenho certeza sempre esteve comigo assim como os meus amigos Rita e Sérgio (in memorian) 


\section{AGRADECIMENTOS}

Agradeço a todas as pessoas que direta ou indiretamente contribuiram por pensamento ou atos, para a realização deste trabalho e em especial:

À profa. Dra. Elisabeth de Oliveira, pela orientação, paciéncia em todos os momentos dificeis e especialmente pela amizade demonstrada;

Ao Instituto de Tecnologia do Paraná (TECPAR), pelo apoio fínanceiro e valiosa oportunidade de desenvolvimento do presente trabalho;

À Maria Paula Assis Yamada, gerente do Núcleo de Qualidade em Saúde e Ambiente pelo apoio valioso;

À Quelcy Barreiros Corréa, gerente do laboratório de Tecnologia e Química Ambiental pelo apoio e principalmente pela amizade;

A todos os colegas do Núcleo de Qualidade em Saúde e Ambiente pelo incentivo e constante apoio;

Aos amigos Anice, Carmen, Lenita, Suzete e Carlos Fior pelas sugestões, ajudas e incentivos;

A Alexandre Akira Takamatsu pelo constante apoio e muito mais pela nossa amizade;

A Bill Jorge Costa pelas revisões dos trabalhos publicados e amizade sincera;

A Cesar Antonio Lenz pelo nosso idealismo, amizade e constante apoio em todas as horas;

A Natalicio Ferreira Leite, pelo treinamento de operação do espectrómetro e principalmente pela amizade demonstrada;

A Lúcio Bolognesi pelo apoio e amizade sincera;

Aos colegas da USP, pela amizade e apoio durante os estudos;

A José Soares e Karem pela grande amizade; 
Aos professores Dr.Nivaldo Baccan e Dr.Roy Edward Bruns, do Instituto de Química da UNICAMP (Campinas) e Dr. Jaim Lichtig do Instituto de Química da USP (São Paulo), pelas sugestões e constante disposição em colaborar;

Ao CNPq pela bolsa de estudo concedida. 


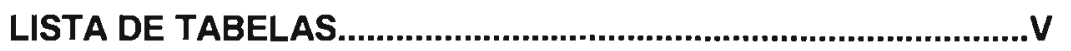

LISTA DE FIGURAS...................................................................... VIII

RESUMO.........................................................................................

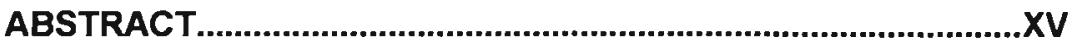

1. INTRODUÇÃO

2. OBJETIVO

2.1. Objetivo geral........................................................................................2

2.2. Objetivos especificos.........................................................................

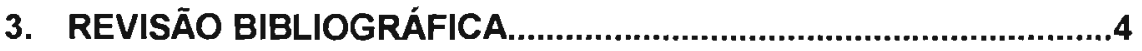

3.1. Processo de obtenção industrial do café solúvel...........................4

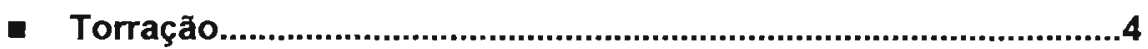

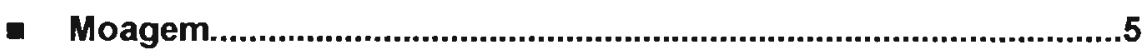

- Extração seguida de desidratação....................................................5

- Descafeinização.................................................................................

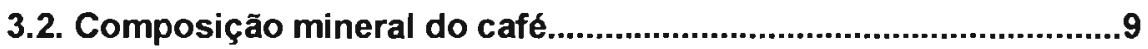

3.3. Tratamento da amostra e análise quimica de metais em café 10

3.4. Espectrometria de emissão atômica com plasma de argônio induzido. .15

3.5. Decomposição de amostras pelo uso de microondas.

3.6. A técnica de geração de hidretos acoplada a espectrometria de emissão atômica (ICP-AES).............................26

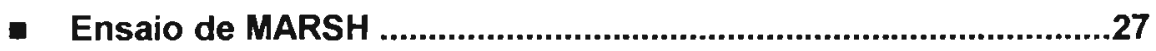

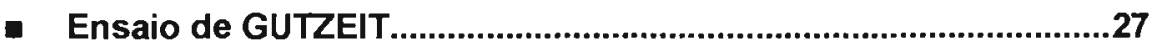


- Geração de hidretos em espectrometria de

emissão atômica. 31

- Estudo de interferências.....................................................................37

3.7. Determinação analítica do mercúrio...................................................38

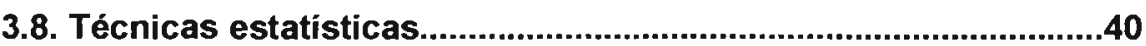

- Análise de componentes principais...............................................40

- Análise de clusters ou agrupamento hierárquico...........................43

4. PARTE EXPERIMENTAL.....................................................................45

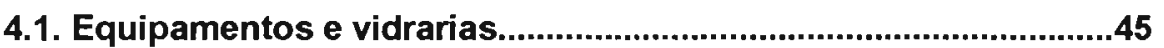

4.2. Reagentes e soluções......................................................................45

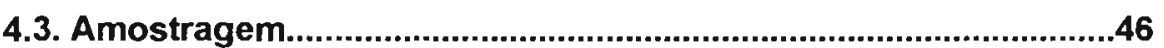

4.4. Métodos de tratamento das amostras............................................46

- Definição do procedimento de mineralização das amostras de café solúvel..........................................................46

- Método de tratamento das amostras para as determinações de $\mathrm{Pb}, \mathrm{Cr}, \mathrm{Hg}$, As e Se.

4.5. Condições instrumentais e de trabalho para as determinações dos elementos por ICP-AES.................................54

- Condições de operação dos espectrômetros.................................54

- Elaboração de programas analíticos no espectrômetro Modula da Spectro.

- Elaboração de programas analíticos no espectrômetro PSX da Baird ......................................................57

4.6. Métodos estatísticos.....................................................................57

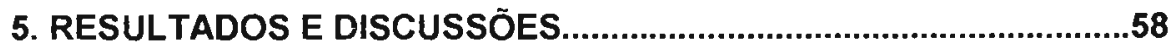

5.1. Métodos de tratamento da amostra: definição do procedimento de mineralização mais adequado . .58 
5.2. Determinação dos elementos em uma amostra de café solúvel e amostra enriquecida utilizando o procedimento de mineralização escolhido.

5.3. Otimização dos parâmetros instrumentais para as determinações do $\mathrm{Sn}, \mathrm{Pb}$ e $\mathrm{Cr}$.

5.4. Otimização dos parâmetros instrumentais para as determinações do As e Se . .74

- Otimização dos parâmetros de operação. .78

- Resultados obtidos das determinações de As e Se nas amostras de café solúvel .86

5.5. Otimização dos parâmetros instrumentais e determinação do $\mathrm{Hg}$

- Otimização dos parâmetros de operação .88

- Resultados obtidos das determinações de $\mathrm{Hg}$ nas amostras de café solúvel..

5.6. Determinações dos elementos: $\mathrm{Na}, \mathrm{K}, \mathrm{Mg}, \mathrm{Al}, \mathrm{P}, \mathrm{S}, \mathrm{Ca}$ $\mathrm{Mn}, \mathrm{Fe}, \mathrm{Cu}, \mathrm{Zn}, \mathrm{Ni}, \mathrm{Cd}, \mathrm{Sb}, \mathrm{Cr}$ e $\mathrm{Pb}$ nas 21 amostras de café solüvel disponiveis no mercado brasileiro. .94

- Elementos de concentrações maiores: macronutrientes. .102

- Elementos de concentrações menores: micronutrientes. 102

- Elementos contaminantes. .104

5.7. Análise de componentes principais e cluster hierárquicos aos dados de concentraçőes referentes aos elementos $\mathrm{Na}, \mathrm{K}, \mathrm{Mg}, \mathrm{Al}, \mathrm{P}, \mathrm{S}, \mathrm{Ca}, \mathrm{Mn}, \mathrm{Fe}, \mathrm{Sn}, \mathrm{Cu}$ e Zn........106

- Análise de Componentes Principais...............................................107

- Análise de Clusters Hierárquicos . .110 


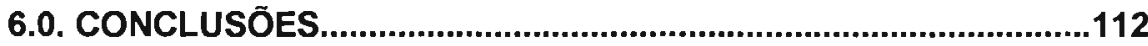

7.0. TRABALHOS FUTUROS..............................................................114

8.0. REFERÊNCIAS BIBLIOGRÁFICAS.........................................115 


\section{LISTA DE TABELAS}

I-Limites máximos de tolerância de contaminantes inorgánicos aplicados ao café...............................................................

II-Composição do grão de café verde e torrado expresso como porcentagem de base seca....................................5

III - Limites de deteç̧ão $\left(\mu \mathrm{gL}^{-1}\right)$ para elementos formadores de hidretos . .30

IV - Propriedades dos hidretos de interesse analítico........................31

V - Efeito de vários elementos na determinação de hidretos..............37

VI - Procedimentos de mineralização utilizados.................................50

VII - Condições operacionais: espectrômetros de emissão atômica com plasma de argônio induzido (ICP-AES)....................54

VIII - Programas analíticos e faixas de concentração utilizadas no preparo das soluções padrão multielementares para o estabelecimento das curvas de calibração .55

IX - Linhas de emissão e parâmetros das curvas de calibração ( $\mathrm{mgL}^{-1} X$ intensidades).

$X$ - Programas analíticos e faixas de concentração utilizadas no preparo das soluções padrão multielementares para o estabelecimento das curvas de calibração para as determinações do As, Se e Hg.

XI-Linhas de emissão e parâmetros das curvas de calibração ( $\mathrm{mgL}^{-1} \mathrm{X}$ intensidades). 
XII - Resultados obtidos na análise de amostra de café solúvel através dos diferentes procedimentos de mineralização, expressos em $\mathrm{g} / 100 \mathrm{~g}$ e $\mathrm{mg} / \mathrm{Kg}$, para os elementos dos programas A, B e C

XIII - Resultados obtidos na análise de amostra de café solúvel através dos diferentes procedimentos de mineralização, expressos em $\mathrm{mg} / \mathrm{Kg}$, para os elementos dos programas E e H (tabela VIII).

XIV - Vantagens e desvantagens dos métodos de mineralização estudados.

XV - Resultados obtidos na avaliação do procedimento de mineralização mais adequado $(n=8)$.

XVI-Valores de concentração e recuperação dos elementos adicionados e recuperados na avaliação de uma amostra de café solúvel enriquecida.

XVII - Valores de recuperação médias de $\mathrm{Sn}, \mathrm{Pb}$ e $\mathrm{Cr}$

na amostra de café solúvel utilizada no item 5.2.

XVIII - Resultados das determinações de As e Se em 21 amostras de café solúvel $(n=3)$

XIX - Valores de recuperação médias de As e Se em três amostras de café solúvel

XX - Resultados da determinação do $\mathrm{Hg}$ nas 21 amostras de café solúvel $(n=3)$

XXI-Valores de recuperação médias de $\mathrm{Hg}$ em três amostras de café solúvel .90

XXII-Concentração e desvios padrão para os 17 elementos inorgânicos determinados nas 21 amostras de café solúvel $(n=3)$. 
XXIII - Contribuição da presença de nutrientes presentes

em amostras de café solúvel do mercado

brasileiro para a Ingestão Diária Recomendada (IDR)

de adultos e crianças................................................................104

XXIV - Estatística final.........................................................................107

XXV - Matriz dos fatores ou componentes .....................................108

$\mathbf{X X V I}$ - Escores dos componentes relacionados com as

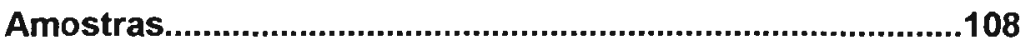




\section{LISTA DE FIGURAS}

1 - Fluxograma básico para obtenção do extrato de

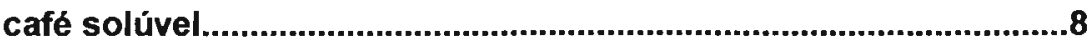

2 - Representação esquemática do processo atomização....................9

3 - Diagrama esquemático de uma tocha.............................................16

4 - Campo magnético induzido..............................................................17

5 - Formação do plasma...........................................................................17

6 - Diagrama esquemático de um sistema ICP-AES..............................19

7 - Distribuição do tempo gasto em uma análise quimica...................20

8 - Distribuição dos erros gerados em uma análise química..............20

9 - Resposta molecular a um campo eletromagnético: moléculas polarizadas alinhadas com os pólos do campo eletromagnético.............................................................22

10 - Resposta molecular a um campo eletromagnético: desordem após remoção do campo eletromagnético..................22

11 - Esquema de aquecimento da amostra por condução....................24

12 - Esquema de aquecimento da amostra por energia microonda..

13 - Sistema microondas focalizado...................................................25

14 - Diagrama esquemático do ensaio de MARSH................................27

15 - Diagrama esquemático do ensaio de GUTZEIT ...........................28

16 - Diagrama esquemático do ensaio de GUTZEIT ..........................28

17-Aparelho para determinação de As por espectrofotometria..............................................................................29

18 - Gerador de hidretos utilizado por THOMPSON et al. [54]............35

19 - Gerador de hidretos utilizado por OZAKI e OLIVEIRA [55]..........35 
20 - Separador de fases ou gerador de hidretos construído e utilizado no presente trabalho de acordo com OLIVEIRA et al.[49]. .36

21 - Representação espacial - componentes principais.....................42

22 - Classe I : microondas focalizado....................................................47

23 - Classe II: via úmida convencional.................................................48

24 - Classe III: sob pressão em bombas de teflon................................49

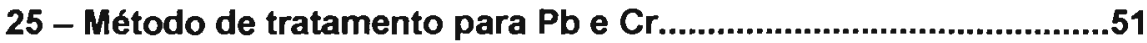

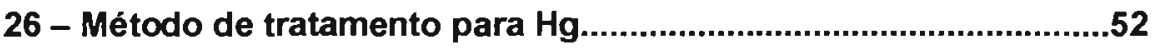

27 - Método de tratamento para As e Se..............................................53

28 - Comparação dos resultados obtidos referentes as determinações dos elementos constituintes da tabela XII, com exceção do Al (<5,0 mg/Kg): Mg, P,

S, Ca, Na e K .59

29 - Comparação dos resultados obtidos referentes as determinações dos elementos constituintes da tabela XII, com exceção do $\mathrm{Al}(<5,0 \mathrm{mg} / \mathrm{Kg})$ : Mn, Fe e Sn. .59

30 - Comparação dos resultados obtidos referentes as determinações dos elementos constituintes da tabela XIII: Cr, Ni, Zn, As, Se, Sb e Pb .60

31 - Comparação dos resultados obtidos referentes as determinações dos elementos constituintes da tabela XIII: $\mathrm{Cu}, \mathrm{Cd}$ e $\mathrm{Hg}$.

32 - Representação dos valores de \% de recuperação dos elementos adicionados. 
34 - Espectro de varredura do Sn (espectrômetro Modula

da Spectro).

35 - Espectro de varredura do $\mathrm{Pb}$ (espectrômetro Modula

da Spectro).

36 - Espectro de varredura do $\mathrm{Pb}$ em 220,35 nm (espectrômetro

Modula da Spectro).

37 - Espectro de varredura do $\mathrm{Cr}$ (espectrômetro Modula

da Spectro).

38 - Espectro de varredura do Cr em 357,869 nm (espectrómetro

Modula da Spectro).

39 - Representação dos valores de \% de recuperação

dos elementos $\mathrm{Sn}, \mathrm{Cr}$ e $\mathrm{Pb}$.

40 - Espectro de varredura do As (espectrômetro Modula

da Spectro).

41 - Espectro de varredura do Se (espectrômetro Modula

da Spectro).

42 - Espectro de varredura do As (espectrômetro PSX

da $B A I R D$ ).

43 - Espectro de varredura do Se (espectrômetro PSX

da BAIRD)

44 - Influência da acidez na sensibilidade da análise dos

hidretos de As e Se.

45 - Espectro de varredura do As: branco + amostra +

padrão $20 \mu \mathrm{gL}^{-1}$

46 - Espectro de varredura do As: amostra + amostra enriquecida com $1 \mu \mathrm{gL}^{-1}+$ padrão $20 \mu \mathrm{gL}^{-1}$

47 - Espectro de varredura do As: amostra + amostra enriquecida

com $5 \mu \mathrm{gL}^{-1}+$ padrão $20 \mu \mathrm{gL}^{-1}$ 
48 - Espectro de varredura do As: amostra + amostra enriquecida com $10 \mu \mathrm{gL}^{-1}+$ padrão $20 \mu \mathrm{gL}^{-1}$

49 - Espectro de varredura do As: amostra + amostra enriquecida com $20 \mu \mathrm{gL}^{-1}+$ padrão $20 \mu \mathrm{gL}^{-1}$

50 - Espectro de varredura do Se: branco + amostra + padrão $20 \mu \mathrm{gL}^{-1}$

51 - Espectro de varredura do Se: amostra + amostra enriquecida com $1 \mu \mathrm{gL}^{-1}+$ padrão $20 \mu \mathrm{gL}^{-1}$

52 - Espectro de varredura do Se: amostra + amostra enriquecida com $5 \mu \mathrm{gL}^{-1}+$ padrão $20 \mu \mathrm{gL}^{-1}$

53 - Espectro de varredura do Se: amostra + amostra enriquecida com $10 \mu \mathrm{gL}^{-1}+$ padrão $20 \mu \mathrm{gL}^{-1}$

54 - Espectro de varredura do Se: amostra + amostra enniquecida com $20 \mu \mathrm{gL}^{-1}+$ padrão $20 \mu \mathrm{gL}^{-1}$

55 - Valores de recuperação em \% de três amostras enriquecidas com As e Se

56 - Espectro de varredura do $\mathrm{Hg}$ (espectrômetro Modula da Spectro).

57 - Valores de recuperação em \% de três amostras enriquecidas com $\mathrm{Hg}$.

58 - Espectro de varredura do $\mathrm{Hg}$ : branco + amostra + padrão $20 \mu \mathrm{gL}^{-1}$

59 - Espectro de varredura do $\mathrm{Hg}$ : amostra + amostra enriquecida com $1 \mu \mathrm{gL}^{-1}+$ padrão $20 \mu \mathrm{gL}^{-1}$

60 - Espectro de varredura do $\mathrm{Hg}$ : amostra + amostra enriquecida com $5 \mu \mathrm{gL}^{-1}+$ padrão $20 \mu \mathrm{gL}^{-1}$

61 - Espectro de varredura do $\mathrm{Hg}$ : amostra + amostra enriquecida com $10 \mu \mathrm{gL}^{-1}+$ padrão $20 \mu \mathrm{gL}^{-1}$ 
62 - Ilustração da concentração presente do Na.................................96

63 - Ilustração da concentração presente do K...................................96

64 - llustração da concentração presente do $\mathrm{Mg}$..............................97

65 - Ilustração da concentração presente do Al................................97

66 - Ilustração da concentração presente do P..................................98

67 - Ilustração da concentração presente do S..................................98

68 - Ilustração da concentração presente do Ca................................99

69 - llustração da concentração presente do Mn................................99

70 - Ilustração da concentração presente do Fe................................100

71 - Ilustração da concentração presente do Sn................................100

72 - Ilustração da concentração presente do Cu................................101

73 - Ilustração da concentração presente do Zn...............................101

74 - Espectro de varredura do $\mathrm{Cr}$ na amostra 13

(espectrômetro Modula da Spectro).............................................106

75 - Análise de componentes principais - componente

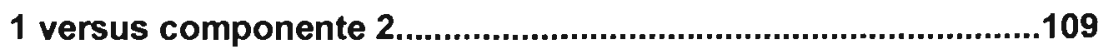

76 - Dendrograma da análise de clusters..........................................110

77 - Análise de componentes principais - componente

1 versus componente 2 com a identificação dos clusters

obtidos do dendrograma na figura 18 


\section{RESUMO}

A produção industrial do café solúvel brasileiro destina-se, na sua maior parte, ao mercado externo, constituindo-se em um importante ítem de exportação do país. O objetivo do presente trabalho foi o desenvolvimento e aprimoramento de métodos de análise quimica adequados à investigação de componentes inorgânicos em café solúvel. Inicialmente foi definido o método de mineralização das amostras através da avaliação de 6 procedimentos diferentes, classificados em 3 classes: (I) microondas focalizado; (II) via úmida convencional e (III) sistema sob pressão em frascos de decomposição com tampas (bombas de teflon). As determinações dos nutrientes e contaminantes inorgânicos: $\mathrm{Na}, \mathrm{K}, \mathrm{Mg}, \mathrm{Al}, \mathrm{P}, \mathrm{S}, \mathrm{Ca}, \mathrm{Mn}, \mathrm{Fe}, \mathrm{Ni}, \mathrm{Cu}, \mathrm{Zn}, \mathrm{Cd}, \mathrm{Sb}, \mathrm{Pb}, \mathrm{Cr}, \mathrm{Sn}, \mathrm{As}, \mathrm{Se}$ e Hg, após a utilização do procedimento de mineralização que emprega o sistema de microondas focalizado com os reagentes $\mathrm{HNO}_{3}$ e $\mathrm{H}_{2} \mathrm{O}_{2}$, foram realizadas por espectrometria de emissão atômica com plasma induzido, ICP-AES (da nomenclatura inglesa Inductively Coupled PlasmaAtomic Emission Spectrometry). Interferências de matriz e/ou espectrais foram detectadas nas determinações de $\mathrm{Pb}, \mathrm{Cr}, \mathrm{Sn}, \mathrm{As}$, Se e $\mathrm{Hg}$. No caso do $\mathrm{Sn}$, optou-se pela correção da radiação de fundo através do software do equipamento, pois outras linhas de emissão deste analito eram menos sensiveis e igualmente sujeitas a interferências espectrais. Para ० $\mathrm{Pb}$ e $\mathrm{Cr}$ a escolha de comprimentos de ondas alternativos eliminou os problemas de interferências espectrais devido à matriz das amostras. A aplicação das técnicas de geração de hidretos para o As e Se e a geração de vapor frio para o $\mathrm{Hg}$, possibilitaram as determinações destes analitos nas amostras de café solúvel, aumentando a sensibilidade das análises. Os resultados obtidos para os teores dos nutrientes e contaminantes inorgânicos em 21 amostras de café solúvel disponíveis no mercado brasileiro, foram aceitáveis para o consumo humano, tanto no aspecto nutricional como toxicológico, com exceção de uma amostra com teor de $\mathrm{Cr}$ igual a $0,52 \pm 0,02 \mathrm{mgKg}^{-1}$, acima do permitido pela legislação brasileira que fixa o valor máximo de $0,10 \mathrm{mg} \mathrm{Kg}^{-1}$. A aplicação de técnicas estatísticas, análise de clusters hierárquicos e componentes principais aos resultados obtidos, possibilitaram investigar a variabilidade das composições minerais e classificar grupos de amostras similares. O emprego da técnica instrumental ICP-AES através do sistema de nebulização convencional e a utilização do sistema de geração de hidretos e vapor frio, mostraram- 
se adequados para as determinações dos nutrientes e contaminantes inorgânicos em café solúvel, uma vez que niveis de precisão e exatidão aceitáveis foram obtidos. 


\begin{abstract}
The production of Brazilian soluble coffee is almost entirely destined for exporting. Therefore, the objective of this work was the development and the establishment of appropriate methods of chemical analysis of inorganic components in soluble coffee. Firstly, the appropriate digestion procedure for soluble coffee samples was defined through the evaluation of six different digestion techniques that were classified into three groups: (I) focused microwave system, (II) conventional wet digestion and (III) pressure digestion system in teflon bombs. The determinations of nutrients and toxic elements: $\mathrm{Na}, \mathrm{K}, \mathrm{Mg}, \mathrm{Al}, \mathrm{P}, \mathrm{S}, \mathrm{Ca}, \mathrm{Mn}, \mathrm{Fe}, \mathrm{Ni}, \mathrm{Cu}, \mathrm{Zn}, \mathrm{Cd}, \mathrm{Sb}, \mathrm{Pb}, \mathrm{Cr}, \mathrm{Sn}, \mathrm{As}$, $\mathrm{Se}$, and $\mathrm{Hg}$ after the utilization of the focused microwave system with $\mathrm{HNO}_{3}$ and $\mathrm{H}_{2} \mathrm{O}_{2}$ reagents, were made by Inductively Coupled Plasma Atomic Emission Spectrometry (ICP-AES) technique. Matrix and spectral interferences were detected in the determination of $\mathrm{Pb}, \mathrm{Cr}, \mathrm{Sn}, \mathrm{As}$, Se and $\mathrm{Hg}$ Correction of the background enhancement by the equipment software was made in the determination of $\mathrm{Sn}$, as other analytical lines were unsuitable for this application. For $\mathrm{Pb}$ and $\mathrm{Cr}$, the choice of other analytical lines eliminated the problem of matrix and spectral interferences. The application of the hydride generation technique for $\mathrm{As}$ and Se and cold atomic vapour with ICPAES for $\mathrm{Hg}$, were suitable methods to determine these analytes in soluble coffee samples with increased sensitivity of the analysis. The results obtained of nutrients and toxic elements in twentyone samples of soluble coffee collected from Brazilian market were acceptable to human consumption at nutritional and toxic level with exception of a sample with $0,52 \pm 0,02 \mathrm{mgKg}^{-1}$ of $\mathrm{Cr}$, above the value specified in Brazilian Food Legislation, that fixes the maximum $\mathrm{Cr}$ contend in 0,10 $\mathrm{mgKg}^{-1}$. The aplication of statistical techniques analysis of principal components and the hierarchical cluster on the results of mineral compositions, enabled to investigate the variability in the composition and to classify groups of similar samples. The application of the ICP-AES technique using the conventional pneumatic nebulization system, the hydride generation technique and the cold vapour for $\mathrm{Hg}$ were suitable to determine the nutrients and toxic elements in soluble coffee, as they provided acceptable results indicating accuracy and precision.
\end{abstract}




\section{INTRODUÇÃO}

O café é um dos produtos agrícolas mais importantes no comércio internacional, o Brasil continua sendo o maior produtor e exportador deste produto e nada indica que deverá perder este título, pelo menos nos próximos anos. Basicamente são produzidos dois tipos de café em nosso país: coffea arabica e coffea canephora robusta. Os principais estados produtores são: Minas Gerais, Espírito Santo, São Paulo e Paraná, além de uma pequena parcela em Rondônia e Bahia. O café no comércio mundial é o segundo produto em termos de valores, movimentando aproximadamente US $\$ 35$ bilhões por ano e perdendo apenas para 0 petróleo.

A produção do café solúvel brasileiro é na maior parte destinada ao mercado externo. Em 1995, as exportações chegaram a 62 mil toneladas, com o faturamento de US\$ 477 milhões. Visando manter a integridade deste produto no comércio internacional, tanto os países produtores como os importadores estabeleceram padrōes comerciais convenientes e legislações específicas para o consumo do produto [1]

Muitas empresas brasileiras encontram certa dificuldade em exportar o café solúvel para alguns países, que, visando manter a qualidade deste produto, exigem a garantia de níveis baixos de elementos tóxicos. Além disto, a determinação de macronutrientes, micronutrientes e elementos tóxicos é de grande interesse, particularmente devido ao grande consumo deste produto por milhões de pessoas no mundo. Neste sentido é fundamental o desenvolvimento e aprimoramento de métodos de análise química adequados à pesquisa destes contaminantes e nutrientes.

A técnica instrumental ICP-AES (espectrometria de emissão atômica com plasma de argônio induzido) é apropriada para este tipo de avaliação, por permitir a detecção dos elementos metálicos em nivel de traços e em níveis maiores de concentração, com grande segurança dos resultados e rapidez de análise [2].

Através deste estudo, espera-se contribuir para o controle de qualidade do café solúvel assegurando sua aceitabilidade no mercado internacional e nacional. 


\section{OBJETIVO}

\subsection{Objetivo geral}

Desenvolver metodologia analítica adequada para determinação dos nutrientes e contaminantes inorgânicos em café solúvel através da técnica instrumental ICP-AES, definindo-se os seguintes elementos químicos a serem pesquisados:

- $\mathrm{Na}, \mathrm{K}, \mathrm{Ca}, \mathrm{Mg}, \mathrm{P}, \mathrm{Fe}, \mathrm{S}, \mathrm{Mn}, \mathrm{Cu}, \mathrm{Zn}, \mathrm{Sb}, \mathrm{Sn}, \mathrm{Ni}, \mathrm{Pb}, \mathrm{Cd}, \mathrm{As}, \mathrm{Hg}, \mathrm{Cr}$, Se e Al; atendendo às especificações definidas pelo Ministério da Saúde [3], de acordo com a tabela I, a seguir.

Tabela l-Limites máximos de tolerância de contaminantes inorgânicos aplicados ao café.

\begin{tabular}{|ll|}
\hline Contaminante inorgânico & limite máximo de tolerância $\left(\mathrm{mgKg}^{-1}\right)$ \\
\hline Antimônio (Sb) & 2,00 \\
Arsênio (As) & 1,00 \\
Cádmio (Cd) & 1,00 \\
Chumbo (Pb) & 1,00 \\
Cobre (Cu) & 30,00 \\
Cromo (Cr) & 0,10 \\
Estanho (Sn) & 150,0 \\
Mercúrio (Hg) & 0,01 \\
Niquel (Ni) & 5,00 \\
Selênio (Se) & 0,30 \\
Zinco (Zn) & 50,00 \\
Aluminio (A) - aditivo intensional & 20000 \\
\hline
\end{tabular}

\subsection{Objetivos especificos}

- Definição do procedimento de mineralização mais adequado através da avaliação de digestão ácida em sistema convencional e microondas focalizado;

- Aplicação do procedimento de mineralização mais adequado na determinação dos nutrientes e contaminantes inorgânicos em uma amostra de café solúvel e amostra enriquecida com quantidades conhecidas dos elementos, para avaliação da precisão e exatidão do método proposto;

- Otimização das condições instrumentais para as determinações dos elementos, com a eliminação de interferências espectrais e de matriz através da utilização de técnicas alternativas acopladas ao ICP-AES, como a geração de hidretos e geração de vapor frio de $\mathrm{Hg}$. 
- Determinação dos nutrientes e contaminantes inorgânicos em amostras disponiveis no mercado brasileiro;

- Aplicação de ferramentas estatísticas (análise de componentes principais e análise de clusters hierárquicos) aos dados obtidos de concentração dos elementos para a identificação de grupos de amostras com composições minerais semelhantes. 


\section{REVISÃO BIBLIOGRÁFICA}

\subsection{Processo de obtenção industrial do café solúvel}

A planta do café pertence ao gênero coffea da família botânica rubiaceae. Embora ocorram numerosas espécies, somente duas são cultivadas no mundo, devido à sua importância econômica, são elas: coffea canephora, sendo a principal variedade coffea robusta e coffea arabica que representa $75 \%$ da produção mundial de café [4].

O café é uma planta proveniente da África e teve sua difusão a partir da Arábia. Foi introduzido no Brasil em 1727. Hoje, Brasil e Colômbia são os principais produtores de café.

O fruto de forma quase esférica, verde durante a formação, tornando-se vermelho quando maduro, é constituido na parte externa por uma espécie de polpa adocicada que envolve geralmente duas sementes ou grãos cobertos por um tegumento pergamináceo. $O$ cafeeiro, em regiões tropicais e equatoriais de clima úmido, solo fértil e bem drenado, produz no terceiro ano já uma quantidade apreciável, porém o período de melhor rendimento se inicia entre 7-8 anos e dura até 15-20 anos de idade. A colheita è realizada manualmente, quando as bagas estão maduras (sem que estejam secas) e são estendidas no solo, em camadas de 10 a $15 \mathrm{~cm}$ de espessura, expostas ao sol durante 3 a 4 semanas, sendo revolvidas continuamente por pás. O café em coco é submetido a uma separação por meio de cilindros, onde separa-se a baga do grão $[4,5]$.

O processamento industrial do café pode seguir 4 etapas

$1^{\circ}$ - Torração - processo essencial para desenvolver propriedades aromáticas do café;

$2^{\circ}$ - Moagem - estágio em que se obtém o pó de café;

$3^{\circ}$ - Extração sequida de desidratação - estágio em que se obtém o café solúvel; $4^{\circ}$ - Descafeinização.

\section{Torraçăo}

Este procedimento consiste na exposição dos gräos de café em um processo de aquecimento rápido, a temperaturas entre $180^{\circ} \mathrm{C}$ a $225^{\circ} \mathrm{C}$, ocorrendo a pirólise que se caracteriza 
por uma reação química provocada pela alta temperatura, sem a presença de oxigênio, modificando a composição química e aspecto exterior do grão de café, desenvolvendo o aroma, a cor e o sabor do produto. A principal modificação física dos grãos durante a torração é o escurecimento, que é consequência da caramelização de açúcares e da reação entre açúcares redutores e aminoácidos. Outra modificação é a perda de peso e densidade aparente [5]. As composições do grão de café verde e torrado são apresentadas na tabela II [4].

Tabela II - composição do grão de café verde e torrado expressa como porcentagem de base seca.

\begin{tabular}{|llrlr|}
\multicolumn{1}{c}{ Componente } & \multicolumn{2}{c|}{ Arabica } & \multicolumn{2}{c|}{ Robusta } \\
\hline Minerais & Verde & Torrado & Verde & Torrado \\
Cafeina & $3.0-4.2 \%$ & $3.5-4.5 \%$ & $4.0-4.5 \%$ & $4.6-5.0 \%$ \\
Trigonelline & $0.9-1.2 \%$ & aprox. $1.0 \%$ & $1.6-2.4 \%$ & aprox. $2.0 \%$ \\
Lipídios & $1.0-1.2 \%$ & $0.5-1.0 \%$ & $0.6-0.75 \%$ & $0.3-0.6 \%$ \\
Ácidos clorogênicos totais & $12.0-18.0 \%$ & $14.5-20 \%$ & $9.0-13.0 \%$ & $11.0-16 \%$ \\
Ácidos alifáticos & $5.5-8.0 \%$ & $1.2-2.3 \%$ & $7.0-10.0 \%$ & $3.9-4.6 \%$ \\
Oligossacarídeos & $1.5-2.0 \%$ & $1.0-1.5 \%$ & $1.5-2.0 \%$ & $1.0-1.5 \%$ \\
Polissacarídeos totais & $6.0-8.0 \%$ & $0-3.5 \%$ & $5.0-7.0 \%$ & $0-3.5 \%$ \\
Ácidos aminos & $50.0-55.0 \%$ & $24.0-39 \%$ & $37.0-47.0 \%$ & - \\
Proteinas & $2.0 \%$ & - & $2.0 \%$ & 0 \\
Ácidos húmicos & $11.0-13.0 \%$ & $13.0-15.0 \%$ & $11.0-13.0 \%$ & $13.0-15 \%$ \\
\hline & - & $16.0-17.0 \%$ & - & $16.0-17 \%$ \\
\hline
\end{tabular}

\section{Moagem - processo final para obtenção do pó de café}

O café torrado é armazenado em silos e protegido por um ambiente de gás carbônico. O moinho é alimentado com o material do silo por gravidade. Vários tipos de moinhos são usados, como os de disco para granulação fina, bastante empregados no Brasil e os de rolo. Aproximadamente a metade do gás carbônico produzido durante a torração é retida no interior dos grãos de café. Durante a moagem, a maior parte deste gás é liberado e protege o produto contra a ação do oxigênio, inclusive durante o armazenamento do café moído [6].

\section{Extração seguida de desidratação - processo de obtenção do café solúvel}

\section{- Extração}

A extração consiste de um fluxo contínuo e semi-contínuo de água potável, a uma temperatura entre $160^{\circ} \mathrm{C}$ e $180^{\circ} \mathrm{C}$, que passa em sentido contrário por colunas de aço inox (percoladores) onde o café moído é colocado. Os extratos dos percoladores são rapidamente 
resfriados a $5^{\circ} \mathrm{C}$, para evitar perdas por volatilização de compostos e proliferação de microorganismos. Após a sedimentação ou centrifugação, o extrato é separado do sedimento [4].

Os cafés mais pobres em compostos aromáticos, como o coffea canephora robusta, são tratados em temperaturas mais altas para se obter uma maior taxa de extração de sólidos solúveis, enquanto os coffea arabica, mais ricos em aroma, são extraídos em temperaturas inferiores, com o objetivo de conservar os compostos aromáticos. O extrato que alimenta os secadores é resultado de uma mistura (conhecida pela palavra inglesa blend) do extrato rico em sólidos solúveis com o extrato rico em compostos aromáticos. A figura1 apresenta o fluxograma básico para obtenção do extrato de café solúvel [7].

\section{- Desidratação}

São duas as principais técnicas: atomizacão (spray dryer) e liofilização (freeze dried). atomizacãóo

O extrato de café solúvel obtido é pulverizado no topo de uma coluna (recipiente de forma cilíndrica na parte superior e cônica na base - figura 2) na qual passa uma corrente de ar quente $\left(250^{\circ} \mathrm{C}\right)$ tangencialmente. Ocorre evaporação da água e o pó do extrato de café é coletado a $50^{\circ} \mathrm{C}$ na base da coluna. O café solúvel é removido da câmara de secagem por meio de válvulas rotativas, que o descarregam sobre transportadores vibracionais para evitar a desintegração de partículas. O produto proveniente do secador é pesado continuamente para permitir o bom controle da operação e da produção $[4,6,8]$.

\section{Liofilização}

Neste processo de desidratação, é necessário o congelamento atè $-50^{\circ} \mathrm{C}$ e a granulação do extrato. Os recipientes com o extrato congelado sāo transferidos para o liofilizador. Em seguida, aplica-se vácuo $(0,01$ a 0,005 psi) e se inicia o aquecimento por radiação ou condução, para compensar a energia consumida na sublimação da água $[4,9]$. Grande parte dos compostos aromáticos e a água sublimada são separados em um condensador a baixa temperatura (geralmente a $-50^{\circ} \mathrm{C}$ ). A água livre, que constitui a maior parte presente no extrato, 
é sublimada em temperatura inferior à temperatura critica de fusão. A liofilização altera menos o sabor e o aroma do café que o processo de atomização $[4,6]$.

O café solúvel é embalado com teor de umidade de $3 \%$ em atmosfera de gás inerte, geralmente nitrogênio. Isto contribui para a estabilidade do aroma e do sabor. Para o consumidor, o café solúvel é embalado em latas e potes de vidro [6]. Para aumentar a velocidade de solubilização do café solúvel, obtido pelo processo de atomização, as partículas podem ser umidecidas, aglomeradas e secas novamente. Quanto maiores as partículas de café solúvel, mais fácil será sua dissolução. O aroma do café recém moído pode ser extraído por meio de solventes. O concentrado, rico em óleo, é atomizado sobre o pó obtido pelo processo de atomização, melhorando bastante a sua aceitação $[4,9]$. 


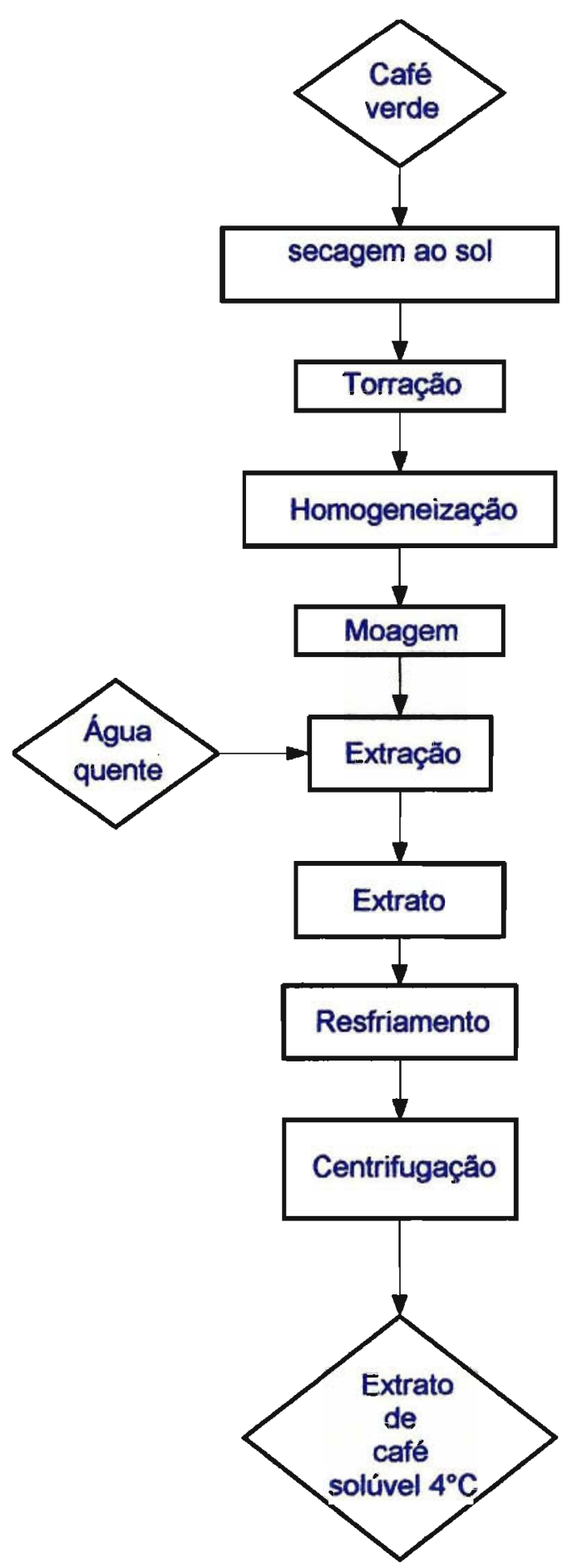

Figura 1 - Fluxograma básico para obtenção do extrato de café solúvel. 


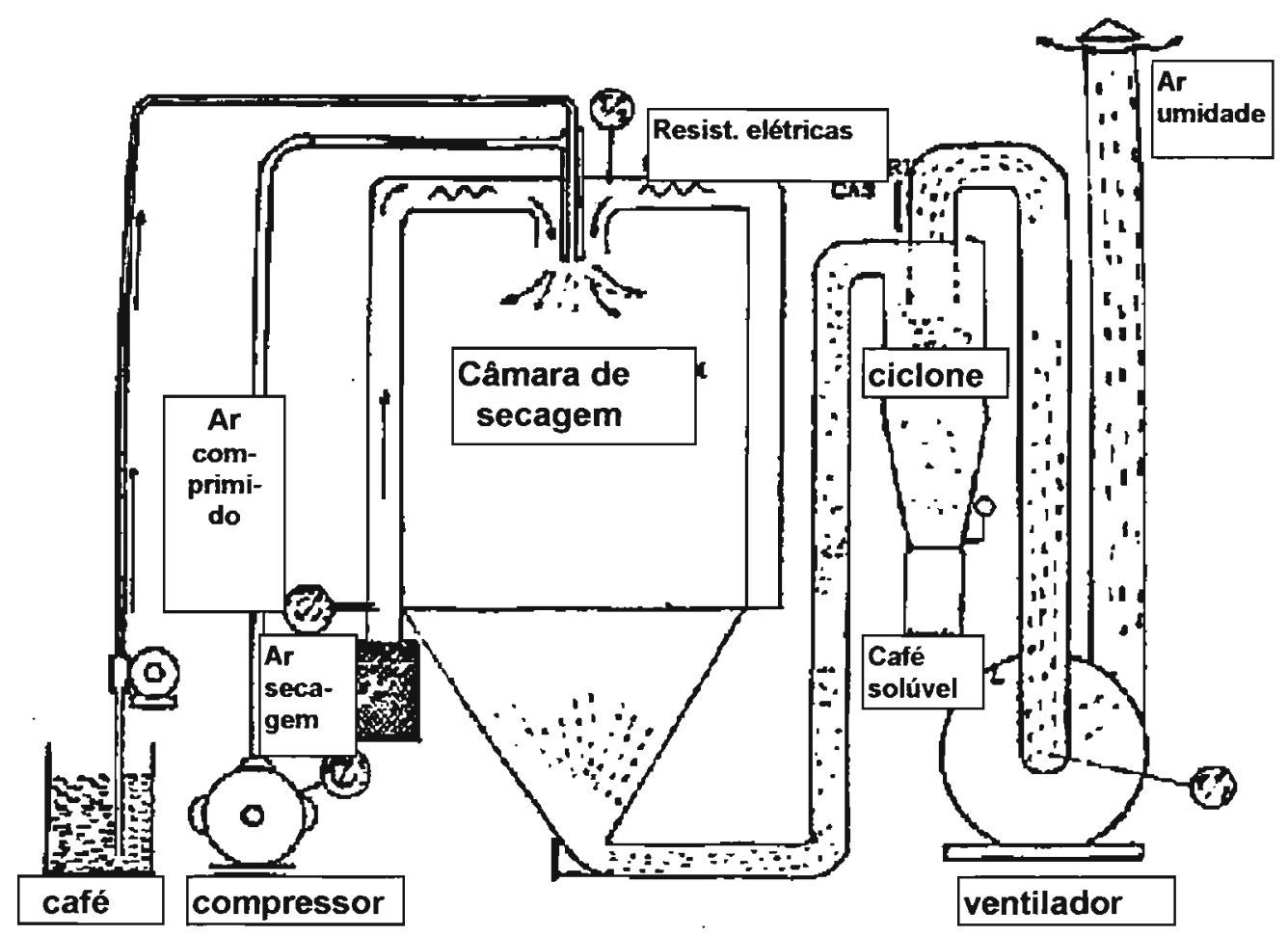

Figura 2 - Representação esquemática do processo de atomização (8).

\section{Descafeinizacão}

O processo consiste em extrair a cafeina com solventes clorados em água quente de café. A espécie coffea canephora robusta contém muito mais cafeína $(1,6$ a $2,5 \%)$ do que a espécie coffea arabica $(0,8$ a 1,5\%), embora entre os vários cultivos e variedades de coffea arabica ocorra uma grande variabilidade quanto ao teor de cafeína [4].

\section{2 - Composição mineral do café}

A composição química do café é muito complexa, segundo DEBRY [4] inclui mais de 200 substâncias. Estas variam de acordo com o tipo do café e a maneira de como este é preparado industrialmente. Nem todos os componentes do café são conhecidos, alguns dos quais têm sido identificados através da observação de efeitos fisiológicos. Da composição mineral do café, $90 \%$ são hidrossolúveis e estão presentes na bebida final [4].

A composição mineral média dos grãos de café verde, expressa em porcentagem de base seca, é a seguinte: 


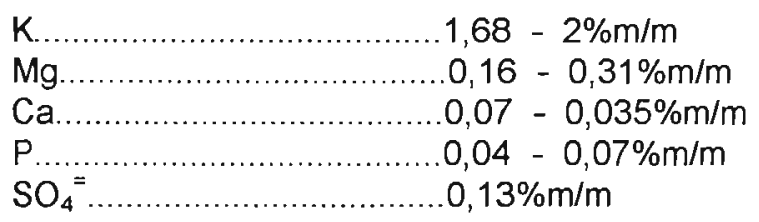

O Mn está presente em maior quantidade no coffea arabica $\left(25-60 \mathrm{mgKg}^{-1}\right)$ do que no coffea canephora robusta (10 - 33 $\left.\mathrm{mgKg}^{-1}\right) .0$ Cu está presente somente em quantidades traços no coffea arabica, porém, em maior quantidade no coffea canephora robusta $\left(1-33 \mathrm{mgKg}^{-1}\right)$. Isto explica a melhor resistência do coffea canephora robusta ao desenvolvimento de fungos comparado ao coffea arabica [4].

No café solúvel, a porcentagem de K extraído do grão verde é alta, acima de $99 \%$, mas como este nível está relacionado com o tipo de técnica usada no processamento do café, o $\mathrm{K}$ torna-se então um bom indicador da relação de extração obtida com a técnica utilizada.

A composição mineral média do café solúvel é a seguinte [4]:

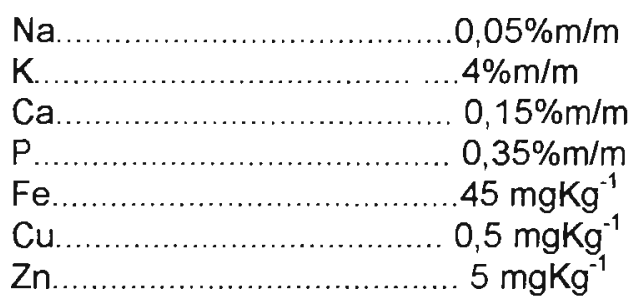

\subsection{Tratamento da amostra e determinação de metais em café}

$\mathrm{Na}$ determinação de elementos maiores, menores e em níveis de traços em alimentos, a digestão via úmida ou $\mathrm{o}$ ataque ácido oxidante são os procedimentos mais utilizados, ao contrário do sistema de digestão via cinzas ou a seco, onde o tempo necessário para destruição da matéria orgânica é muito extenso, aliado a problemas de volatilizações de elementos metálicos, como o $\mathrm{Cd}, \mathrm{Pb}$ e As, além de riscos maiores de contaminações, limitando desta maneira o uso desła técnica. Os reagentes mais utilizados na digestão via úmida são $\mathrm{HNO}_{3}$, $\mathrm{HCl}, \mathrm{H}_{2} \mathrm{SO}_{4}, \mathrm{HClO}_{4}, \mathrm{HF}$ e $\mathrm{H}_{2} \mathrm{O}_{2}$. Dependendo da composição química da amostra e do elemento de interesse, estes reagentes podem ser utilizados isolados ou combinados [10].

A AOAC (da abreviatura inglesa Association of Official Analytical Chemists) [11] tem recomendado em muitos de seus procedimentos a mistura $\mathrm{HNO}_{3}$ e $\mathrm{H}_{2} \mathrm{O}_{2}$ na determinação de 
metais traços contaminantes em alimentos como o $\mathrm{Pb}$ e $\mathrm{Cd}$. Alguns trabalhos relatam as vantagens do uso desta mistura aliado ao aquecimento por microondas, com o objetivo de destruir a matéria orgânica e solubilizar amostras de alimentos e amostras de origem biológicas $[12,13,14]$

$\mathrm{Na}$ análise de café e seus produtos, os trabalhos realizados utilizaram com mais frequência procedimentos convencionais de mineralização das amostras por via úmida e seca.

HORWITZ e VAN DER LINDEN [15] determinaram o teor de Cd e Co por espectrometria de absorção atômica (EAA) em chá e café (pó e café solúvel). Avaliaram dois métodos de mineralização das amostras: cinzas a baixa temperatura $\left(350^{\circ} \mathrm{C}\right)$ com posterior dissolução em $\mathrm{HCl} 1 \mathrm{~mol} / \mathrm{L}$ e digestão ácida direta com $\mathrm{HNO}_{3}$ e $\mathrm{H}_{2} \mathrm{SO}_{4}$. A recuperação de $\mathrm{Cd}$ em amostras contaminadas foi baixa pelo processo de cinzas, ao contrário do Co, com $100 \%$ de recuperação. A digestão ácida foi o melhor método de mineralização para o $\mathrm{Cd}$, sendo a porcentagem de recuperação na faixa de 95 a 110\% e o teor deste metal presente no café com valores entre 0,013 a 0,052 $\mathrm{mg} \mathrm{Kg}^{-1}$. Uma tentativa de extração do $\mathrm{Cd}$ com dietilditiocarbamato de sódio em MIBK (metilisobutilcetona) foi realizada, mas mostrou não ser adequada, pois muito sedimento passava para a fase orgânica causando o entupimento e/ou incrustações no capilar e nebulizador do equipamento. Os autores não descreveram o método de tratamento prévio da amostra para a posterior extração com solvente. O Co apresentou altos valores de recuperação pelo processo de digestão ácida, na faixa de 112 a $140 \%$, com o teor deste metal presente no café entre 0,68 a $2,76 \mathrm{mgKg}^{-1}$. Não foram investigadas as causas da alta porcentagem de recuperação, as quais poderiam estar relacionadas com interferências espectrais ou de matriz. O objetivo principal do trabalho era determinar os teores destes dois metais e relacionar a concentração presente com possiveis problemas toxicológicos ao organismo humano.

LARA et al. [16] determinaram o teor de Cu por EAA em 100 amostras de café torrado, moído (pó) e na bebida de diferentes partes do Brasil. Cinzas das amostras de café torrado e moido foram obtidas a $500^{\circ} \mathrm{C}$, seguindo extrações com $\mathrm{HCl} 20 \% \mathrm{v} / \mathrm{v}$. As amostras de bebida foram preparadas através de extração a quente com água desionizada do pó de café. Os 
resultados encontrados mostraram um valor médio de $17,3 \mathrm{mgKg}^{-1}$ para os pós e 1,2 $\mathrm{mgKg}^{-1}$ para a bebida.

KRIVAN et al. [17] realizaram um estudo bastante abrangente em grãos de café crú, analisando 20 elementos (metais e não metais) utilizando várias técnicas analíticas. Na análise de $\mathrm{Ca}, \mathrm{Mg}$ e $\mathrm{Zn}$ por EAA e $\mathrm{Cu}, \mathrm{Cr}, \mathrm{Fe}, \mathrm{Mn}$ e $\mathrm{Sr}$ por EAA com forno de grafite, as amostras foram mineralizadas através de digestão ácida com $\mathrm{HNO}_{3}$ e $\mathrm{HF}$ em frascos de decomposição com tampas (bombas de teflon) a uma temperatura de $160^{\circ} \mathrm{C}$ por 4 horas. Os outros metais foram determinados pela técnica de ativação de neutrôns. O objetivo do trabalho era de identificar através da análise química, o país de origem do grão de café exportado para a Europa.

ORLIC et al. [18] através da técnica de espectroscopia de fluorescência de raios $X$ (XRFS) determinaram em grãos de café cru 13 elementos metálicos. A concentração de alguns elementos de interesse como o As e Pb estiveram muito próximos do limite mínimo de detecção e como consequência os resultados obtidos relacionados com as massas da amostra sob análise deveriam ser avaliados com muito cuidado. Estes casos ressaltam a importância da utilização de técnicas de pré-concentração, através de mineralização úmida com posterior precipitação dos metais de interesse com agentes quelantes como o APDC (pirrolidinaditiocarbamato de amônio) ou através de mineralização seca a baixas temperaturas com o objetivo de melhorar os níveis de determinação dos metais pesquisados.

KAPUR e WEST [19] trabalharam na determinação de Pb em amostras de chá e café solúvel por EAA com forno de grafite. Realizaram análise da solução de extração (água desionizada a quente) das amostras de café solúvel. Mas, devido à matriz complexa, obtiveram recuperação de apenas $50 \%$ do total do $\mathrm{Pb}$ adicionado. Contornaram o problema através da dissolução das amostras em solução de citrato de amônio, o qual, além de solubilizar a matriz, mantinha o $\mathrm{Pb}$ em solução como um complexo na faixa de $\mathrm{pH}$ entre 8,7 a 9,3. Também utilizaram a técnica de extração por solvente por associação iônica do $\mathrm{Pb}$ com o KI em MIBK (metilisobutilcetona) onde obtiveram $96 \%$ de extração do metal. Um problema no uso desta técnica foi a presença de sedimento que passou para a fase orgânica, necessitando 
centrifugação antes da determinação. Não foi avaliada a possibilidade da presença de $\mathrm{Pb}$ neste sedimento e o teor encontrado esteve na faixa de $0,5-1,5 \mathrm{mg} \mathrm{Kg}^{-1}$.

$\mathrm{KOCH}$ et al. [20] através de ICP-AES e EAA com forno de grafite, determinaram o teor de Al em folhas de chá e em grãos de café, bem como em chá e café disponíveis no mercado em pequenos envelopes usados para infusão em água fervente. As amostras de grãos de café e folhas de chá $(0,25 \mathrm{~g})$ foram tratadas com $\mathrm{HNO}_{3}$ e $\mathrm{HCIO}_{4}(4: 1)$, digeridas até destruição total da matéria orgânica. Café e chá para infusão $(0,5 \mathrm{~g})$ foram imersos em $45 \mathrm{~mL}$ de água desionizada a $95^{\circ} \mathrm{C}$. O teor de AI nos grãos de café analisados por ICP-AES foi de $11 \mathrm{mgKg}^{-1}$ (originários da Colômbia, Costa Rica e Guatemala). Para grãos de origem Africana, o teor foi de $21 \mathrm{mgKg}^{-1}$. As amostras de café para infusão foram analisadas por EAA com forno de grafite e apresentaram valores entre 0,23 e $0,34 \mathrm{mgL}^{-1} \mathrm{com}$ tempo de infusão de 5 minutos. Devido às condiçōes instrumentais do equipamento utilizado, a linha de emissão do Al na análise por ICP-AES, utilizada neste trabalho, foi de $308,220 \mathrm{~nm}$, menos sensível que a $167,080 \mathrm{~nm}$, sendo necessária a utilização da técnica EAA com forno de grafite para análise dos baixos teores deste analito, presente nas soluções de extração das amostras de café e chá para infusão.

KUENNEN et al. [21] trabalharam em um método para determinação de Sb por geração de hidretos acoplado a EAA, em grãos de café crú e café processado. A necessidade desta determinação surgiu após a contaminação acidental de um carregamento de grãos de café crú com $\mathrm{Sb}_{2} \mathrm{O}_{3}$. As amostras de café processado foram tratadas com mistura dos ácidos $\mathrm{HNO}_{3}$, $\mathrm{HClO}_{4}$ e $\mathrm{H}_{2} \mathrm{SO}_{4}(4: 1: 1)$ e o café crú apenas com $\mathrm{HCl} 6$ mol/L para extração de $\mathrm{Sb}_{2} \mathrm{O}_{3}$ da superfície dos grãos. Alíquotas destas soluções foram tratadas com o reagente $\mathrm{KI}$ para reduzir o Sb V para Sb III, sendo a seguir gerado o hidreto $\mathrm{SbH}_{3}$ pela reação com $\mathrm{NaBH}_{4}$. Amostras de grãos de café crú contaminados apresentaram teores médios de $3,6 \mathrm{mgkg}^{-1}$ de $\mathrm{Sb}$, valor confirmado pela técnica ICP-AES na qual a linha de emissão utilizada foi a de 217,6 nm. Após o processo de descontaminação, os teores de Sb em amostras de café processado apresentaram valores de $0,01 \mathrm{mg} \mathrm{Kg}^{-1}$, que foram confirmados pela técnica de análise por ativaçāo de neutrôns. O método desenvolvido apresentou precisão e exatidão aceitáveis com recuperações em 
amostras enriquecidas com Sb na faixa de 85 a $120 \%$, com baixo limite de deteç̧ão $\left(2 \mu \mathrm{gL}^{-1}\right)$, sendo portanto uma técnica alternativa, quando se necessita da avaliação deste elemento em niveis menores que o estabelecido pela legislação brasileira de alimentos [3], que fixa o valor máximo tolerável de $2 \mathrm{mgKg}^{-1}$ de Sb.

SUZUKI et al. [22] determinaram $\mathrm{Pb}$ e Cu em vários alimentos, incluindo uma amostra de café solúvel, pela técnica EAA com forno de grafite. As amostras sólidas, tal como o café solúvel, foram tratadas com $\mathrm{HNO}_{3}$ em frascos de decomposição com tampas (bombas de teflon) e aquecidas a $130^{\circ} \mathrm{C}$ por $1,5 \mathrm{~h}$. A amostra de café solúvel apresentou valores de $6,6 \mathrm{mgKg}^{-1}$ de $\mathrm{Pb}$ e $2,4 \mathrm{mgKg}^{-1}$ de $\mathrm{Cu}$. Os autores utilizaram padrões certificados de fígado de bovino e folhas de pomar para validação do método proposto. Porém, no caso do café solúvel, nāo foi realizado estudo com amostra enriquecida para verificação da porcentagem de recuperação e também não foram usadas técnicas alternativas para confirmação dos valores encontrados destes elementos.

GILLIES e BIRKBECK [23] realizaram estudos sobre a presença de minerais presentes no chá e café solúvel consumidos na Nova Zelândia. Amostras de café solúvel foram dissolvidas em água potável $\left(8,5 \mathrm{gL}^{-1}\right)$ e conservadas em frascos de polietileno com $\mathrm{HNO}_{3} \mathrm{com}$ concentração final de $1 \%(\mathrm{v} / \mathrm{v})$, sendo determinados os teores dos metais diretamente nestas soluções por EAA. Os resultados obtidos nestas amostras foram os seguintes: Cu 18,8 - 56,5 $\mathrm{mgKg}^{-1}$; Zn 12,9-14,0 $\mathrm{mgKg}^{-1} ; \mathrm{Na} 0,10-0,15 \mathrm{~g}^{100 g^{-1}} ; \mathrm{Fe} 28,2-35,3 \mathrm{mgKg}^{-1} ; \mathrm{Mn} 16,5-17,6$

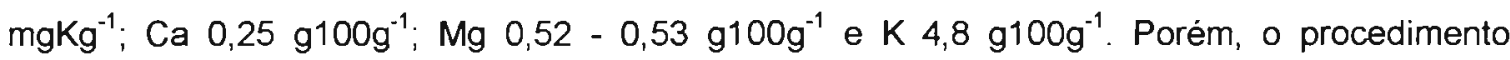
adotado para o tratamento das amostras não foi avaliado em termos de presença ou não de interferências espectrais e/ou de matriz, nem se realizou estudo de amostras enriquecidas com quantidades conhecidas dos elementos sob pesquisa. 


\subsection{Espectrometria de emissão atómica com plasma de argónio induzido}

A espectrometria de emissão atômica com plasma de argônio induzido, ICP-AES (da nomenclatura inglesa Inductively Coupled Plasma Atomic Emission Spectrometry), é uma técnica analítica que pode ser utilizada para determinação de elementos maiores, menores e em níveis de traços baseada nos espectros de emissão dos elementos. Resultados analíticos favoráveis são obtidos na prática para aproximadamente 70 elementos, com limites de detecção geralmente alcançando niveis de ppb (partes por bilhão) sendo a maioria das amostras introduzidas na forma líquida como soluções aquosas [24].

Os primeiros resultados analíticos, utilizando ICP como fonte de excitação, foram publicados por GREENFIELD et al. [25] em 1964 utilizando um plasma que operava a alta frequência (36 MHz). Também FASSEL e WENDT [26] em 1965 descreveram um sistema de plasma operando a baixa frequência $(3,4 \mathrm{MHz})$. Ambos os grupos de pesquisa concluiram que a nova ferramenta analítica apresentava alta sensibilidade, relativamente livre de efeitos interferentes quando comparada com outras técnicas espectroscópicas [24].

O sucesso da técnica é devido principalmente à capacidade da realização de uma análise multielementar e à determinação com uma faixa ampla de concentração dos elementos em uma mesma amostra. A alta temperatura e a atmosfera inerte do gás argônio do plasma também diminuem as interferências químicas de matriz, resultando em boa sensibilidade, alta precisão e exatidão com baixos limites de detecção, requisitos fundamentais para aplicação na análise de alimentos [27].

Um plasma é uma nuvem de gás fortemente ionizado, composto por elétrons, íons e partículas neutras, sendo que mais de $1 \%$ do total de átomos do gás estão ionizados. O plasma com acoplamento indutivo forma-se numa tocha de quartzo (figura 3), constituída por três tubos concêntricos com entradas de gás independentes. O fluxo de argônio que flui tangencialmente entre o tubo exterior e o intermediário (12-18 $\left.\mathrm{Lmin}^{-1}\right)$ é o gás refrigerante ou plasma gás que atua para formar o plasma e previnir o aquecimento. O tubo intermediário carrega o fluxo de gás argônio auxiliar a cerca de $1,0 \mathrm{Lmin}^{-1}$, este fluxo é semeado com íons e elétrons por meio de 
uma bobina tesla. O tubo central é o que conduz a amostra em forma de aerosol para dentro do plasma $\left(0,7-1,5 \mathrm{Lmin}^{-1}\right)$, denominado gás de arraste.

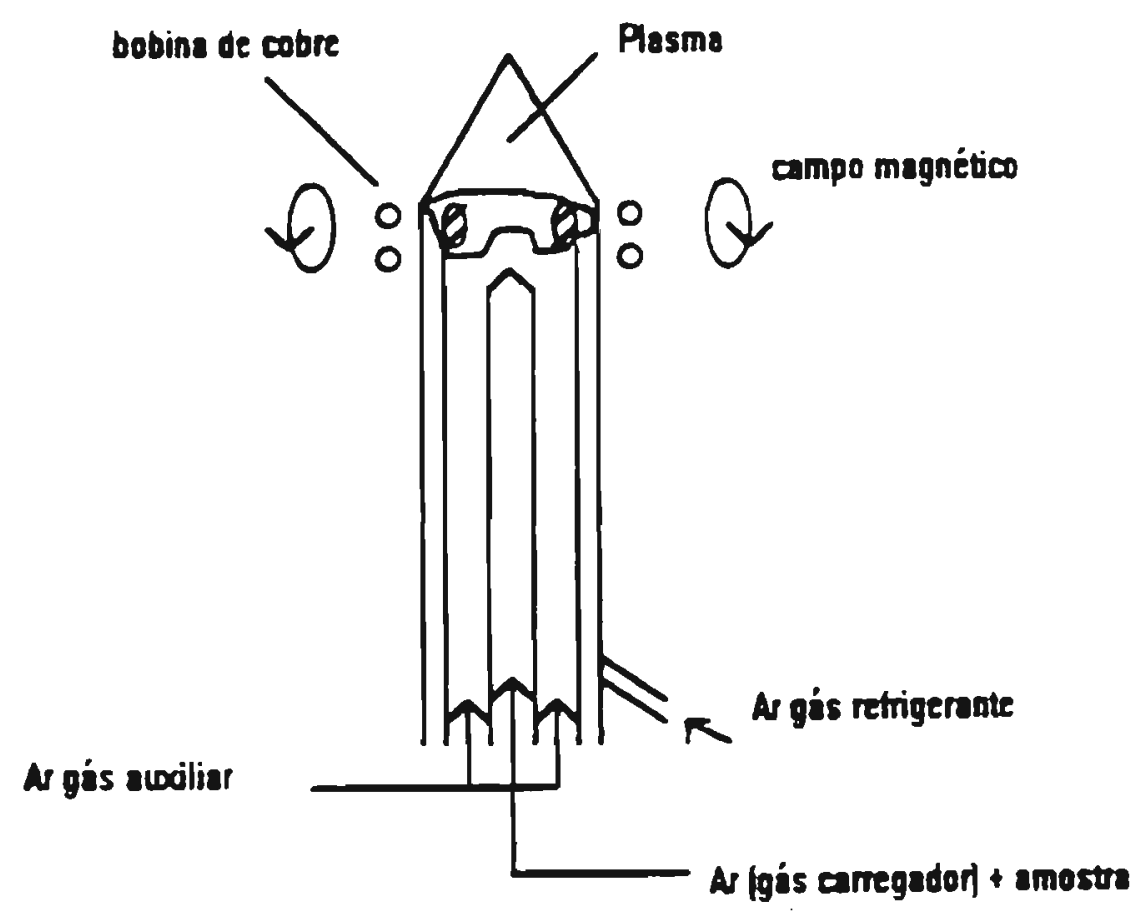

Figura 3 - diagrama esquemático de uma tocha [27]. 
A energia para formação e manutenção do plasma é proporcionada pela fonte externa geradora de radiofrequência, a qual induz um campo magnético oscilante com linhas de força (H) orientadas axialmente à tocha (figura 4). Os primeiros elétrons são fornecidos pela bobina tesla e a ação do campo magnético permite a aceleração dos elétrons em trajetórias perpendiculares ao campo, descrevendo uma helicóide. O campo magnético é oscilante por ser induzido por uma corrente alternada RF (fonte de radiofrequência), isto leva à aceleração dos elétrons e ions em contrafluxo em ambos os sentidos, facilitando a transferência de energia cinética para os átomos, produzindo ionizações e maior número de elétrons, entrando em um processo de cascata, até atingir o equilibrio dinâmico (figura 5) $[27,28,29,30]$.

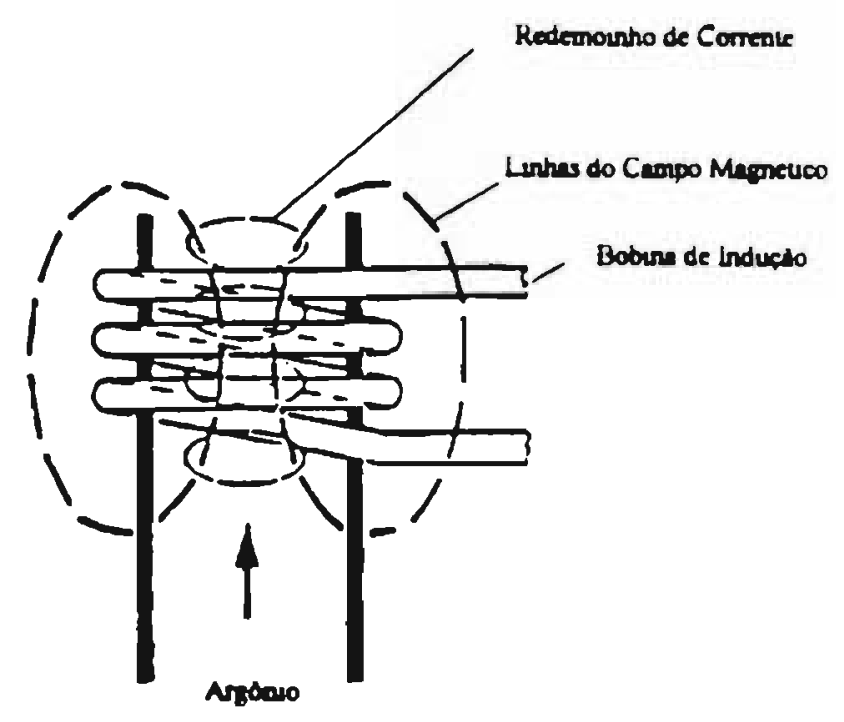

Figura 4 - Campo magnético induzido $\mathrm{H}$ [27]

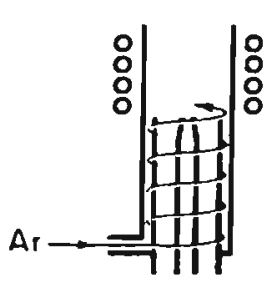

A

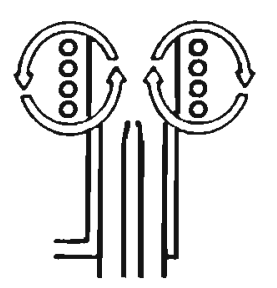

B

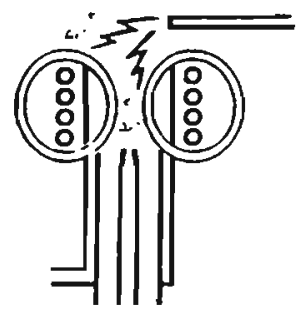

c

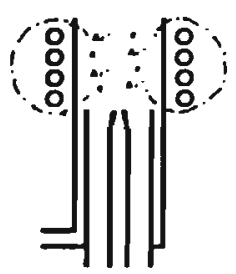

D

Figura 5 - Formação do plasma : a - gás Argônio entrando tangencialmente na tocha; b - força RF é aplicada na bobina; c - uma faísca produz alguns elétrons livres no Ar; $\mathbf{d}$ - os elétrons são acelerados pelo campo magnético causando ionizações e formando o plasma [29]. 
A amostra, geralmente uma solução líquida, é introduzida no plasma em forma de aerosol por meio de um sistema nebulizador. A primeira função da alta temperatura do plasma é a remoção do solvente através da evaporação, deixando partículas microscópicas sólidas (sais dos elementos constituintes da amostra). A etapa seguinte envolve a volatilização-dissociação, com a produção de vapores atômicos - vapores iônicos, os quais são excitados na forma de átomos-ions. O mecanismo de excitação é do tipo colisacional, no qual a energia cinética das partículas que colidem (íons-átomos da amostra com elétrons-ions do argônio) se transforma em todo ou em parte em energia de excitação e haverá passagem de elétrons dos íons-átomos da amostra, do nivel fundamental ou de menor energia, para um nivel de maior energia, ficando assim as partículas excitadas. A tendência dos elétrons excitados é de retornarem ao estado fundamental e ao fazerem-no, devolvem a energia na forma de emissão de radiação eletromagnética, onde os comprimentos de onda são característicos de cada elemento e a intensidade da linha do espectro de emissão é proporcional à concentração do elemento sob análise. O espectro de emissão contém todas as raias emitidas pela amostra. As raias passam através de uma fenda e incidem em um sistema ótico com monocromadores, que isola as raias de emissão de interesse, sendo estas enviadas para o foto-multiplicador do sistema detector, representado na figura 6 a seguir $[29,30]$. 


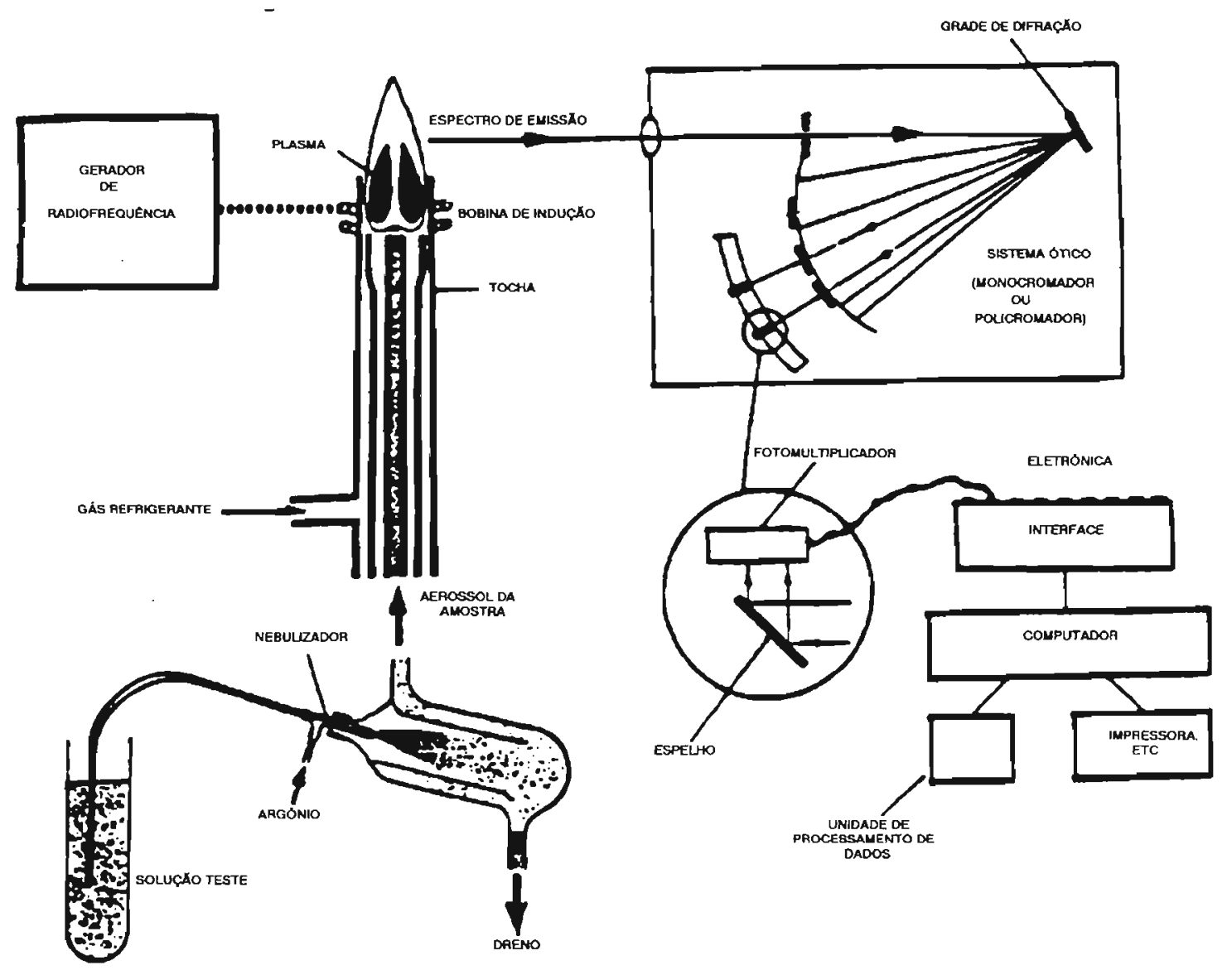

Figura 6 - Diagrama esquemático de um sistema ICP-AES [30].

\subsection{Decomposição de amostras pelo uso de microondas}

Uma das etapas mais importantes na determinação de elementos maiores, menores e em níveis de traços em alimentos é a solubilização da amostra. Procedimentos convencionais de abertura por via úmida e cinzas envolvem o aquecimento da amostra em chapa elétrica, banho-maria, banho de areia ou mufla, na presença de ácidos por longos períodos de tempo, necessitando um trabalho de laboratório intenso e cuidadoso (figura 7). A etapa de solubilização da amostra, entre todas as operações analíticas, é a mais crítica, onde se consome maior tempo e normalmente se cometem erros e, portanto é a etapa de maior custo (figura 8). A solubilização pelo uso de microondas é uma alternativa que torna este processo mais rápido, efetuando solubilizaçōes mais confiáveis e exatas que as efetuadas pelos métodos convencionais, com maior eficiência e menor tempo $[31,32]$. 


\section{Distribuição do tempo gasto em uma análise química}

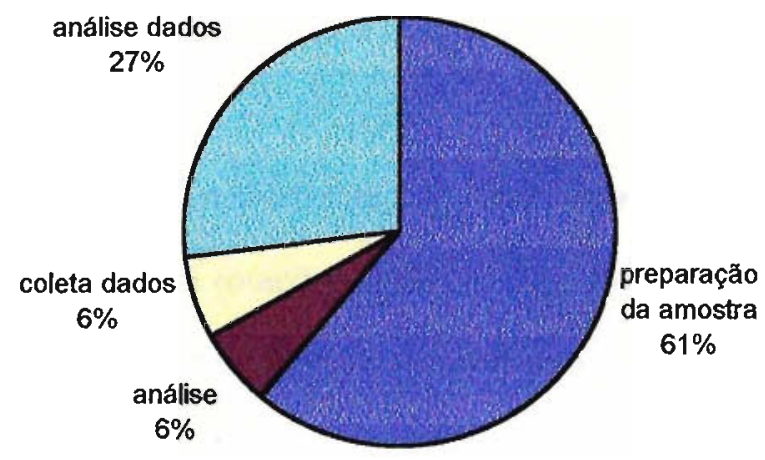

Figura 7 : distribuição do tempo gasto em uma análise química [31].

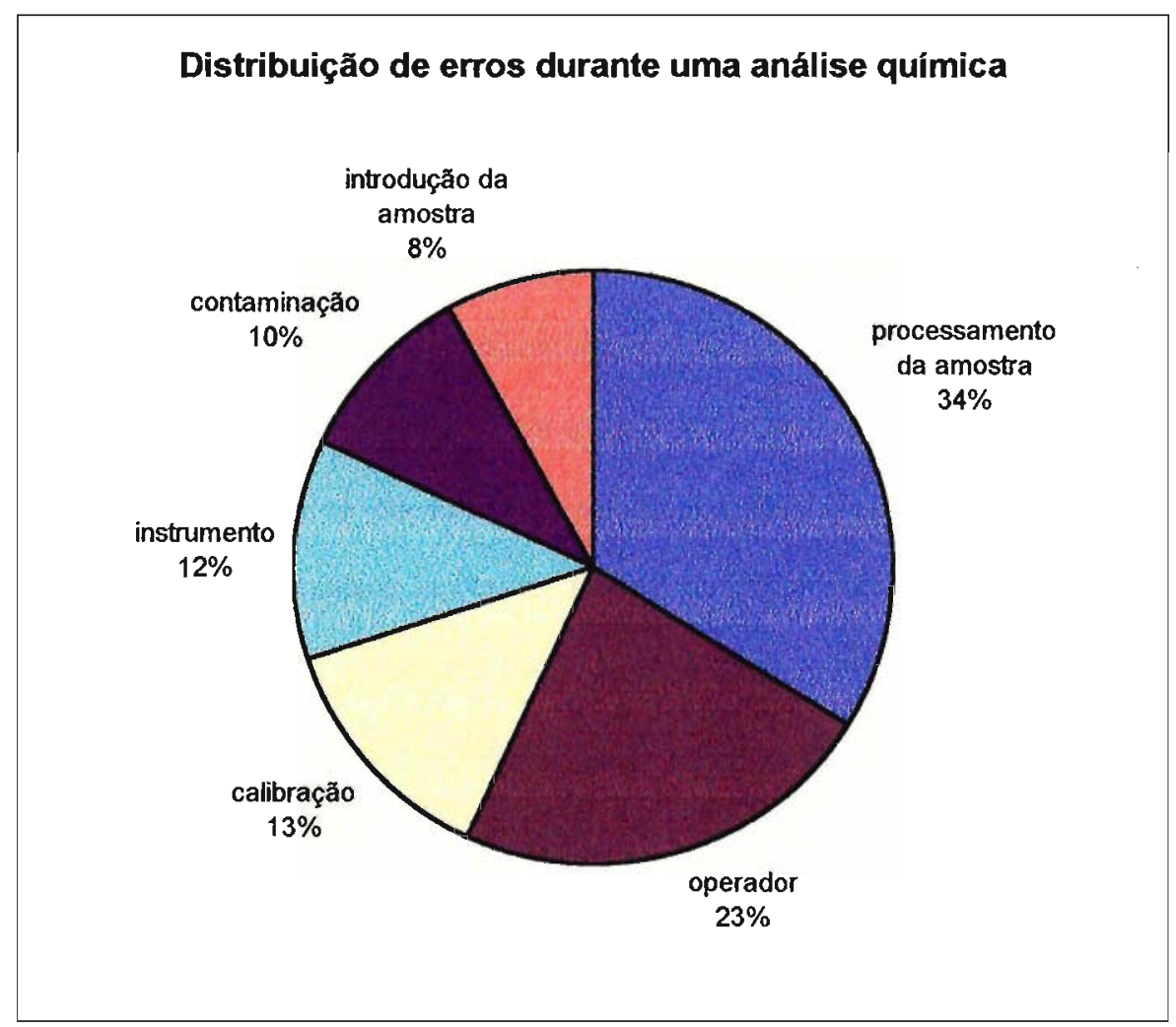

Figura 8: distribuição dos erros gerados em uma análise química[31]. 
Microondas é uma forma de energia eletromagnética não ionizante, que causa movimentos moleculares através da migração dos íons elou rotação de dipolos sem, contudo, causar mudanças nas estruturas moleculares. A energia de microondas está situada dentro do espectro eletromagnético entre as frequências de 300 a $300.000 \mathrm{MHz}$, sendo que a mais utilizada em instrumentos de laboratório é a frequência de $2450 \mathrm{MHz}$ com comprimento de onda ( $\lambda$ ) próximo a $12,2 \mathrm{~cm}[31,33]$

Tipicamente, energia de microondas é transformada em energia térmica através de dois mecanismos: condução iônica e rotação de dipolo. Em muitas aplicações práticas, estes dois fenômenos ocorrem simultaneamente. Na condução iônica, soluções líquidas contendo ácidos minerais ou sais, contêm íons (cátions e ânions) que são condutores de corrente elétrica. $\mathrm{Na}$ presença de um campo elétrico de energia de microondas, estes íons migrarão se alinhando ao campo elétrico. Este campo elétrico muda de polaridade em um número elevado de vezes a cada segundo, forçando os íons a mudarem de direção também muitas vezes por segundo. Durante a migração, ocorrerão colisões entre estes íons solvatados com moléculas vizinhas, aumentando a energia cinética e consequentemente a temperatura da solução $[31,34]$.

No caso da rotação de dipolo ocorre quando moléculas que possuem dipólos elétricos permanentes (solventes polares) como a água, na presença de um campo elétrico de energia de microondas, irão se alinhar ou rotacionar em resposta a este campo. Esta rotação causará colisões com moléculas vizinhas (figuras 9 e 10), provocando um aumento da energia cinética e consequentemente aumento da temperatura da solução. A oscilação do campo elétrico da energia de microondas causará, portanto, muitas colisões provocando um rápido aumento da temperatura. A rotação da molécula com dipólo permanente é dependente da viscosidade. Como o liquido aquece, sua viscosidade diminui, aumentando desta maneira a absorção de energia de microondas $[31,34]$. 


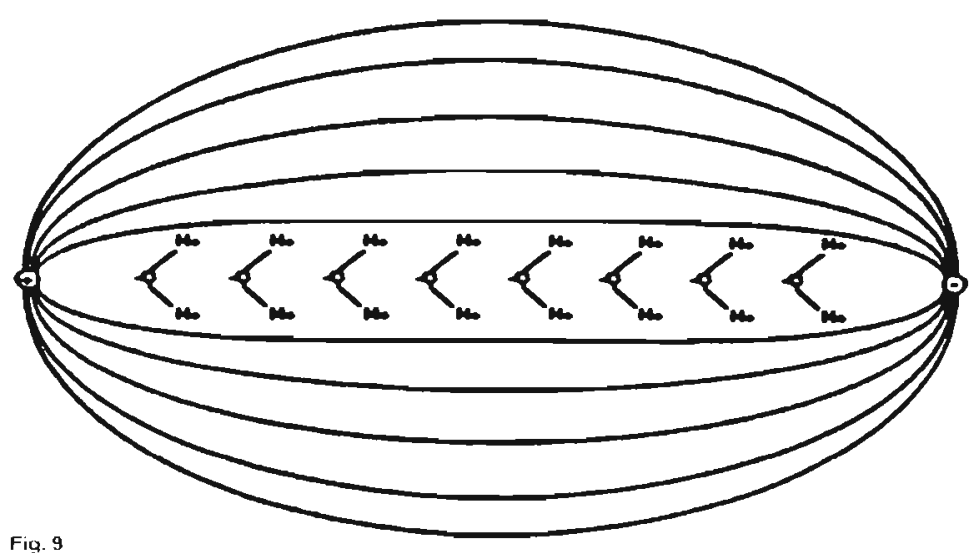

Fiq. 9

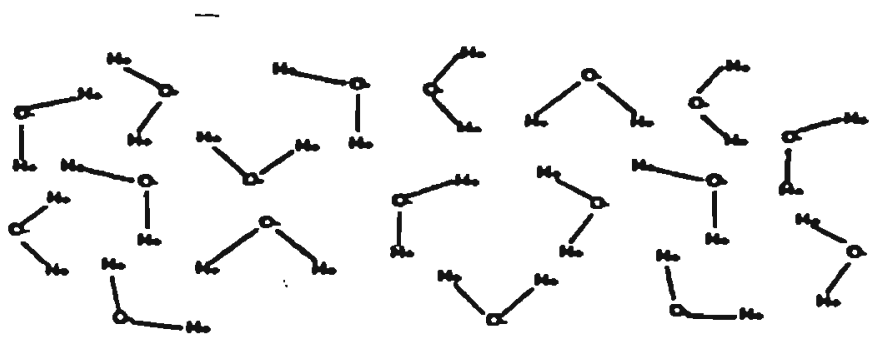

Fig. 10

Figuras 9 e 10 - Resposta molecular a um campo eletromagnético: 9 - moléculas polarizadas alinhadas com os pólos do campo eletromagnético; 10 - desordem após remoção do campo eletromagnético [31].

Em grande extensão, é a temperatura que determina a contribuição de cada um dos dois mecanismos de conversão de energia. Para pequenas moléculas, como água e outros solventes presentes em uma amostra, a perda dielétrica devida à contribuição da rotação de dipolo diminui com o aumento da temperatura. Ao contrário, a perda dielétrica devida à condução iônica é elevada com o aumento da temperatura. Desta maneira, se uma amostra iônica é aquecida por energia de microondas, a perda dielétrica da amostra é inicialmente dominada pela contribuição 
da rotação de dipólo. Quanto mais a temperatura aumenta, a perda dielétrica é dominada pela condução iônica. A contribuição porcentual destes dois mecanismos de aquecimento depende em grande parte da mobilidade e concentração dos íons na amostra [31,34].

No sistema convencional, o tempo normalmente necessário para se completar uma digestão via úmida é de 1 a $2 \mathrm{~h}$. Em alguns casos, um tempo muito maior é consumido. Os frascos de reação usados geralmente não são bons condutores de calor, exigindo tempo considerável para seu aquecimento e transferência do calor para a solução. Devido à vaporização que ocorre na superfície dos líquidos, um gradiente térmico é estabelecido através de uma corrente de convecção e somente uma pequena porção do fluído está à temperatura de aquecimento aplicada ao frasco de reação (figura 11). Desta maneira, resulta um aquecimento não uniforme e portanto uma digestão da amostra com baixa eficiência, requerendo tempo relativamente elevado para completá-la.

Por outro lado, o aquecimento por microondas aquece toda a solução, simultaneamente, alcançando o ponto de ebulição mais rapidamente e em recipientes abertos podem ser completados de 5 a 15 minutos. Devido a velocidade de aquecimento ser muito alta, um superaquecimento localizado pode ocorrer (figura 12). 


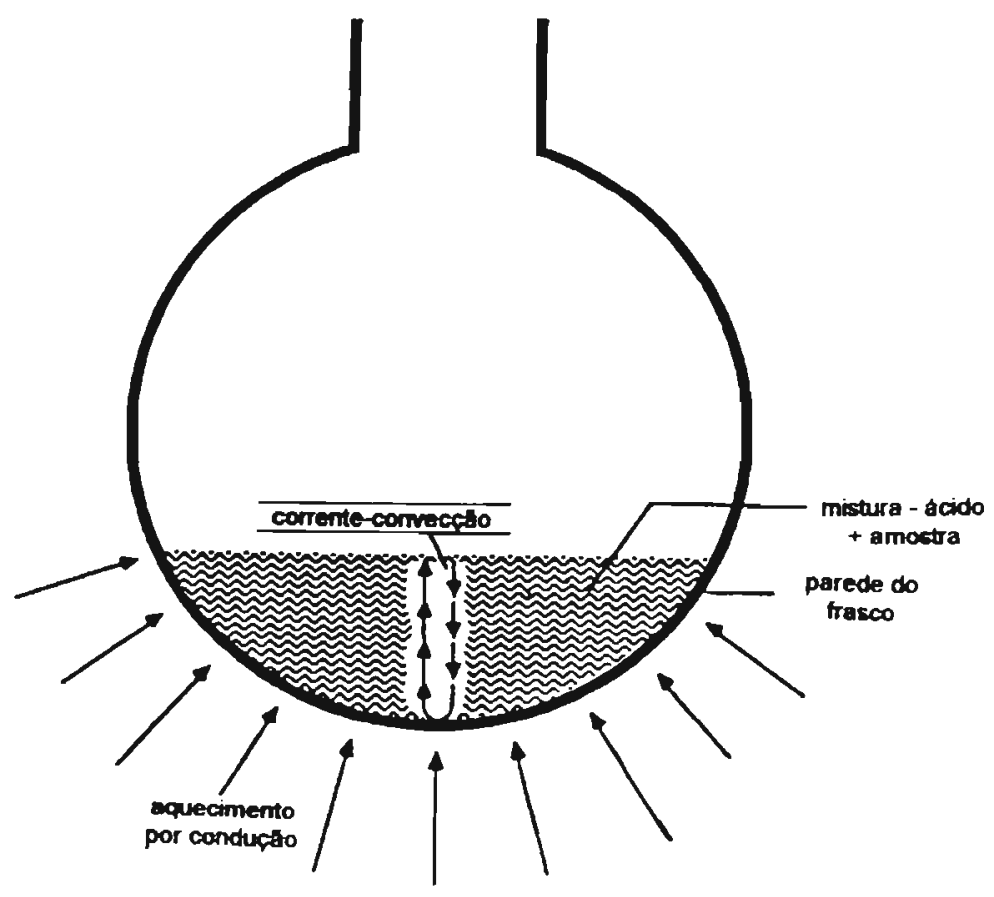

Figura 11 - esquema de aquecimento da amostra por condução [31].

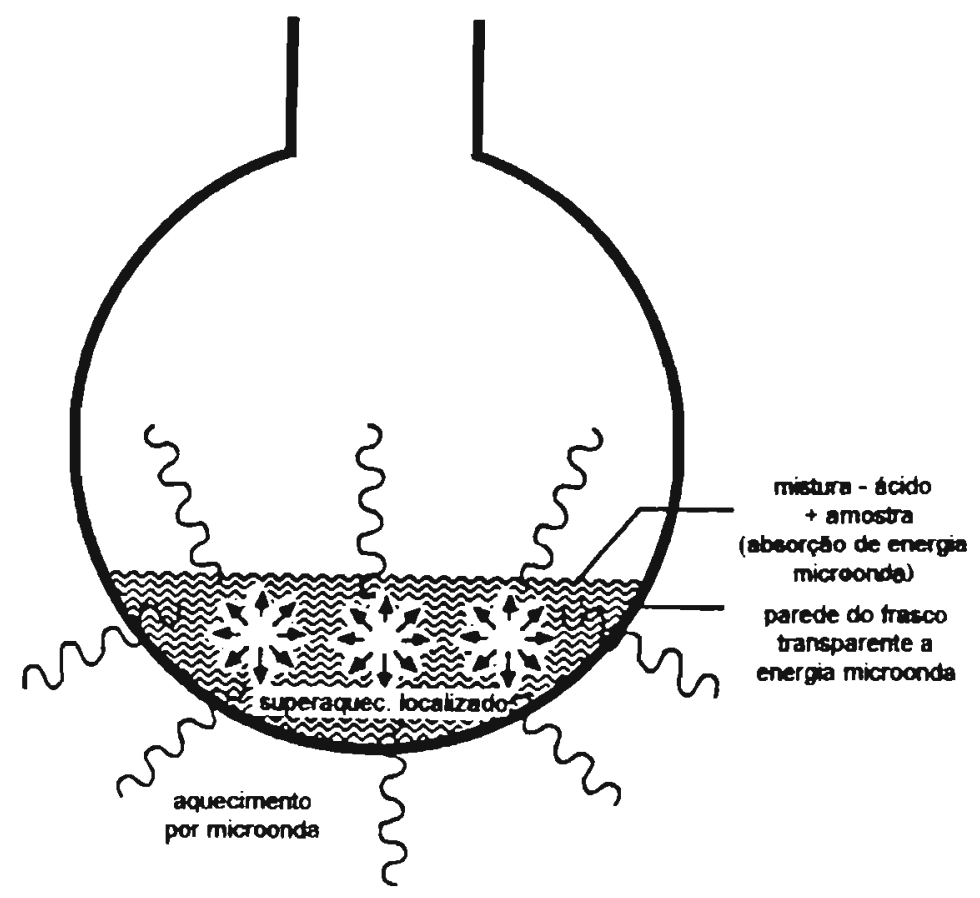

Figura 12 - Esquema de aquecimento por energia microonda [31]. 
Neste trabalho, foi utilizado o forno microondas com sistema focalizado, operando à pressão atmosférica. A figura 13 apresenta as partes constituintes deste sistema. As vantagens da mineralização por microondas incluem:

- velocidades de reação mais altas;

- decréscimo de contaminação pelo ambiente do laboratório;

- uso de menor quantidade de reagentes;

- solubilização mais controlada e portanto mais maleável para automação.

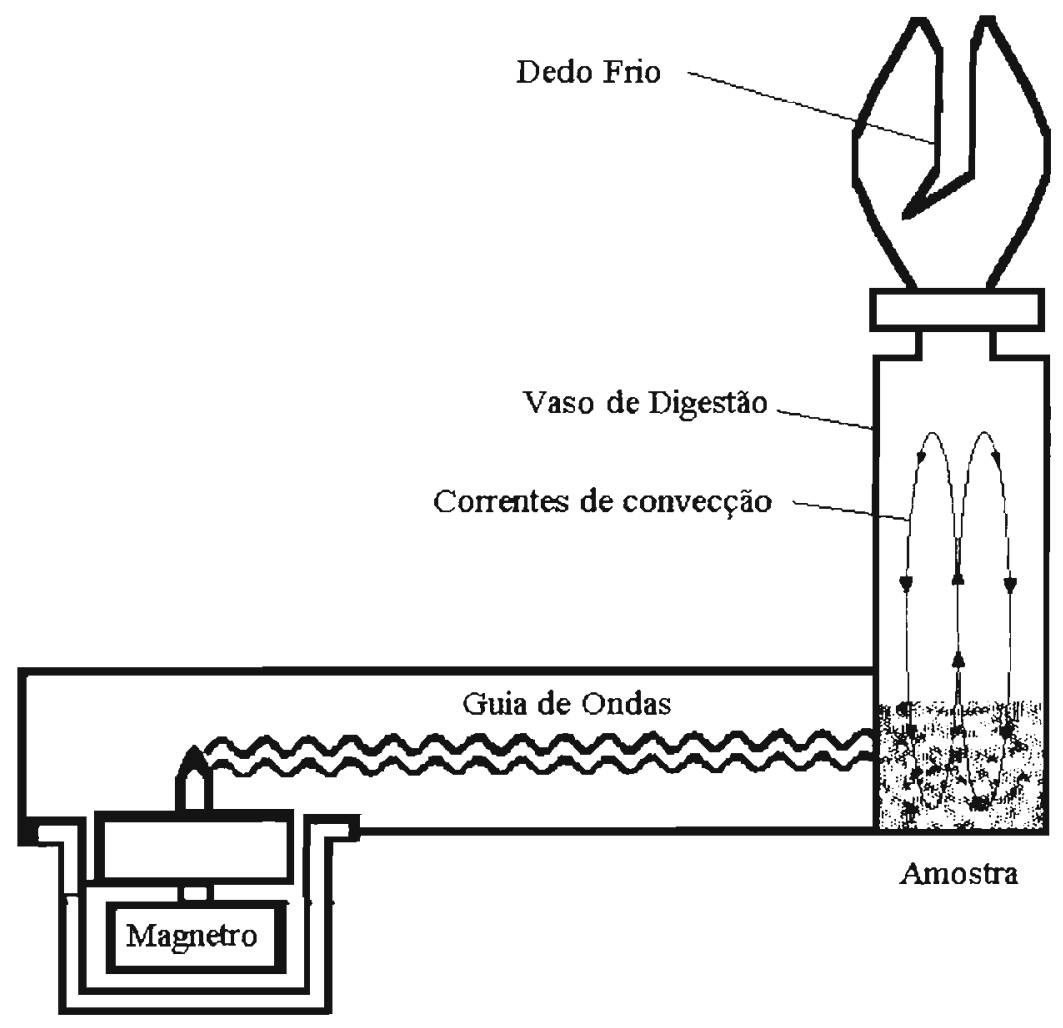

Figura 13 - Sistema microondas focalizado [31]. 


\subsection{A técnica de geração de hidretos acoplada a espectrometria de emissão atômica (ICP-AES)}

A técnica de geração de hidretos é uma poderosa ferramenta que pode ser utilizada como método de separação em química analítica. Em conjunto com a espectrometria de absorção atômica ou com a espectrometria de emissão atômica por plasma, permite a préconcentração dos analitos formadores de hidretos voláteis, como o As e Se, eliminando problemas de matriz presentes em amostras complexas e melhorando sensivelmente os limites de detecção encontrados na análise direta das soluções pelo sistema convencional.

O conceito mais usado, segundo HUSSEL [33], define hidretos como os compostos nos quais o hidrogênio está ligado a um elemento mais eletropositivo. O átomo de hidrogênio pode receber um elétron para preencher o orbital $1 \mathrm{~s}$, resultando no ion hidreto $\mathrm{H}^{-}$. Isto ocorre com elementos altamente positivos, como os metais alcalinos e alcalino terrosos. Esses hidretos podem ser preparados pela combinação direta dos elementos a temperaturas elevadas. A reação, (1) , para obtenção de hidreto de sódio, segundo HUSSEL [33], é a seguinte:

$$
\mathrm{Na}(\mathrm{I})+2 \mathrm{H}^{\circ}=\mathrm{NaH}_{2}\left(400^{\circ} \mathrm{C}\right) \text { (1) }
$$

Hidretos iônicos possuem características salinas típicas. São sólidos cristalinos, brancos, com retículos compostos de íons metálicos e íons hidretos. Contudo, o hidrogênio também pode adquirir o estado -1 , compartilhando um elétron com um átomo mais eletropositivo, o que ocorre em hidretos covalentes, tais como $\mathrm{AsH}_{3}$ e $\mathrm{SbH}_{3}$. Diferente dos hidretos iônicos, são substâncias voláteis, porque as atrações intermoleculares são forças fracas de London ou forças de dispersão (momento dipolar momentâneo em um átomo ou molécula) [33], sendo esta propriedade de grande interesse para a quimica analítica.

A geração de hidretos tem sido utilizada há mais de 100 anos em ambos procedimentos de teste qualitativo e quantitativo, conhecidos como ensaio de MARSH e ensaio de GUTZEIT [35]. 


\section{Ensaio de MARSH}

Os compostos de As são reduzidos por meio de hidrogênio nascente em solução ácida, produzindo a arsina $\left(\mathrm{AsH}_{3}\right)$. O gás misturado com hidrogênio é conduzido por um tubo de vidro aquecido e se decompõe em hidrogênio e arsênio metálico, que se deposita, formando um espelho preto pardacento, logo acima da parte aquecida do tubo (figura 14). As seguintes equações químicas, $(2,3,4)$, representam o processo:

$$
\begin{aligned}
& \mathrm{As}^{3+}+3 \mathrm{Zn}^{\circ}+3 \mathrm{H}^{+}=\mathrm{AsH}_{3}(\mathrm{~g})+3 \mathrm{Zn}^{2+} \\
& \mathrm{AsO}_{4}{ }^{3-}+4 \mathrm{Zn}^{\circ}+11 \mathrm{H}^{+}=\mathrm{AsH}_{3}(\mathrm{~g})+4 \mathrm{Zn}^{2+}+4 \mathrm{H}_{2} \mathrm{O} \\
& 4 \mathrm{AsH}_{3}(\mathrm{~g})+\text { calor }=4 \mathrm{As}^{\circ}+6 \mathrm{H}_{2}(\mathrm{~g})
\end{aligned}
$$

Pela comparação com espelhos padrões, pode-se estimar a concentração de As presente na amostra [36].

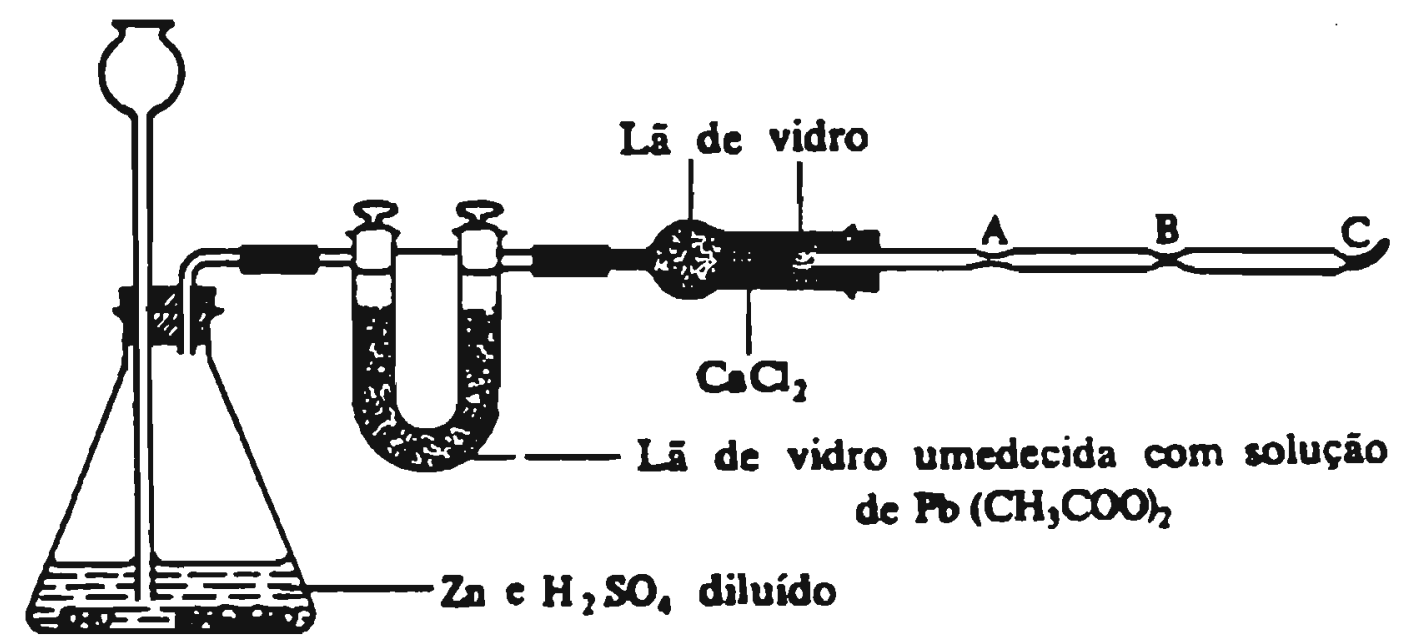

Figura 14 - diagrama esquemático do ensaio de MARSH [35].

\section{Ensaio de GUTZEIT}

Em 1857 GUTZEIT modificou o ensaio de MARSH onde a principal diferença consiste em que apenas é necessário um tubo de ensaio (figura 15) onde $\mathrm{AsH}_{3}$ é detectada pelo $\mathrm{AgNO}_{3}$ 
ou $\mathrm{HgCl}_{2}$. A figura 16 apresenta o esquema de análise de As pelo gerador de hidretos de Gutzeit . Pela comparação com papeis sensibilizados com $\mathrm{AgNO}_{3}$ ou $\mathrm{HgCl}_{2}$ após a geração de quantidades conhecidas de As, pode-se estimar a concentração presente na amostra.
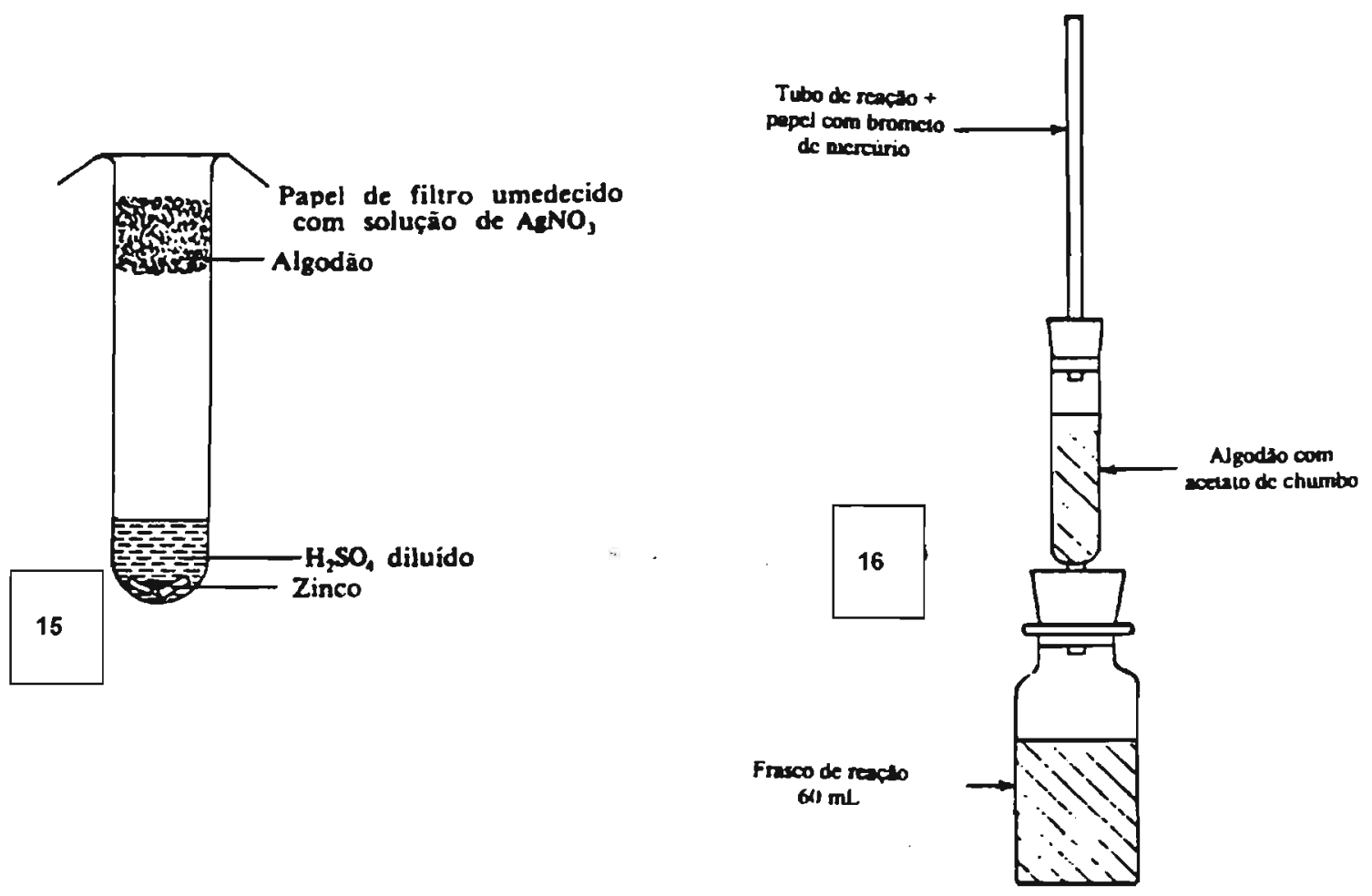

Figuras 15 e 16 - diagrama esquemático do ensaio de GUTZEIT $[35,36]$.

O uso da técnica de geração de hidretos para aplicação em análise espectrofotométrica também teve início com a determinação do As. Um dos primeiros procedimentos descreve a geração de $\mathrm{AsH}_{3}$ pela reação de $\mathrm{Zn}^{\circ} \mathrm{com} \mathrm{HCl} / \mathrm{H}_{2} \mathrm{SO}_{4}$ e os produtos da reação eram borbulhados em uma solução contendo molibdato de amônio e sulfato de hidrazina (figura 17). A arsina $\left(\mathrm{AsH}_{3}\right)$ reage com o molibdato, formando o composto chamado heteropolimolibdoarsenato (arsenomolibdato), o qual é reduzido pela ação do sulfato de hidrazina, formando um composto de coloração azul, o azul de molibdênio. Este composto tem uma absorção máxima a $840 \mathrm{~nm}$ e 
não evidencia modificação apreciável por 24 horas. Esta análise e também a reação com o dietilditiocarbamato de prata são ainda muito utilizadas atualmente $[35,37]$.

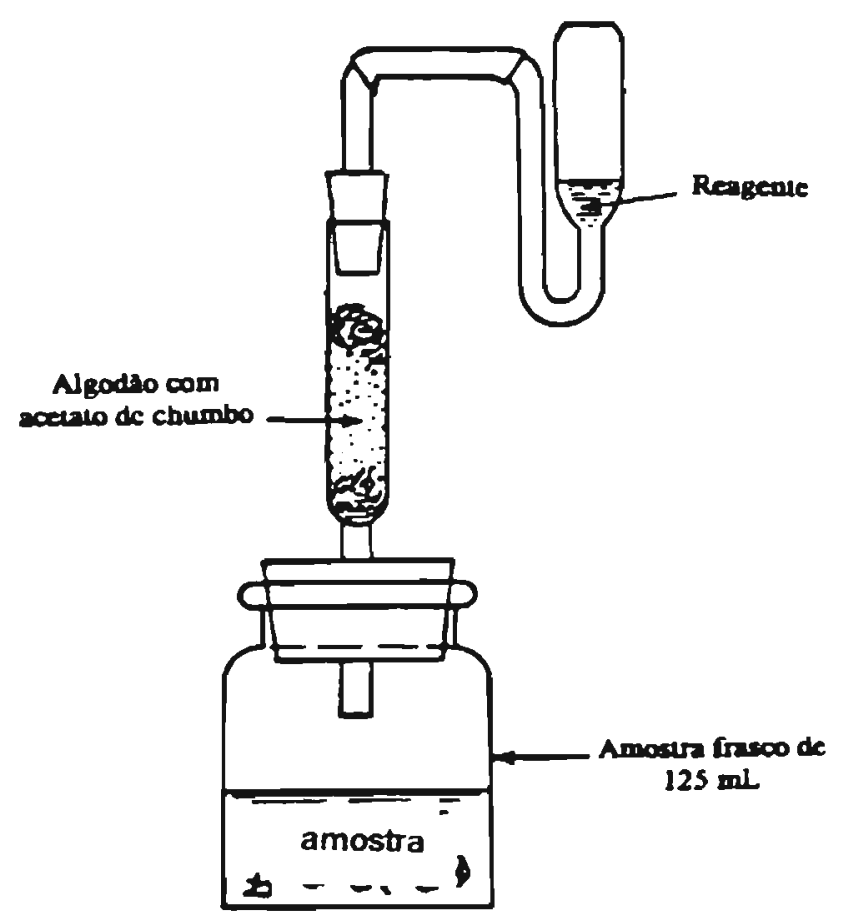

Figura 17 - aparelho para determinação de As por espectrofotometria [37]

A partir da descrição deste procedimento em 1951, publicou-se um número muito grande de outros procedimentos espectrofotométricos similares envolvendo a geração de hidretos $[35,36,37]$.

O rápido desenvolvimento da espectrometria de absorção atômica, introduzida em 1955 , com seus aspectos relevantes se iniciando em 1960, atingiu rapidamente sucesso comercial, devido à sua especificidade, sensibilidade e facilidade de operação na determinação de metais de um modo geral e também na determinação de traços de elementos [38]. A nebulização direta da solução era quase que exclusivamente usada como método de introdução da amostra. Contudo, a atomização em chama mostrava-se ineficiente para a determinação de alguns elementos em nivel de traços, particularmente em casos envolvendo elementos cujas linhas de 
absorção ótimas eram localizadas na região do ultravioleta do espectro eletromagnético, tais como As $(193,7 \mathrm{~nm})$ e Se $(196,0 \mathrm{~nm})$. Uma das dificuldades primárias encontradas era a presença de absorção de radiação de fundo que chegava a $60 \%$ usando uma chama ar/acetileno. KAHN e SCHALLIS [39] introduziram a chama de argônio/hidrogênio, mais fria que a chama ar/acetileno, em 1968, o qual reduziu a absorção de fundo para $15 \%$. Contudo este significante abaixamento de temperatura também aumentava o potencial para reações químicas envolvendo o analito com outros compostos presentes na chama. Em 1969, HOLAK [40] gerou $\mathrm{AsH}_{3}$ pela reação do $\mathrm{Zn}^{\circ}$ com $\mathrm{HCl}$, transportando-a para a chama de ar/acetileno para a determinação de As por EAA. Ele demonstrou que as interferências eram substancialmente reduzidas ou eliminadas. Hoje, esta técnica é bastante utilizada devido aos valores favoráveis para os limites de detecção alcançados, quando comparados com as técnicas de nebulizações convencionais. A tabela III apresenta os limites de detecção aplicados às técnicas EAA e ICPAES, segundo CARUSSO et al. [41].

Tabela III - limites de detecção $\left(\mu \mathrm{gL}^{-1}\right)$ para elementos formadores de hidretos [41].

\begin{tabular}{|l|c|c|c|c|}
\hline ELEMENTO & $\begin{array}{c}\text { Nebulização } \\
\text { convencional } \\
\text { (ICP) }\end{array}$ & $\begin{array}{c}\text { Gerador de } \\
\text { hidretos } \\
\text { (ICP) }\end{array}$ & $\begin{array}{c}\text { Nebulização } \\
\text { convencional } \\
\text { (EAA) }\end{array}$ & $\begin{array}{c}\text { Gerador de } \\
\text { hidretos } \\
\text { (EAA) }\end{array}$ \\
\hline $\mathrm{Ge}$ & 200 & 0.25 & 20 & 4 \\
$\mathrm{As}$ & 20 & 0.23 & 630 & 0.8 \\
$\mathrm{Se}$ & 20 & 0.37 & 230 & 1.8 \\
$\mathrm{Sn}$ & 100 & 0.37 & 150 & 0.5 \\
$\mathrm{Sb}$ & 20 & 0.31 & 60 & 0.5 \\
$\mathrm{Te}$ & 20 & 0.96 & 44 & 1.5 \\
$\mathrm{~Pb}$ & 30 & 1 & 17 & 0.1 \\
$\mathrm{Bi}$ & 40 & 0.26 & 44 & 0.2 \\
\hline
\end{tabular}


A combinação EAA-HG proposta em 1969 só foi acrescida de ICP-AES-HG em 1978 por indicação de THOMPSON et al.[42]. Desde então houve um aumento no número de publicações. Embora a proposta original tenha sido dirigida especialmente para solucionar as dificuldades encontradas com As e Se, atualmente as determinações foram estendidas para $\mathrm{Bi}$, $\mathrm{Ge}, \mathrm{Pb}, \mathrm{Sn}, \mathrm{Te}, \mathrm{Sb}$ e contemplam tentativas para a determinação de Tl e In [38].

A tabela IV mostra algumas propriedades físicas dos hidretos covalentes [38].

Tabela IV- Propriedades dos hidretos de interesse analítico [38].

\begin{tabular}{|l|c|c|c|}
\hline ELEMENTO & HIDRETO & $\begin{array}{c}\text { Ponto } \\
\text { fusão }\left({ }^{\circ} \mathrm{C}\right)\end{array}$ & $\begin{array}{c}\text { Ponto } \\
\text { ebulição }\left({ }^{\circ} \mathrm{C}\right)\end{array}$ \\
\hline $\mathrm{As}$ & $\mathrm{AsH}$ & -116.6 & -62.5 \\
$\mathrm{Bi}$ & $\mathrm{BiH}_{3}$ & -22 \\
$\mathrm{~Pb}$ & $\mathrm{GeH}_{4}$ & -165.9 & -88.5 \\
$\mathrm{Sb}$ & $\mathrm{PbH}_{4}$ & -13 \\
$\mathrm{Se}$ & $\mathrm{SbH}_{3}$ & -88 & -18.4 \\
$\mathrm{Sn}$ & $\mathrm{SeH}_{2}$ & -65.7 & -41.3 \\
$\mathrm{Te}$ & $\mathrm{SnH}_{4}$ & -150 & -51.8 \\
\hline
\end{tabular}

\section{Geracão de Hidretos em espectrometria de emissão atômica}

Segundo LAJUNEN [43] os métodos de geração de hidretos basicamente envolvem três passos sucessivos:

$1^{\circ}$ - o hidreto é gerado pela redução química da amostra;

$2^{\circ}$ - o hidreto formado é transportado por um gás carregador para a fonte de plasma;

$3^{\circ}$ - o hidreto é decomposto na fonte de plasma.

\section{Métodos de redução}

Os primeiros métodos utilizavam redução ácida/metal os quais os reagentes mais utilizados nesta categoria eram o $\mathrm{Zn}^{\circ}$ e $\circ \mathrm{HCl}$. A redução é representada de acordo com as seguintes equações químicas: 
$\mathrm{Zn}^{\circ}+2 \mathrm{H}^{+}+2 \mathrm{Cl}^{-} \rightarrow \mathrm{Zn}^{2+}+2 \mathrm{Cl}^{-}+2 \mathrm{H}^{\circ}$

$E^{m+}+(m+n+2) H^{\circ} \rightarrow E H n+H_{2}$ (excesso $)+m^{+}$

onde: $\mathbf{E}$ é o analito e $\mathbf{m}$ pode ou não ser igual a $\mathbf{n}$ (exemplo: $\mathrm{As}^{3+}$ e $\mathrm{As}^{5+}$ são ambos reduzidos a $\mathrm{AsH}_{3}$.

Outras reações ácido/metal investigadas incluem misturas de $\mathrm{Mg}^{\circ}$ e $\mathrm{TiCl}_{3} \mathrm{com} \mathrm{HCl} \mathrm{e}$ $\mathrm{H}_{2} \mathrm{SO}_{4}$ para produzir $\mathrm{AsH}_{3}, \mathrm{SeH}_{2}, \mathrm{SbH}_{3}, \mathrm{BiH}_{3}$ e $\mathrm{TeH}_{2}$ [43,44]. Para alguns elementos, especialmente $\mathrm{Sn}, \mathrm{Pb}$ e Te, a reação de formação de hidreto é relativamente lenta e portanto um recipiente de coleta é necessário [43]. No caso do As, em reações envolvendo ácido/metal, é necessário fazer redução prévia de $\mathrm{As}^{5+}$ para $\mathrm{As}^{3+}$, com o objetivo de aumentar a velocidade de formação da arsina $\left(\mathrm{AsH}_{3}\right)$, pela combinação de $\mathrm{SnCl}_{2}$ e $\mathrm{KI}$ antes da formação do hidreto. ROBBINS e CARUSSO [44] afirmam que a redução ácido/metal é capaz de formar mais eficientemente apenas os hidretos de As, Se e Sb.

O segundo tipo de reação, o mais utilizado atualmente, emprega o uso do $\mathrm{NaBH}_{4}$ (borohidreto de sódio) como método de geração de hidretos. A redução é representada de acordo com as equações químicas (7) e (8) a seguir $[43,44]$ :

$\mathrm{BH}_{4}^{-}+\mathrm{H}^{+}+3 \mathrm{H}_{2} \mathrm{O} \rightarrow \mathrm{H}_{3} \mathrm{BO}_{3}+8 \mathrm{H}^{\circ} \quad$ (7)

$E^{m+}+(m+n+2) H^{\circ} \rightarrow E H n+H_{2}$ (excesso $)+m H^{+}$

onde: $\mathbf{E}$ é o analito e $\mathbf{m}$ pode ou não ser igual a $\mathbf{n}$ [44].

As soluções do $\mathrm{NaBH}_{4}$ utilizadas são estabilizadas pelo seu preparo em meio alcalino $(\mathrm{NaOH}$ 0,1M) devido à hidrólise, de acordo com Lajunen [43]

$\mathrm{NaBH}_{4}+2 \mathrm{H}_{2} \mathrm{O} \rightarrow 4 \mathrm{H}_{2}+\mathrm{NaBO}_{2}$

As principais vantagens do uso do $\mathrm{NaBH}_{4}$ como redutor são [43]

- tempo de reação (varia de 10 a 30 segundos);

- $\mathrm{NaBH}_{4}$ pode ser empregado para produzir todos os oito elementos formadores de hidretos voláteis;

- $\mathrm{NaBH}_{4}$ pode ser adicionado em forma de solução. 
Com a introdução deste redutor, uma mudança marcante ocorreu na técnica de geração de hidretos. Usando o $\mathrm{NaBH}_{4}$, SHIMIDT e ROYER [45] determinaram $\mathrm{Sb}, \mathrm{As}, \mathrm{Bi}$, e $\mathrm{Se}$; POLLOCK e WEST [46] determinaram Ge; e FERNANDEZ [47] otimizou as condições para estes elementos e também para Te e Sn. THOMPSON e THOMERSON [48] relataram 0 sucesso na determinação do $\mathrm{Pb}$ usando $\circ \mathrm{NaBH}_{4}$ como redutor e assim aumentaram para oito 0 número de metais que podem ser determinados por esta técnica. Além disto o uso deste reagente possibilita a determinação simultânea de elementos formadores de hidretos, entre eles, o As e Se, elementos determinados no presente trabalho.

OLIVEIRA et al. [49] descrevem a determinação simultânea de As, Se e também do Sb em amostras marinhas utilizando $\circ \mathrm{NaBH}_{4}$ como redutor. $\mathrm{O}$ ataque oxidante usado nos procedimentos de digestões das amostras levaram os elementos As e Se aos seus mais elevados estados de oxidação, resultando portanto em As (V) como $\mathrm{AsO}_{4}{ }^{3-}$ e Se (VI) como $\mathrm{SeO}_{4}{ }^{2-}$. Vários autores $[50,51,52]$ relatam a necessidade de uma pré-redução do $\mathrm{As}(\mathrm{V})$ e $\mathrm{Sb}(\mathrm{V})$ para $\mathrm{As}(\mathrm{III})$ e respectivamente $\mathrm{Sb}(\mathrm{III})$, com o objetivo de melhorar a sensibilidade da análise, aumentando a velocidade de formação da arsina $\left(\mathrm{AsH}_{3}\right)$ e estibina $\left(\mathrm{SbH}_{3}\right)$, através do tratamento da solução da amostra com o reagente redutor $\mathrm{Kl}$, como mostram as seguintes equações químicas:

$$
\begin{aligned}
& \mathrm{AsO}_{4}{ }^{3-}+2 \mathrm{I}^{-}+2 \mathrm{H}^{+} \rightarrow \mathrm{AsO}_{3}{ }^{3-}+\mathrm{I}_{2}(\mathrm{~g})+\mathrm{H}_{2} \mathrm{O} \\
& \mathrm{SbO}_{4}{ }^{3-}+2 \mathrm{I}^{-}+2 \mathrm{H}^{+} \rightarrow \mathrm{SbO}_{3}{ }^{3-}+\mathrm{I}_{2}(\mathrm{~g})+\mathrm{H}_{2} \mathrm{O}
\end{aligned}
$$

Porém, seria impossivel a utilização deste recurso para determinação simultânea do As e Se, pois Se (VI) e Se (IV) são reduzidos ao estado elementar pela ação do Kl, equaçōes químicas (12) e (13), não produzindo hidreto volátil:

$$
\begin{aligned}
& \mathrm{SeO}_{4}{ }^{2-}+4 \mathrm{I}^{-}+8 \mathrm{H}^{+} \rightarrow \mathrm{Se}^{0}+2 \mathrm{I}_{2}(\mathrm{~g})+4 \mathrm{H}_{2} \mathrm{O} \\
& \mathrm{SeO}_{3}{ }^{2-}+4 \mathrm{I}^{-}+6 \mathrm{H}^{+} \rightarrow \mathrm{Se}^{0}+2 \mathrm{I}_{2}(\mathrm{~g})+3 \mathrm{H}_{2} \mathrm{O}
\end{aligned}
$$

Ao realizar o estudo de intensidade relativa dos analitos em diferentes estados de oxidação, OLIVEIRA et al. [49] mostraram que a diferença de intensidade relativa produzida pelo As(III) e $A s(V)$ é pequena, ao contrário do $S b(I I I)$ e $S b(V)$. Sendo assim, a determinação 
simultânea de As e Se é possível sem a utilização do reagente redutor $\mathrm{KI}$, sendo necessário apenas tratar a amostra de modo a reduzir quantitativamente o $\mathrm{Se}(\mathrm{VI})$ para $\mathrm{Se}(\mathrm{IV})$. Com esta finalidade, BRIMMER, FAWEETT e KULHAVY [53] realizaram estudo sobre a redução quantitativa de ions selenatos $\left(\mathrm{SeO}_{4}{ }^{2-}\right)$ a ions selenitos $\left(\mathrm{SeO}_{3}{ }^{2-}\right)$ e concluíram que as condições mais adequadas eram obtidas através do uso de $\mathrm{HCl} 6 \mathrm{~mol} / \mathrm{L}$ com aquecimento a $90^{\circ} \mathrm{C}$ por 30 minutos. Neste processo $99,9 \%$ de $\mathrm{SeO}_{4}{ }^{2-}$ foi convertido a $\mathrm{SeO}_{3}{ }^{2-}$.

As seguintes reações, representadas pelas equações químicas a seguir, ocorrem no processo de análise simultânea de As e Se:

$$
\begin{aligned}
& \mathrm{SeO}_{4}{ }^{2-}+4 \mathrm{H}^{+}+2 \mathrm{Cl}^{-} \stackrel{90^{\circ} \mathrm{C}}{\rightarrow} \mathrm{H}_{2} \mathrm{SeO}_{3}+\mathrm{H}_{2} \mathrm{O}+\mathrm{Cl}_{2}(\mathrm{~g}) \\
& \mathrm{BH}_{4}{ }^{-}+\mathrm{H}^{+}+3 \mathrm{H} 2 \mathrm{O} \rightarrow \mathrm{H}_{3} \mathrm{BO}_{3}+8 \mathrm{H}^{\circ} \\
& 8 \mathrm{H}^{\circ}+5 \mathrm{H}^{+}+\mathrm{AsO}_{4}{ }^{3-} \rightarrow \mathrm{AsH}_{3}(\mathrm{~g})+4 \mathrm{H}_{2} \mathrm{O}+\mathrm{H}_{2}(\mathrm{~g}) \\
& 8 \mathrm{H}^{\circ}+2 \mathrm{H}^{+}+\mathrm{SeO}_{3}{ }^{2-} \rightarrow \mathrm{SeH}_{2}(\mathrm{~g})+3 \mathrm{H}_{2} \mathrm{O}+\mathrm{H}_{2}(\mathrm{~g})
\end{aligned}
$$

\section{Transporte do hidreto formado para a fonte de plasma}

Em ICP-AES, para o transporte do hidreto formado utiliza-se mais frequentemente o sistema de geração contínua. $\mathrm{O}(\mathrm{s})$ reagente(s) e amostra são continuamente bombeados, geralmente por uma bomba peristáltica multicanal, até um tubo misturador, onde ocorre a reação da amostra com o $\mathrm{NaBH}_{4}$ e/ou $\mathrm{HCl}$. Os produtos formados na reação, ou seja, o hidrogênio e os hidretos, sāo então arrastados até o sistema de separação líquido-gás, onde o líquido se dirige para o dreno e a mistura gasosa é levada ao plasma com auxilio do gás carregador, ocorrendo então o processo de emissão atômica [41].

Muitos dos métodos de geração contínua de hidretos seguem as sugestōes de THOMPSON et al. [54] na determinação multielementar de $\mathrm{As}, \mathrm{Bi}, \mathrm{Sb}$, Se e Te. Um diagrama esquemático do gerador de hidretos utilizado por THOMPSON et al. [54] é apresentado na figura 18. OZAKI e OLIVEIRA [55] utilizaram o gerador de hidretos apresentado na figura 19, na pesquisa de $\mathrm{As}, \mathrm{Bi}$, e $\mathrm{Sb}$ em ligas de níquel e aços, sendo que o separador de fases consiste de dois blocos de acrílico separados por uma fita de teflon. No presente trabalho foi construido um 
separador de fases de acordo com o modelo utilizado por OLIVEIRA et al. [49] na determinação simultânea de As e Se, figura 20 .

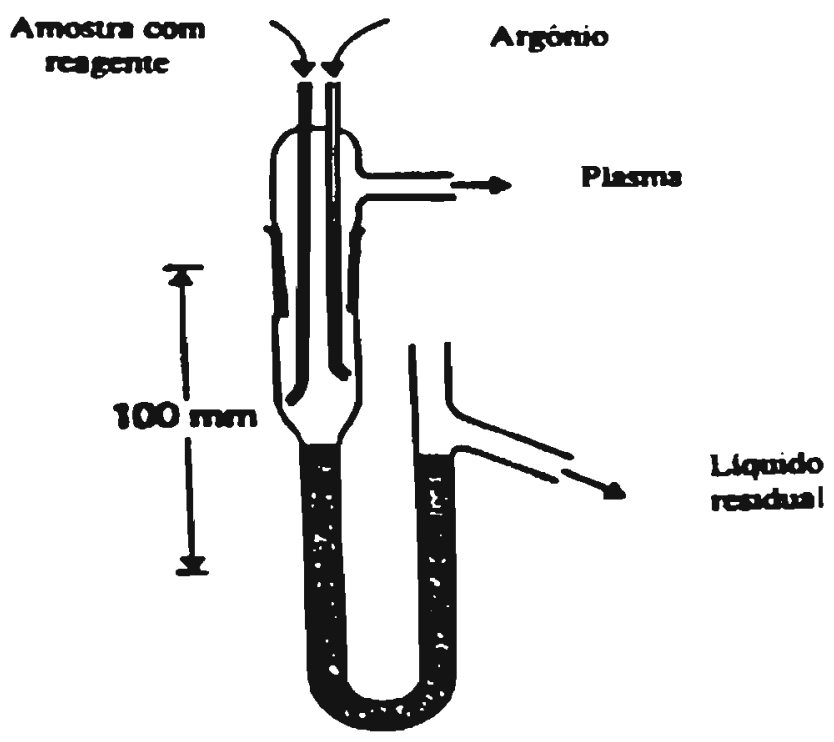

Figura 18 - Diagrama do gerador de hidretos utilizado por THOMPSON et al. [54].

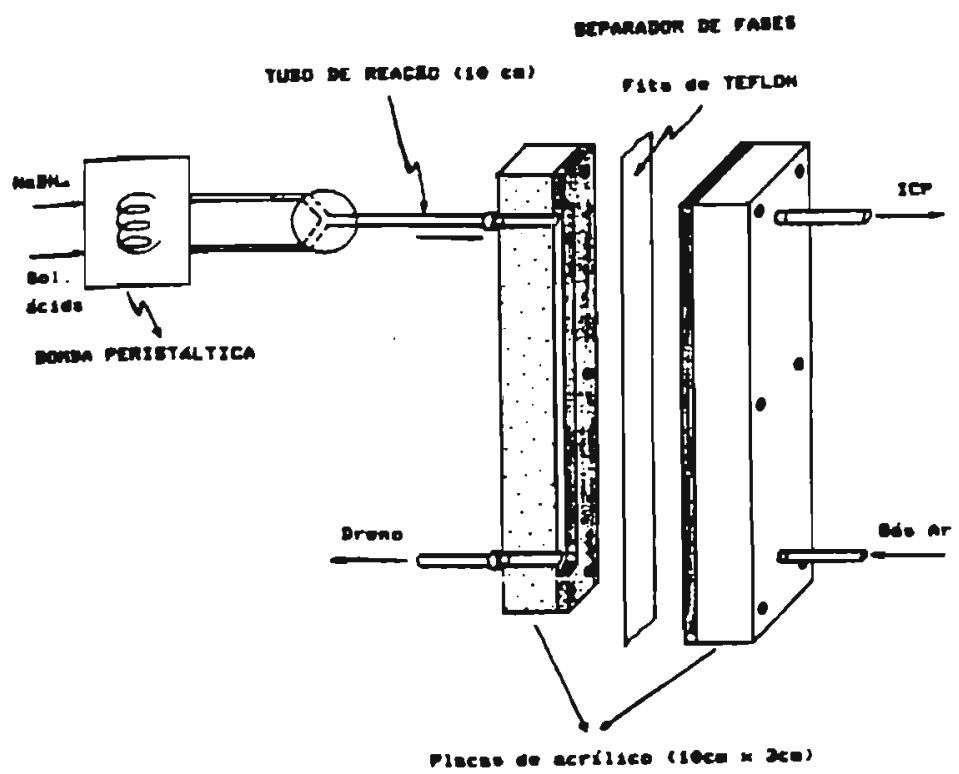

Figura 19 -Diagrama do gerador de hidretos utilizado por OZAKI e OLIVEIRA [55]. 


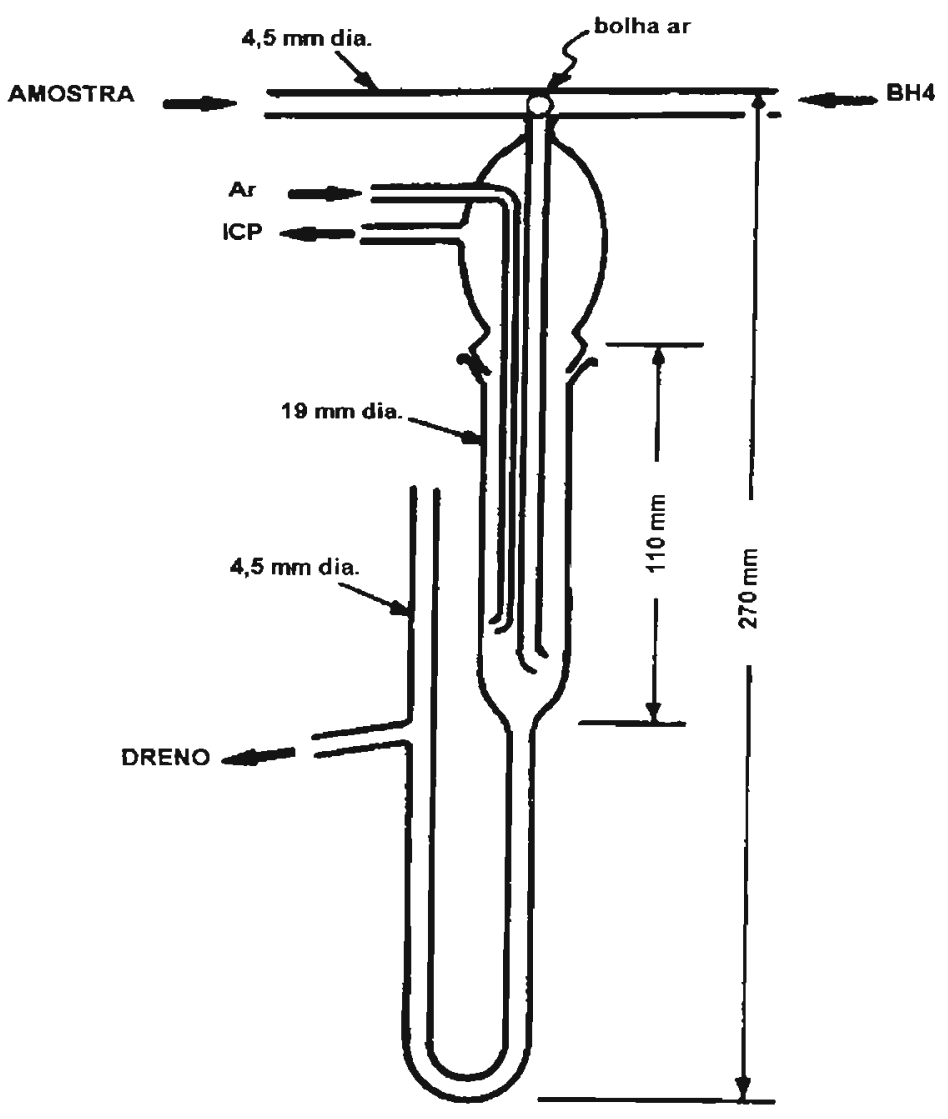

Figura 20 - Separador de fases ou gerador de hidretos construído e utilizado no presente trabalho de acordo com OLIVEIRA et al.[49].

De acordo com THOMPSON et al. [54], os principais requisitos de um gerador de hidretos são:

- mistura eficiente da solução da amostra ácida com o $\mathrm{NaBH}_{4}$;

- um curto período de tempo para a completa reação;

- separação eficiente dos produtos gasosos do líquido;

- mistura uniforme dos produtos gasosos com o gás argônio que os conduz ao plasma;

- uma pequena pressão positiva para condução dos produtos gasosos ao plasma.

Decomposição do hidreto formado na fonte de plasma

$\mathrm{Na}$ fonte de plasma, a energia normalmente necessária para desolvatação e vaporização de um elemento metálico de uma amostra líquida está disponivel para a atomização 
e excitação do elemento formador de hidreto, intensificando deste modo o sinal de emissão e melhorando a sensibilidade e o limite de detecção [41].

\section{Estudo de Interferências}

THOMPSON et al. [42] em 1978 apresentaram um dos estudos mais completos sobre interferências quando da geração de hidretos voláteis para ICP-AES. Efeitos de interferências mútuas entre elementos que formam hidretos são negligenciáveis em situações em que todos os elementos de uma amostra são constituintes traços ou menores. A tabela $V$ apresenta os efeitos de vários elementos na determinação de hidretos [42].

Tabela V - efeito de vários elementos na determinação de hidretos [42].

\begin{tabular}{|c|c|c|c|c|c|c|}
\hline \multirow[b]{2}{*}{ Interferente } & \multirow[b]{2}{*}{$\begin{array}{c}\text { Concentração } \\
\left(\mu \mathrm{gL} \mathrm{m}^{-1}\right)\end{array}$} & \multicolumn{5}{|c|}{ Mudanca no sinal do analito, $\%$} \\
\hline & & As & Sb & $\mathrm{Bi}$ & Se & Te \\
\hline $\mathrm{Na}$ (I) & 10000 & 0 & 0 & -2 & +2 & +2 \\
\hline$K(I)$ & 10000 & 0 & 0 & 0 & +1 & +1 \\
\hline$M g$ (II) & 10000 & 0 & +1 & +1 & 0 & +1 \\
\hline $\mathrm{Ca}$ (II) & 10000 & +2 & -2 & 0 & +2 & +1 \\
\hline \multirow[t]{2}{*}{$\mathrm{Fe}$ (iil) } & 10000 & -2 & -5 & -8 & -26 & -10 \\
\hline & 1000 & 0 & 0 & 0 & -6 & -3 \\
\hline $\mathrm{Fe}$ (II) & 10000 & 0 & +6 & +10 & -81 & 0 \\
\hline $\operatorname{Mn}(\mathrm{II})$ & 10000 & +1 & +2 & 0 & 0 & -10 \\
\hline Al (III) & 10000 & +1 & +7 & 0 & 0 & -6 \\
\hline Ti (IV) & 1000 & +1 & -1 & -1 & -3 & -5 \\
\hline \multirow{2}{*}{$v(v)$} & 1000 & 0 & -15 & 0 & -11 & -50 \\
\hline & 100 & 0 & 0 & 0 & -1 & -1 \\
\hline \multirow[t]{2}{*}{$\operatorname{Cr}(\mathrm{VI})$} & 1000 & -50 & -34 & -2 & -5 & -60 \\
\hline & 100 & -5 & -2 & 0 & 0 & -8 \\
\hline $\operatorname{Cr}$ (III) & 1000 & -3 & -3 & -1 & 0 & -4 \\
\hline $\operatorname{Mo}(\mathrm{VI})$ & 1000 & 0 & 0 & 0 & -15 & -10 \\
\hline \multirow[t]{2}{*}{ Co (II) } & 1000 & +1 & +1 & -4 & -4 & -39 \\
\hline & 100 & 0 & 0 & 0 & 0 & 0 \\
\hline \multirow[t]{2}{*}{ Ni (II) } & 1000 & -2 & -11 & -6 & -12 & -72 \\
\hline & 100 & 0 & 0 & -1 & 0 & 0 \\
\hline \multirow[t]{2}{*}{ Cu (II) } & 1000 & 0 & -4 & -92 & -99 & -99 \\
\hline & 100 & 0 & 0 & -77 & -77 & -99 \\
\hline \multirow[t]{2}{*}{$\mathrm{Zn}$ (II) } & 1000 & -6 & -7 & -3 & -7 & -61 \\
\hline & 100 & 0 & 0 & 0 & 0 & -3 \\
\hline \multirow[t]{2}{*}{ Cd (II) } & 1000 & +2 & -7 & -4 & -12 & -99 \\
\hline & 100 & +1 & +2 & 0 & -2 & -3 \\
\hline \multirow[t]{2}{*}{$\mathrm{Hg}(\mathrm{II})$} & 1000 & 0 & +15 & -83 & 0 & -70 \\
\hline & 100 & 0 & +10 & -20 & 0 & -15 \\
\hline \multirow[t]{2}{*}{$\mathrm{Pb}$ (II) } & 1000 & -2 & -16 & -5 & -53 & -99 \\
\hline & 100 & 0 & 0 & 0 & -2 & -12 \\
\hline
\end{tabular}


No caso específico da determinação simultânea de As e Se, pequenas variações no sinal da intensidade de emissão ocorrem quando as matrizes ácidas são variadas, sendo importante o mesmo tratamento aplicado a amostra e padrões [37]. De acordo com o estudo realizado por THOMPSON et al. [42] os elementos $\mathrm{Fe}$ (II), $\mathrm{Cu}$ (II) e $\mathrm{Pb}$ (II) para o hidreto de $\mathrm{Se}$ e $\mathrm{Cr}$ (VI) para o hidreto de As, são os que podem reduzir mais significativamente a resposta de intensidade de emissão destes analitos. Contudo, de acordo com Standard Methods for the Examination of Water and Wastewater [37], estas interferências são menos pronunciadas quando a concentração ácida está entre 4 a $6 \mathrm{~mol} / \mathrm{L}$ em $\mathrm{HCl}$. Óxidos de nitrogênio resultantes da digestão com $\mathrm{HNO}_{3}$ também podem diminuir a resposta analítica dos hidretos de As e Se. No presente trabalho, as amostras foram tratadas de maneira a eliminar o excesso de $\mathrm{HNO}_{3}$ utilizado durante o processo de mineralização das amostras de café solúvel $[37,49,53]$.

\subsection{Determinação analítica do mercúrio}

O método de análise mais utilizado para a determinação do $\mathrm{Hg}$ é o da espectrometria de absorção atômica por geração de vapor frio, que consiste em produzir e arrastar o vapor deste elemento para uma cela de absorção, no caminho ótico do espectrômetro, onde a absorção pode ser medida a $253,7 \mathrm{~nm}$ (quando é utilizado ar como gás de arraste) ou 184,95 nm (quando é utilizado nitrogênio ou argônio como gás de arraste). A transformação das diferentes espécies químicas de $\mathrm{Hg}$ presentes nas amostras em ions $\mathrm{Hg}^{2+}$ é realizada por via úmida através de oxidantes fortes em meio ácido. Normalmente, a amostra é tratada com uma mistura de $\mathrm{H}_{2} \mathrm{SO}_{4} \mathrm{e}$ $\mathrm{KMnO}_{4}$ onde o permanganato oxida compostos organomercuriais, bem como $\circ \mathrm{Hg}$ elementar para a produção de ions $\mathrm{Hg}^{2+}$. $\mathrm{O}$ excesso de permanganato é destruido com hidroxilamina e um agente redutor, normalmente o $\mathrm{SnCl}_{2}$, é adicionado para redução dos ions $\mathrm{Hg}^{2+}$ a Hg elementar Este, devido à sua pressão de vapor favorável, é arrastado por um gás inerte (injetado na solução) até a cela de absorção de quartzo. Nesta cela, o feixe de luz, emitido por uma lâmpada de cátodo oco de $\mathrm{Hg}$ com comprimento de onda $(\lambda)$ especifico deste analito, é absorvido pelos átomos de $\mathrm{Hg}$, sendo a absorção proporcional à sua concentração. As seguintes equações quimicas, representam o processo $[37,56,57]$ : 
$5 \mathrm{Hg}^{\circ}+2 \mathrm{MnO}_{4}^{-}+16 \mathrm{H}^{+} \rightarrow 5 \mathrm{Hg}^{2+}+2 \mathrm{Mn}^{2+}+8 \mathrm{H}_{2} \mathrm{O}\left(+{ }^{*} \times \mathrm{CO}_{2}\right)$

(' R-Hg-R')

$6 \mathrm{MnO}_{4}^{-}+5 \mathrm{NH}_{4} \mathrm{OH}+13 \mathrm{H}^{+} \rightarrow 6 \mathrm{Mn}^{2+}+5 \mathrm{NO}_{3}^{-}+14 \mathrm{H}_{2} \mathrm{O}$

$\mathrm{Hg}^{2+}+\mathrm{SnCl}_{2}+2 \mathrm{Cl}^{-} \rightarrow \mathrm{Hg}^{\circ}+\mathrm{SnCl}_{4}$

(' $\mathrm{R}-\mathrm{Hg}-\mathrm{R}$ ' onde R e R’ representam grupamentos orgânicos)

$\mathrm{O}$ uso do $\mathrm{NaBH}_{4}$ na determinação do $\mathrm{Hg}$ foi proposto inicialmente por TOFFALETTI e SAVORI [58] e ROONEY [59]. $\mathrm{O} \mathrm{NaBH}_{4}$ é capaz de reduzir os íons $\mathrm{Hg}^{2+}$ em soluções fortemente ácidas, o que pode ser utilizado empregando-se o sistema de análise em fluxo contínuo acoplado ao ICP-AES (exemplo figura 20), da mesma maneira que para as determinações dos elementos formadores de hidretos. As maiores diferenças entre os dois redutores, $\mathrm{NaBH}_{4} \mathrm{e}$ $\mathrm{SnCl}_{2}$, é que $\circ \mathrm{NaBH}_{4}$ é um agente redutor mais forte, liberando uma grande quantidade de $\mathrm{H}_{2}$ durante a reação com a amostra ácida, o que contribui para o transporte da maior parte do vapor de $\mathrm{Hg}$ formado até a cela de absorção, no caso da EAA, ou fonte de atomização no ICPAES. No sistema que utiliza o $\mathrm{SnCl}_{2}$, a solução do redutor é injetada no frasco de reação, reagindo com a solução ácida da amostra e formando o $\mathrm{Hg}$ metálico. Neste processo normalmente é recomendado um tempo de espera de 1 minuto, durante o qual um equilíbrio é estabelecido entre a fase aquosa e a fase gasosa no interior do frasco de reação. A seguir, o gás inerte é injetado para o interior da cela de reação, arrastando o vapor do $\mathrm{Hg}$ até a cela de absorção, na qual através do sistema de integração de pico mede-se a absorbância em função do tempo. Já no sistema que utiliza o $\mathrm{NaBH}_{4}$, em fluxo contínuo acoplado ao ICP-AES, o redutor reage continuamente com a amostra formando gás $\mathrm{H}_{2}$ e vapor do $\mathrm{Hg}$, sendo portanto a reação de formação do analito imediata. Simultaneamente o sistema é alimentado pelo gás argônio de arraste, que transporta os gases e vapor do $\mathrm{Hg}$ formados diretamente para a fonte do plasma. $\mathrm{A}$ dinâmica do sinal assim gerado é normalmente um pouco menor que aquela produzida pelo sistema que utiliza $\circ \mathrm{SnCl}_{2}$, contudo esta pequena desvantagem é equilibrada pela alta frequência de amostragem oferecida pelo sistema de geração contínua [60,61].

Mais recentemente, THOMPSON e WALSH [30], no caso da determinação de $\mathrm{Hg}$ por ICP-AES, reforçaram as vantagens do uso do $\mathrm{NaBH}_{4}$ como redutor, empregando um sistema de 
geração contínua construído conforme a figura 18. Os autores destacam a baixa emissão de radiação de fundo, principalmente em relação à nebulização convencional da amostra; a alta eficiência de transferência do analito para o plasma (próximo de $100 \%$ em relação a $2-5 \%$ obtido na nebulização pneumática) e a separação do analito da matriz da amostra. Este último fator é relevante no caso do $\mathrm{Hg}$, que pode sofrer interferência de emissão de radiação de fundo e espectral quando $\mathrm{Mg}, \mathrm{Ca}, \mathrm{Al}, \mathrm{Fe}, \mathrm{Mn}$ e Ti estão presentes. O emprego deste sistema acoplado ao ICP-AES também possibilita a determinação do $\mathrm{Hg}$ em linhas de emissão mais sensíveis, situadas na região do UV mais afastadas, como 194,163 nm e 184,95 nm, sem necessidade de alterar as condições de trabalho.

\subsection{Técnicas Estatisticas}

\section{Análise de componentes principais}

Esta ferramenta estatistica permite que variáveis altamente correlacionadas sejam determinadas, de modo que a variabilidade de um sistema complexo possa ser expressa por estas variáveis tão bem quanto seria se usássemos o conjunto das variáveis originais. O método matemático utilizado é sofisticado e pode ser aplicado através do uso de programas computacionais, como SPSS para windows (da abreviatura inglesa Statistical Package for Social Sciences) [62]

O objetivo principal da análise de componentes principais, segundo KAUFMANN [63], é a redução de dados de uma determinada matriz, por exemplo, matriz $Z$ que relaciona amostras de café solúvel com as variáveis que são os valores de concentrações dos elementos químicos (nutrientes e contaminantes inorgânicos), no caso do presente trabalho. Através deste método, uma nova matriz é produzida com poucas variáveis, que são os componentes principais. Esta nova matriz $Z$ deverá conter tantas informações quanto possivel da matriz $Z$ original. $A$ análise de componentes principais poderá ser realizada com sucesso somente se existir correlações entre as variáveis contidas na matriz $Z$ original. Caso não ocorram correlaçōes, a matriz Z original não poderá ser substituída por uma nova matriz Z com menos variáveis. Somente a remoção de informações redundantes (correlação) permitirá a redução dos dados. A primeira 
variável (componente principal 01) pertencente à nova matriz $Z$ representa a direção da major quantidade de variância explicada dos dados. A porcentagem de variância explicada por componente diminui à medida que são obtidas novas componentes [63].

A matriz original de dados $\mathrm{Z}$ de ordem $\mathrm{n} \times \mathrm{m}$, utilizada na análise de componentes principais, pode ser representada geometricamente, considerando-se as $\mathbf{m}$ variáveis (elementos químicos) como eixos cartesianos e as $\mathbf{n}$ amostras como pontos distribuídos dentro do espaço $\mathbf{m}$ dimensional. A matriz transformada $Z$ dos componentes principais é de ordem $\mathrm{n} \times$ a onde $\mathrm{a}<\mathrm{n}$. Os componentes principais são combinações lineares obtidas a partir das variáveis originais e são representados pelos autovetores no espaço. O primeiro autovetor, correspondente ao maior autovalor, é por definição a direção no espaço definido pelas colunas da matriz $Z$ que descreve a fração máxima da variação das amostras. A figura 21 mostra como exemplo a representação gráfica de um espaço definido por três variáveis. As amostras são representadas através dos pontos $\mathrm{x}$ e os componentes principais correspondem às duas retas ortogonais contidas dentro do espaço tridimensional, que passam pelo ponto médio Teoricamente pode haver tantos componentes quanto o número de variáveis, mas a grande vantagem deste modelo é que somente com alguns componentes (os componentes principais) consegue-se explicar a maior parte da variância total do sistema. No exemplo ilustrado na figura 21 a dimensionalidade do sistema é reduzida de três variáveis para dois componentes principais [64]. Na notação da análise de componentes principais, os pesos dos componentes (loadings) são dados pelos cossenos dos ângulos formados entre as retas dos componentes principais e os eixos das variáveis originais. No exemplo correspondem aos ângulos a1, a2 e a3 com o componente 01. Esses pesos podem variar de $-1 \mathrm{a}+1$ e quanto mais altos forem os seus valores, maior será a correlação entre o componente e a variável (elemento químico analisado). Por outro lado, os escores dos componentes representam as projeções de cada ponto $\mathbf{x}$ (amostras) no plano definido dos componentes principais 01 e 02, representados através dos pontos $\mathbf{x}$. A distância $t$ entre as projeções $\mathbf{x}$ de cada ponto $\mathbf{x}$ no espaço definido através dos 
componentes principais e o ponto médio correspondem aos escores dos componentes, os quais indicam a correlação entre cada componente e as amostras [64,65].

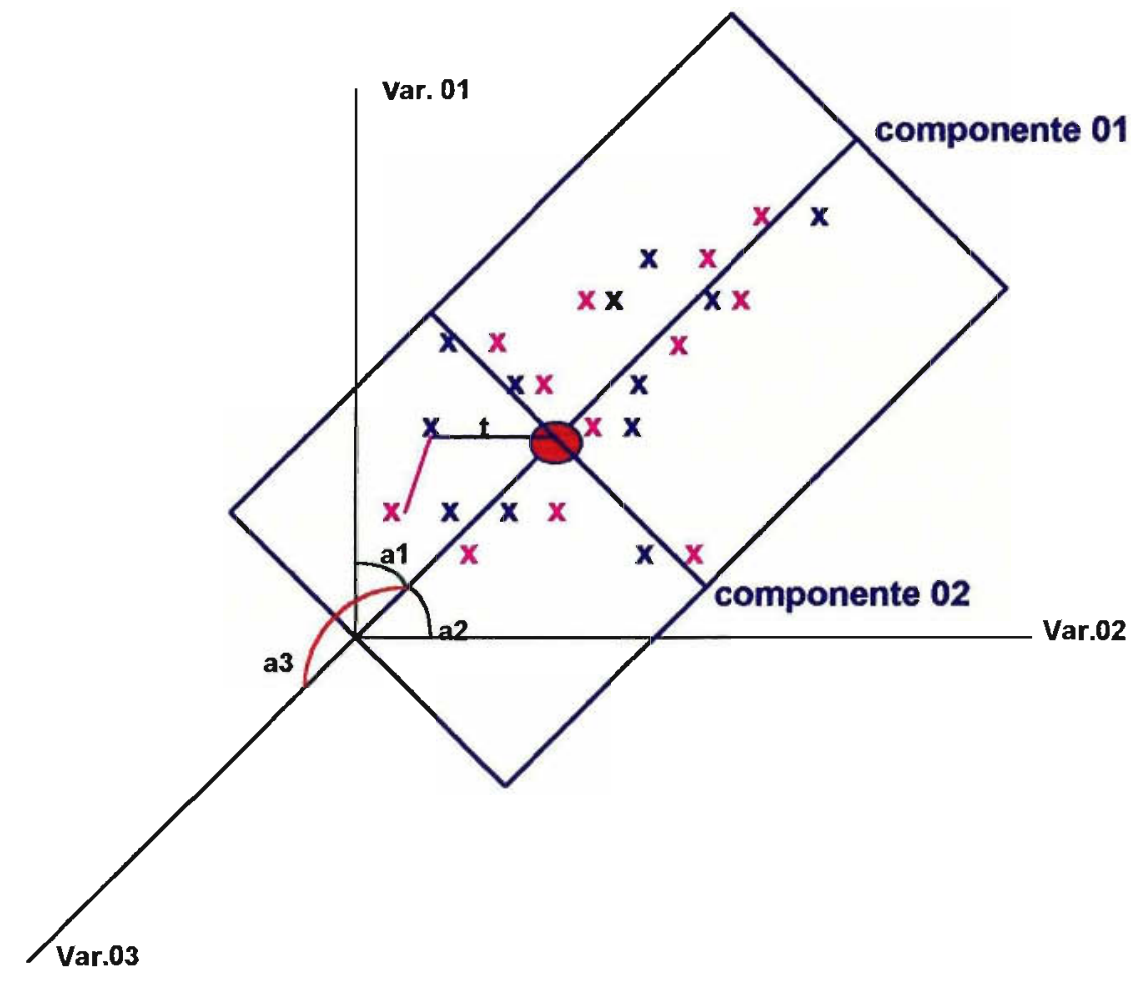

Figura 21:representação espacial - componentes principais

Esta figura representa um exemplo com três variáveis e seguiu as seguintes etapas para a sua construção:

$1^{\circ}$ - As amostras foram distribuidas no espaço tridimensional de acordo com os valores das três variáveis e a seguir foi determinado o ponto central ou ponto médio onde o valor médio para cada elemento analisado é representado.

$2^{\circ}$ - Foi utilizada uma reta para melhorar o modelo matemático: modelo linear o qual minimiza as distâncias perpendiculares entre os pontos e a reta, isto é o COMPONENTE: PRINCIPAL 01. A porcentagem de variância que ela explica é $\pm 40 \%$.

$3^{\circ}$ - Os pontos estão próximos da reta mas para ajustá-los melhor foi estabelecido o COMPONENTE PRINCIPAL 02 perpendicular a $1^{\circ}$ que passa pelo ponto central com o objetivo de explicar a maior quantidade possivel de variância não explicada pelo componente 01 .

$4^{\circ}$ - Alguns pontos podem cair fora destas 2 retas (muito acima ou muito abaixo) e portanto podemos calcular o $3^{\circ}$ componente para explicar estes residuos.

$5^{\circ}$ - Na prática foi realizada a projeção bidimensional do espaço $p$-dimensional pela projeção dos pontos no plano definido através dos 2 componentes principais. 
$6^{\circ}$ - O plano foi traçado e os pontos $\mathbf{x}$ formam uma estrutura que aproxima o comportamento dos dados reais em $\mathbf{x}$.

portanto: $\quad \mathbf{x}=$ pontos originais. O computador faz cálculos exatos usando estes pontos.

$\mathbf{x}=$ projeção dos pontos originais no plano definido pelos componentes principais é o que o cientista visualiza.

\section{Análise de Clusters ou agrupamento hierárquico}

Esta ferramenta estatística consiste em classificar objetos ou elementos similares (dentro de um espaço definido) baseando-se em medidas de distância ou similaridade [64].

Os métodos de agrupamento se iniciam com a construção da matriz de distância ou similaridade entre os objetos e resultam em um dendrograma ilustrando as sucessivas fusões dos objetos e grupos até o estágio máximo alcançado, quando todos os objetos são unidos em um só conjunto [66].

Primeiramente recomenda-se autoescalonar os dados. Esta normalização também é realizada através do " $Z$ score" onde a concentração de cada variável é substituída em :

$$
\mathrm{Zij}=[\mathrm{Cij}-\mathrm{C} \text { (médio)ij }] \div \text { Sci }
$$

onde $\mathrm{Ci}=$ concentração da variável $\mathrm{i}$

Sci $=$ desvio padrão

A seguir é calculada a matriz de distância para todos os valores, sendo a distância euclideana ao quadrado (SED, Square Euclidean Distance) uma das mais utilizadas correspondendo à soma dos quadrados das diferenças dos valores das coordenadas de cada amostra [64]:

$$
\operatorname{SED}=\sum_{K=1}^{m}\left(X_{i k}-X_{j k}\right)^{2}
$$

onde $\mathbf{X}_{\mathrm{ik}}=$ valor da i-nésima variável para $\mathrm{k}$-inésima amostra, $\mathrm{e}$

$\mathbf{X}_{\mathrm{jk}}=$ valor da $\mathrm{j}$-nésima variável para $\mathrm{k}$-inésima amostra

Uma vez obtida a matriz de distância para todos os valores, o processo de agrupamento segue as seguintes etapas: 
$1^{\circ}$ - são determinados os elementos com valores menores na matriz de distância e estes são unidos formando um cluster inicial;

$2^{\circ}$ - a seguir é calculada a nova matriz de distância considerando que os dois valores que formaram o primeiro cluster na etapa anterior representam um novo elemento ou objeto nesta nova matriz;

$3^{\circ}$ - estas duas etapas são aplicadas repetitivamente até ser obtido o último cluster [66].

Há uma série de métodos de agrupamentos disponiveis que se diferenciam principalmente na implementação da $2^{\circ}$ etapa. Segundo ADAMS [66], a nova matriz de distância pode ser definida em termos gerais através da fórmula matemática:

$$
d_{k(i, j)}=\alpha_{i} d_{k, i}+\alpha_{j} d_{k, j}+\beta d_{i, j}+\gamma\left|d_{k, i}-d_{k, j}\right|
$$

onde $\mathbf{d}_{\mathbf{i}, \mathbf{j}}$ é a distância entre os objetos $\mathbf{i}$ e $\mathbf{j}$ e $\mathbf{d}_{\mathbf{k}(\mathbf{i}, \mathbf{j})}$ é a distância entre o grupo $\mathbf{K}$ e o novo grupo (i, j) formado da fusāo dos grupos i e j. Os valores dos coeficientes $\alpha_{\mathbf{i}}, \alpha_{\mathbf{j}}, \beta$ e $\gamma$ são escolhidos de acordo com o método de agrupamento a ser utilizado.

Todos os métodos de agrupamento hierárquico são conceitualmente iguais, porém com variações matemáticas nas definições de grupos e como estes grupos se relacionam com outros grupos de pontos. Um dos mais utilizados em quimiometria é o método de Ward, onde um ponto central é calculado para todas as combinações de dois clusters e a distância entre este ponto e todos os objetos são calculadas. Na prática esta técnica favorece a produção de pequenos clusters. Os coeficientes utilizados na equação acima, através da aplicação do método de Ward, são os seguintes [66]:

$$
\alpha_{i}=\frac{\underline{n}_{k}+n_{i}}{n_{k}+n_{i}+n_{j}} \quad \alpha_{j}=\frac{\underline{n}_{k}+n_{j}}{n_{k}+n_{i}+n_{j}} \quad \beta=\frac{-n_{k}}{n_{k}+n_{i}+n j} \quad \gamma=0
$$

onde o número de objetos em um cluster i é $\mathbf{n}_{\mathbf{i}}$.

Da mesma forma que na análise de componentes principais, este método também foi aplicado através do programa computacional SPSS para windows [62] 


\section{PARTE EXPERIMENTAL}

\subsection{Equipamentos e vidrarias}

- Espectrômetros de emissão atômica de plasma indutivamente acoplado (ICP-AES) modelo Modula da Spectro Co. e PSX da BAIRD Co.,com as condições instrumentais e de trabalho definidas no item 4.5, página 54;

- Forno de microondas focalizado modelo 350 da Spex equipado com tubos de vidro com capacidade de $250 \mathrm{~mL}$;

- Balança analítica, Mettler,

- Chapa elétrica de aquecimento;

- Micropipeta $20-200 \mu \mathrm{L}$;

- Micropipeta $100-1000 \mu \mathrm{L}$;

- Copos de bequer de fôrma alta, $400 \mathrm{~mL}$;

- Pipetas graduadas de $10 \mathrm{~mL}$ e $5 \mathrm{~mL}$;

- Pipeta volumétrica de $5 \mathrm{~mL}$;

- Pipeta volumétrica de $25 \mathrm{~mL}$;

- Vidros de relógio;

- Bombas de teflon (frascos de decomposição com tampas), capacidade de $45 \mathrm{~mL}$;

- Bloco digestor com capacidade para 5 bombas de teflon, Tecnal;

- Separador de fases ou gerador de hidretos construido conforme figura 20.

\subsection{Reagentes e soluçð̃es}

- Água destilada-desionizada (deionizador permution);

- Soluções padrões de $1000 \mathrm{mgL}^{-1}$ de todos os elementos sob análise, Titrisol merck e Carlo Erba;

- $\mathrm{HNO}_{3}$, Merck, min. $65 \% \mathrm{pa}$;

- $\mathrm{HCl}$, Merck, $\min .37 \%$ pa:

- $\mathrm{H}_{2} \mathrm{O}_{2}$, Merck, min. $30 \%$ pa; 
- $\mathrm{H}_{2} \mathrm{SO}_{4}$, Merck, min. $98 \%$ pa;

- $\mathrm{NaBH}_{4}$, Merck, min.99,9\% pa, uso de solução $1 \% \mathrm{~m} / \mathrm{v}$ em $\mathrm{NaOH} 0,1 \mathrm{M}$;

- $\mathrm{KI}$, Merck, $\min .99,9 \%$ pa, uso de solução $5 \% \mathrm{~m} / \mathrm{v}$;

- $\mathrm{NaOH}$, Merck, min. $99,9 \%$ pa.

\subsection{Amostragem}

As amostras de café solúvel foram adquiridas no mercado brasileiro, marcas: Café Pelé, Gran Classic, Nescafé Matinal, Nescafé Tradição, Café do Ponto Freeze-Dried, Café do Ponto Descafeinado, Café Solúvel Parmalat, Ariscafé, Café Solúvel Iguaçu e Bassil Coffee. Para a definição do procedimento adequado de mineralização foram utilizadas duas amostras de café solúvel, de um mesmo produtor, sendo que a primeira estava contaminada com os metais: $\mathrm{Cr}$, $\mathrm{Ni}, \mathrm{Cd}, \mathrm{Sb}$ e $\mathrm{Pb}$ e, não disponivel no mercado.

\subsection{Métodos de tratamento das amostras}

\section{Definicão do procedimento de mineralizacão das amostras de café solúvel}

Inicialmente foram testados 6 procedimentos diferentes de mineralização, classificados em 3 classes:

I - microondas focalizado;

II - via úmida convencional;

III - sob pressão em frascos de decomposição com tampas (bombas de teflon).

As figuras 22,23 e 24 a seguir apresentam os fluxogramas dos três processos gerais 


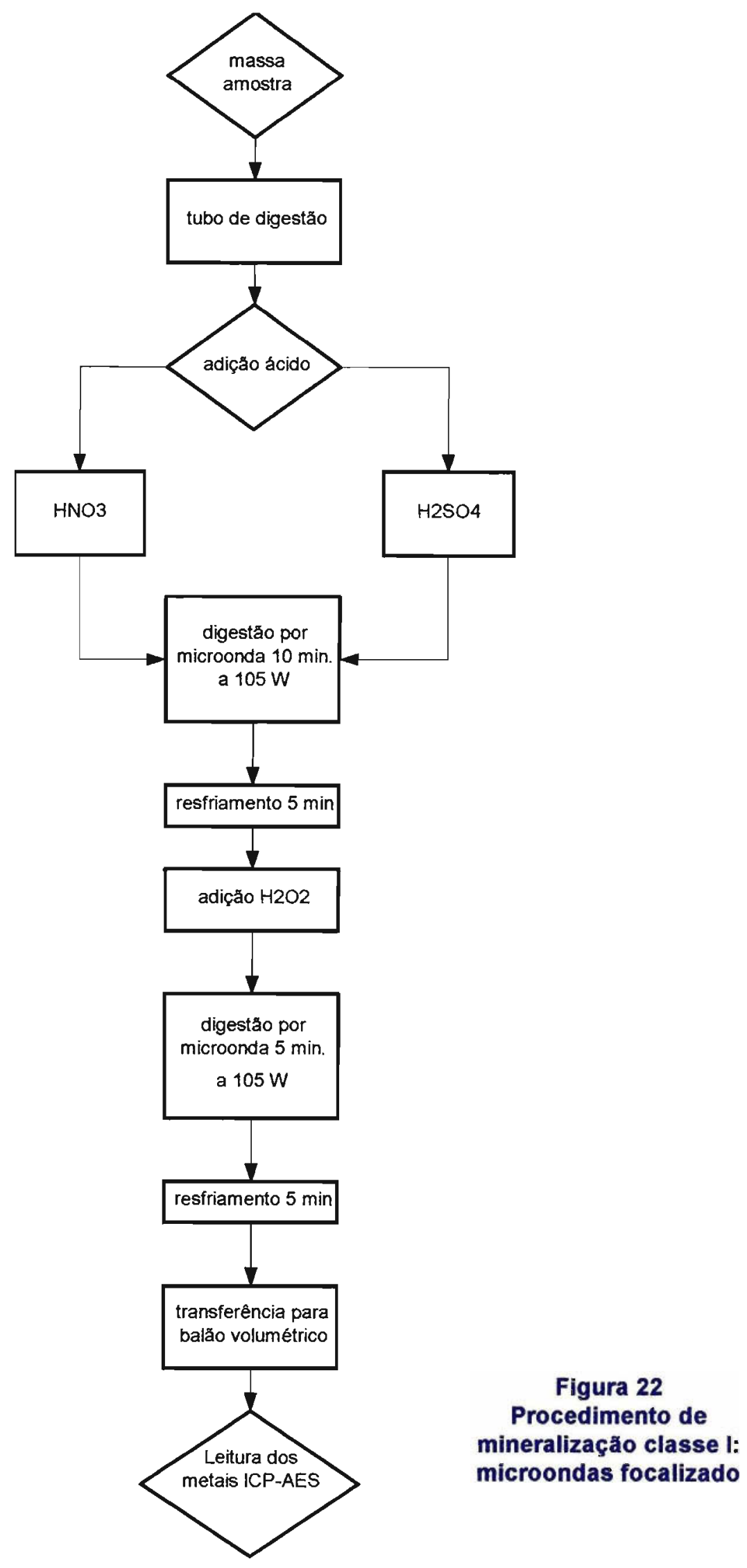




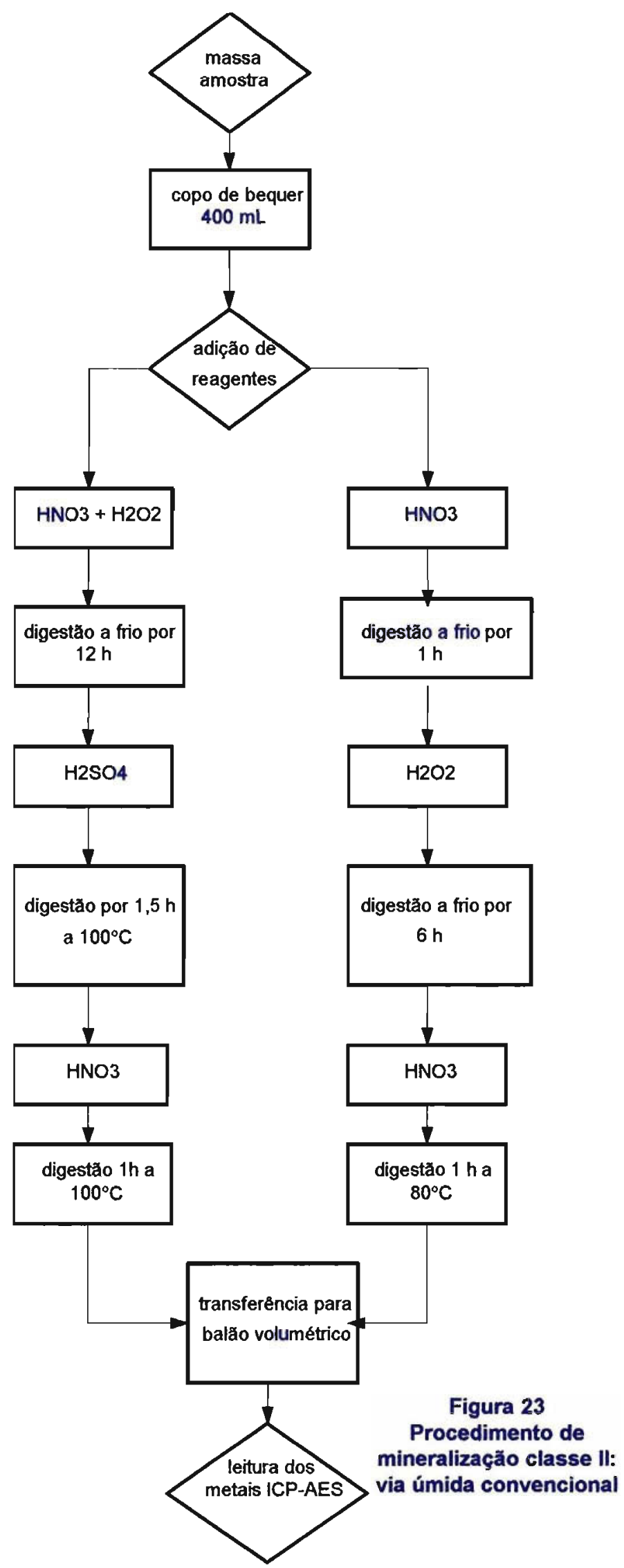




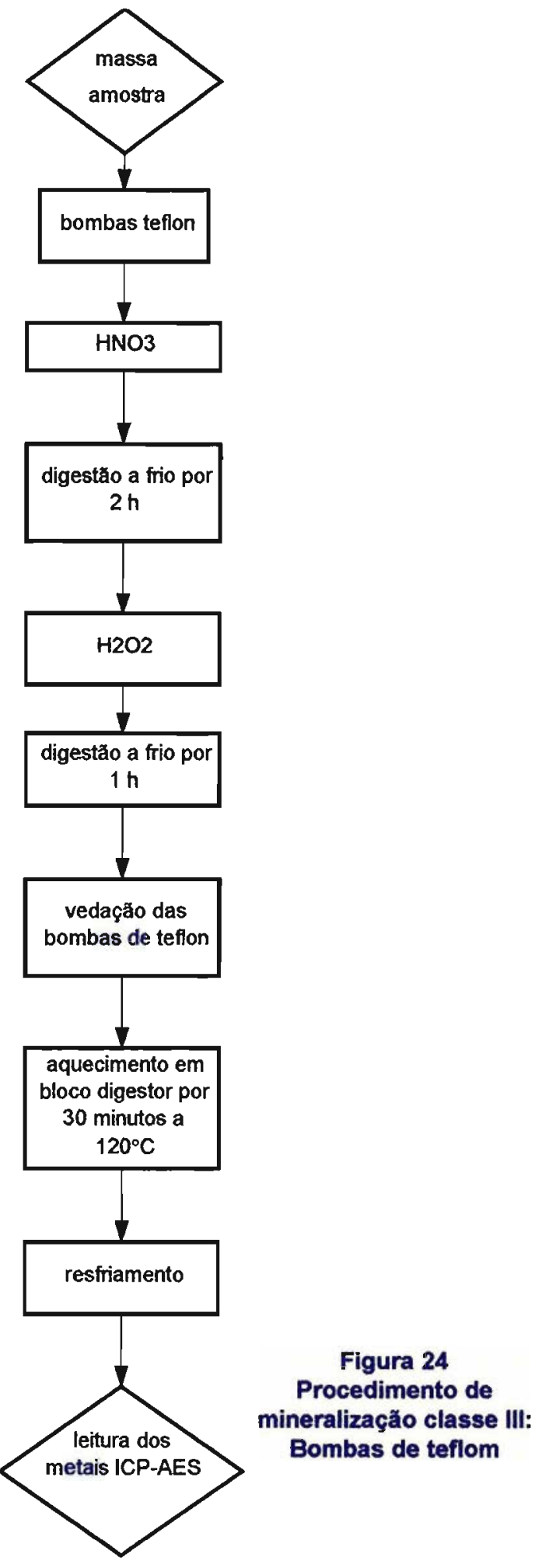


A tabela VI a seguir apresenta os 6 procedimentos de mineralização utilizados:

Tabela VI - procedimentos de mineralização utilizados.

\begin{tabular}{|c|c|c|c|c|c|}
\hline Identificacáo & classe & sistoma & $\begin{array}{c}\text { Massa amostra } \\
\text { (g)! } \\
\text { Volume final (mL) }\end{array}$ & Reagentes & $\begin{array}{l}\text { Tempo/poténcia } \\
\text { ou temperatura }\end{array}$ \\
\hline 1 & I & $\begin{array}{l}\text { Microondas } \\
\text { Focalizado }\end{array}$ & $1,0 / 50$ & $\begin{array}{l}H(103(6 \mathrm{~mL}) \\
1202(0,6 \mathrm{~mL})\end{array}$ & $\begin{array}{l}10 \mathrm{~min} / 105 \mathrm{~W} \\
5 \mathrm{~min} / 105 \mathrm{~W}\end{array}$ \\
\hline 2 & 1 & $\begin{array}{l}\text { Microondas } \\
\text { Focalizado }\end{array}$ & $2,0 / 100$ & $\begin{array}{l}\mathrm{H} 2504(15 \mathrm{~mL}) \\
\mathrm{H} 202(10 \mathrm{~mL})\end{array}$ & $\begin{array}{c}10 \mathrm{~min} / 105 \mathrm{~W} \\
5 \mathrm{~min} / 105 \mathrm{~W}\end{array}$ \\
\hline 3 & I & $\begin{array}{l}\text { Mieroondas } \\
\text { Focalizado }\end{array}$ & $2,0 / 100$ & $\begin{array}{l}\mathrm{HNO}(15 \mathrm{~mL}) \\
\mathrm{H} 2 \mathrm{O} 2(10 \mathrm{~mL})\end{array}$ & $\begin{array}{l}10 \mathrm{~min} / 105 \mathrm{~W} \\
5 \mathrm{~min} / 105 \mathrm{~W}\end{array}$ \\
\hline 4 & II & $\begin{array}{l}\text { Via úmida } \\
\text { convencional }\end{array}$ & $1,0 / 100$ & $\begin{array}{l}\text { HNOS }(6 \mathrm{~mL}) \\
\text { H2O2 (1 mL) } \\
\text { H2SO4 }(3 \mathrm{~mL}) \\
\text { HNO3 }(6 \mathrm{~mL})\end{array}$ & $\begin{array}{c}12 \mathrm{~h} \\
1,5 \mathrm{~h} / 100^{\circ} \mathrm{C} \\
1 \mathrm{~h} / 100^{\circ} \mathrm{C}\end{array}$ \\
\hline 5 & II & $\begin{array}{l}\text { Va úmida } \\
\text { convenoional }\end{array}$ & $1,0 / 50$ & $\begin{array}{l}\text { HNOS }(5 \mathrm{~mL}) \\
\text { H2O2 }(3 \mathrm{~mL}) \\
\text { HIVOS }(5 \mathrm{~mL})\end{array}$ & $\begin{array}{c}1 \mathrm{~h} \\
6 \mathrm{~h} \\
1 \mathrm{~h} / 80^{\circ} \mathrm{C}\end{array}$ \\
\hline 6 & III & $\begin{array}{l}\text { Sob pressaáo em } \\
\text { frascos de } \\
\text { decomposiçáo } \\
\text { com tampas } \\
\text { (bombas de } \\
\text { tellon) }\end{array}$ & $1,0 / 100$ & $\begin{array}{l}\text { HNOS }(6 \mathrm{~mL}) \\
\text { H2On }(0,5 \mathrm{~mL})\end{array}$ & $\begin{array}{c}2 \mathrm{~h} \\
1 \mathrm{~h} \\
30 \mathrm{~min} . / 120^{\circ} \mathrm{C}\end{array}$ \\
\hline
\end{tabular}

Método de tratamento das amostras para as determinacões de $\mathrm{Pb}, \mathrm{Cr}, \mathrm{Hg}$, As e Se

As figuras 25 a 27 a seguir apresentam os fluxogramas dos processos de tratamento das amostras utilizados para as determinaçöes de $\mathrm{Pb}, \mathrm{Cr}, \mathrm{Hg}$, As e Se. 


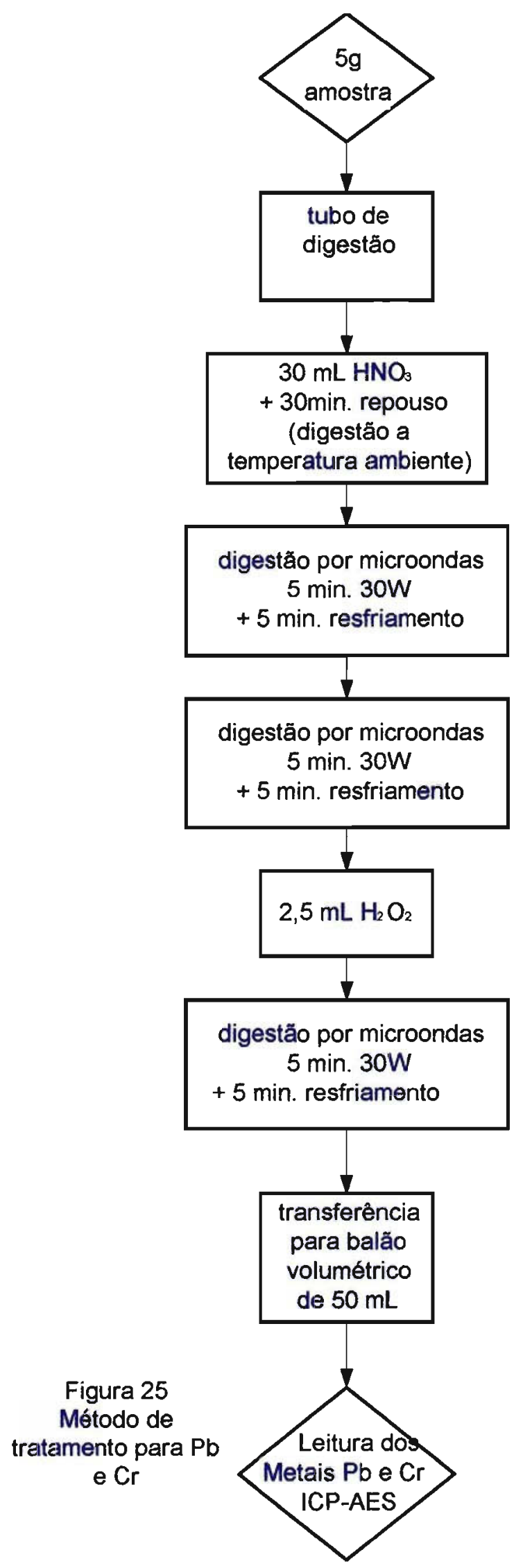




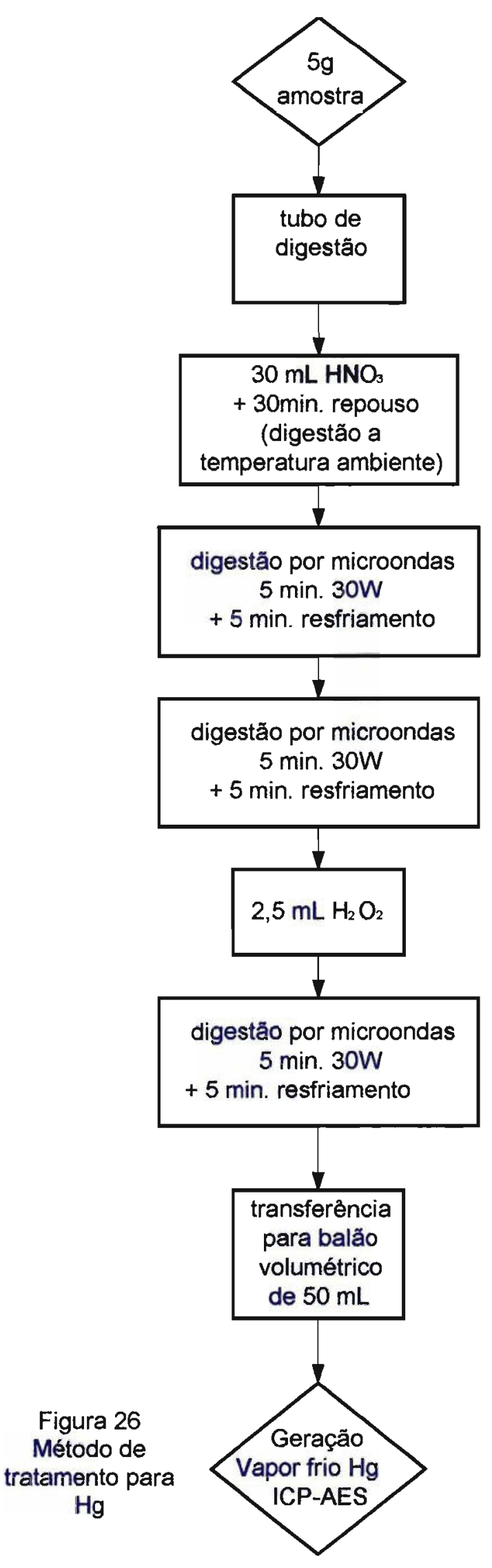




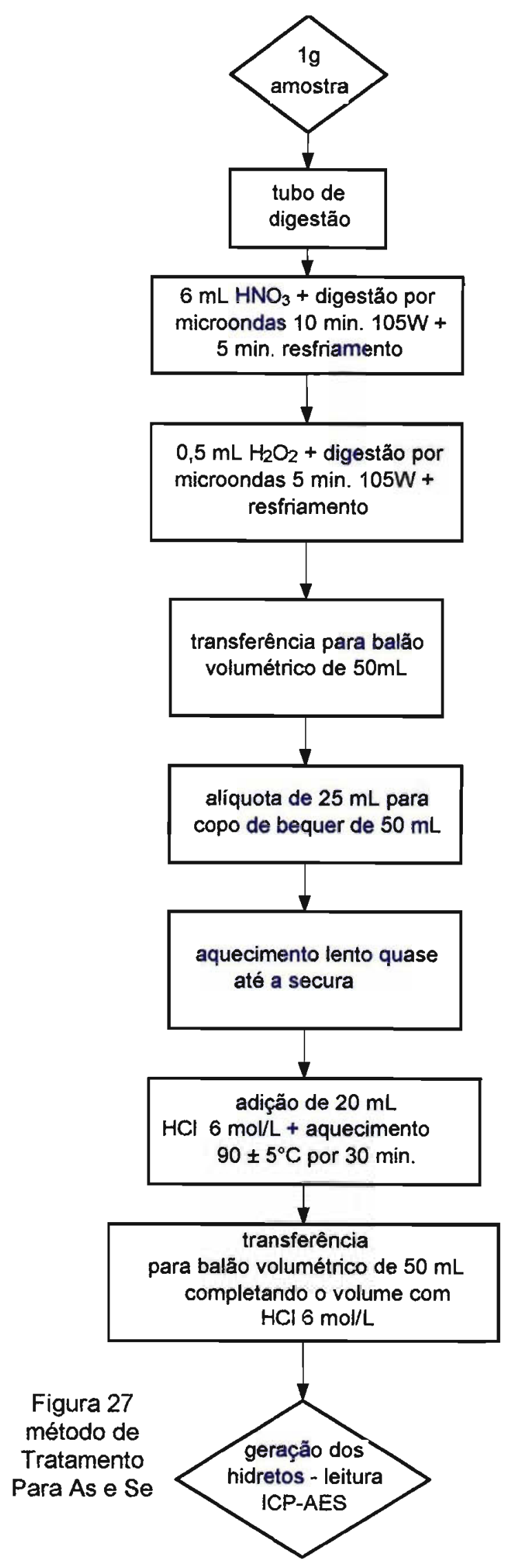


4.5. Condições instrumentais e de trabalho para a determinação dos elementos por ICP-AES.

\section{Condicões de operacão dos espectrômetros}

As condições de operação dos equipamentos espectrômetros de emissão atômica foram utilizadas de acordo com a tabela VII a seguir.

Tabela VII- condições operacionais: espectrômetros de emissão atômica com plasma de argônio induzido (ICP-AES).

\begin{tabular}{|c|c|c|}
\hline Espoctrometro & $\begin{array}{l}\text { Spectro, modelo } \\
\text { Modula }\end{array}$ & $\begin{array}{l}\text { Ball } \text { modelo PSX } \\
\text { (determinacóes de Hg, As e Se) }\end{array}$ \\
\hline Potencia & $1,2 \mathrm{~kW}$ & $1,0 \mathrm{~kW}$ \\
\hline Tempo is integracio & $5 \mathrm{ds}$ & tas \\
\hline Fluxo do gás refrigerante Ar & $12,0 \mathrm{~L} \mathrm{~min}^{-1}$ & $7,51 \min ^{-1}$ \\
\hline fluxo do gás carregador Ar & $1,2 \mathrm{~L} \mathrm{~min}^{-1}$ & $0,6 \mathrm{Lmin}^{1}$ \\
\hline Fluxo do gás guxillar Ar & $1,0\left\llcorner\mathrm{~min}^{-1}\right.$ & $121 \mathrm{~min}^{-1}$ \\
\hline $\begin{array}{l}\text { Vazáo de introducalo da } \\
\text { amostra }\end{array}$ & $1,5 \mathrm{~mL} \mathrm{~min}^{-1}$ & 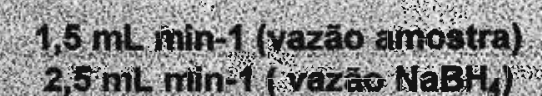 \\
\hline Pressáo do nebulizador & $26 \mathrm{psi}$ & $26 \mathrm{psi}$ \\
\hline $\begin{array}{l}\text { Aluyra de observacăo } \\
\text { (actina da bobina de } \\
\text { lindicto) }\end{array}$ & $12 \mathrm{~mm}$ & $12 \mathrm{~mm}$ \\
\hline
\end{tabular}

\section{Elaboracão de programas analiticos no espectrómetro Modula da Spectro}

Inicialmente foram elaborados programas analíticos para a determinação de todos os elementos de interesse. O espectrômetro de emissão atômica modelo Modula da Spectro Co. dispõe de recursos em seu software que permitem fazer uma escolha criteriosa das linhas de emissão a serem utilizadas para cada elemento. Utilizou-se o método da curva de calibração na determinação dos elementos, através do uso de soluções padrão multielementares de todos os elementos presentes. As faixas de concentração e os programas analíticos realizados no espectrômetro de emissão atômica da Spectro, modelo Modula, são apresentados na tabela VIII a seguir. 
Tabela VIII - Programas analíticos e faixas de concentração utilizadas no preparo das soluções padrão multielementares para o estabelecimento das curvas de calibração.

\begin{tabular}{|c|c|c|}
\hline IDENWIFICACAO & ELEMENTOS & FAIXA DE CONCENTRACAO \\
\hline PROGRAMAA & $\mathrm{NaOK}$ & $100,0-500,0 \mathrm{mgl}^{1 /}$ \\
\hline PROGRAMAB & K & $100,0-500,0-1000,0 \mathrm{mgL}^{-1}$ \\
\hline PROGRAMAC & Mg, Al, P, S, Ca, Mn, Fe e Sn & $1,0-10,0-100,0 \mathrm{mgl}^{-1}$ \\
\hline PROGRAMA D & $\mathrm{Mg}, \mathrm{Al}, \mathrm{P}, \mathrm{S}, \mathrm{Ca}, \mathrm{Mn}$ e Fe & $1,0-10,0-100,0 \mathrm{mgL}^{-1}$ \\
\hline PROGRAMAE & $\mathrm{Cr}, \mathrm{Ni}, \mathrm{Cu}, \mathrm{Zn}, \mathrm{As}, \mathrm{Se}, \mathrm{Cd}, \mathrm{Sb}$ e Pb & $0,1-1,0-10,0 \mathrm{mgl}^{-1}$ \\
\hline PROGRAMA F*: & $\mathrm{Ni}, \mathrm{Cu}, \mathrm{Zn}_{\mathrm{n}} \mathrm{Cd}$ e $\mathrm{Sb}$ & $0,1-1,0-10,0 \mathrm{mgL}^{-1}$ \\
\hline PROGRAMA G & CrePb & $0,1-1,0-10,0 \mathrm{mgL}^{-1}$ \\
\hline PROGRAMA H & $\mathrm{Hg}$ & $0,01-0,1-1,0-10,0 \mathrm{mgL}^{-1}$ \\
\hline PROGRAMAI & $\mathrm{Sn}$ & $0,1-1,0-10,0 \mathrm{mgL}^{-1}$ \\
\hline
\end{tabular}

"Excluído Sn, "excluído As, Se, Pb e Cr.

As curvas de calibração obtidas são representadas pela equação da reta ou regressão linear, sendo a concentração de cada analito dada pela equação :

Conc. $\left(\mathrm{mgL}^{-1}\right)=\mathrm{Ao}_{0}+\mathrm{A}_{1} . \mathrm{IR}$

onde: $A_{0}=$ coeficiente linear;

A1 = coeficiente angular da regressão;

IR = intensidade relativa da emissão do analito.

De acordo com THOMPSON [67], o limite de detecção instrumental é definido como a concentração do analito que fornece uma resposta igual a três vezes o valor do desvio padrão do branco ou background, o qual, no presente trabalho, foi calculado pelo software do equipamento. Contudo, para maior segurança das determinações, devido à matriz das amostras de café, foram utilizados valores de limites de detecção práticos ou limites de determinação, que, de acordo com THOMPSON [67], correspondem a 5 vezes o limite de detecção instrumental. No caso do $\mathrm{Cr}$, no comprimento de onda $357,869 \mathrm{~nm}$, foi possivel utilizar o limite de detecção instrumental como limite de detecção prático ou limite de determinação. A tabela IX a seguir apresenta as linhas de emissão e parâmetros das curvas de calibração. 
Tabela IX - Linhas de emissão e parâmetros das curvas de calibração ( $\mathrm{mgL}^{-1} \mathrm{x}$ intensidade).

\begin{tabular}{|c|c|c|c|c|c|c|}
\hline Elemento & $\begin{array}{c}\text { Linha de } \\
\text { emissăo }(\lambda) \\
\text { nm }\end{array}$ & $\begin{array}{l}\text { Coeficiente } \\
\text { linear }(A 0)\end{array}$ & $\begin{array}{l}\text { coeficiente } \\
\text { angular (A1) }\end{array}$ & $\begin{array}{l}\text { Coeficiente } \\
\text { de correlaçäo } \\
\text { linear }(r)\end{array}$ & $\begin{array}{l}\text { Concentraçäo } \\
\text { máxima } \\
\text { (mgL) }\end{array}$ & $\begin{array}{l}\text { limite de } \\
\text { determinaçäo } \\
\text { LD (mingL') }\end{array}$ \\
\hline $\mathrm{Na}$ & 588,995 & $-0,7743$ & $1,0369 \times 10^{4}$ & 1,0000 & 600 & 0,1 \\
\hline K & 766,491 & $-3,3549$ & $1,1777 \times 10^{-3}$ & 1,0000 & 600 & 0,5 \\
\hline$K^{*}$ & 766,491 & $-9,7663$ & $1,5488 \times 10^{3}$ & 0,9996 & 1000 & 1,0 \\
\hline Mg & 285,213 & $-0,3579$ & $9,1608 \times 10^{-6}$ & 1,0000 & 120 & 0,05 \\
\hline Al & 167,080 & $-1,0510$ & $1,6801 \times 10^{-5}$ & 0,9994 & 120 & 0,1 \\
\hline $\mathbf{P}$ & 178,290 & $-0,3985$ & $1,6906 \times 10^{-4}$ & 1,0000 & 120 & 0,05 \\
\hline $\mathrm{s}$ & 182,040 & $-0,9916$ & $1,5915 \times 10^{-4}$ & 1,0000 & 120 & 0,1 \\
\hline $\mathrm{Ca}$ & 422,673 & $-0,5674$ & $2,7911 \times 10^{-6}$ & 0,9999 & 120 & 0,1 \\
\hline $\mathrm{Mn}$ & 293,930 & $-0,6073$ & $2,9262 \times 10^{-4}$ & 1,0000 & 120 & 0,05 \\
\hline $\mathrm{Fe}$ & 259,940 & $-1,0930$ & $2,6105 \times 10^{-3}$ & 0,9999 & 120 & 0,1 \\
\hline Sn & 189,926 & $-0,3620$ & $1,6229 \times 10^{4}$ & 1,0000 & 120 & 0,05 \\
\hline $\mathrm{Sn}^{\star \star}$ & 189,926 & $-0,1410$ & $9,3238 \times 10^{-4}$ & 0,9995 & 12 & 0,1 \\
\hline $\mathrm{Cr}$ & 284,325 & $-0,3955$ & $2,7761 \times 10^{-4}$ & 1,0000 & 12 & 0,04 \\
\hline $\mathrm{Cr}^{* *}$ & 357,869 & $-0,3776$ & $8,9826 \times 10^{6}$ & 1,0000 & 12 & 0,01 \\
\hline $\mathrm{Ni}$ & 352,454 & $-1,3386$ & $4,1800 \times 10^{-4}$ & 1,0000 & 12 & 0,05 \\
\hline $\mathrm{Cu}$ & 324,754 & $-0,08817$ & $1,5887 \times 10^{-6}$ & 1,0000 & 12 & 0,01 \\
\hline $\mathrm{Zn}$ & 213,856 & $-0,07228$ & $5,9600 \times 10^{-6}$ & 1,0000 & 12 & 0,005 \\
\hline As & 188,979 & $-0,3619$ & $1,9970 \times 10^{-4}$ & 1,0000 & 12 & 0,05 \\
\hline $\mathrm{Se}$ & 196,020 & $-0,6121$ & $2,0057 \times 10^{-4}$ & 1,0000 & 12 & 0,1 \\
\hline Cd & 226,502 & $-0,06134$ & $9,9533 \times 10^{-6}$ & 1,0000 & 12 & 0,005 \\
\hline $\mathrm{Sb}$ & 217,581 & $-0,8281$ & $1,7265 \times 10^{-4}$ & 1,0000 & 12 & 0,04 \\
\hline $\mathrm{Pb}$ & 168,220 & $-0,2301$ & $4,5517 \times 10^{-4}$ & 1,0000 & 12 & 0,045 \\
\hline $\mathrm{Pb}^{* *}$ & 220,353 & $-2,2400$ & $1,0236 \times 10^{-3}$ & 0,9999 & 12 & 0,10 \\
\hline $\mathrm{Hg}$ & 184,950 & $-0,1302$ & $4,7160 \times 10^{-6}$ & 1,0000 & 12 & 0,005 \\
\hline
\end{tabular}


*Para a determinação do $\mathrm{K}$ em amostras com teores maiores que $600 \mathrm{mgL}^{-1}$ na soluçăo de análise;

*Nos casos do $\mathrm{Cr}$ e $\mathrm{Pb}$ foram escolhidos comprimentos de ondas alternativos e para o $\mathrm{Sn}$ foi realizada correção de radiaçăo de fundo.

\section{Elaboracão de programas analíticos no espectrómetro PSX da Baird}

As determinações dos analitos $\mathrm{As}$, Se e $\mathrm{Hg}$ foram realizadas no espectrômetro de emissão atỏmica Baird, modelo PSX. Os programas analíticos são apresentados na tabela X.

Tabela X-Programas analíticos e faixas de concentração utilizadas no preparo das soluções padrão multielementares para o estabelecimento das curvas de calibração para as determinações do As, Se e $\mathrm{Hg}$.

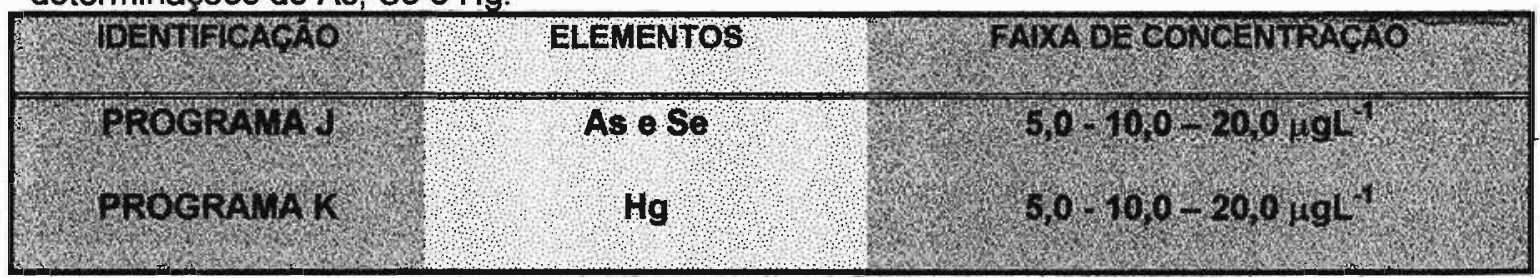

As linhas de emissão e parâmetros das curvas de calibração são apresentadas na tabela XI.

Tabela XI - Linhas de emissão e parâmetros das curvas de calibração ( $\mathrm{mgL}^{-1} \mathrm{x}$ intensidade).

\begin{tabular}{|c|c|c|c|c|c|c|}
\hline fermento & $\begin{array}{c}\text { linha de } \\
\text { emissao }(\lambda) \\
\text { nm }\end{array}$ & $\begin{array}{l}\text { Coeficleme } \\
\text { her }(A \circ)\end{array}$ & $\begin{array}{l}\text { Coeficiente } \\
\text { angular (A1) }\end{array}$ & 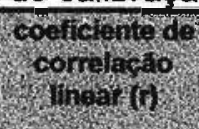 & $\begin{array}{c}\text { Concenitracáo } \\
\text { maxina } \\
\left(4 L^{\prime}\right) \text { ) }\end{array}$ & 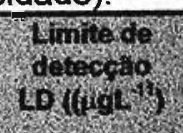 \\
\hline $\begin{array}{l}A s \\
\mathrm{Se} \\
\mathrm{Hg}\end{array}$ & $\begin{array}{l}193,696 \\
196,026 \\
194,163\end{array}$ & $\begin{array}{r}24,1218 \\
13,8789 \\
-5,9155\end{array}$ & $\begin{array}{l}5,744 \times 10^{-1} \\
3,6250 \times 10^{-1} \\
8,6700 \times 10^{-2}\end{array}$ & $\begin{array}{r}0,9982 \\
0,9976 \\
0,9986\end{array}$ & 30 & $\begin{array}{l}1,0 \\
2,0^{\circ} \\
0,5 \\
1,0 \% \\
9,98 \\
1,0 \%\end{array}$ \\
\hline
\end{tabular}

"limites de detecção instrumentais calculados como três vezes o desvio padräo do branco.

**limites de detecção práticos (limites de determinaçăo): menor quantidade possível de ser detectada com segurança

\subsection{Métodos Estatísticos}

Todo o tratamento estatístico através da utilização dos métodos da análise de clusters hierárquicos e componentes principais foi realizado utilizando-se os programas computacionais do SPSS para windows de acordo com NORUSIS [62]. 


\section{RESULTADOS E DISCUSSÕES}

\subsection{Métodos de tratamento da amostra: definição do procedimento de mineralização mais adequado}

$\mathrm{Na}$ avaliação da eficiência dos diferentes procedimentos de mineralização, inicialmente foi utilizada uma amostra de café solúvel que, de acordo com o produtor, estava contaminada com $\mathrm{Cr}, \mathrm{Ni}, \mathrm{Cd}, \mathrm{Sb}$ e $\mathrm{Pb}$. Os resultados obtidos são apresentados a seguir nas tabelas XII e XIII.

Tabela XII - resultados obtidos na análise de amostra de café solúvel através dos diferentes procedimentos de mineralização, expressos em $\mathrm{g} / 100 \mathrm{~g}$ e $\mathrm{mg} / \mathrm{Kg}$, para os elementos dos programas A, B e C (tabela VIII, página 55).

\begin{tabular}{|c|c|c|c|c|c|c|c|c|c|c|}
\hline $\begin{array}{c}\text { Identificação } \\
\text { (") }\end{array}$ & $\underset{g / 100 g}{M g}$ & $\begin{array}{c}\mathrm{Al} \\
\mathrm{mg} / \mathrm{Kg}\end{array}$ & $\begin{array}{c}P \\
g / 100 g\end{array}$ & $\begin{array}{c}S \\
g / 100 g\end{array}$ & $\begin{array}{c}\mathrm{Ca} \\
\mathrm{g} / 100 \mathrm{~g}\end{array}$ & $\underset{\mathrm{mg} / \mathrm{Kg}}{\mathrm{Mn}}$ & $\begin{array}{c}\mathrm{Fe} \\
\mathrm{mg} / \mathrm{Kg}\end{array}$ & $\begin{array}{c}\mathrm{Sn} \\
\mathrm{mg} / \mathrm{Kg}\end{array}$ & $\begin{array}{c}\mathrm{Na} \\
\mathrm{g} / 100 \mathrm{~g}\end{array}$ & $\begin{array}{c}K \\
g / 100 g\end{array}$ \\
\hline 1 & 0,35 & $<5,0$ & 0,44 & 0,20 & 0,13 & 18,0 & 60,0 & 7,0 & 0,060 & 3,74 \\
\hline 2 & 0,23 & $<5,0$ & 0,41 & - & 0,09 & 8,5 & 52,0 & 37,5 & 0,043 & 2,53 \\
\hline 3 & 0,36 & $<5,0$ & 0,43 & 0,21 & 0,13 & 18,5 & 57,5 & 10,0 & 0,065 & 3,80 \\
\hline 4 & 0,34 & $<10,0$ & 0,42 & - & 0,12 & 18,0 & 57,5 & 20,0 & 0,052 & 3,57 \\
\hline 5 & 0,36 & $<5,0$ & 0,44 & 0,21 & 0,12 & 21,0 & 61,0 & 29,0 & 0,060 & 3,42 \\
\hline 6 & 0,36 & $<10,0$ & 0,44 & 0,21 & 0,14 & 21,5 & 62,5 & 6,5 & 0,063 & 3,50 \\
\hline
\end{tabular}

(*) identificação dos métodos de mineralização conforme tabela VI, página 50.

Tabela XIII - resultados obtidos na análise de amostra de café solúvel através dos diferentes procedimentos de mineralização, expressos em $\mathrm{mg} / \mathrm{Kg}$, para os elementos dos programas $\mathrm{E} \mathrm{e} \mathrm{H}$ (tabela VIII, página 55).

\begin{tabular}{|c|c|c|c|c|c|c|c|c|c|c|}
\hline $\begin{array}{l}\text { Identifica- } \\
\text { são (") } \\
\end{array}$ & $\begin{array}{c}\mathrm{Cr} \\
\mathrm{mg} / \mathrm{Kg}\end{array}$ & $\begin{array}{c}\mathrm{Ni} \\
\mathbf{M g} / \mathrm{Kg}\end{array}$ & $\begin{array}{c}\mathrm{Cu} \\
\mathrm{mg} / \mathrm{Kg}\end{array}$ & $\begin{array}{c}\mathrm{Zn} \\
\mathrm{mg} / \mathrm{Kg}\end{array}$ & $\begin{array}{c}\text { As } \\
\mathrm{mg} / \mathrm{Kg}\end{array}$ & $\begin{array}{c}\mathrm{Se} \\
\mathrm{mg} / \mathrm{Kg}\end{array}$ & $\begin{array}{c}\mathrm{Cd} \\
\mathrm{mg} / \mathrm{Kg}\end{array}$ & $\begin{array}{c}\mathrm{Sb} \\
\mathrm{mg} / \mathrm{Kg}\end{array}$ & $\begin{array}{c}\mathrm{Pb} \\
\mathrm{mg} / \mathrm{Kg}\end{array}$ & $\begin{array}{c}\mathrm{Hg} \\
\mathrm{mg} / \mathrm{Kg}\end{array}$ \\
\hline 1 & 2,93 & 4,38 & 0,54 & 2,87 & 6,00 & 8,90 & 0,50 & 5,01 & 12,24 & 0,43 \\
\hline 2 & $<2,0$ & $<2,50$ & $<0,50$ & 2,08 & 4,66 & 6,19 & 0,40 & $<2,00$ & 2,44 & 0,10 \\
\hline 3 & 3,12 & 5,07 & 0,53 & 3,25 & 5,54 & 8,10 & 0,45 & 4,67 & 11,07 & 0,40 \\
\hline 4 & 3,18 & 6,01 & $<1,0$ & 5,24 & 4,63 & 7,01 & 0,61 & 8,46 & 4,16 & 0,20 \\
\hline 5 & 3,59 & 6,72 & 1,16 & 4,25 & 10,21 & 11,21 & 1,13 & 11,64 & 15,57 & 0,52 \\
\hline 6 & 2,17 & 4,05 & 0,73 & 3,00 & 6,50 & 10,00 & 0,68 & 7,71 & 11,75 & 0,42 \\
\hline
\end{tabular}

(*) identificação dos métodos de mineralização conforme tabela VI, página 50.

Nas determinações dos elementos constituintes da tabela XII, observa-se que resultados equivalentes, com exceção do estanho, são obtidos para os métodos de mineralização $1,3,4,5$ e 6 , demonstrados nas figuras 28 e 29 . As determinações dos elementos constituintes da tabela XIII apresentam considerável variação de resultados entre os elementos. De uma maneira geral os métodos 1 e 3 apresentam resultados equivalentes, conforme demonstrado nas figuras 30 e 31 . 


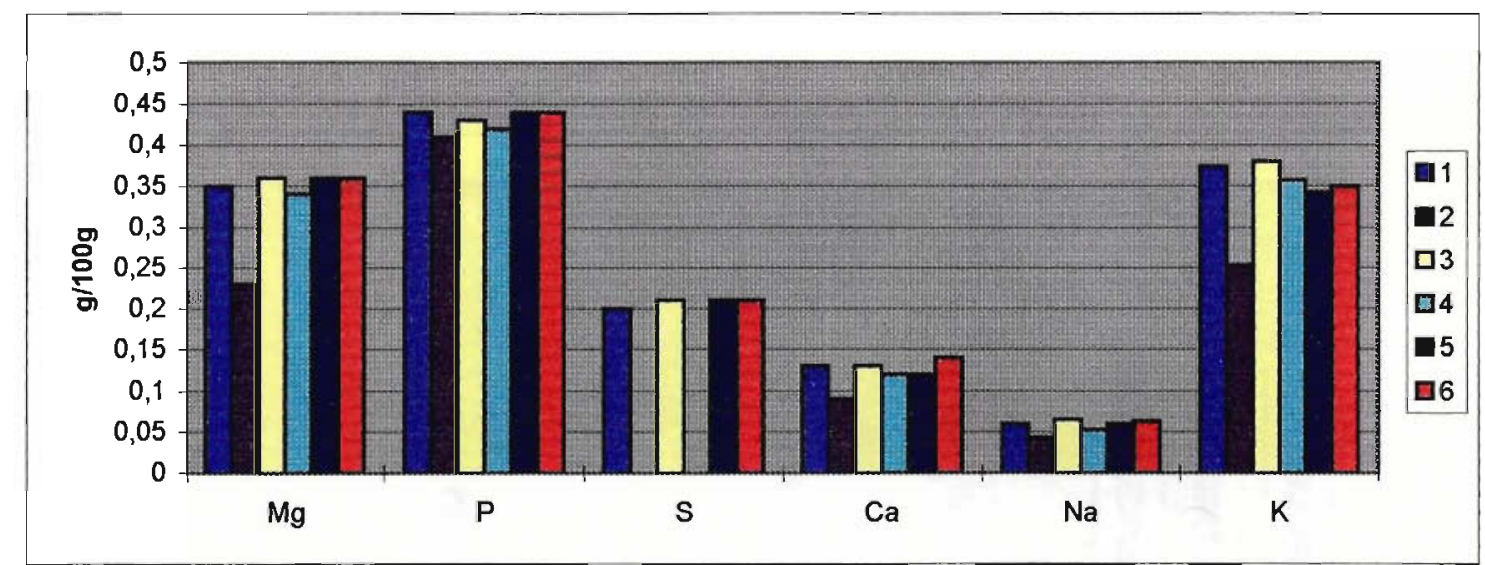

* $\mathrm{K}$ : valores expressos como $\left(\mathrm{g} 100 \mathrm{~g}^{-1}\right) \times 10^{+1}$

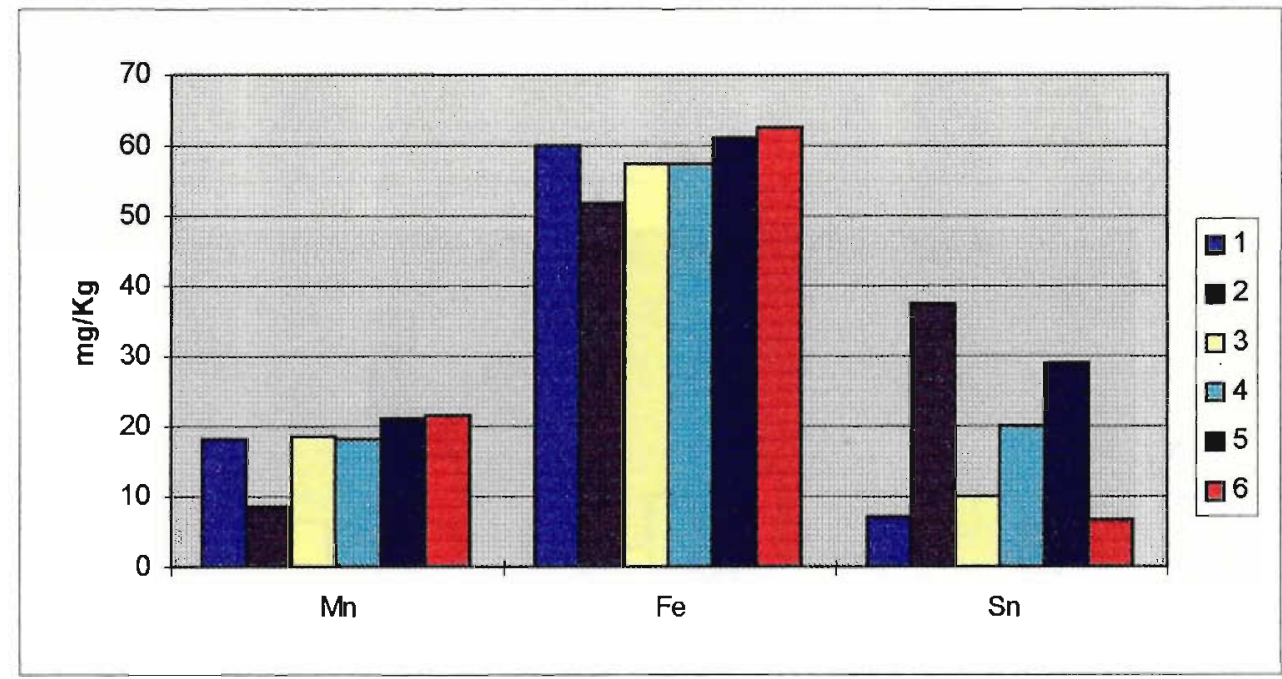

Figuras 28 e 29: comparação dos resultados obtidos referentes às determinações dos elementos constituintes da tabela XII, com exceção do $\mathrm{Al}(<5,0 \mathrm{mg} / \mathrm{Kg})$. 

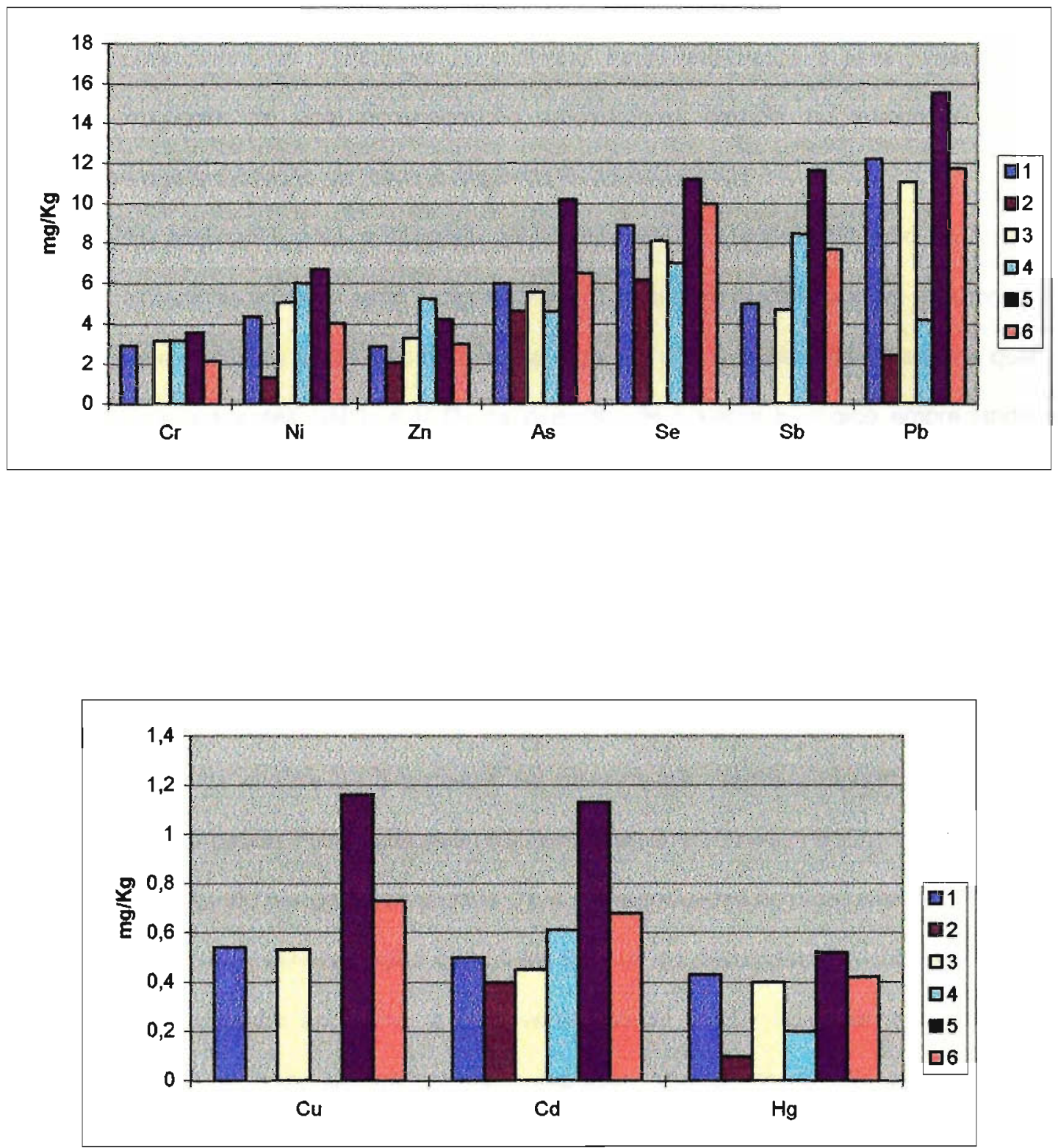

Figuras 30 e 31: comparação dos resultados obtidos referentes às determinações dos elementos constituintes da tabela XIII. 
A recuperação de metais traços em várias matrizes ricas em matéria orgânica, como alimentos e materiais biológicos, tem sido objeto de muitos estudos. Contudo, poucos se propõem a estabelecer uma maneira de avaliação da eliminação da matéria orgânica presente. Estudos essencialmente qualitativos ou indiretos foram realizados a este respeito. Se uma solução resultante de uma mineralização apresenta-se límpida ou levemente amarelada, assume-se que a oxidação da matéria orgânica foi completa [12]

Uma alternativa para a obtenção desta informação é a determinação do conteúdo de carbono residual na amostra após a digestão. NAKASHIMA et al. [68] usaram este método para mostrar que a completa destruição da matéria orgânica não é totalmente alcançada quando da utilização dos reagentes $\mathrm{HNO}_{3}$ e $\mathrm{H}_{2} \mathrm{O}_{2}$ na digestão de material biológico empregando vários sistemas fechados de aquecimento com microondas.

O procedimento de digestão escolhido como o mais adequado foi o $n^{\circ} \mathbf{1}$, da classe $\mathrm{I}$, sistema microondas focalizado, pois é o que emprega a menor quantidade de reagentes aliado ao tempo e facilidade de mineralização da amostra.

O fator limitante na utilização dos métodos de mineralização que empregam $\mathrm{H}_{2} \mathrm{SO}_{4}$ é a impossibilidade da análise de $S$ presente na amostra, não sendo adequados também para a análise de $\mathrm{Pb}$ a baixas concentrações [10], formando o composto $\mathrm{PbSO}_{4}$, sal de solubilidade muito baixa, tornando portanto os métodos 2 e 4 não adequados às propostas deste trabalho.

O método de mineralização que utiliza frascos de decomposição com tampas (bombas de teflon) sob pressão apresenta a inconveniência de admitir somente massa reduzida de amostra, devido a riscos de vazamento e explosão resultantes da alta pressão dos gases produzidos como produtos da oxidação da matéria orgânica, representado pelas equaçōes

$$
\begin{aligned}
& \text { químicas: }{ }^{*}\left(\mathrm{CH}_{2}\right) \mathrm{x}+2 \mathrm{HNO}_{3} \rightarrow \mathrm{CO}_{2}(\mathrm{~g})+2 \mathrm{NO}(\mathrm{g})+2 \mathrm{H}_{2} \mathrm{O} \\
& \mathrm{NO}(\mathrm{g})+1 / 2 \mathrm{O}_{2}(\mathrm{~g}) \rightarrow \mathrm{NO}_{2}(\mathrm{~g}) \\
& \mathrm{H}_{2} \mathrm{O}_{2} \rightarrow \mathrm{H}_{2} \mathrm{O}+1 / 2 \mathrm{O}_{2}(\mathrm{~g}) \\
& \mathrm{H}_{2} \mathrm{O}_{2}+{ }^{*}\left(\mathrm{CH}_{2}\right) x+\mathrm{O}_{2}(\mathrm{~g}) \underset{\mathrm{H}^{*}}{\rightarrow} \mathrm{CO}_{2}(\mathrm{~g})+2 \mathrm{H}_{2} \mathrm{O}
\end{aligned}
$$

\footnotetext{
* matéria orgânica
} 
A quantidade de amostra utilizada nesta etapa do trabalho causou vazamento em alguns frascos de decomposição com tampas (bombas de teflon), demonstrando ser necessária uma avaliação cuidadosa da quantidade limite de amostra necessária para digestão segura.

A tabela XIV a seguir apresenta de forma resumida as vantagens e desvantagens dos métodos de mineralização estudados.

Tabela XIV- vantagens e desvantagens dos métodos de mineralização estudados.

\begin{tabular}{|c|c|c|}
\hline MÉTODO & VANTAGENS & DESVANTAGENS \\
\hline 01 & $\begin{array}{l}\text { - MINERALIZAÇÃO EFICIENTE } \\
\text { - QUANTIDADE REAGENTES } \\
\text { - TEMPO }\end{array}$ & \\
\hline 02 & - & $\begin{array}{l}\text { - USO } \mathrm{H}_{2} \mathrm{SO}_{4} \\
\text { - MINERALIZAÇ̃̃O NÃO EFICIENTE }\end{array}$ \\
\hline 03 & $\begin{array}{l}\text { - MINERALIZAÇÃO EFICIENTE } \\
\text { - TEMPO }\end{array}$ & $\begin{array}{l}\text { - MAIOR QUANTIDADE DE REAGENTES } \\
\text { EM RELAÇÃO AO MÉTODO } 01\end{array}$ \\
\hline 04 & - MINERALIZAÇÃo EFICIENTE & $\begin{array}{l}\text { - USO } \mathrm{H}_{2} \mathrm{SO}_{4} \\
\text { - TEMPO }\end{array}$ \\
\hline 05 & - MINERALIZAÇÃO EFICIENTE & - TEMPO \\
\hline 06 & - MINERALIZAÇÃo EFICIENTE & $\begin{array}{l}\text { - } \text { TEMPO } \\
\text { - RISCOS DE EXPLOSÃO } \\
\text { - FATOR LIMITANTE : RELAÇÃO } \\
\text { MASSANOLUME }\end{array}$ \\
\hline
\end{tabular}

5.2 - Determinação dos elementos em uma amostra de café solúvel e amostra enriquecida utilizando o procedimento de mineralização escolhido

Uma nova amostra de café solúvel, do mesmo produtor que a anterior, foi submetida à análise empregando o procedimento de mineralização escolhido como o mais adequado:

- sistema : microondas focalizado;

- massa da amostra: $1,0 \mathrm{~g}$;

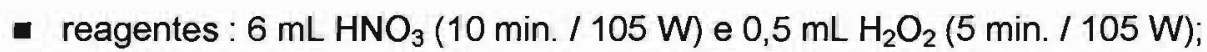

- volume final da solução de trabalho : $50 \mathrm{~mL}$.

Os resultados obtidos, com número de repetição igual a 8 , são apresentados na tabela $\mathrm{XV}$. 
Tabela XV: resultados obtidos na avaliação do procedimento de mineralização mais adequado $(n=8)$.

\begin{tabular}{|c|c|c|}
\hline Elemento & Concentração presente & Coeficiente de variação \\
\hline Mg & $0,334 \pm 0,004 \mathrm{~g} / 100 \mathrm{~g}$ & 3,0 \\
\hline Al & $<5,0 \mathrm{mg} / \mathrm{Kg}$ & - \\
\hline $\mathbf{P}$ & $0,335 \pm 0,010 \mathrm{~g} / 100 \mathrm{~g}$ & 3,0 \\
\hline $\mathrm{Ca}$ & $0,131 \pm 0,003 \mathrm{~g} / 100 \mathrm{~g}$ & 2,3 \\
\hline Mn & $7,00 \pm 0,50 \mathrm{mg} / \mathrm{Kg}$ & 7,1 \\
\hline $\mathrm{Fe}$ & $38,0 \pm 2,5 \mathrm{mg} / \mathrm{Kg}$ & 6,6 \\
\hline Sn & $16,0 \pm 4,0 \mathrm{mg} / \mathrm{Kg}$ & 25 \\
\hline s & $0,180 \pm 0,008 \mathrm{~g} / 100 \mathrm{~g}$ & 4,2 \\
\hline $\mathrm{Na}$ & $0,0580 \pm 0,0015 \mathrm{~g} / 100 \mathrm{~g}$ & 2,6 \\
\hline K & $3,77 \pm 0,06 \mathrm{~g} / 100 \mathrm{~g}$ & 1,6 \\
\hline Cr & $1,50 \pm 0,5 \mathrm{mg} / \mathrm{Kg}$ & 33 \\
\hline $\mathrm{Ni}$ & $<2,50 \mathrm{mg} / \mathrm{Kg}$ & - \\
\hline $\mathrm{Cu}$ & $1,55 \pm 0,15 \mathrm{mg} / \mathrm{Kg}$ & 9,7 \\
\hline $\mathrm{Zn}$ & $3,75 \pm 0,35 \mathrm{mg} / \mathrm{Kg}$ & 9,3 \\
\hline As & $3,95 \pm 0,55 \mathrm{mg} / \mathrm{Kg}$ & 14 \\
\hline $\mathrm{Se}$ & $3,30 \pm 1,10 \mathrm{mg} / \mathrm{Kg}$ & 33 \\
\hline $\mathrm{Cd}$ & $<0,25 \mathrm{mg} / \mathrm{Kg}$ & - \\
\hline Sb & $<2,00 \mathrm{mg} / \mathrm{Kg}$ & - \\
\hline $\mathrm{Pb}$ & $17,0 \pm 3,5 \mathrm{mg} / \mathrm{Kg}$ & 21 \\
\hline $\mathrm{Hg}$ & $2,40 \pm 1,3 \mathrm{mg} / \mathrm{Kg}$ & 54 \\
\hline
\end{tabular}

Devido à inexistência de amostras de referência certificadas de café solúvel, foi realizado estudo em amostras enriquecidas sinteticamente com quantidades conhecidas dos elementos, passando estas por todas as etapas do processo de análise sofrido pela amostra, realizando-se 3 repetições. Os resultados são apresentados na tabela XVI e na figura 32. 
Tabela XVI: valores de concentração e recuperação dos elementos adicionados e recuperados na avaliação de uma amostra de café solúvel enriquecida.

\begin{tabular}{|c|c|c|c|c|}
\hline Elemento & $\begin{array}{c}\text { Concentração } \\
\text { presente }^{*}\end{array}$ & $\begin{array}{c}\text { Concentração } \\
\text { Adicionada }\end{array}$ & $\begin{array}{c}\text { Recuperação } \\
(n=3)\end{array}$ & \% Recuperaçäo \\
\hline $\mathrm{Mg}$ & $0,334 \pm 0,004 \mathrm{~g} / 100 \mathrm{~g}$ & $0,250 \mathrm{~g} / 100 \mathrm{~g}$ & $0,206 \pm 0,005 \mathrm{~g} / 100 \mathrm{~g}$ & $82,4 \pm 2,2$ \\
\hline Al & $<5,0 \mathrm{mg} / \mathrm{Kg}$ & $25,0 \mathrm{mg} / \mathrm{Kg}$ & $21,0 \pm 1,0 \mathrm{mg} / \mathrm{Kg}$ & $84,0 \pm 4,0$ \\
\hline $\mathbf{P}$ & $0,335 \pm 0,010 \mathrm{~g} / 100 \mathrm{~g}$ & $0,250 \mathrm{~g} / 100 \mathrm{~g}$ & $0,236 \pm 0,018 \mathrm{~g} / 100 \mathrm{~g}$ & $94,4 \pm 7,2$ \\
\hline $\mathrm{Ca}$ & $0,131 \pm 0,003 \mathrm{~g} / 100 \mathrm{~g}$ & $0,125 \mathrm{~g} / 100 \mathrm{~g}$ & $0,118 \pm 0,012 \mathrm{~g} / 100 \mathrm{~g}$ & $94,4 \pm 9,6$ \\
\hline Mn & $7,00 \pm 0,50 \mathrm{mg} / \mathrm{Kg}$ & $25,0 \mathrm{mg} / \mathrm{Kg}$ & $24,5 \pm 2,0 \mathrm{mg} / \mathrm{Kg}$ & $98,0 \pm 8,0$ \\
\hline $\mathrm{Fe}$ & $38,0 \pm 2,5 \mathrm{mg} / \mathrm{Kg}$ & $50,0 \mathrm{mg} / \mathrm{Kg}$ & $47,0 \pm 3,5 \mathrm{mg} / \mathrm{Kg}$ & $94,0 \pm 7,0$ \\
\hline Sn & $16,0 \pm 4,0 \mathrm{mg} / \mathrm{Kg}$ & $25,0 \mathrm{mg} / \mathrm{Kg}$ & $20,0 \pm 4,5 \mathrm{mg} / \mathrm{Kg}$ & $80,0 \pm 18,0$ \\
\hline $\mathbf{s}$ & $0,180 \pm 0,008 \mathrm{~g} / 100 \mathrm{~g}$ & $0,125 \mathrm{~g} / 100 \mathrm{~g}$ & $0,139 \pm 0,014 \mathrm{~g} / 100 \mathrm{~g}$ & $111,2 \pm 11,2$ \\
\hline $\mathrm{Na}$ & $0,0580 \pm 0,0015 \mathrm{~g} / 100 \mathrm{~g}$ & $0,0500 \mathrm{~g} / 100 \mathrm{~g}$ & $0,0495 \pm 0,005 \mathrm{~g} / 100 \mathrm{~g}$ & $99,0 \pm 10,0$ \\
\hline K & $3,77 \pm 0,06 \mathrm{~g} / 100 \mathrm{~g}$ & $0,50 \mathrm{~g} / 100 \mathrm{~g}$ & $0,41 \pm 0,02 \mathrm{~g} / 100 \mathrm{~g}$ & $82,5 \pm 4,0$ \\
\hline Gr & $1,50 \pm 0,5 \mathrm{mg} / \mathrm{Kg}$ & $25,0 \mathrm{mg} / \mathrm{Kg}$ & $23,5 \pm 0,5 \mathrm{mg} / \mathrm{Kg}$ & $94,0 \pm 2,0$ \\
\hline $\mathrm{Ni}$ & $<2,50 \mathrm{mg} / \mathrm{Kg}$ & $25,0 \mathrm{mg} / \mathrm{Kg}$ & $20,0 \pm 0,5 \mathrm{mg} / \mathrm{Kg}$ & $80,0 \pm 2,0$ \\
\hline $\mathrm{Cu}$ & $1,55 \pm 0,15 \mathrm{mg} / \mathrm{Kg}$ & $25,0 \mathrm{mg} / \mathrm{Kg}$ & $23,5 \pm 0,5 \mathrm{mg} / \mathrm{Kg}$ & $94,0 \pm 2,0$ \\
\hline $\mathrm{Zn}$ & $3,75 \pm 0,35 \mathrm{mg} / \mathrm{Kg}$ & $25,0 \mathrm{mg} / \mathrm{Kg}$ & $21,5 \pm 1,5 \mathrm{mg} / \mathrm{Kg}$ & $86,0 \pm 6,0$ \\
\hline As & $3,95 \pm 0,55 \mathrm{mg} / \mathrm{Kg}$ & $25,0 \mathrm{mg} / \mathrm{Kg}$ & $27,0 \pm 1,0 \mathrm{mg} / \mathrm{Kg}$ & $108,0 \pm 4,0$ \\
\hline Se & $3,30 \pm 1,10 \mathrm{mg} / \mathrm{Kg}$ & $25,0 \mathrm{mg} / \mathrm{Kg}$ & $31,0 \pm 1,0 \mathrm{mg} / \mathrm{Kg}$ & $124,0 \pm 4,0$ \\
\hline Cd & $<0,25 \mathrm{mg} / \mathrm{Kg}$ & $25,0 \mathrm{mg} / \mathrm{Kg}$ & $22,0 \pm 0,5 \mathrm{mg} / \mathrm{Kg}$ & $88,0 \pm 2,0$ \\
\hline Sb & $<2,00 \mathrm{mg} / \mathrm{Kg}$ & $25,0 \mathrm{mg} / \mathrm{Kg}$ & $21,5 \pm 1,0 \mathrm{mg} / \mathrm{Kg}$ & $86,0 \pm 4,0$ \\
\hline $\mathrm{Pb}$ & $17,0 \pm 3,5 \mathrm{mg} / \mathrm{Kg}$ & $25,0 \mathrm{mg} / \mathrm{Kg}$ & $37,0 \pm 9,0 \mathrm{mg} / \mathrm{Kg}$ & $148,0 \pm 36,0$ \\
\hline $\mathrm{Hg}$ & $2,40 \pm 1,3 \mathrm{mg} / \mathrm{Kg}$ & $25,0 \mathrm{mg} / \mathrm{Kg}$ & $22,5 \pm 1,0 \mathrm{mg} / \mathrm{Kg}$ & $90,0 \pm 4,0$ \\
\hline
\end{tabular}

* concentração presente de acordo com a tabela XV, página 63. 


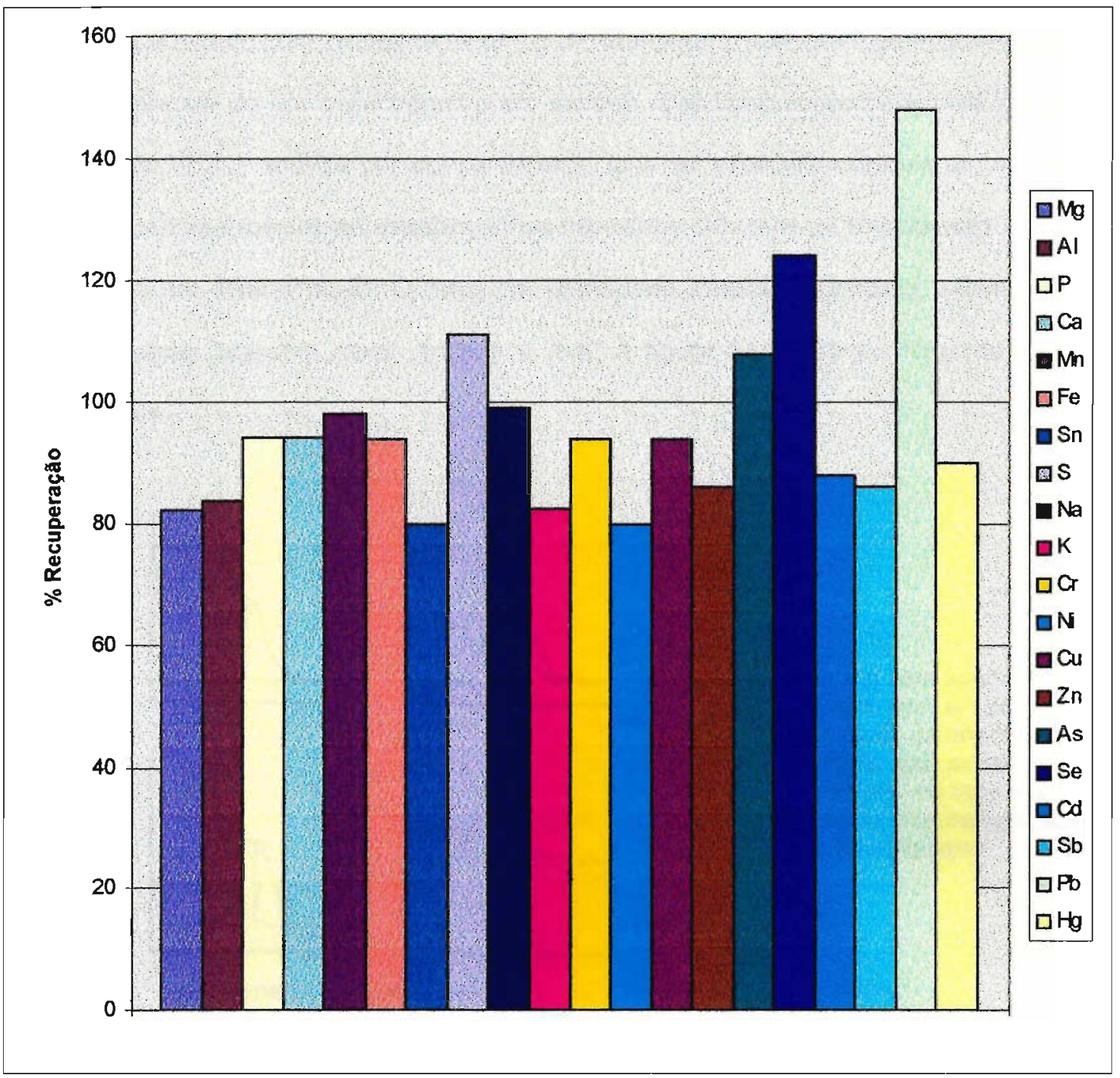

Figura 32: representação dos valores de \% de recuperação dos elementos adicionados.

Valores muito altos de recuperaçăo foram obtidos apenas para o $\mathrm{Pb}$ e $\mathrm{Se}$, conforme pode ser observado na tabela XVI, página 64 , e figura 32. Recuperações entre 80 a $120 \%$ são consideradas aceitáveis para o caso da análise de metais, ânions e nutrientes, de acordo com Standard Methods of the Examination of Water and Wastewater [37], incluindo portanto, a maioria dos elementos.

Os resultados obtidos, expressos na tabela XV, página 63 , indicam boa precisão na determinaçäo dos elementos cujos coeficientes de variação apresentam valores abaixo de $10 \%$. Já os elementos $\mathrm{Sn}, \mathrm{Pb}, \mathrm{Cr}, \mathrm{As}, \mathrm{Se}$, e Hg, por apresentarem valores do coeficiente de variação 
relativamente altos, indicam baixa reprodutibilidade nos resultados, indicando possivelmente a presença de problemas relacionados a algum tipo de interferência (matriz e/ou espectral).

De acordo com THOMPSON [67] e OLIVEIRA [27], interferências espectrais resultam da não habilidade de um espectrômetro em separar uma linha espectral emitida por um analito especifico da luz emitida por outros átomos, ions ou espécies moleculares, ou seja, ocorre quando outras espécies apresentam linhas espectrais próximas ou coincidentes com aquela do elemento em determinação. O valor da intensidade medida será maior, resultando em uma concentração aparente maior do que a real. A figura 33 ilustra os tipos de interferências espectrais

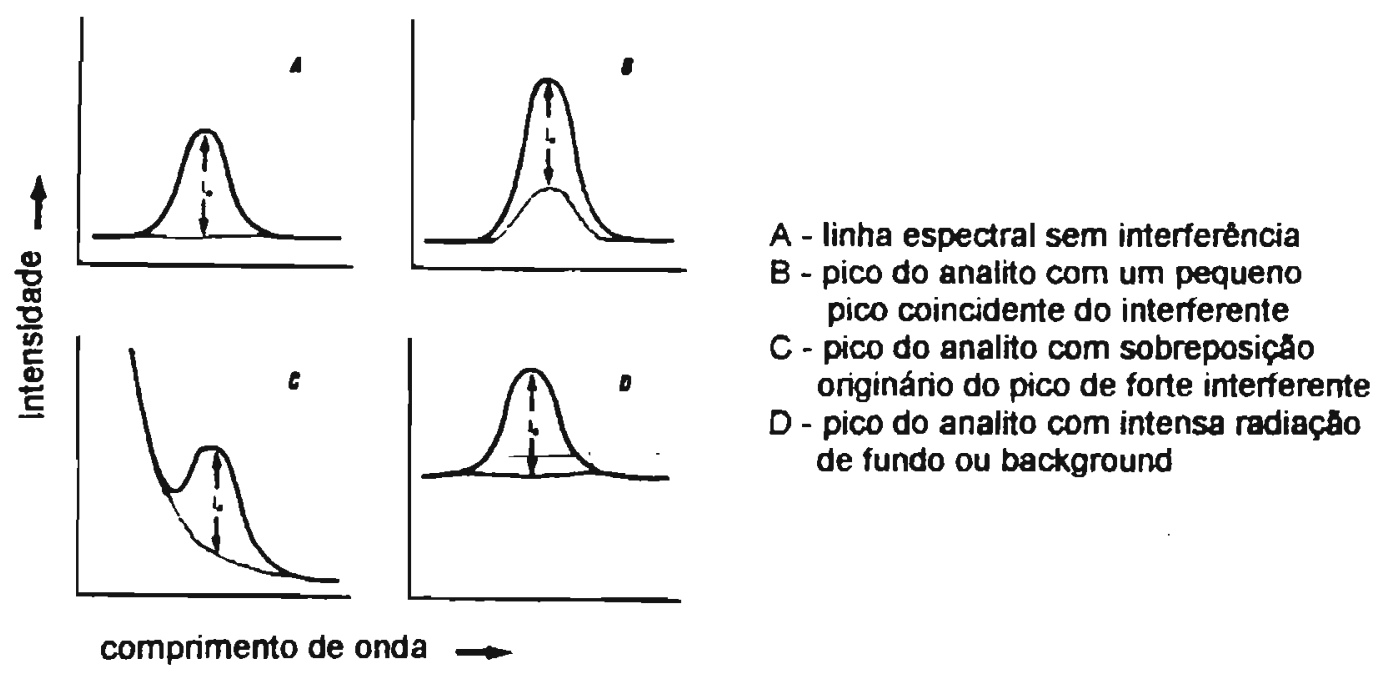

Figura 33 : tipos de interferências espectrais [67].

A interferência de matriz se relaciona a todas as etapas do processo que se inicia desde a introdução da amostra até a excitação e emissão. As interferências associadas às etapas de nebulização, transporte, desolvatação e vaporização estāo ligadas à mudança na velocidade com que a amostra é transportada para a fonte de excitação e formação do aerosol (devido às propriedades físicas da amostra em solução, como a tensão superficial, viscosidade, densidade e presença de sólidos em suspensão) sendo recomendável a preparação de padrões semelhantes à amostra ou equivalência de matriz. Nas interferências associadas à etapa de 
atomização e ionização, o efeito é fortemente relacionado à energia necessária para elevar átomos-íons do analito do estado fundamental ou de um estado de menor nível de energia para um estado de maior nível de energia. Linhas do analito com alto potencial de excitação são mais suscetiveis ao efeito do que aqueles com baixos potenciais de excitação. No caso da fonte plasma, devido à alta temperatura atingida, as linhas de emissão de ions constituem a maior parte das linhas de leitura. Em alguns casos, como para o $\mathrm{Na} \mathrm{e} \mathrm{K}$, a energia da fonte não é suficiente para excitar os íns, sendo detectadas as linhas de emissão de átomos $[27,67]$.

O item 5.3 a seguir apresenta as otimizações dos parâmetros instrumentais para as determinações dos elementos $\mathrm{Sn}, \mathrm{Pb}$ e $\mathrm{Cr}$ através do espectrômetro Modula da Spectro e os itens 5.4 e 5.5 apresentam as otimizações dos parâmetros instrumentais e os resultados das determinações dos elementos As, Se e Hg em 21 amostras de café solúvel disponiveis no mercado brasileiro, através do espectrômetro PSX da Baird.

\subsection{Otimização dos parâmetros instrumentais para as determinações do $\mathrm{Sn}, \mathrm{Pb}$ e $\mathrm{Cr}$}

Os espectros de varredura (intensidade de emissão versus comprimento de onda) foram obtidos para os elementos $\mathrm{Sn}, \mathrm{Pb}$ e $\mathrm{Cr}$, e estão ilustrados nas figuras 34 a 38 . No caso do $\mathrm{Sn}, \mathrm{a}$ elevação da emissão de radiação de fundo apresentada pela amostra estava presente no comprimento de onda escolhido $(189,926 \mathrm{~nm})$. Optou-se por efetuar a correção da radiação de fundo através do software do equipamento neste comprimento de onda, pois outras linhas de emissão do analito se mostraram menos sensiveis e mais sujeitas a interferências espectrais devido a matriz das amostras

A correção foi realizada nos seguintes comprimentos de onda :

- comprimento de onda prático de emissão do Sn: 189,903 nm;

- correçāo à direita: $189,923 \mathrm{~nm}$;

- correção à esquerda: $189,883 \mathrm{~nm}$.

A figura 34 a seguir apresenta as posições das correções de emissão de radiação de fundo. 


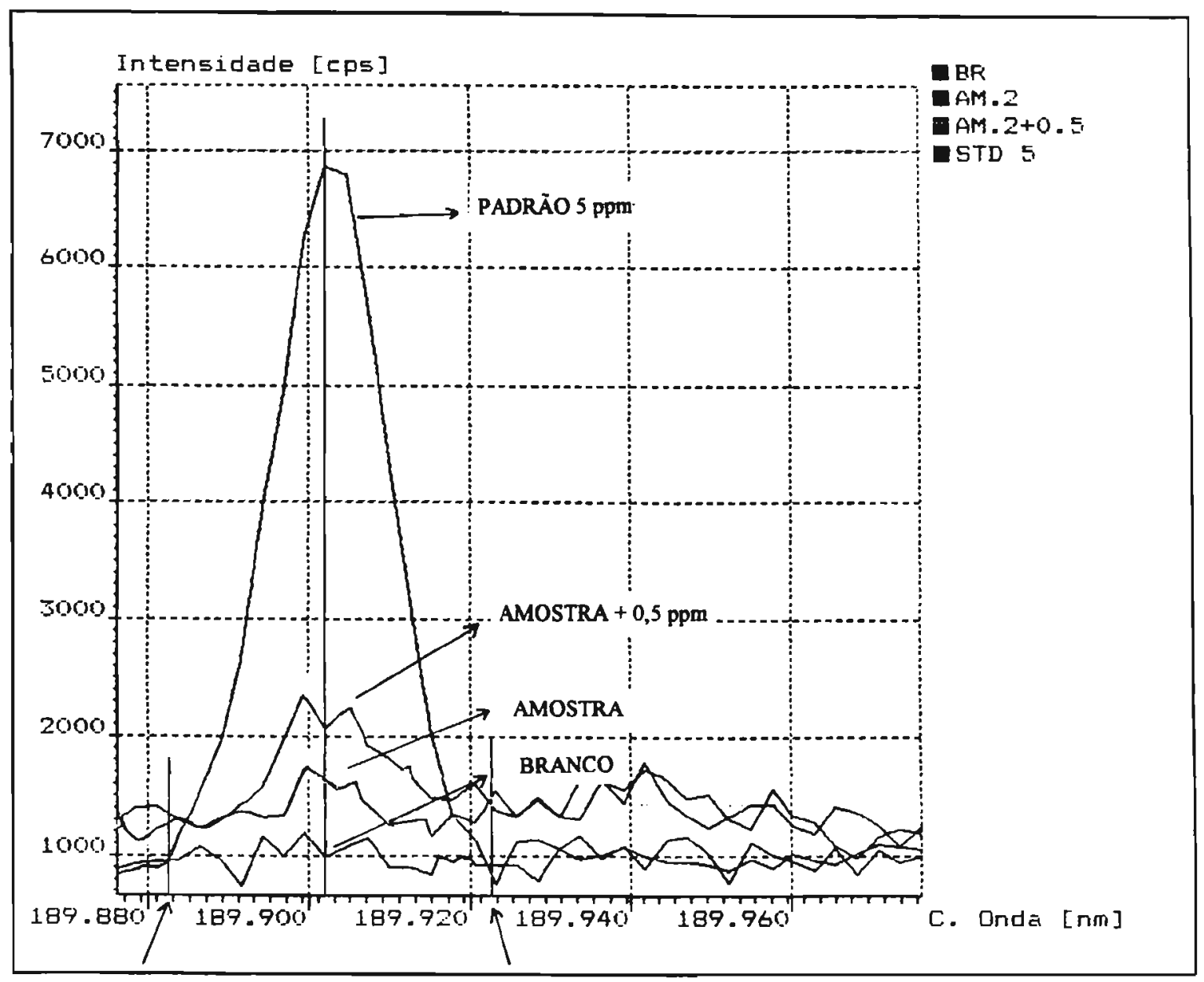

Figura 34 - espectro de varredura do Sn (espectrômetro Modula da Spectro).

No caso do $\mathrm{Pb}$, o espectro de varredura, figura 35, apresentou diferenças significativas de intensidade da linha base de emissão da amostra com a linha base de emissão do padrão $\left(1 \mathrm{mgL}^{-1}\right)$ e um pico próximo de um ou mais elementos presentes na matriz. Neste caso, optou-se pela escolha de um comprimento de onda alternativo, sendo definida a linha de emissão 220,35 nm que apresentou-se livre de interferências espectrais e de matriz, conforme pode ser visto na figura 36 .

O espectro de varredura apresentado pelo $\mathrm{Cr}$, figura 37 , apresentou instabilidade do sinal emitido pelo analito da amostra, estando muito próximo ao sinal emitido pelo branco. Como 
no caso do $\mathrm{Pb}$, também optou-se pela escolha de um comprimento de onda alternativo, sendo definida a linha de emissão $357,869 \mathrm{~nm}$.

Nos casos do $\mathrm{Pb}$ e $\mathrm{Cr}$, como as linhas de emissão selecionadas não apresentaram sensibilidade adequada, a relação massa de amostra/volume de solução relacionada com os limites de determinaçōes destes elementos $\left(\mathrm{Cr}: 0,01 \mu \mathrm{gmL}^{-1}\right.$ e $\mathrm{Pb}: 0,10 \mu \mathrm{gmL}^{-1}$, conforme tabela IX, página 56) não foi conveniente para os níveis exigidos pela legislação brasileira vigente [3] que fixa os valores máximos permitidos de $1 \mathrm{mg} \mathrm{Kg}^{-1}$ para o $\mathrm{Pb}$ e $0,1 \mathrm{mg} \mathrm{Kg}^{-1}$ para o $\mathrm{Cr}$. Por isto, estabeleceu-se o aumento da relação massa de amostra/volume de solução de $1 \mathrm{~g}$ para $5 \mathrm{~g}$, implicando em um maior cuidado na mineralização da amostra e definindo-se as melhores condições conforme descrito no item 4.4.2, figura 25.

A amostra de café solúvel utilizada no item 5.2 , página 62 , foi enriquecida com $\mathrm{Sn}$ a uma concentração de $25 \mathrm{mg} \mathrm{Kg}^{-1}$ (equivalente a $0,5 \mu \mathrm{gmL}^{-1}$ na solução de análise) e tratada conforme descrito neste item. Os elementos $\mathrm{Pb}$ e $\mathrm{Cr}$ foram adicionados em concentrações de 5 $\mathrm{mgKg}^{-1}$, equivalentes a $0,5 \mu \mathrm{gmL}^{-1}$ na solução de análise e a amostra foi tratada conforme descrito no item 4.4.2, figura 25.

A tabela XVII a seguir e a figura 39 , apresentam os valores de recuperação médias destes elementos.

Tabela XVII: valores de recuperação médias de $\mathrm{Sn}, \mathrm{Pb}$ e $\mathrm{Cr}$ na amostra de café solúvel utilizada no item 5.2.

\begin{tabular}{|cccc|}
\hline Elemento & $\begin{array}{c}\text { Concentração } \\
\text { presente }\end{array}$ & $\begin{array}{c}\text { Concentração } \\
\text { adicionada }\end{array}$ & $\begin{array}{c}\text { Recuperado } \\
(\mathrm{n}=3)\end{array}$ \\
\hline $\mathrm{Sn}$ & $7,5 \mathrm{mgKg}^{-1}$ & $25,0 \mathrm{mgKg}^{-1}$ & $26,0 \pm 0,3 \mathrm{mgKg}^{-1}$ \\
$\mathrm{~Pb}$ & $<1,0 \mathrm{mgKg}^{-1}$ & $5,0 \mathrm{mgKg}^{-1}$ & $5,1 \pm 0,5 \mathrm{mgKg}^{-1}$ \\
$\mathrm{Cr}$ & $<0,10 \mathrm{mgKg}^{-1}$ & $5,0 \mathrm{mgKg}^{-1}$ & $4,8 \pm 0,3 \mathrm{mgKg}^{-1}$ \\
\hline
\end{tabular}




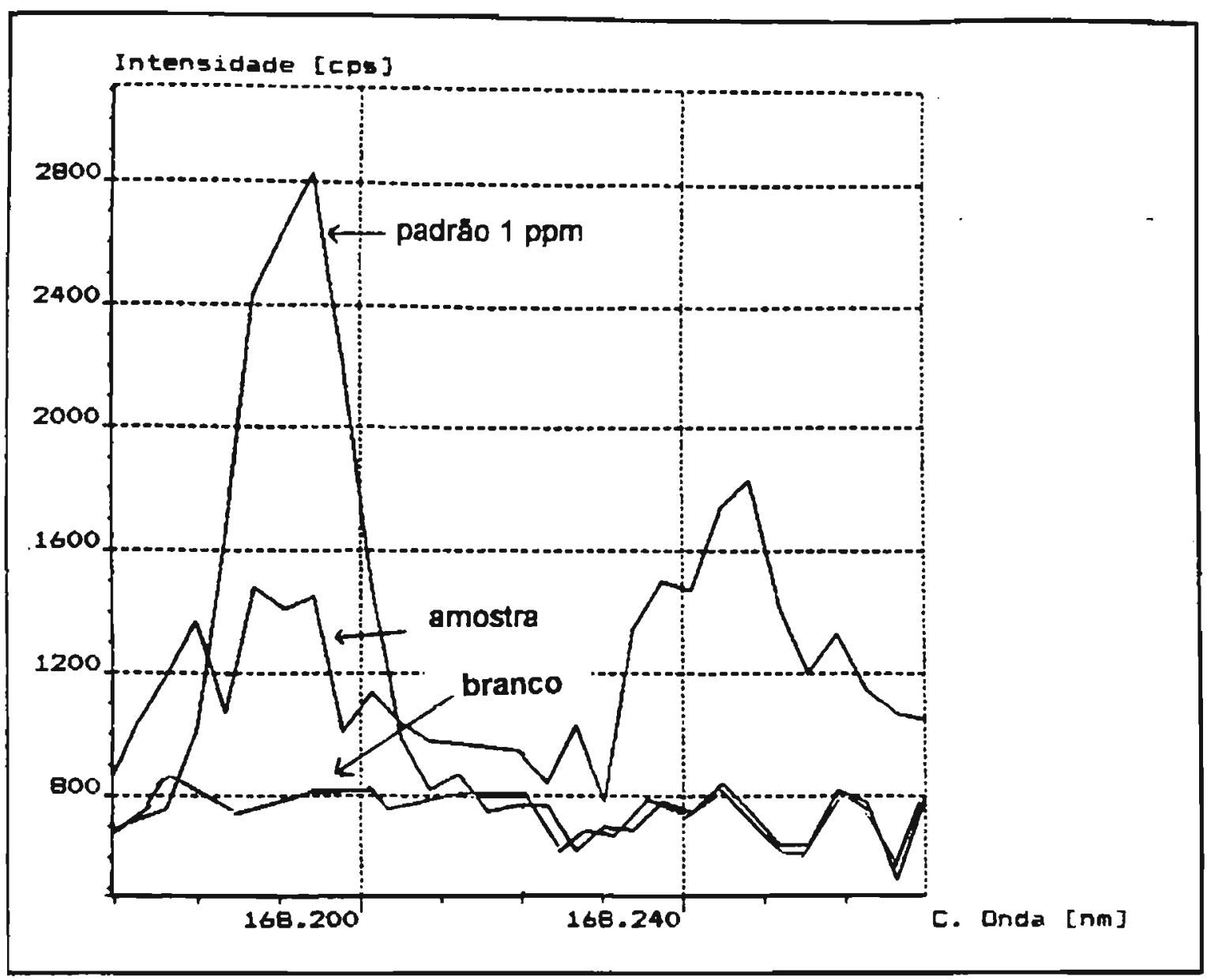

Figura 35 - espectro de varredura do Pb (espectrômetro Modula da Spectro). 


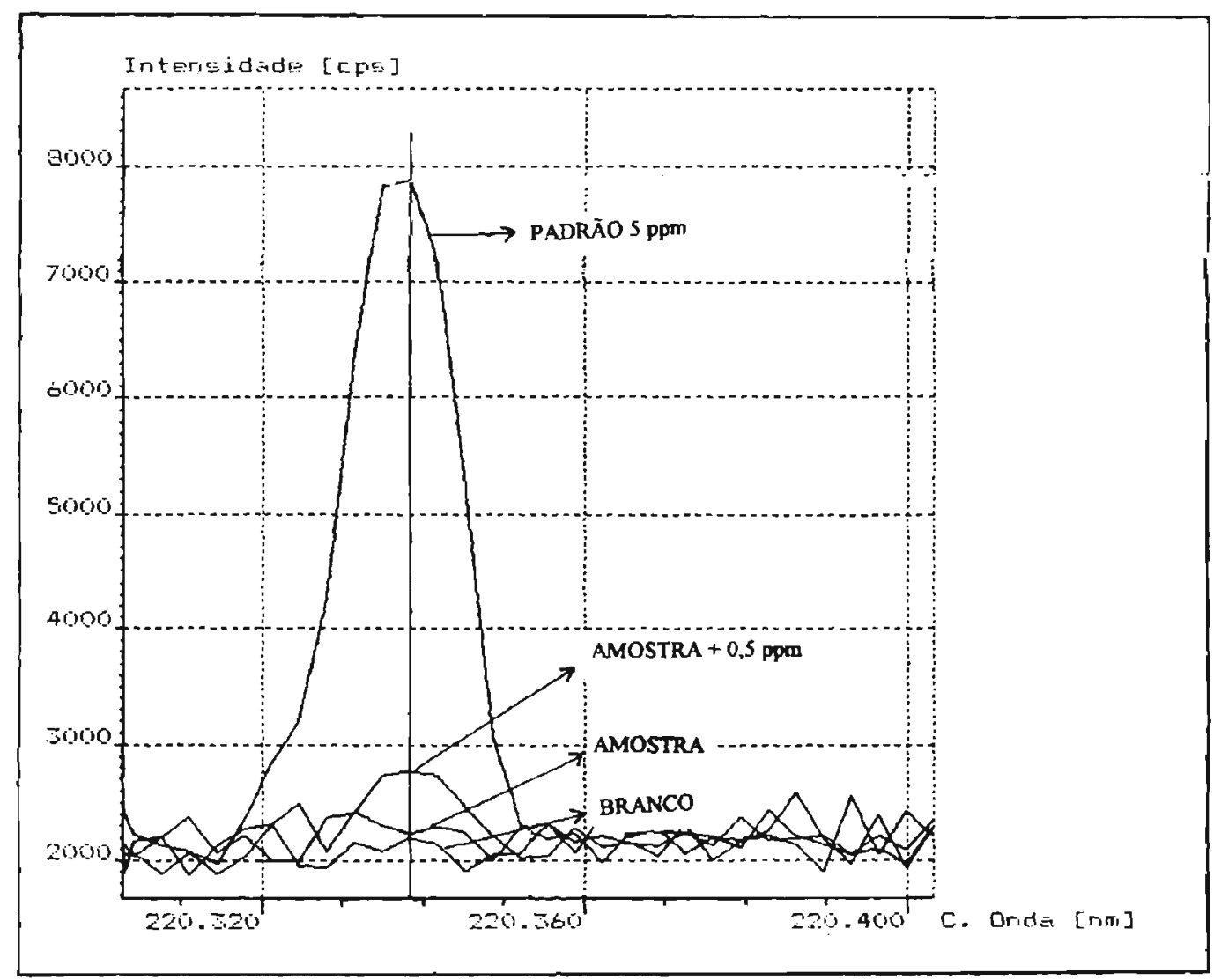

Figura 36 - espectro de varredura do $\mathrm{Pb}$ em 220,35 nm (espectrômetro Modula da Spectro). 


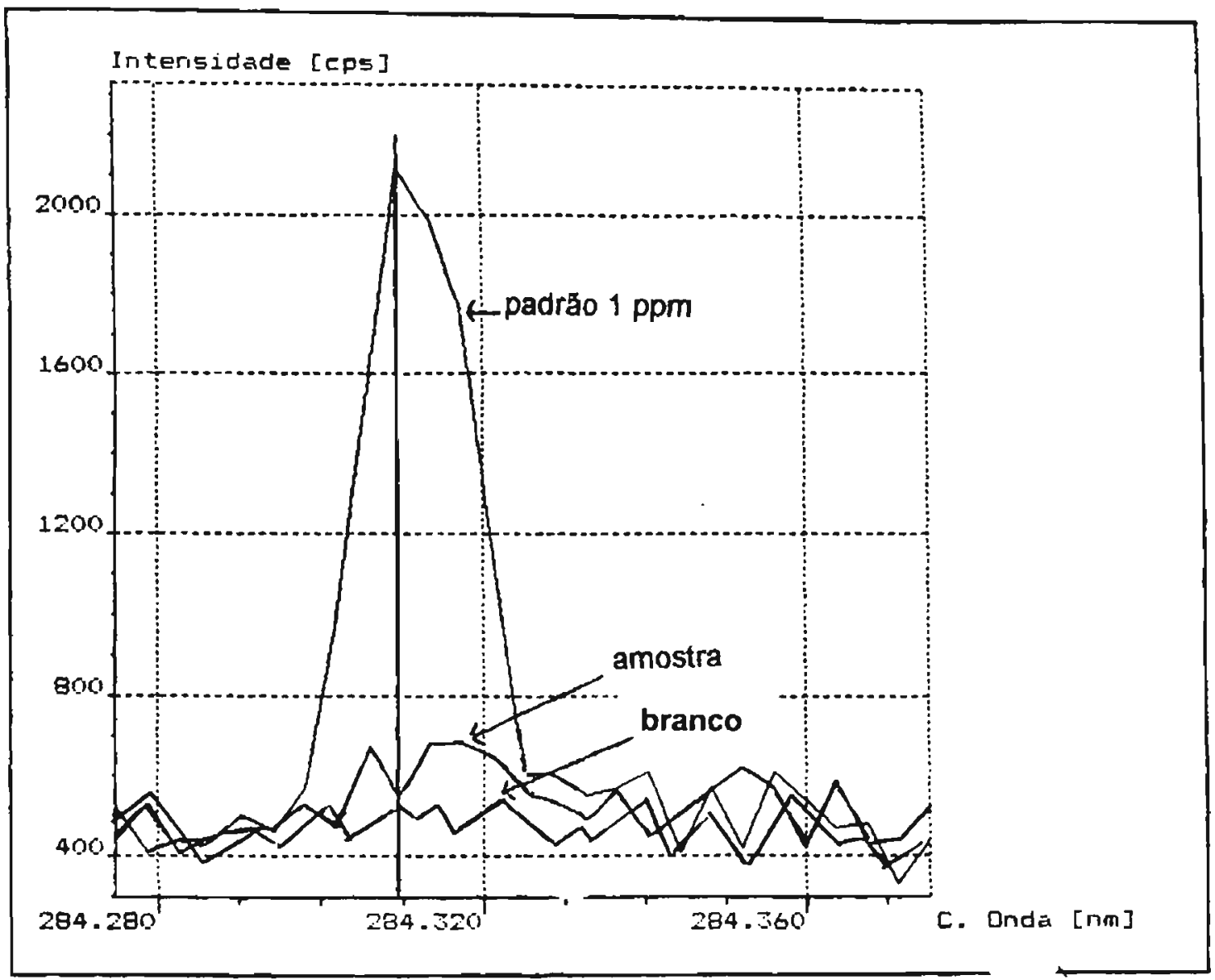

Figura 37 - espectro de varredura do $\mathrm{Cr}$ (espectrômetro Modula da Spectro). 


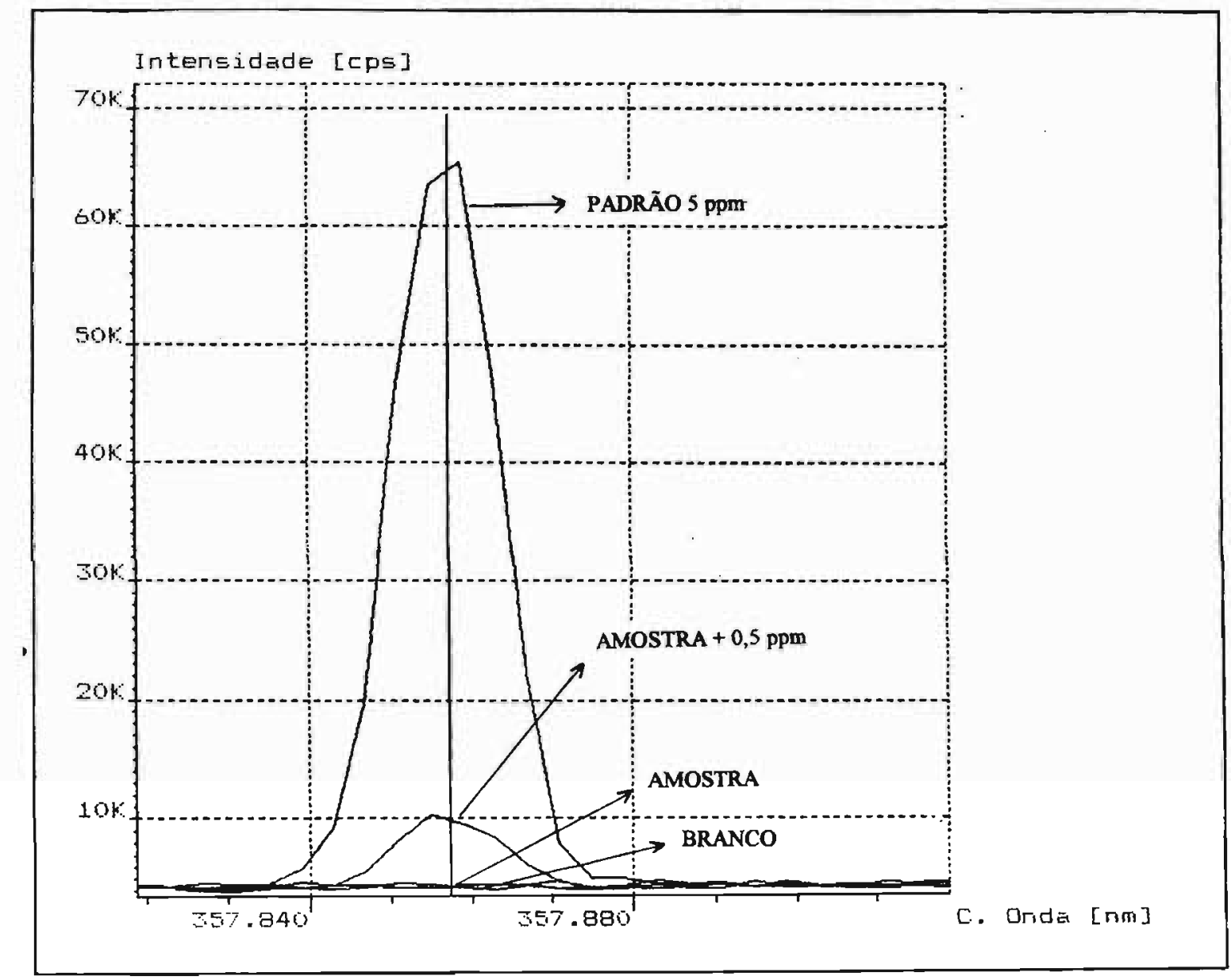

Figura 38 - espectro de varredura do $\mathrm{Cr}$ em 357,869 nm (espectrômetro Modula da Spectro). 


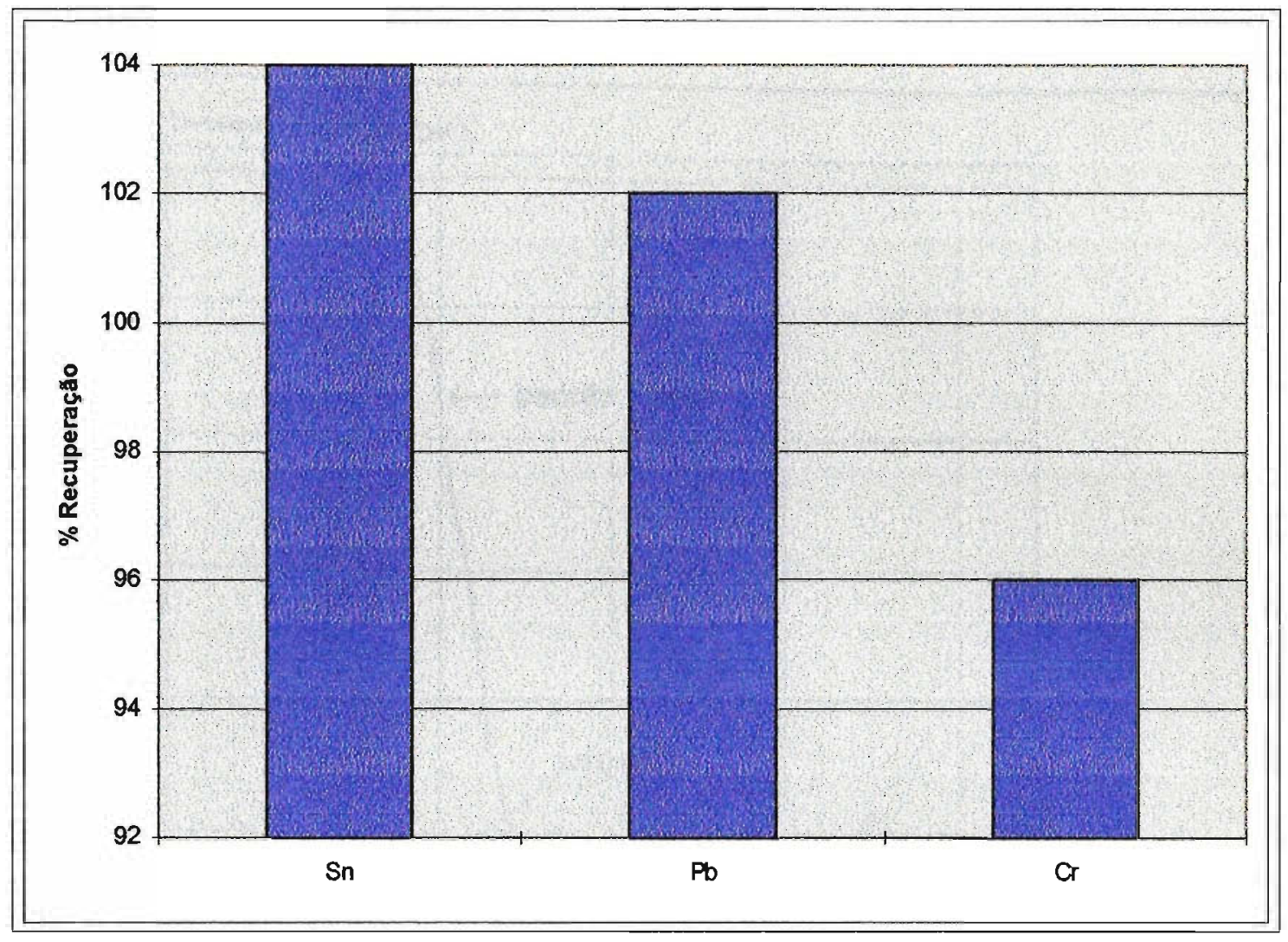

Figura 39: representação dos valores de \% de recuperaçăo dos elementos $\mathrm{Sn}, \mathrm{Cr}$ e $\mathrm{Pb}$.

\subsection{Otimização dos parâmetros instrumentais e determinação do As e Se}

Foram obtidos os espectros de varreduras referentes aos elementos As e Se, figuras 40 a 43, nas mesmas soluções da amostra, em dois espectrômetros diferentes: Modula da Spectro e PSX da Baird. Estes espectros revelam a elevação da radiação de fundo nas determinações destes dois analitos, além de não apresentarem picos de emissão bem definidos, representados pela instabilidade do sinal emitido pela amostra (próximo ao sinal emitido pelo branco). Para as determinações do As e Se optou-se pela aplicação da técnica de geração de hidretos que permite a formação dos hidretos voláteis destes dois elementos separando-os da matriz da amostra e produzindo mais eficientemente átomos e ions destes analitos no plasma reduzindo, portanto, interferências de matriz e espectral e fornecendo menores valores de limites de determinação [69]. 


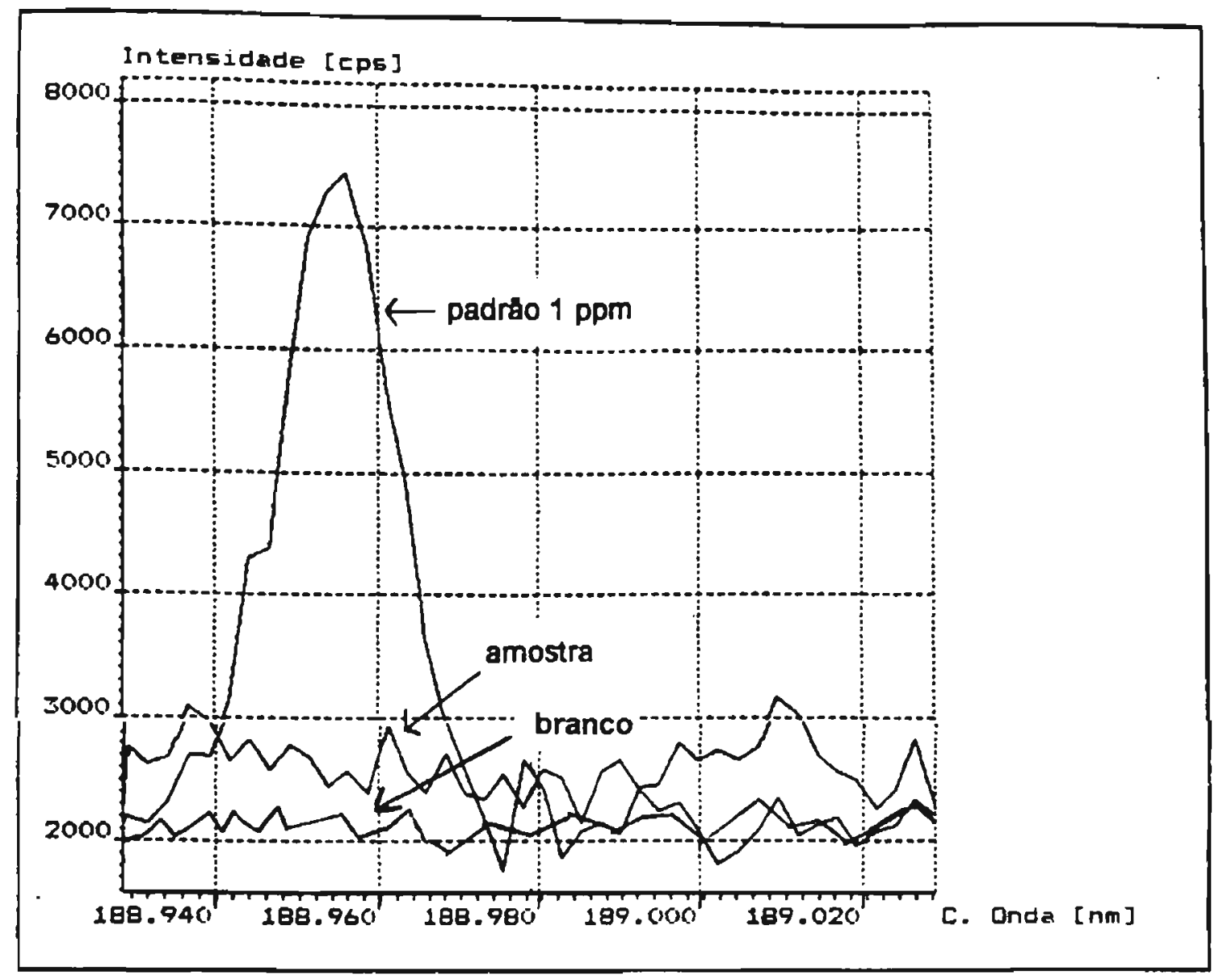

Figura 40 - espectro de varredura do As (espectrômetro Modula da Spectro). 


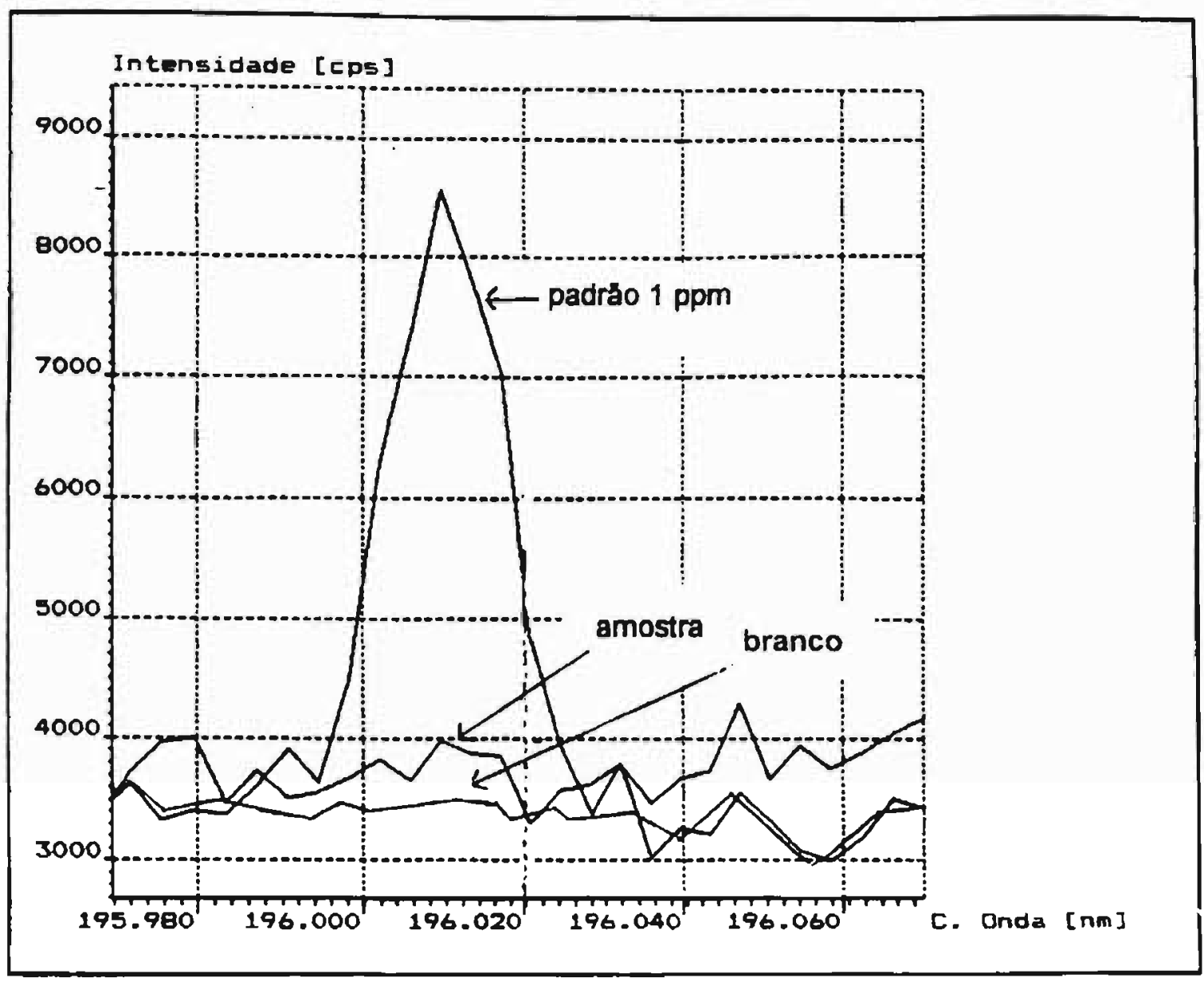

Figura 41 - espectro de varredura do Se (espectrômetro Modula da Spectro). 


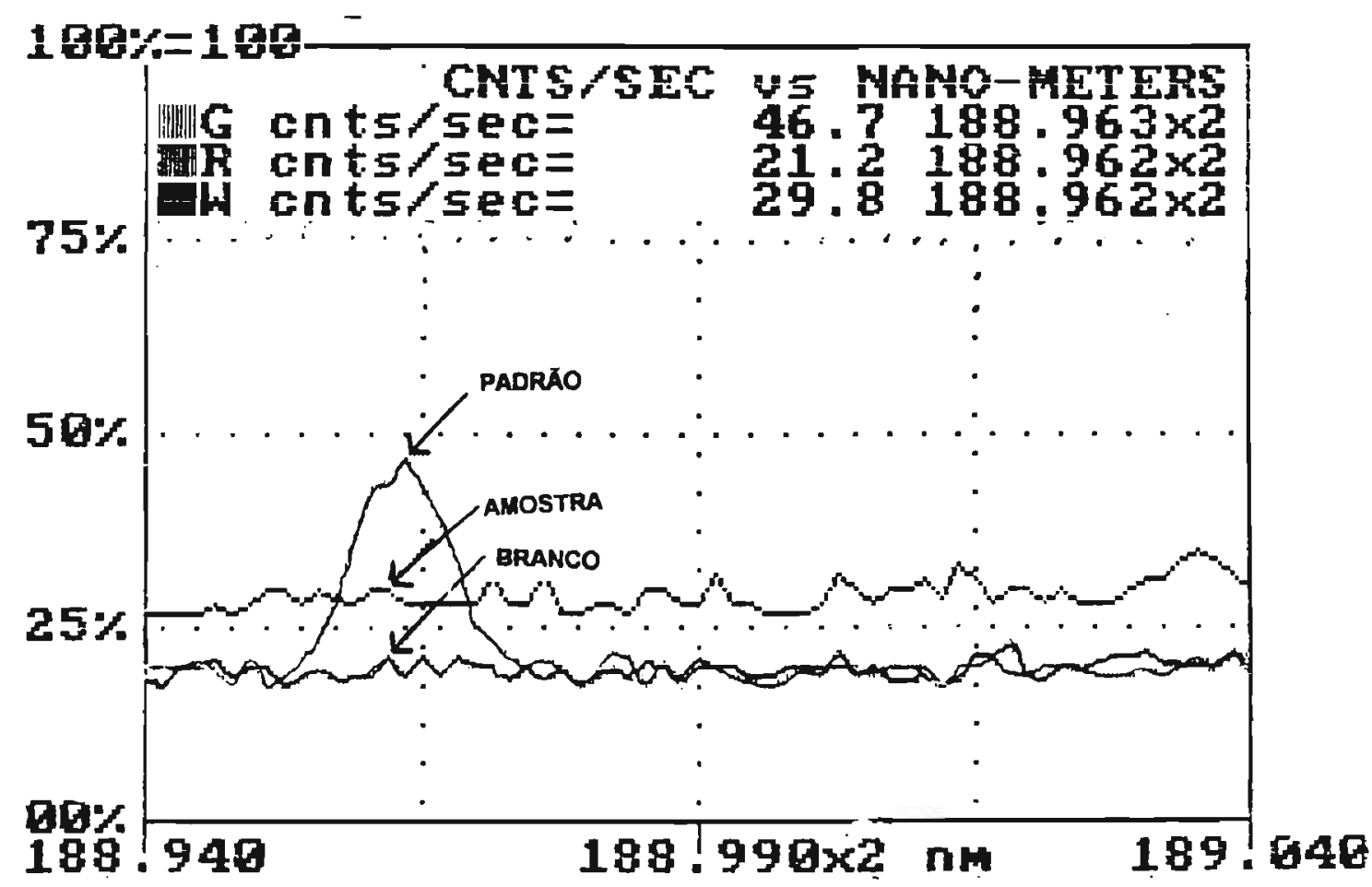

Figura 42 - espectro de varredura do As (espectrômetro PSX da Bairo) 


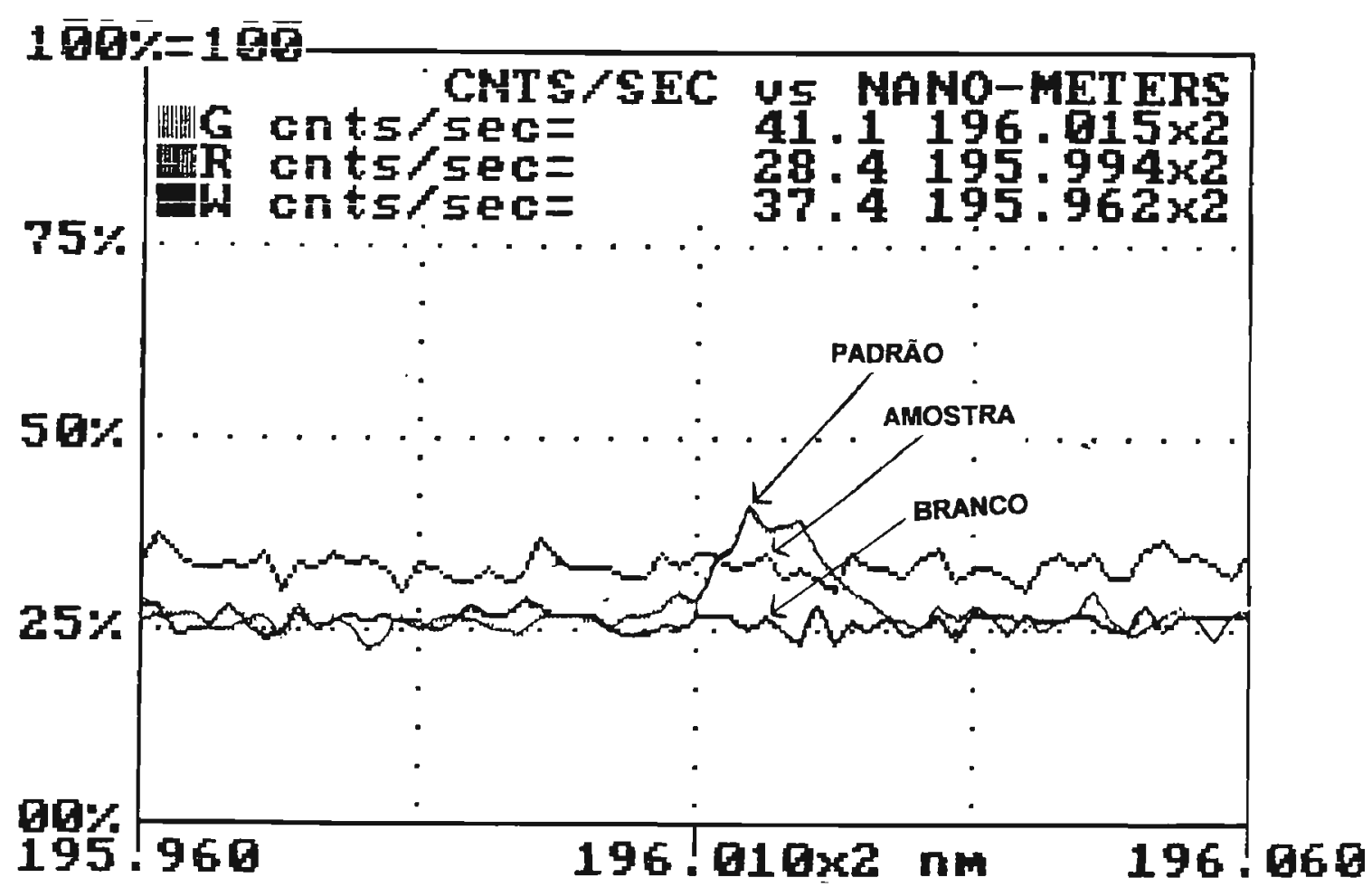

Figura 43 - espectro de varredura do Se ( espectrômetro PSX da Baird).

\section{Otimizacão dos parámetros de operacão}

O separador de fases ou gerador de hidretos construido de acordo com as especificações contidas no artigo publicado por OLIVEIRA et al. [49], figura 20, foi utilizado com sucesso sob as condições operacionais do espectrômetro PSX da Baird, tabela VII, página 54. O fluxo do gás argônio carregador de $0,6 \mathrm{~L} \mathrm{~min}^{-1}$, normalmente usado na nebulização convencional por este equipamento, mostrou ser estável também para as determinações dos hidretos de As e Se. Com fluxo menores que este valor, a formação de bolhas (de gás hidrogênio) era alta e o dreno do separador de fases não funcionava perfeitamente. Em fluxos maiores, o argônio forçava todo o liquido do dreno a sair para fora do separador de fases com bastante violência, causando mudanças drásticas de pressão e como consequência a extinção do plasma.

Estudou-se também como OLIVEIRA et al. [49], a influência da concentração do $\mathrm{HCl}$ na sensibilidade da análise e o efeito da adição do $\mathrm{KI}(5 \mathrm{~mL}$ de uma solução a $5 \% \mathrm{~m} / \mathrm{v})$ como redutor do $\mathrm{As}(\mathrm{V})$ a $\mathrm{As}(\mathrm{III})$. Para este estudo foram preparadas as seguintes soluções: 
- soluções do branco $(\mathrm{Br})$ em concentrações de $\mathrm{HCl}$ de 1 a $7 \mathrm{~mol} / \mathrm{L}$;

- soluções de $50 \mu \mathrm{gL}^{-1}$ de $\mathrm{As}(\mathrm{V})$ e Se(IV) em HCl (1 a $\left.7 \mathrm{~mol} / \mathrm{L}\right)$;

- soluçōes de $50 \mu \mathrm{gL}^{-1}$ de $\mathrm{As}(\mathrm{V})$ e $\mathrm{Se}(\mathrm{IV})$ em HCl (1 a $7 \mathrm{~mol} / \mathrm{L}$ ) com adição de $5 \mathrm{~mL}$ de solução de $\mathrm{KI}(5 \% \mathrm{~m} / \mathrm{v})$ com a geração dos hidretos realizada após 30 minutos de repouso, de acordo com Standard Methods for the Examination of Water and Wastewater [37];

- solução de $\mathrm{NaBH}_{4} 1 \% \mathrm{~m} / \mathrm{v}$ em NaOH 0,1 mol/L.

A figura 44 apresenta as diferentes concentraçöes de $\mathrm{HCl}$ versus as intensidades de emissões em cps (contagens por segundo) dos analitos As e Se presentes nas condições especiais descritas acima.

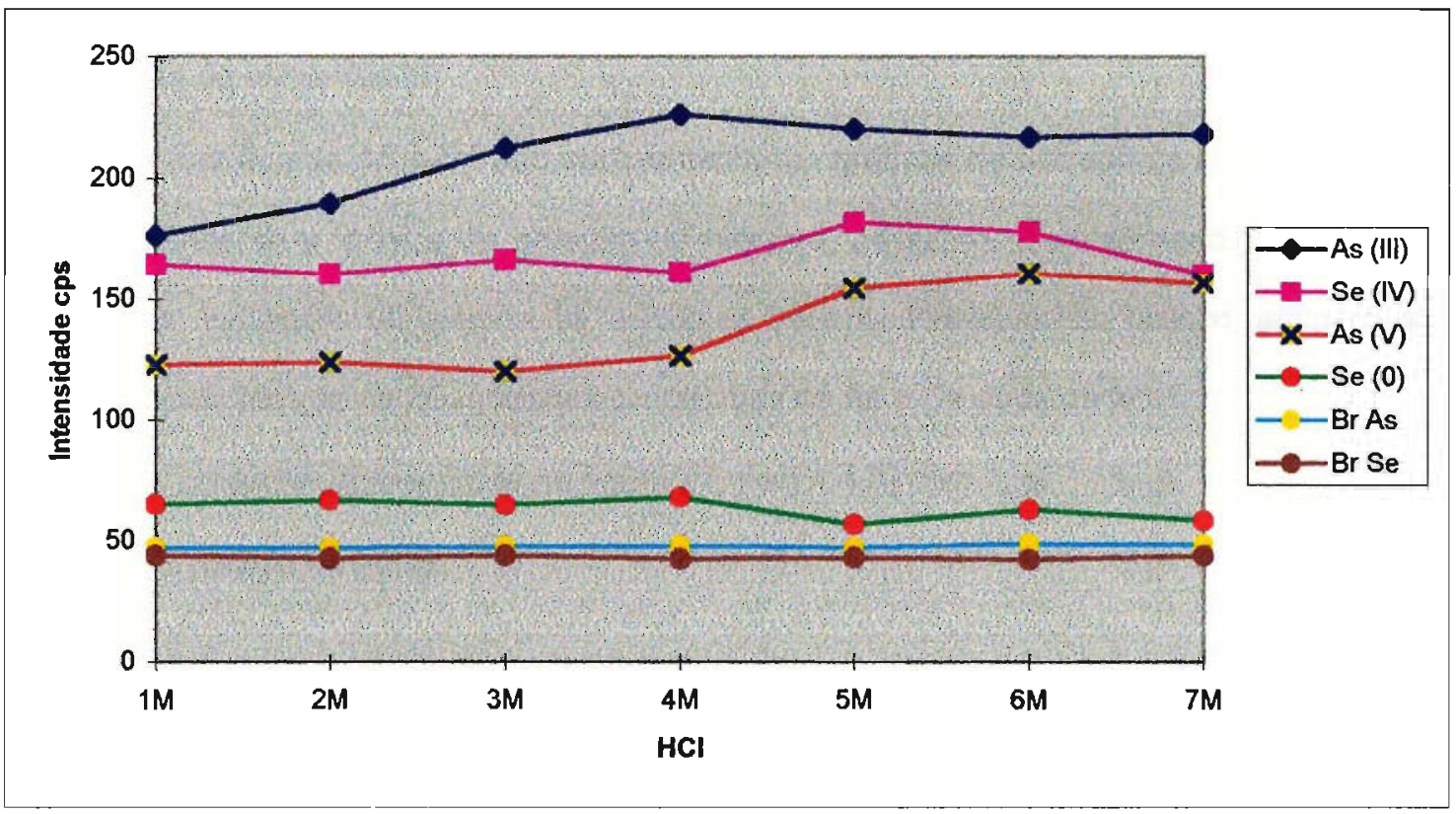

Figura 44 - Influência da acidez na sensibilidade da análise dos hidretos de As e Se.

A linha de base representada pela solução do branco $(\mathrm{Br})$ tanto do $\mathrm{As}$ como do Se apresentou-se com valores constantes nas diferentes concentrações do $\mathrm{HCl}$. Uma maior sensibilidade, representada pela maior intensidade de emissão, é apresentada pelo Se(IV) em $\mathrm{HCl} 5 \mathrm{~mol} / \mathrm{L}$ e $6 \mathrm{~mol} / \mathrm{L}$, porém a ação dos íons I" como redutores do Se(IV) a Se elementar ficou evidenciada, resultando na emissão constante deste analito com intensidade próxima a linha de base do branco. A experiência também evidenciou a ação dos íons I na redução do $A s(V)$ a 
As(III) o qual melhorou a sensibilidade de análise deste analito pelo aumento da intensidade de emissāo, como relatado por vários autores [49,50,51,52], contudo impede a determinação simultânea do Se(IV). Baseado nestas informações e no estudo realizado por BRIMMER, FAWEETT e KULHAVY [53], a concentração de ácido da matriz escolhida para a análise simultânea do As e Se foi $6 \mathrm{~mol} / \mathrm{L}$, sendo realizada eliminação prévia do $\mathrm{HNO}_{3}$ através de evaporação lenta quase até a secura e redução do $\mathrm{Se}(\mathrm{VI})$ a Se(IV) através de aquecimento a $90 \pm 5^{\circ} \mathrm{C}$ por 30 minutos em $\mathrm{HCl} 6 \mathrm{~mol} / \mathrm{L}$, conforme descrito no item 4.4.2, figura 27 .

As matrizes das amostras influenciaram diferentemente na intensidade da radiação de fundo daquelas produzidas pelo branco e padrões durante a geração de hidretos. Para maior segurança da análise utilizou-se valores do limite de detecção prático ou limite de determinação, sendo $2 \mu \mathrm{gL}^{-1}$ para o As e $1 \mu \mathrm{gL}^{-1}$ para o Se. Estes limites, quando relacionados à massa de amostra e ao volume de solução, apresentam valores que atendem aos fixados pela legislação brasileira de alimentos [3].

Nas figuras 45 a 54 são apresentados os gráficos de varreduras dos analitos As e Se empregando-se a técnica de geração de hidretos, de acordo com as condições instrumentais defindas na tabela VII, página 54 , sendo os espectros relativos ao branco, amostra, amostra enriquecida (adição de quantidades conhecidas de As e Se após mineralização e tratamento da amostra conforme apresentado na figura 27 , item 4.4.2) com $1 \mu \mathrm{gL}^{-1}, 5 \mu \mathrm{gL}^{-1}, 10 \mu \mathrm{gL}^{-1}, 20 \mu \mathrm{gL}^{-1}$, branco e padrão de $20 \mu \mathrm{gL}^{-1}$. 


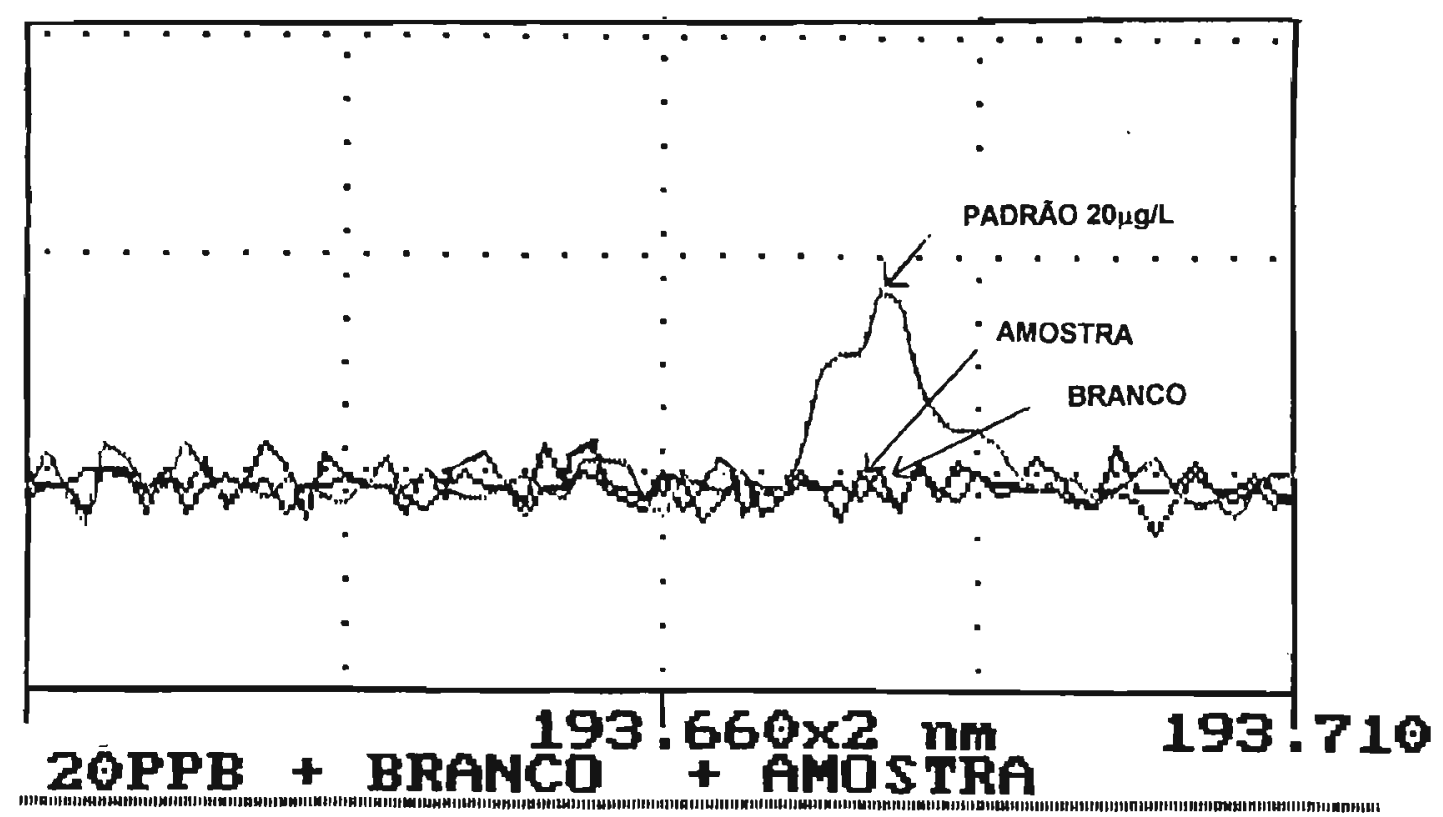

Figura 45 - espectro de varredura do As: branco +amostra + padrão de $20 \mu \mathrm{gL}^{-1}$.

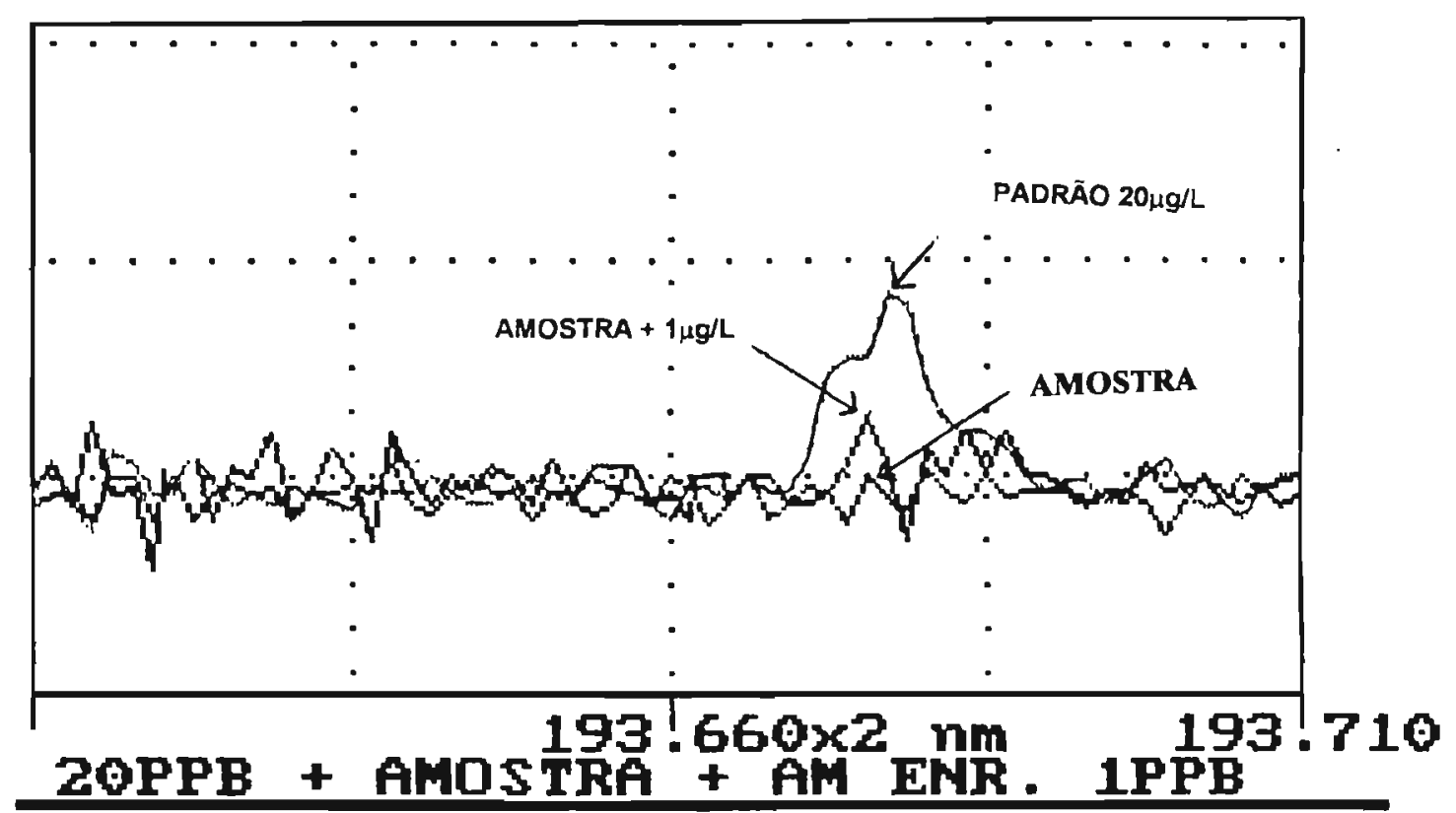

Figura 46 - espectro de varredura do As: amostra + amostra enriquecida com $1 \mu \mathrm{gL}^{-1}+$ padrão de $20 \mu \mathrm{gL}^{-1}$. 


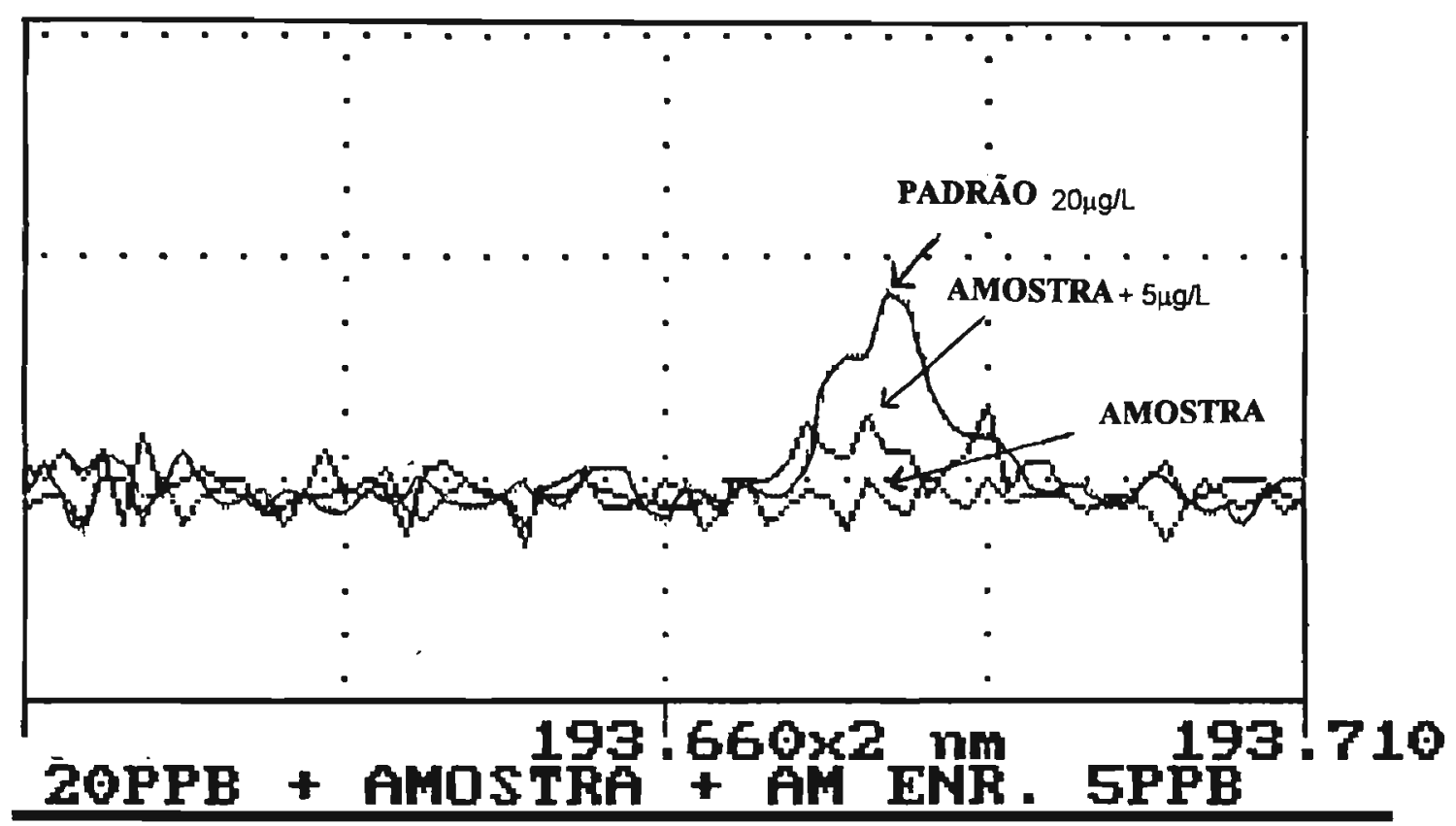

Figura 47 - espectro de varredura do As: amostra + amostra enriquecida com $5 \mu \mathrm{gL}^{-1}+$ padrão de $20 \mu \mathrm{gL}^{-1}$.

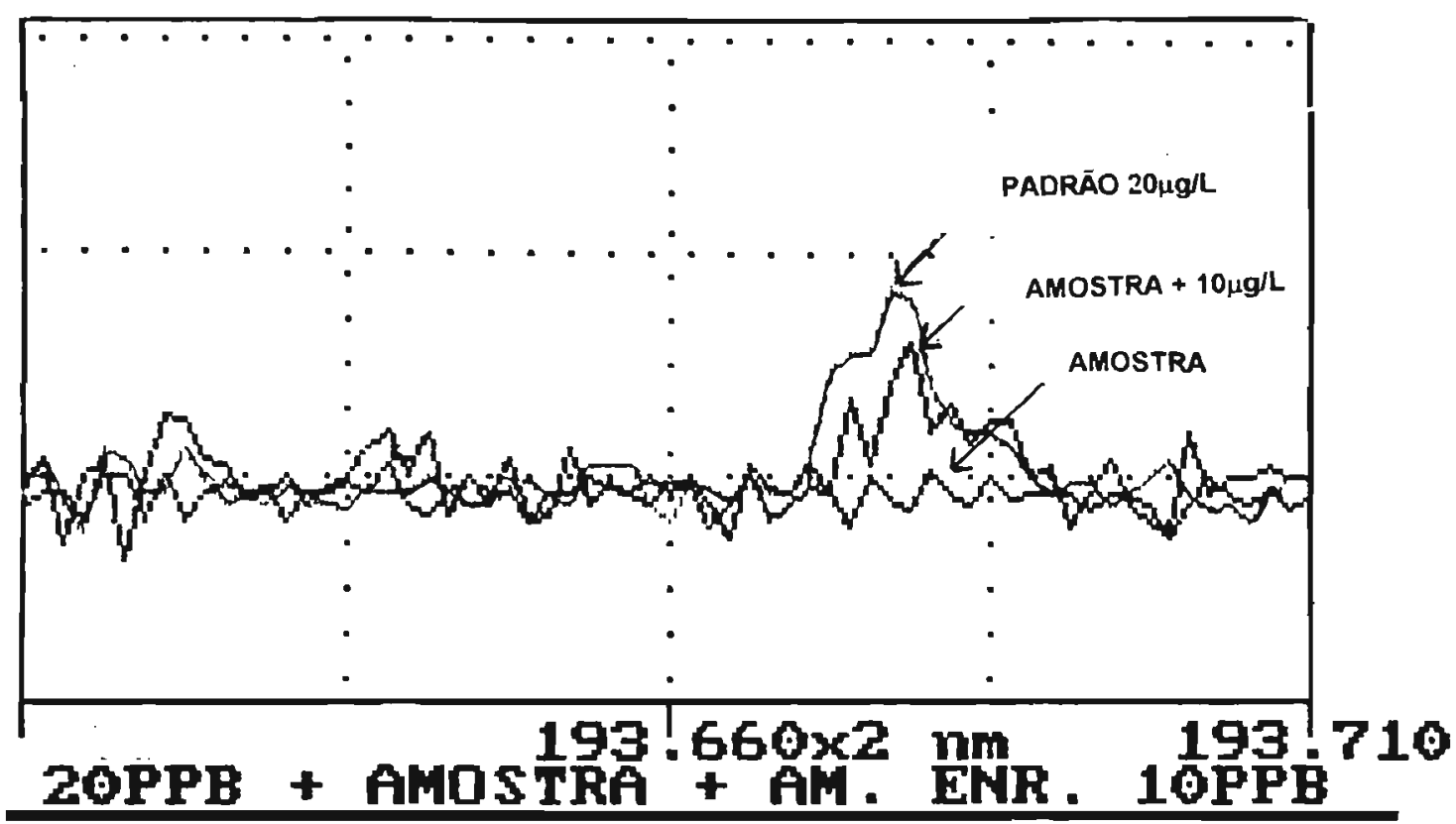

Figura 48 - espectro de varredura do As: amostra + amostra enriquecida com $10 \mu \mathrm{gL}^{-1}+$ padrão de $20 \mu \mathrm{gL}^{-1}$. 


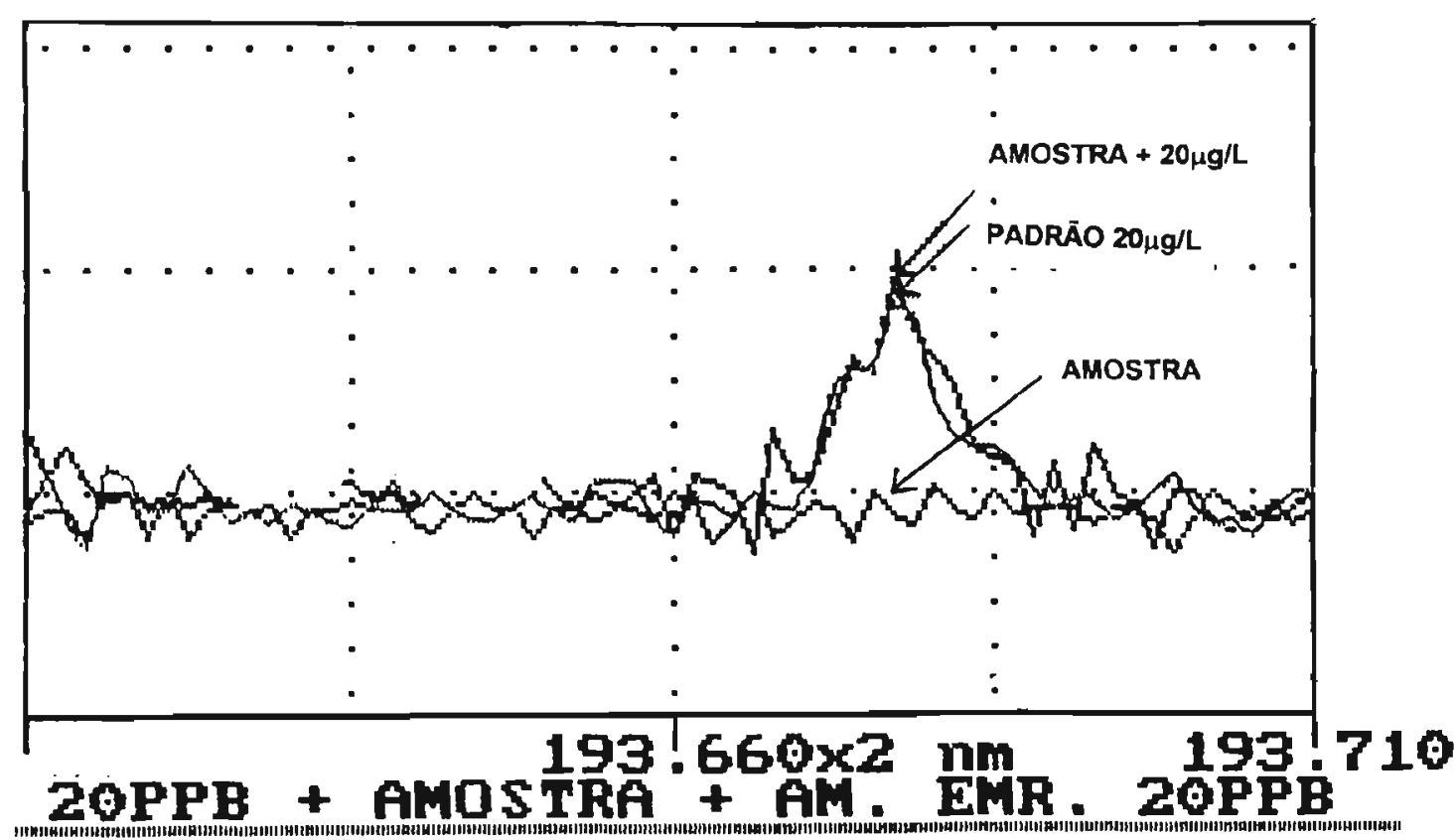

Figura 49 - espectro de varredura do As: amostra + amostra enriquecida com $20 \mu \mathrm{gL}^{-1}+$ padrão de $20 \mu \mathrm{gL}^{-1}$.

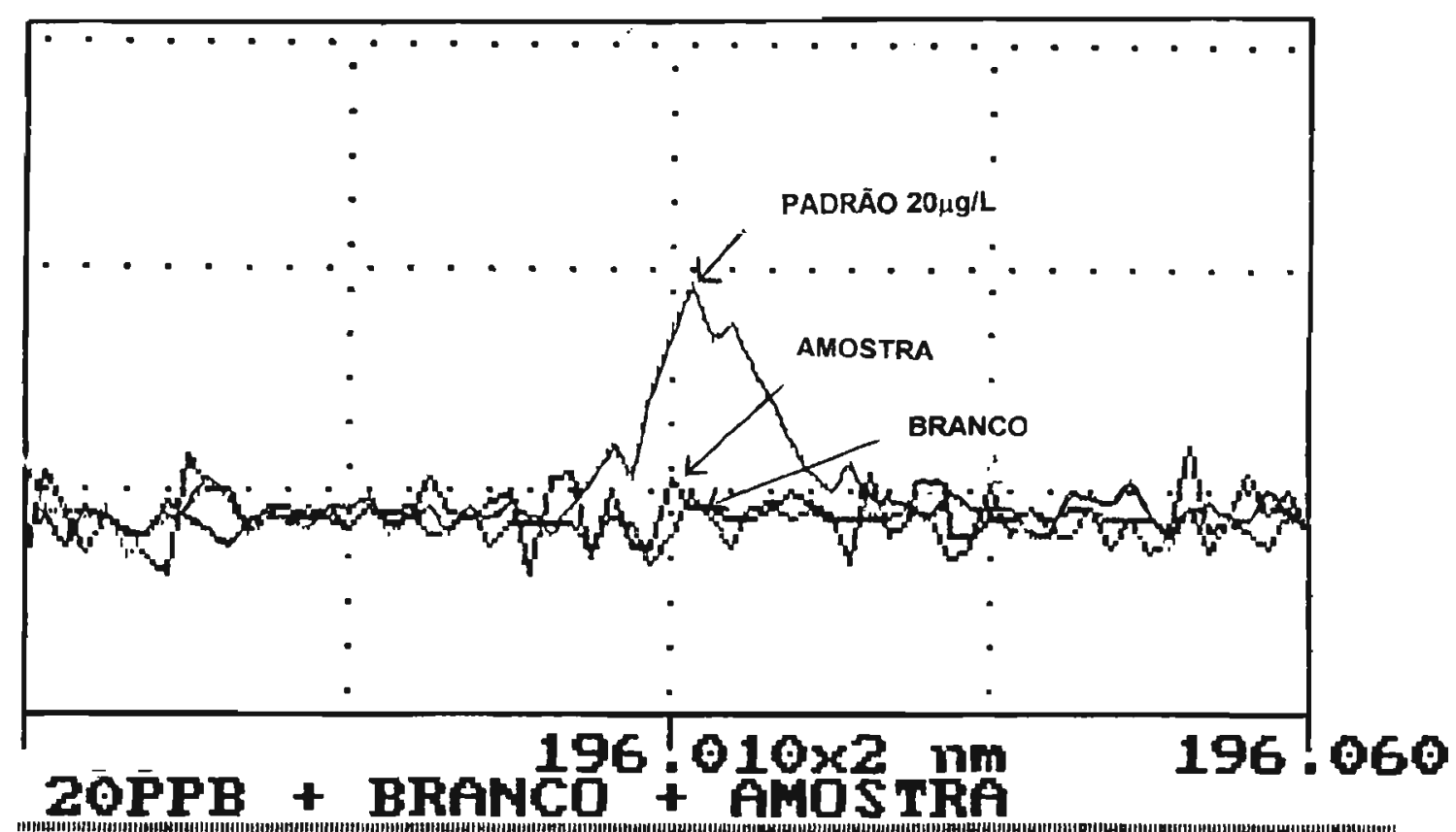

Figura 50 - espectro de varredura do Se: branco +amostra + padrão de $20 \mu \mathrm{gL}^{-1}$. 


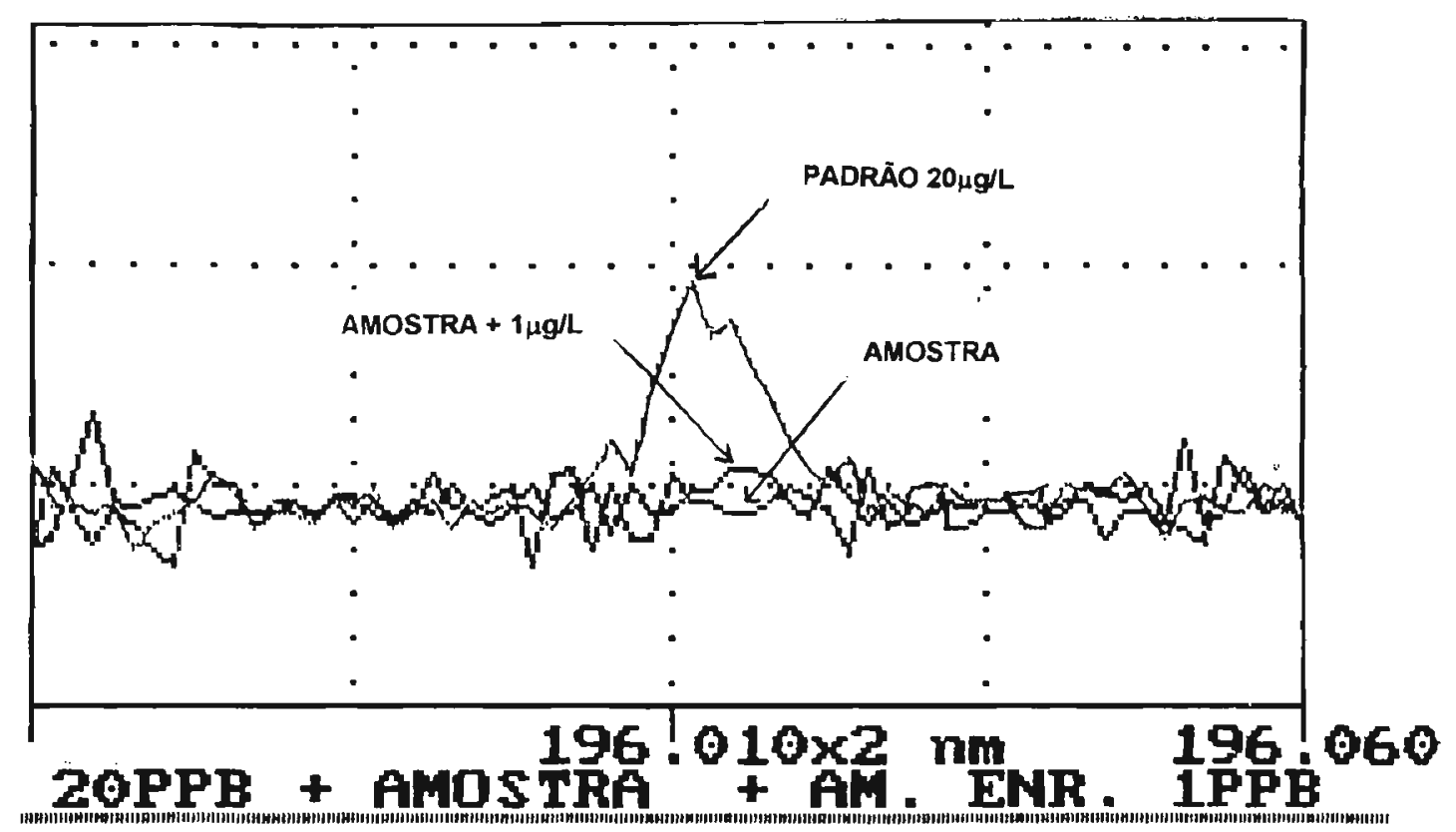

Figura 51 - espectro de varredura do Se: amostra + amostra enriquecida com $1 \mu \mathrm{gL}^{-1}+$ padrão de $20 \mu \mathrm{gL}^{-1}$.

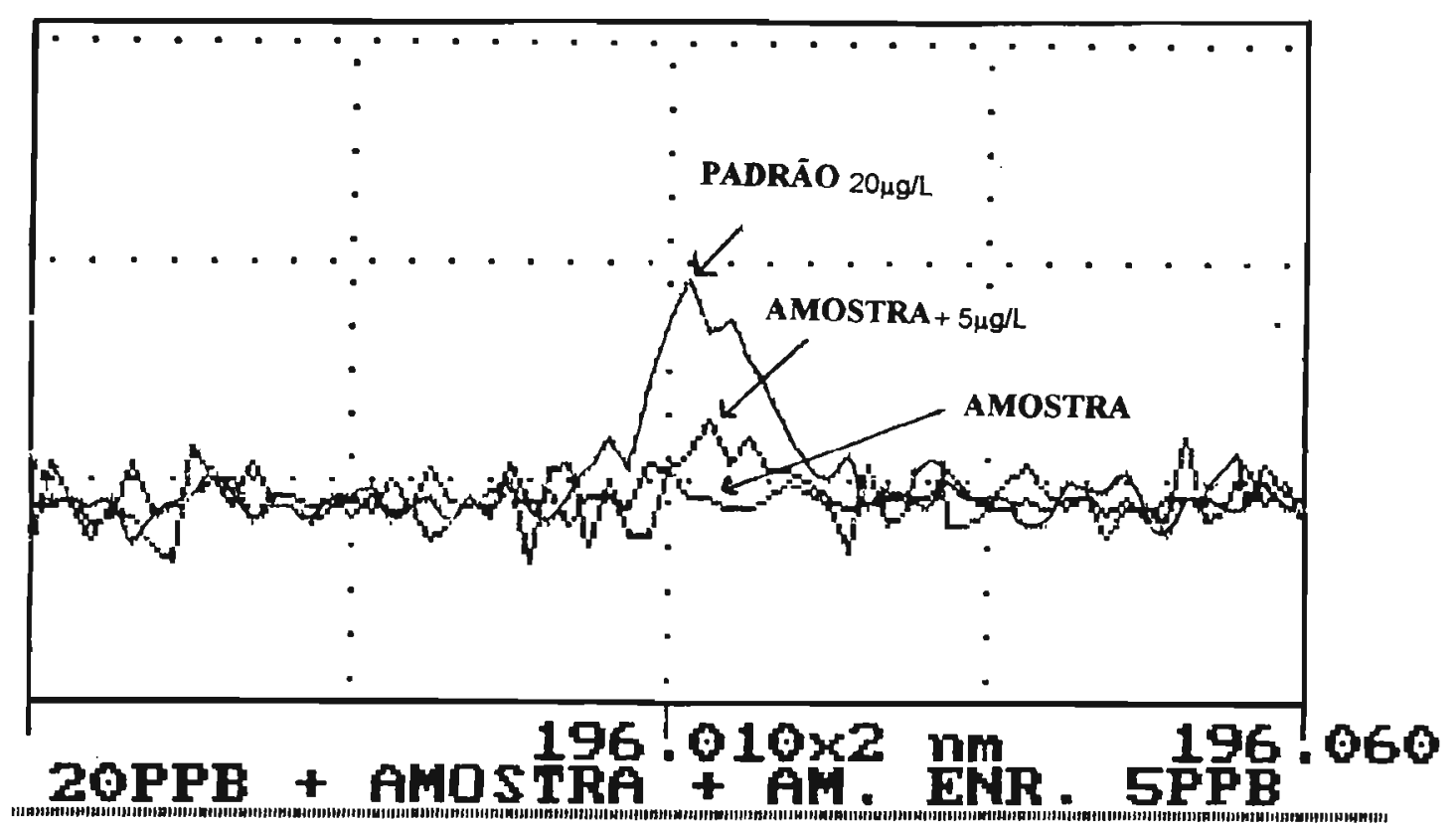

Figura 52 - espectro de varredura do Se: amostra + amostra enriquecida com $5 \mu \mathrm{gL}^{-1}+$ padrão de $20 \mu \mathrm{gL}^{-1}$ 


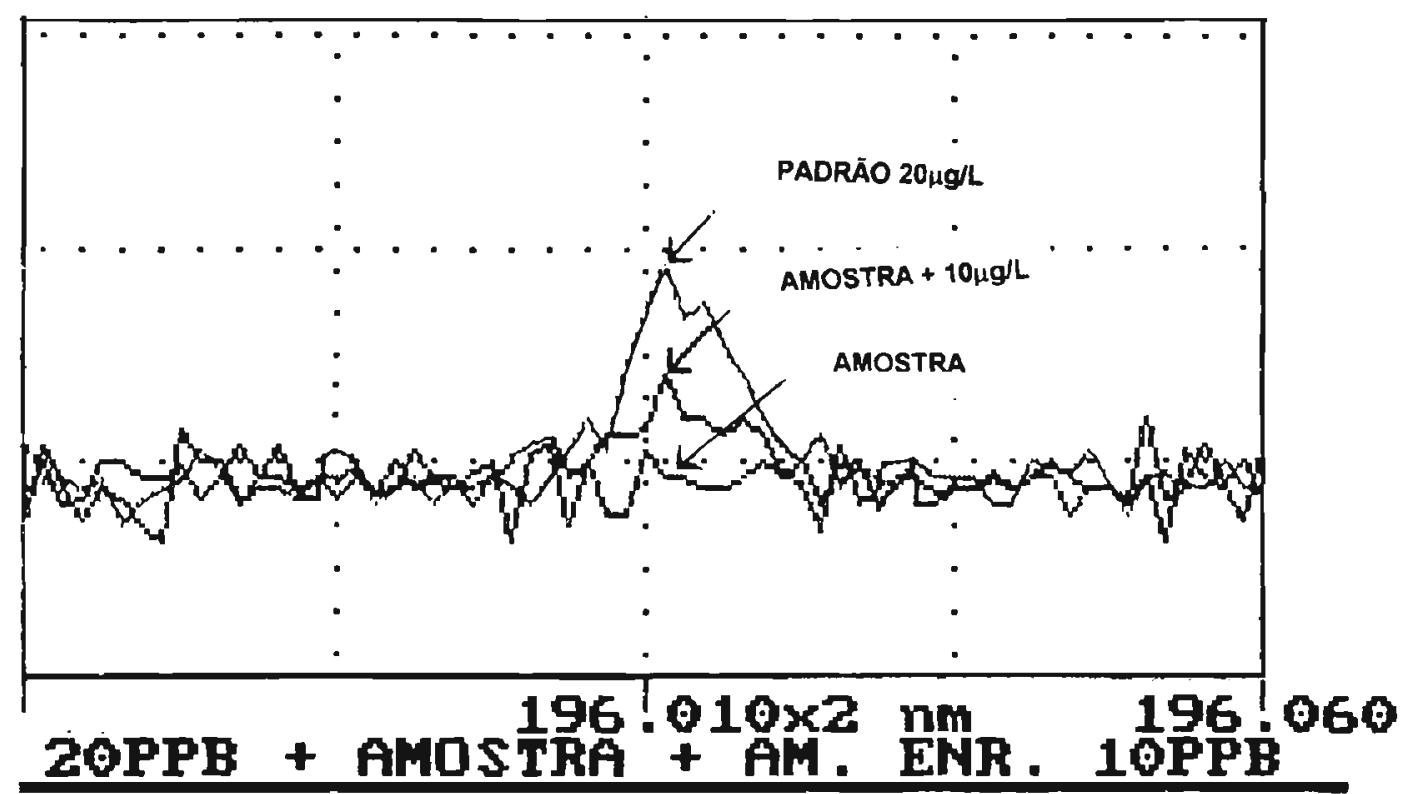

Figura 53 - espectro de varredura do Se: amostra + amostra enriquecida com $10 \mu \mathrm{gL}^{-1}+$ padrão de $20 \mu \mathrm{gL}^{-1}$.

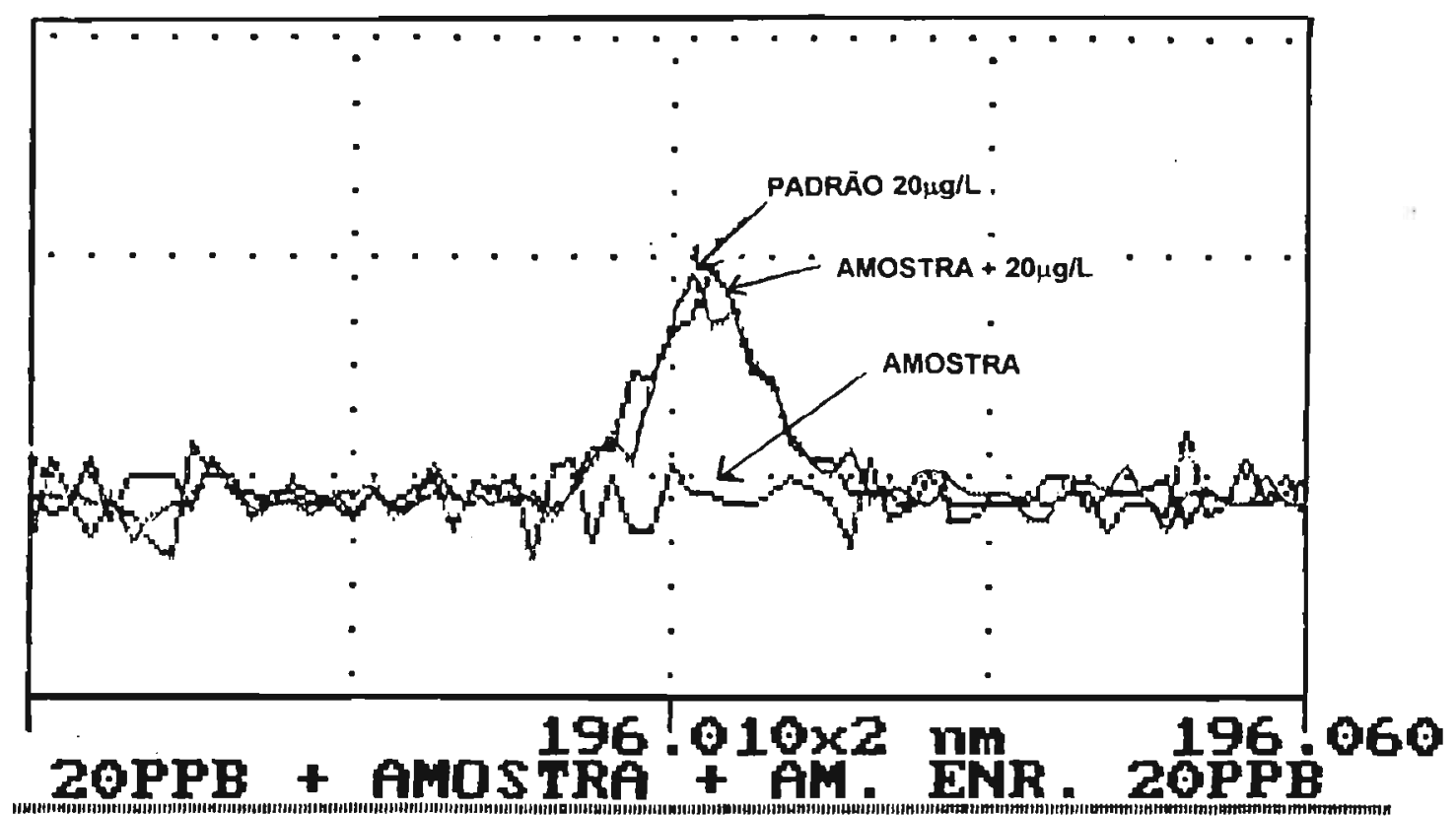

Figura 54 - espectro de varredura do Se: amostra + amostra enriquecida com $20 \mu \mathrm{gL}^{-1}+$ padrão de $20 \mu \mathrm{gL}^{-1}$. 


\section{Resultados obtidos das determinacões de As e Se nas amostras de café solúvel}

A tabela XVIII apresenta os resultados das determinaçöes de As e Se realizadas em triplicata em 21 amostras de café solúvel disponíveis no mercado brasileiro utilizando o espectrômetro PSX da Baird, de acordo com as condições instrumentais definidas na tabela VII, página 54.

Tabela XVIII: resultados das determinações de As e Se nas 21 amostras de café solúvel $(n=3)$.

\begin{tabular}{|c|c|c|c|}
\hline Amostra & Elemento & $\begin{array}{c}\text { As } \\
\mathrm{mgkg}^{-1}\end{array}$ & $\begin{array}{c}\mathrm{Se} \\
\mathrm{mgKg}^{-1}\end{array}$ \\
\hline 01 & & $<0,2$ & $<0,1$ \\
\hline 02 & & $<0,2$ & $<0,1$ \\
\hline 03 & & $<0,2$ & $<0,1$ \\
\hline 04 & & $<0,2$ & $<0,1$ \\
\hline 05 & & $<0,2$ & $<0,1$ \\
\hline 06 & & $<0,2$ & $<0,1$ \\
\hline 07 & & $<0,2$ & $<0,1$ \\
\hline 08 & & $<0,2$ & $<0,1$ \\
\hline 09 & & $<0,2$ & $<0,1$ \\
\hline 10 & & $<0,2$ & $<0,1$ \\
\hline 11 & & $<0,2$ & $<0,1$ \\
\hline 12 & & $<0,2$ & $<0,1$ \\
\hline 13 & & $<0,2$ & $<0,1$ \\
\hline 14 & & $<0,2$ & $<0,1$ \\
\hline 15 & & $<0,2$ & $<0,1$ \\
\hline 16 & & $<0,2$ & $<0,1$ \\
\hline 17 & & $<0,2$ & $<0,1$ \\
\hline 18 & & $<0,2$ & $<0,1$ \\
\hline 19 & & $<0,2$ & $<0,1$ \\
\hline 20 & & $<0,2$ & $<0,1$ \\
\hline 21 & & $<0,2$ & $<0,1$ \\
\hline
\end{tabular}

Os resultados obtidos apresentaram-se abaixo dos limites de determinação atendendo aos valores estabelecidos pela legislação brasileira de alimentos vigente [3], que fixa concentraçöes máximas para o As de $1,00 \mathrm{mg} \mathrm{Kg}^{-1}$ e Se de $0,3 \mathrm{mgKg}^{-1}$. Três amostras enriquecidas com $1 \mathrm{mgKg}^{-1}$ equivalente a $10 \mu \mathrm{gL}^{-1}$ de As e Se nas soluções de análise, passando por todo o processo de preparação das amostras, apresentaram valores médios de recuperações aceitáveis. A tabela XIX e a figura 55 a seguir apresentam estes valores para cada amostra. 
Tabela XIX: valores de recuperação médias de As e Se em três amostras de café solúvel.

\begin{tabular}{|ccc|}
\hline Amostra & As mgKg $^{-1}$ & Se ngKg \\
\hline 02 & $1,0 \pm 0,1$ & $1,1 \pm 0,1$ \\
05 & $1,0 \pm 0,1$ & $1,0 \pm 0,1$ \\
13 & $1,1 \pm 0,1$ & $1,0 \pm 0,1$ \\
\hline
\end{tabular}

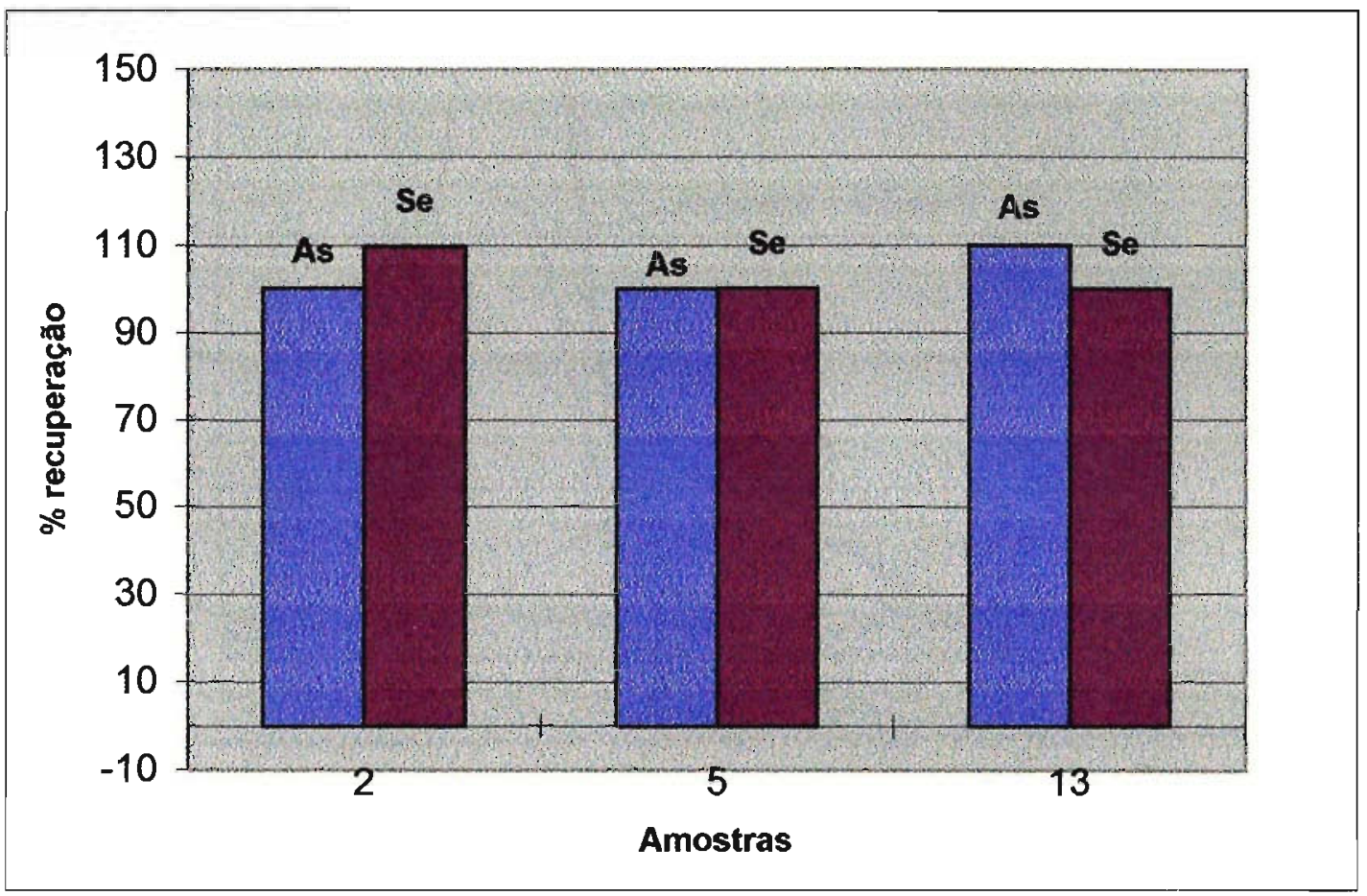

Figura 55 - valores de recuperação em \% de três amostras enriquecidas com As e Se.

\subsection{Otimizaçăo dos parâmetros instrumentais e determinação do $\mathrm{Hg}$}

De acordo com a tabela XVI, página 64 , a determinação do $\mathrm{Hg}$ através do sistema de nebulização convencional apresentou boa porcentagem de recuperação, contudo baixa precisāo. O espectro de varredura obtido, figura 56 a seguir, apresentou pequena variação do sinal emitido pela amostra, e o pico de emissão do analito não esta bem definido. Além disto o limite de determinação $\left(0,005 \mathrm{mgL}^{-1}\right)$, quando relacionado com a massa de amostra e volume da solução de análise (1g/50mL), não é adequado para garantir níveis de concentrações abaixo do especificado pela legislação brasileira de alimentos [3]. Um método alternativo para avaliação segura do Hg sem a presença de interferência de matriz e espectral é a utilização da técnica de geração de vapor frio que foi aplicado no presente trabalho para a determinação deste analito. 


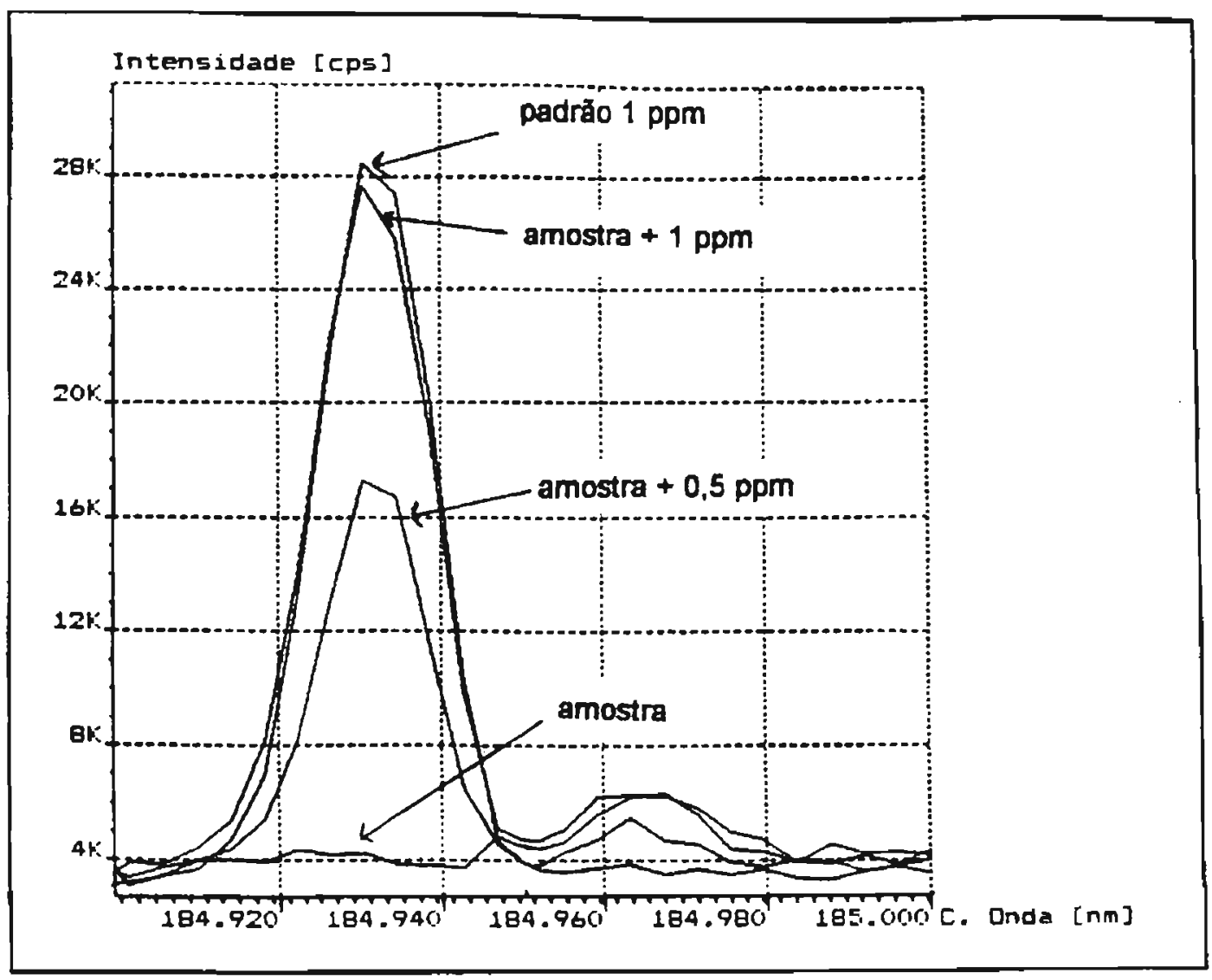

Figura 56 - espectro de varredura do Hg (espec..trômetro Modula da Spectro).

\section{Otimizacão dos parámetros de operacão}

Da mesma maneira que nas determinaçōes do As e Se, o separador de fases ou gerador de hidretos construido de acordo com as especificações contidas no artigo publicado por OLIVEIRA et al.[49], figura 20 , foi utilizado com sucesso sob as condiçōes operacionais do espectrômetro PSX da Baird. As soluções padrões de $\mathrm{Hg}$ foram preparadas levando-se em conta a concentração de $\mathrm{HNO}_{3}$ adicionado às ${ }^{a}$.mostras, ou seja, $60 \% \mathrm{v} / \mathrm{v}$, e mesmo através desta elevada acidez, o sistema apresentou-se estável, sendo obtido bons valores de intensidades de emissão representados pelo aceitável coeficiente de correlação linear, tabela $\mathrm{XI}$, página 57. 


\section{Resultados obtidos das determinaç̃es de $\mathrm{Hg}$ nas amostras de café solúvel}

Os resultados da determinação do $\mathrm{Hg}$ realizadas em triplicata nas 21 amostras de café solúvel são apresentados na tabela XX.

Tabela XX: resultados da determinação do $\mathrm{Hg}$ nas 21 amostras de café solúvel $(n=3)$

\begin{tabular}{|cc|}
\hline Amostras & $\begin{array}{c}\mathrm{Hg}^{-1} \\
\mathrm{mgkg}^{-1}\end{array}$ \\
\hline 01 & $<0,01$ \\
02 & $<0,01$ \\
03 & $<0,01$ \\
04 & $<0,01$ \\
05 & $<0,01$ \\
06 & $<0,01$ \\
07 & $<0,01$ \\
08 & $<0,01$ \\
09 & $<0,01$ \\
10 & $<0,01$ \\
11 & $<0,01$ \\
12 & $<0,01$ \\
13 & $<0,01$ \\
14 & $<0,01$ \\
15 & $<0,01$ \\
16 & $<0,01$ \\
17 & $<0,01$ \\
18 & $<0,01$ \\
19 & $<0,01$ \\
20 & $<0,01$ \\
21 & $<0,01$ \\
\hline
\end{tabular}

Os resultados obtidos apresentaram-se abaixo do limite de determinação da técnica, porém atendendo ao valor estabelecido pela legislação brasileira de alimentos vigente [3], que fixa a concentração máxima para $\circ \mathrm{Hg}$ de $0,01 \mathrm{mgKg}^{-1}$. Três amostras enriquecidas com $0,1 \mathrm{mgKg}^{-1}$ deste elemento, equivalente a $10 \mu \mathrm{gL}^{-1}$ na solução de análise, apresentaram recuperaçōes médias de 70 a $95 \%$, considerados bons valores levando em consideração a possibilidade de perda por volatilização deste analito que pode ocorrer no presente método de análise proposto. A tabela XXI e figura 57 a seguir apresentam estes valores para cada amostra. 
Tabela XXI: valores de recuperação médias de $\mathrm{Hg}$ em três amostras de café solúvel.

\begin{tabular}{|cc|}
\hline Amostra & $\mathrm{Hg} \mathrm{mg} \mathrm{Kg}^{-1}$ \\
\hline 02 & $0,073 \pm 0,012$ \\
05 & $0,094 \pm 0,018$ \\
13 & $0,083 \pm 0,006$ \\
\hline
\end{tabular}

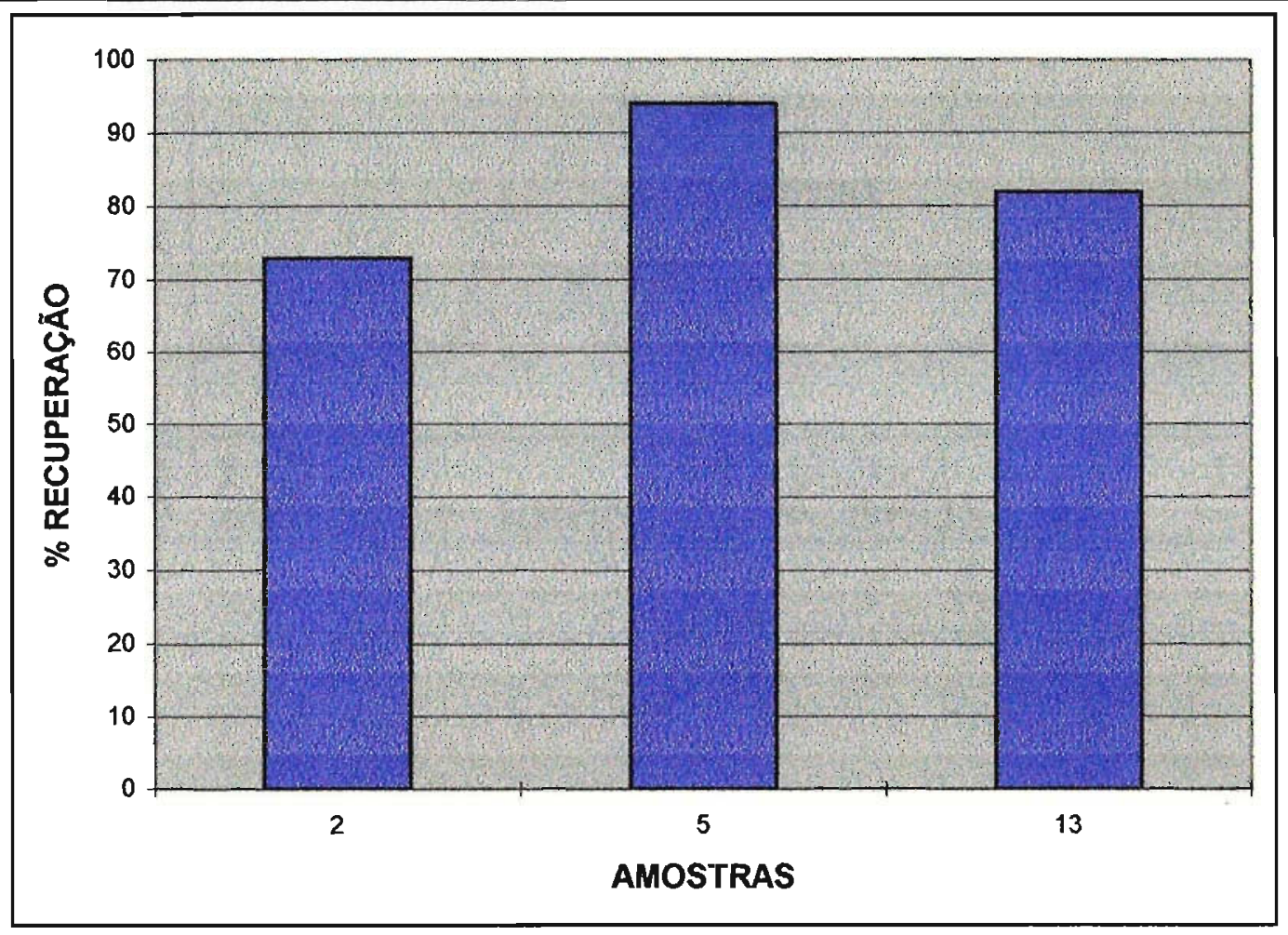

Figura 57 - valores de recuperação em \% de très amostras enriquecidas com $\mathrm{Hg}$.

As matrizes das amostras não causaram nenhum tipo de instabilidade no sistema nem apresentaram variaçōes significativas de intensidades de emissão durante a reação com o $\mathrm{NaBH}_{4}$, onde o vapor de $\mathrm{Hg}$, caso presente, era formado através da reação de redução com este reagente. Desta maneira foi possível a utilização do limite de deteç̧ão instrumental de $0,98 \mu \mathrm{gL}^{-1}$ ou $1,0 \mu \mathrm{gL}^{-1}$, como limite de deteç̧ão prático ou limite de determinação. As figuras 58 a 61 , apresentam gráficos de varredura de uma amostra, amostra enriquecida (adição de quantidades conhecidas de $\mathrm{Hg}$ após mineralização e tratamento da amostra conforme apresentado na figura 26 , item 4.4.2) com de $1 \mu \mathrm{gL}^{-1}, 5 \mu \mathrm{gL}^{-1}, 10 \mu \mathrm{gL}^{-1}$, branco e padrão de $20 \mu \mathrm{gL}^{-1}$. 


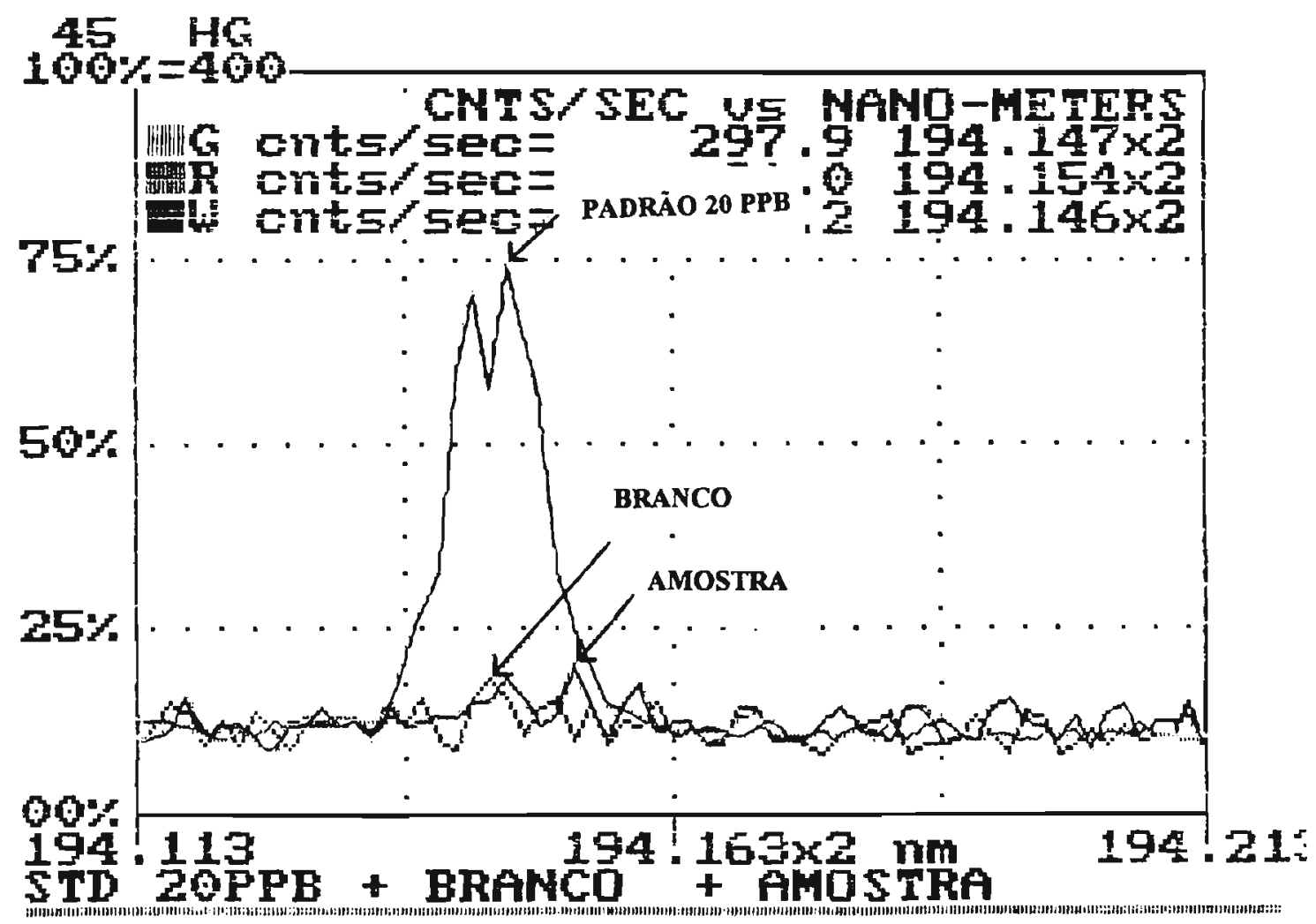

Figura 58 - espectro de varredura do $\mathrm{Hg}$ : branco + amostra + padrão de $20 \mu \mathrm{gL}^{-1}$. 


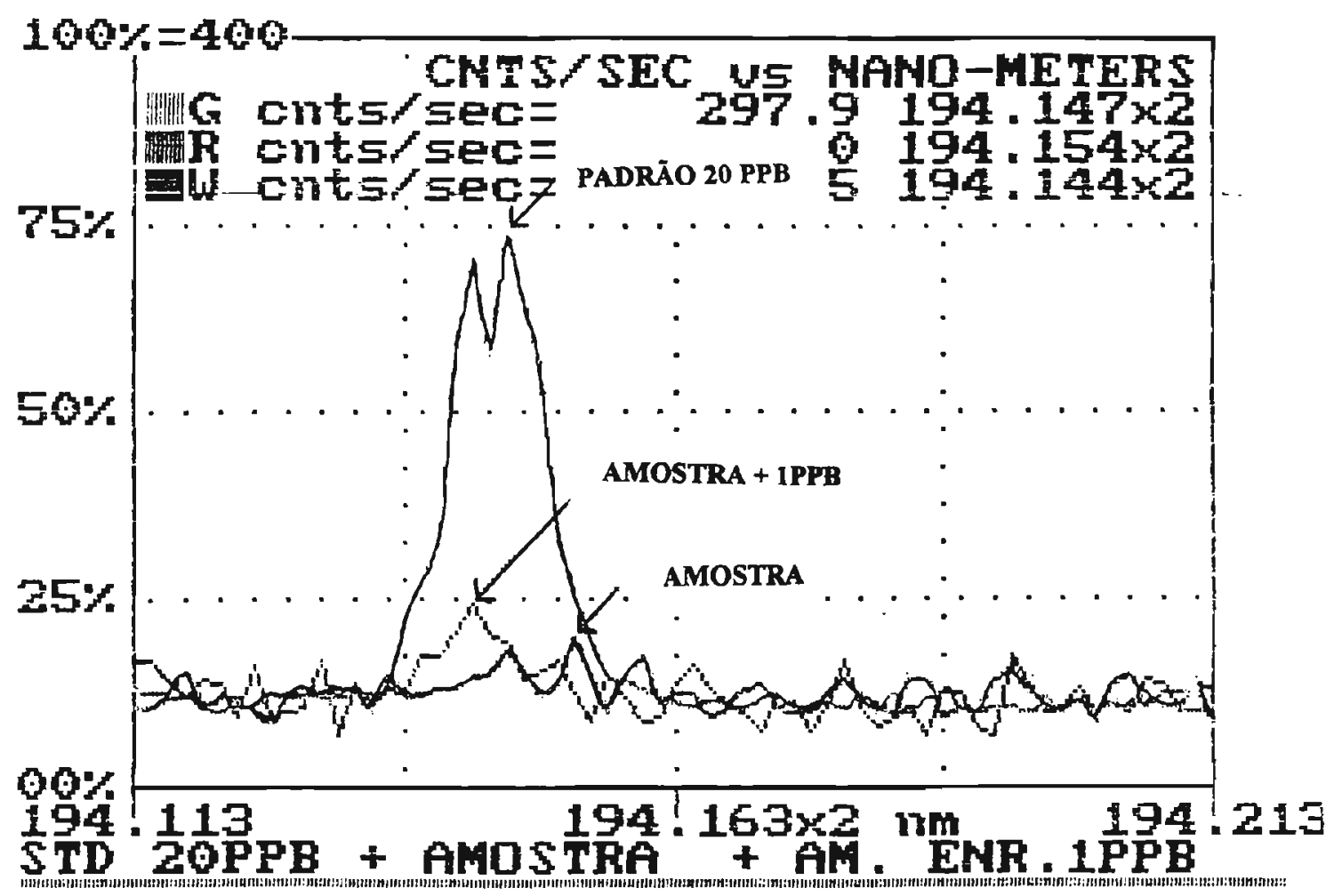

Figura 59 - espectro de varredura do $\mathrm{Hg}$ : amostra + amostra enriquecida com $1 \mu \mathrm{gL}^{-1}+$ padrão de $20 \mu \mathrm{gL}^{-1}$. 


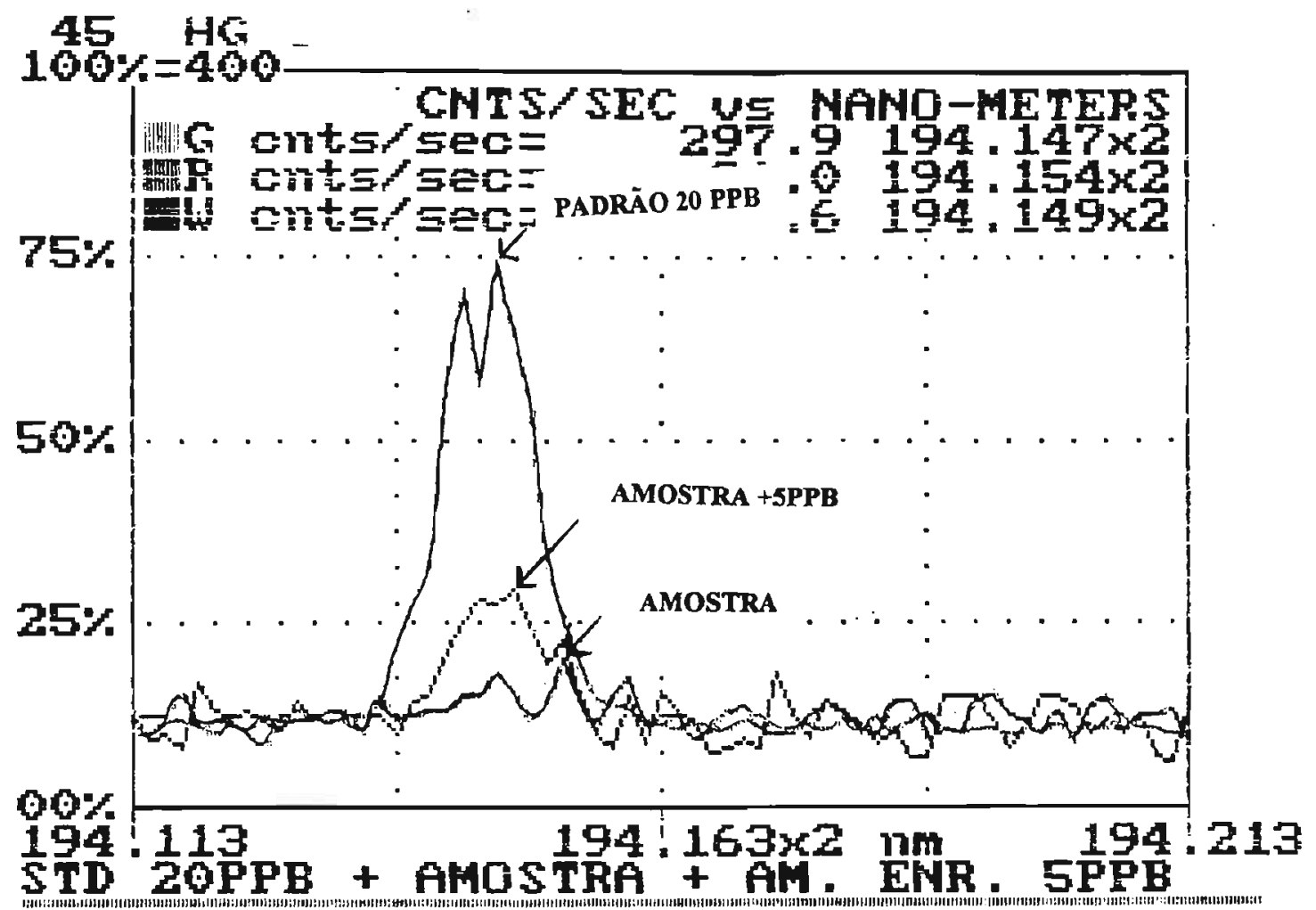

Figura 60 - espectro de varredura do $\mathrm{Hg}$ : amostra + amostra enriquecida com $5 \mu \mathrm{gL}^{-1}+$ padrão de $20 \mathrm{\mu gL}^{-1}$. 


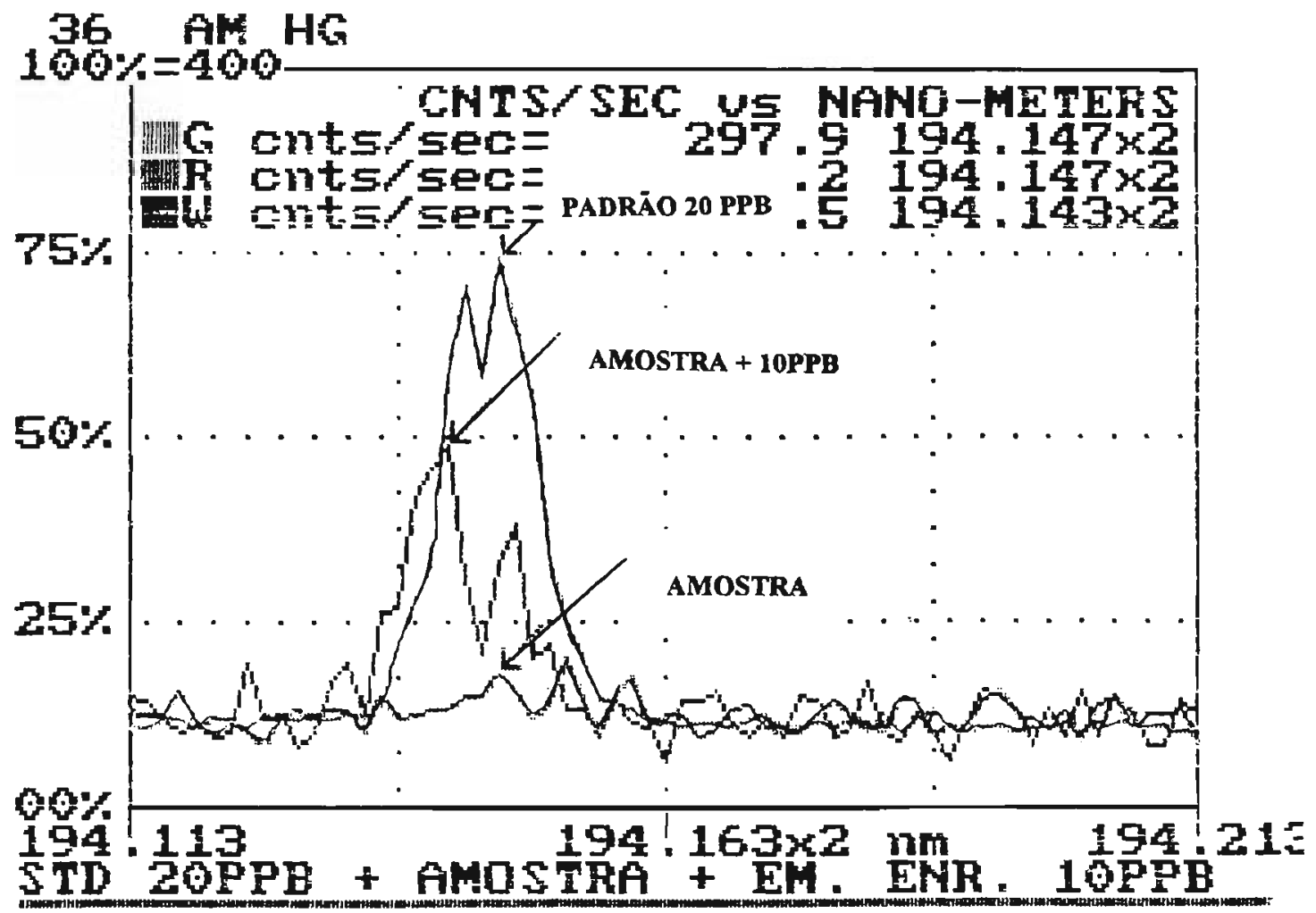

Figura 61 - espectro de varredura do $\mathrm{Hg}$ : amostra + amostra enriquecida com $10 \mu \mathrm{gL}^{-1}+$ padrão de $20 \mu \mathrm{gL}^{-1}$.

5.6. Determinaçర̃es dos elementos: $\mathrm{Na}, \mathrm{K}, \mathrm{Mg}, \mathrm{Al}, \mathrm{P}, \mathrm{S}, \mathrm{Ca}, \mathrm{Mn}, \mathrm{Fe}, \mathrm{Cu}, \mathrm{Zn}, \mathrm{Ni}, \mathrm{Cd}$, $\mathrm{Sb}, \mathrm{Cr}$ e $\mathrm{Pb}$ nas 21 amostras de café solúvel disponiveis no mercado brasileiro

A tabela XXIl a seguir apresenta os valores de concentração e desvios padrão obtidos das determinações realizadas em triplicatas de cada amostra de café solúvel. As figuras 62 a 73 ilustram as concentrações de $\mathrm{Na}, \mathrm{K}, \mathrm{Mg}, \mathrm{Al}, \mathrm{P}, \mathrm{S}, \mathrm{Ca}, \mathrm{Mn}, \mathrm{Fe}, \mathrm{Sn}, \mathrm{Cu}$ e $\mathrm{Zn}$ presente nas diferentes amostras. Os elementos $\mathrm{Ni}, \mathrm{Cd}, \mathrm{Sb}, \mathrm{Cr}$ (exceção amostra 13) e $\mathrm{Pb}$ não foram detectados nos níveis dos limites de determinação. 


\begin{tabular}{|c|c|c|c|c|c|c|c|c|c|c|c|c|c|c|c|c|c|c|c|c|c|}
\hline 을 & $\frac{8}{\mathrm{v}}$ & $\frac{8}{i}$ & $\frac{8}{i}$ & $\frac{8}{i}$ & $\frac{8}{\dot{v}}$ & $\frac{8}{\dot{v}}$ & $\frac{8}{\bar{v}}$ & $\frac{8}{\bar{v}}$ & $\frac{8}{\bar{v}}$ & $\frac{8}{\bar{v}}$ & 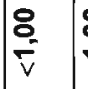 & $\frac{8}{i}$ & $\frac{8}{\bar{v}}$ & $\frac{8}{\bar{v}}$ & $\frac{8}{\bar{v}}$ & $\frac{8}{\square}$ & $\frac{8}{i v}$ & $\frac{8}{\bar{v}}$ & $\frac{8}{\bar{v}}$ & $\frac{8}{\frac{8}{v}}$ & $\frac{8}{\bar{v}}$ \\
\hline ¿ & $\overline{\mathrm{v}}$ & V. & 家 & $\bar{v}$ & $\bar{v}$ & 审 & के & î & हे & i. & $\bar{v}$ & í & $\mid$ & $\bar{\sigma}$ & $\bar{i}$ & $\overline{8}$ & i & ít & $\overline{\bar{v}}$ & i & i \\
\hline क & 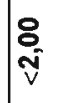 & 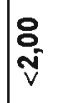 & ठ্ & ষ্ণ & ষ্ & ठ্ & 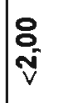 & 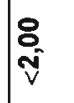 & 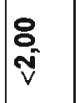 & ठ্ & ठ̊ & 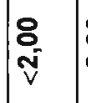 & ষ্ & 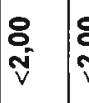 & 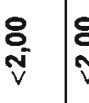 & ষ্ণ & ठ্ণ & 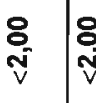 & ষ্ণ & ষ্ & ठ̊ \\
\hline ठ & 产 & 识 & 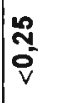 & 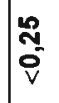 & ñ & 恕 & 商 & 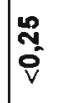 & 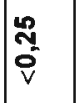 & $\begin{array}{l}\text { No } \\
\text { Ô. } \\
\text { V. }\end{array}$ & 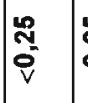 & ָั & 战 & 昰 & $\begin{array}{c}\text { in } \\
\text { on } \\
0\end{array}$ & :ू & : & חָ & ָֻุ & स् & W \\
\hline 之荡 & 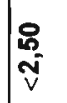 & $\begin{array}{l}\mathscr{B} \\
\text { v } \\
\text { v }\end{array}$ & 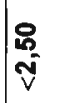 & 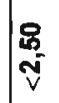 & 只 & 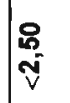 & $\begin{array}{l}\stackrel{8}{0} \\
\text { vive }\end{array}$ & 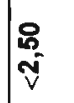 & 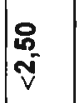 & 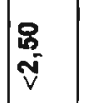 & $\mid$ & 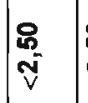 & 艿 & 孞 & 足 & 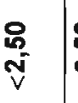 & 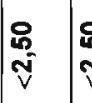 & 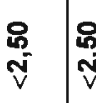 & 品 & 怘 & 品 \\
\hline & 今 & 10 & ${ }_{0}^{\infty}$ & $=0$ & 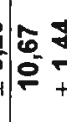 & $\mid \begin{array}{l}0 \\
2 \\
2\end{array}$ & $\begin{array}{l}8.5 \\
0.0 \\
0 \\
0\end{array}$ & $\frac{8}{80}$ & $\mid \begin{array}{rr}5 & 0 \\
0 & 0 \\
0 & 0 \\
-1 & +1\end{array}$ & 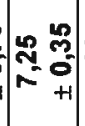 & 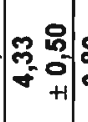 & 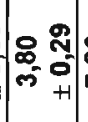 & $\mid$ & 总 & & & 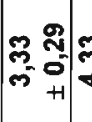 & 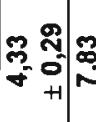 & 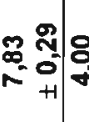 & $\begin{array}{c}8 \\
8 \\
\end{array}$ & 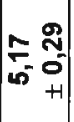 \\
\hline & 象 & + & + & No & ma & 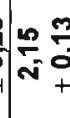 & $\stackrel{2}{2}$ & ${ }_{0}^{0}$ & 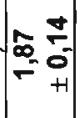 & 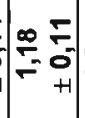 & 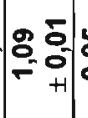 & 象 & - & $\mid$ & & 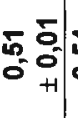 & $\mid \begin{array}{cc}10 \\
0 \\
0 & 0 \\
0 & 0 \\
0 & 0\end{array}$ & 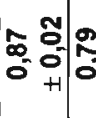 & حר. & 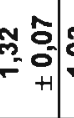 & $\mid \begin{array}{ll} & 0 \\
0 & 0 \\
- & 0 \\
- & +1\end{array}$ \\
\hline & & & $0^{\circ}$ & $\sigma^{-6}$ & 9 & $0^{\circ}$ & $\infty_{+1}^{\infty}-$ & $\frac{1}{6}$ & 今. & 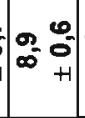 & $\mid \begin{array}{l}\theta \\
\sigma_{0}^{\circ}\end{array}$ & & & & & & & & & $\begin{array}{c}0 \\
0 \\
0 \\
0 \\
0 \\
+1\end{array}$ & 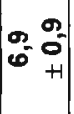 \\
\hline 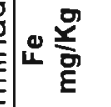 & $\left.\right|^{\infty}{ }^{-0}$ & I & $\overline{\text { E্ল }}$ & $\frac{\infty}{m}$ & ? & $=7$ & & 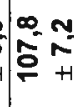 & 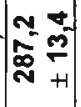 & $\begin{array}{l}0 \\
\vdots \\
0 \\
0\end{array}$ & $\mid \begin{array}{ll}0 & = \\
-1 & =\end{array}$ & & & & & & $\left|\begin{array}{ccc}\infty & 1 \\
0 & 0 & 0 \\
0 & 0\end{array}\right|$ & $\frac{0}{9}$ & 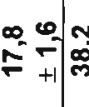 & 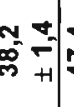 & $\left|\begin{array}{ll}0 & 0 \\
5 & 0 \\
7 & +1\end{array}\right|$ \\
\hline & 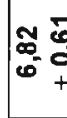 & $\mid e_{0}^{\infty}$ & 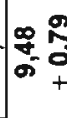 & \pm & $\mid \begin{array}{l}80 \\
N \\
N\end{array}$ & 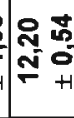 & 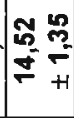 & $\frac{\infty}{\infty}$ & 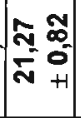 & 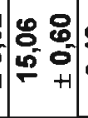 & 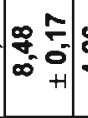 & & & 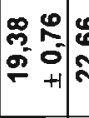 & & & $\mid \begin{array}{c}0 \\
0 \\
0 \\
0 \\
0\end{array}$ & 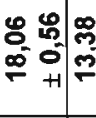 & 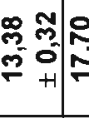 & \begin{tabular}{l}
0 \\
0 \\
\hdashline \\
\hdashline \\
\hdashline \\
+1
\end{tabular} & $\left|\begin{array}{cc}0 & 0 \\
0 & 0 \\
\hdashline & 0 \\
\hdashline & 0 \\
-1\end{array}\right|$ \\
\hline Uू & 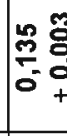 & $\frac{0}{0}$ & $\frac{10}{0}$ & $\frac{0}{0}$ & 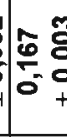 & $\left\{\begin{array}{l}0 \\
\frac{0}{0} \\
0 \\
0\end{array}\right.$ & 然 & $\mid$\begin{tabular}{l}
0 \\
$\frac{2}{0}$ \\
\hdashline-0 \\
0
\end{tabular} & $\mid$\begin{tabular}{ll}
1 & 0 \\
\hdashline & 0 \\
0 & 0 \\
0 & 0
\end{tabular} & $\left|\begin{array}{cc}0 \\
\hdashline \\
0 \\
0 & 0 \\
0 & 0\end{array}\right|$ & $\left.\mid \begin{array}{cc}0 & 0 \\
\hdashline & 0 \\
0 & 0 \\
0 & 0\end{array}\right]$ & & & & & \begin{tabular}{ccc}
0 \\
\hdashline \\
0 \\
0
\end{tabular} & 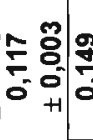 & 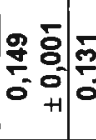 & 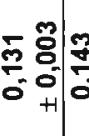 & 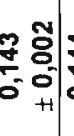 & $\left|\begin{array}{cc} & \overline{0} \\
\vdots & 0 \\
0 & 0 \\
0 & 0 \\
+1\end{array}\right|$ \\
\hline m $\frac{8}{\frac{8}{0}}$ & $\frac{1}{R}$ & $\frac{R}{R}$ & $\frac{1}{\mathfrak{N}}$ & $\frac{8}{0}$ & $\frac{\sigma}{5}$ & $\mathscr{C}_{0}^{\circ}$ & $\mid \begin{array}{c}\infty \\
0 \\
0 \\
\end{array}$ & $\mid \begin{array}{l}\tilde{0} \\
0 \\
0\end{array}$ & $\mid$\begin{tabular}{ll}
$\mathfrak{R}$ & 2 \\
\hdashline & 0 \\
\hdashline & 0 \\
0 & 0
\end{tabular} & 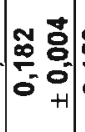 & $\mid$ & $\mid$\begin{tabular}{c}
0 \\
\hdashline \\
0 \\
0 \\
0 \\
0
\end{tabular} & $\mid$ & & & 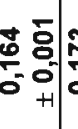 & 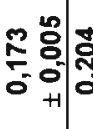 & 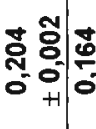 & 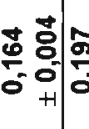 & 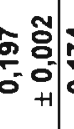 & 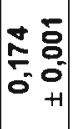 \\
\hline 2 $\frac{0}{\frac{0}{6}}$ & 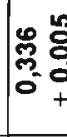 & $\left\{\begin{array}{l}0 \\
0 \\
0 \\
0\end{array}\right.$ & 总 & . & 秎 & ㅇㅇㅇ & 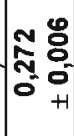 & 尊 & $\mid \begin{array}{ll}5 & 0 \\
0 & 0 \\
0 & 0 \\
+1\end{array}$ & $\mid$\begin{tabular}{c}
0 \\
\hdashline \\
$\vdots$ \\
0 \\
0 \\
0 \\
0 \\
0
\end{tabular} & 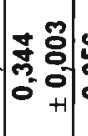 & $\left.\mid \begin{array}{l}0 \\
0 \\
0 \\
0 \\
0\end{array}\right]$ & 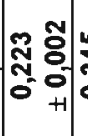 & & & 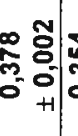 & 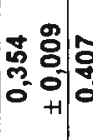 & 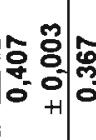 & $\begin{array}{c}0 \\
0 \\
0 \\
0 \\
0\end{array}$ & $\begin{array}{c}0 \\
0\end{array}$ & 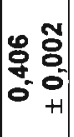 \\
\hline 区 & 星 & o & 最 & 是 & 是 & 品 & $\mid \begin{array}{ll}0 & 0 \\
0 & -0 \\
0 & 0 \\
= & 0\end{array}$ & $\begin{array}{l}5 \\
5 \\
5\end{array}$ & 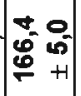 & 品 & 总 & 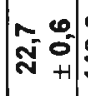 & 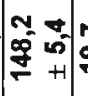 & $\hat{\sigma}^{2}=$ & 总 & $\begin{array}{l}\text { is } \\
\text { of } \\
v\end{array}$ & 星 & 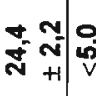 & 웅 & 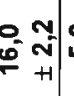 & $\mid \begin{array}{l}0 \\
\text { is } \\
v\end{array}$ \\
\hline$\frac{80}{\frac{0}{6}}$ & 성영 & 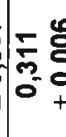 & & & 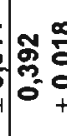 & $\frac{10}{0}$ & 㤐 : & $\mid \begin{array}{l}0 \\
:\end{array}$ & 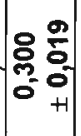 & 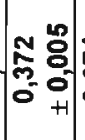 & 作 & 赵 & 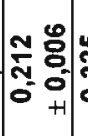 & & & 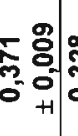 & స్లై & 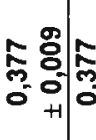 & 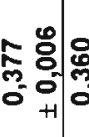 & 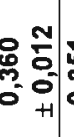 & 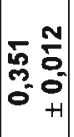 \\
\hline$=\frac{8}{6}$ & $\mathbb{B}_{0}^{\infty}$ & $\operatorname{lig}_{0}^{\circ}$ & o & 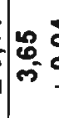 & Is & ${ }_{0}^{8} 8$ & $\frac{\pi}{0} \frac{0}{0}$ & 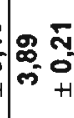 & 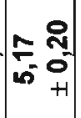 & $\mid \begin{array}{ll}0 & \\
0 & - \\
0 & 0 \\
+1\end{array}$ & 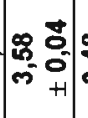 & 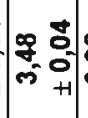 & $\mid$ & 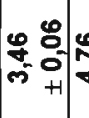 & & 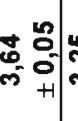 & و & 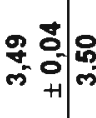 & 定 & 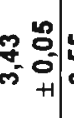 & $\left|\begin{array}{ccc} & 0 \\
0 & 0 \\
0 & 0 \\
0 & 0 \\
0 & +1\end{array}\right|$ \\
\hline 픙 & 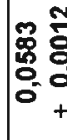 & $\bar{p}$ & 足 & $\left(\begin{array}{l}0 \\
2 \\
0 \\
0\end{array}\right.$ & 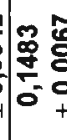 & 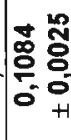 & $\begin{array}{l}\text { No } \\
\vdots \\
0 \\
0 \\
0\end{array}$ & $\left\{\begin{array}{l}2 \\
\mathbb{N} \\
0 \\
0 \\
0\end{array}\right.$ & $\left.\mid \begin{array}{ll}0 & 0 \\
0 & 0 \\
0 & 0 \\
0 & 0 \\
0 & +1\end{array}\right]$ & $\mid$ & $\mid$ & 总 & 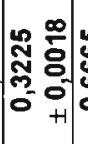 & 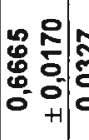 & & 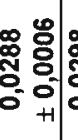 & 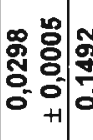 & 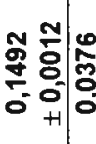 & 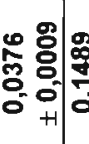 & $\begin{array}{c}0 \\
8 \\
\\
\\
0\end{array}$ & 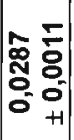 \\
\hline$\frac{\bar{\sigma}}{\mathbf{w}}$ & $\delta$ & $\delta$ & $\%$ & 8 & $\mathscr{0}$ & 8 & Ió & $\mathscr{8}$ & 18 & I? & $\mp$ & $\mid \mp$ & $m$ & 士 & $\stackrel{20}{2}$ & $\stackrel{\varphi}{\oplus}$ & $\approx$ & $\stackrel{\infty}{-}$ & $\stackrel{2}{2}$ & సి & $\bar{N}$ \\
\hline
\end{tabular}


Figuras 62 a 73-ilustração das concentrações presentes de $\mathrm{Na}, \mathrm{K}, \mathrm{Mg}, \mathrm{Al}, \mathrm{P}, \mathrm{S}, \mathrm{Ca}, \mathrm{Mn}, \mathrm{Fe}, \mathrm{Sn}$, Cu e Zn nas amostras.
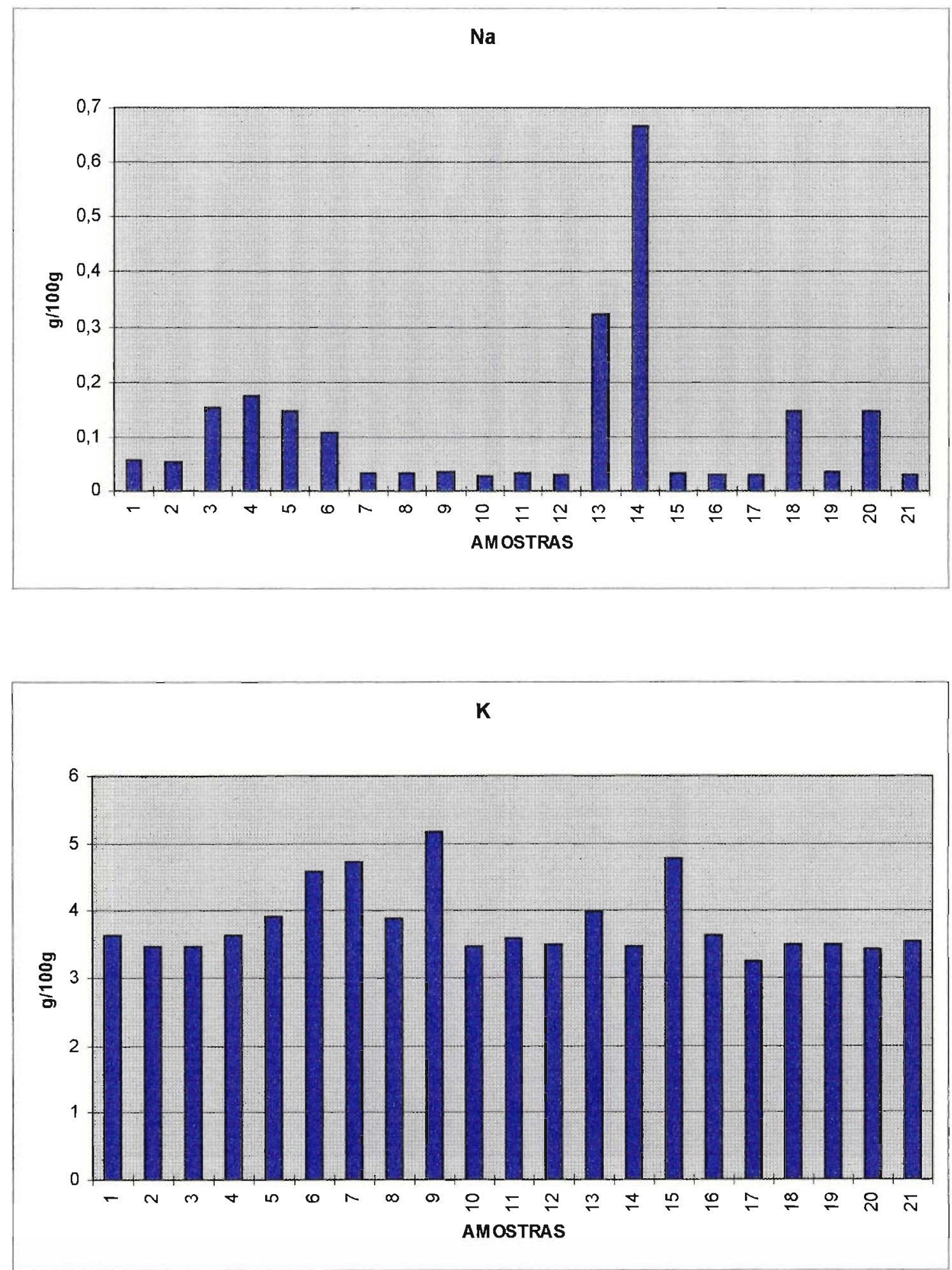

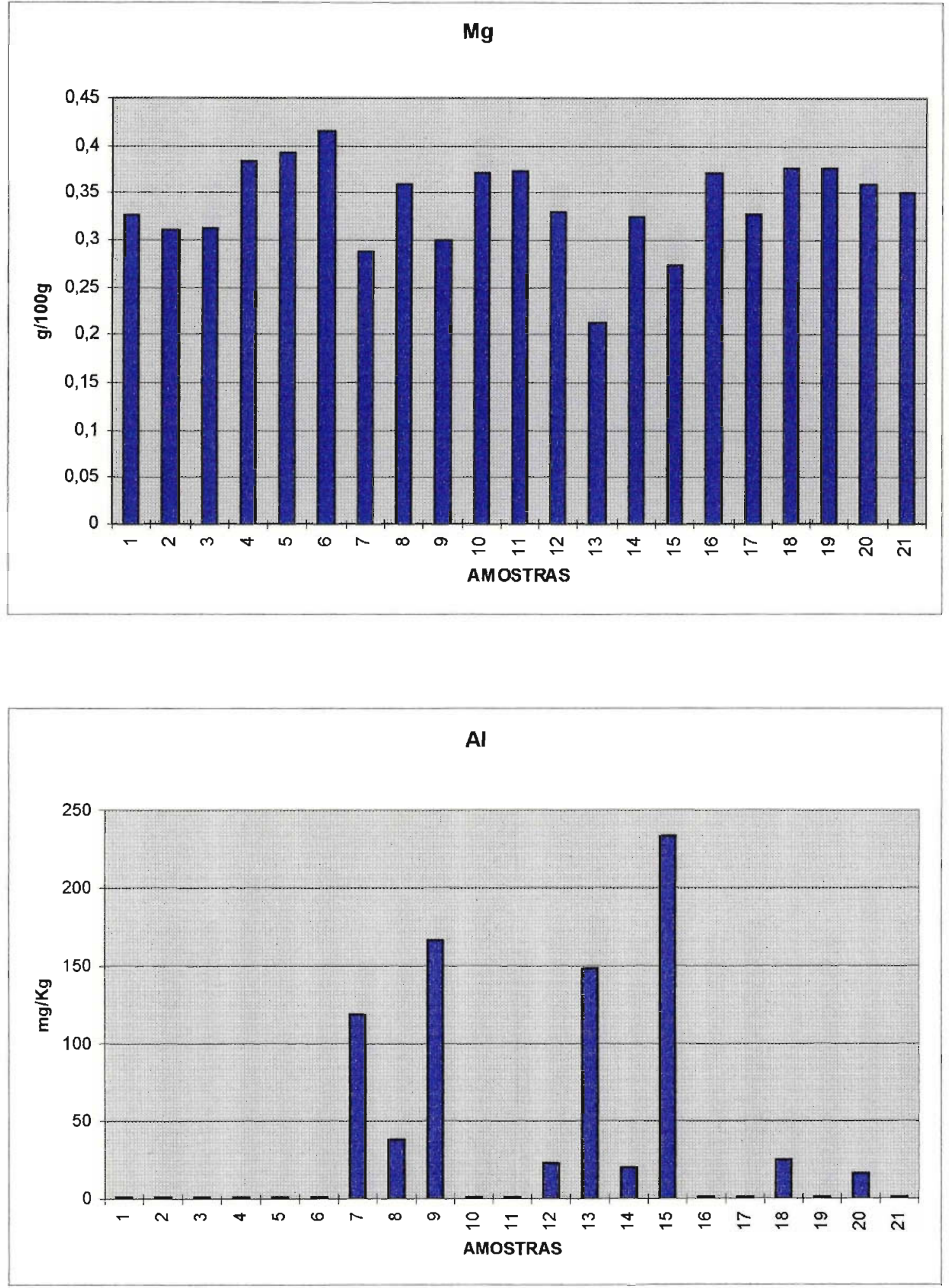

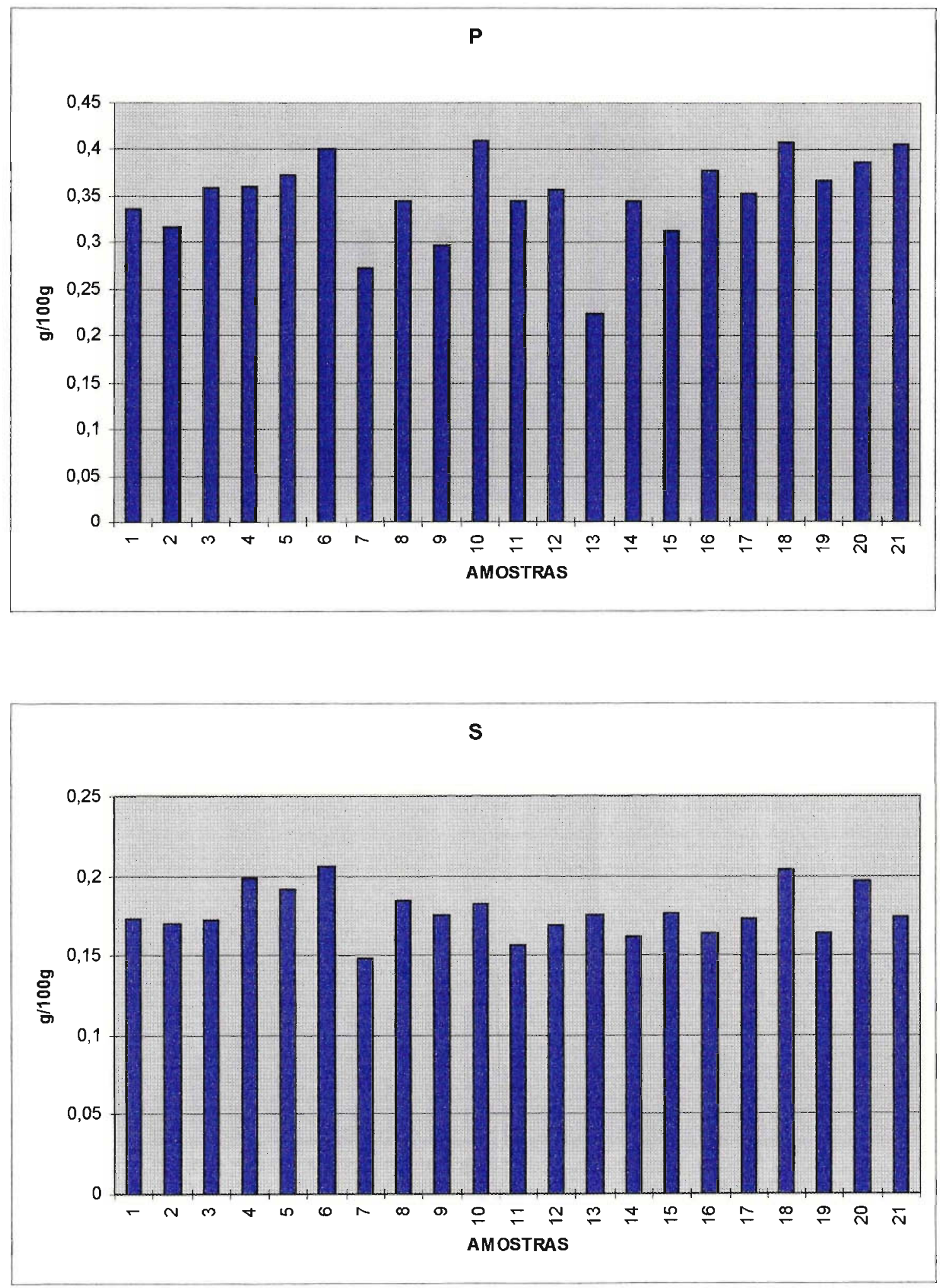

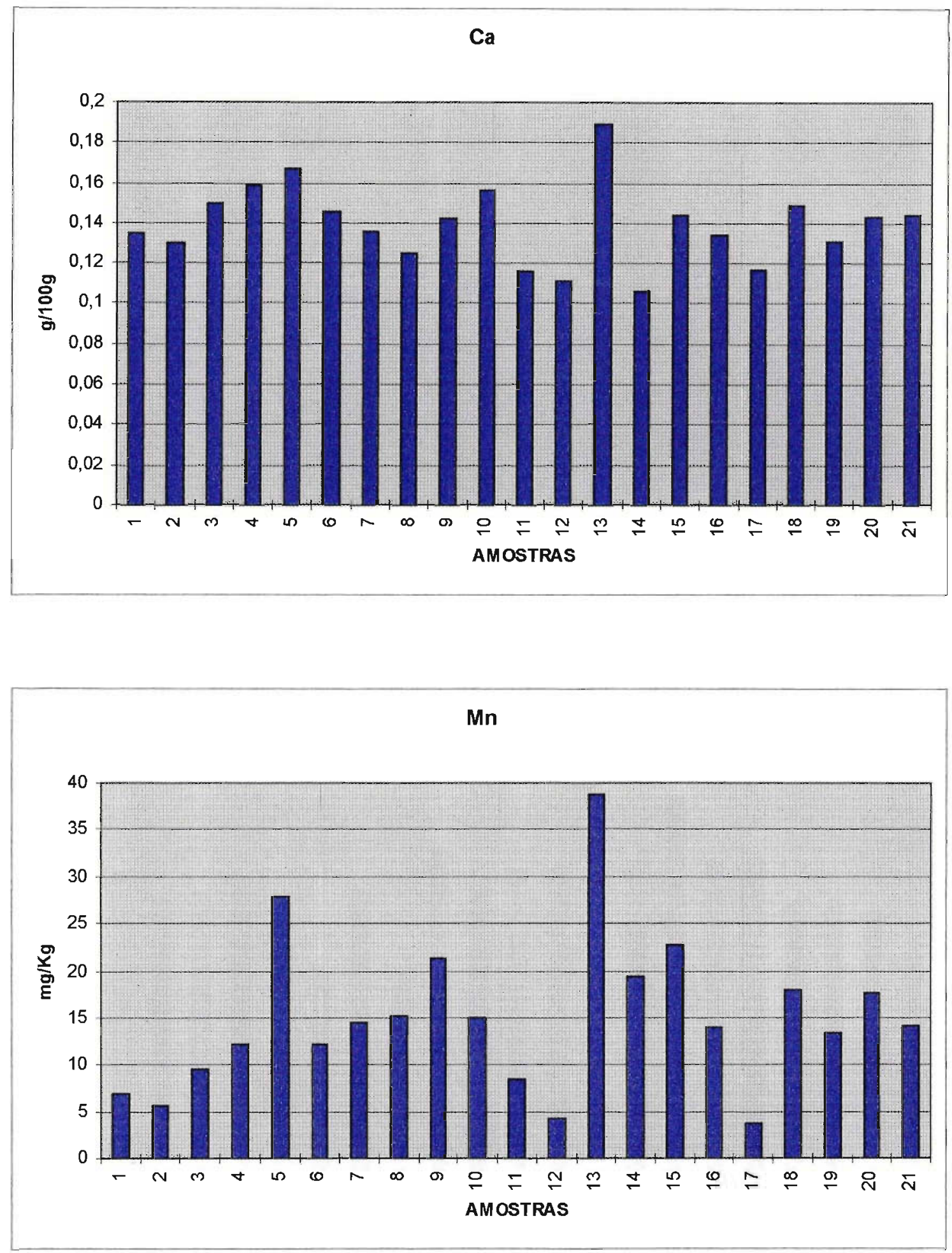

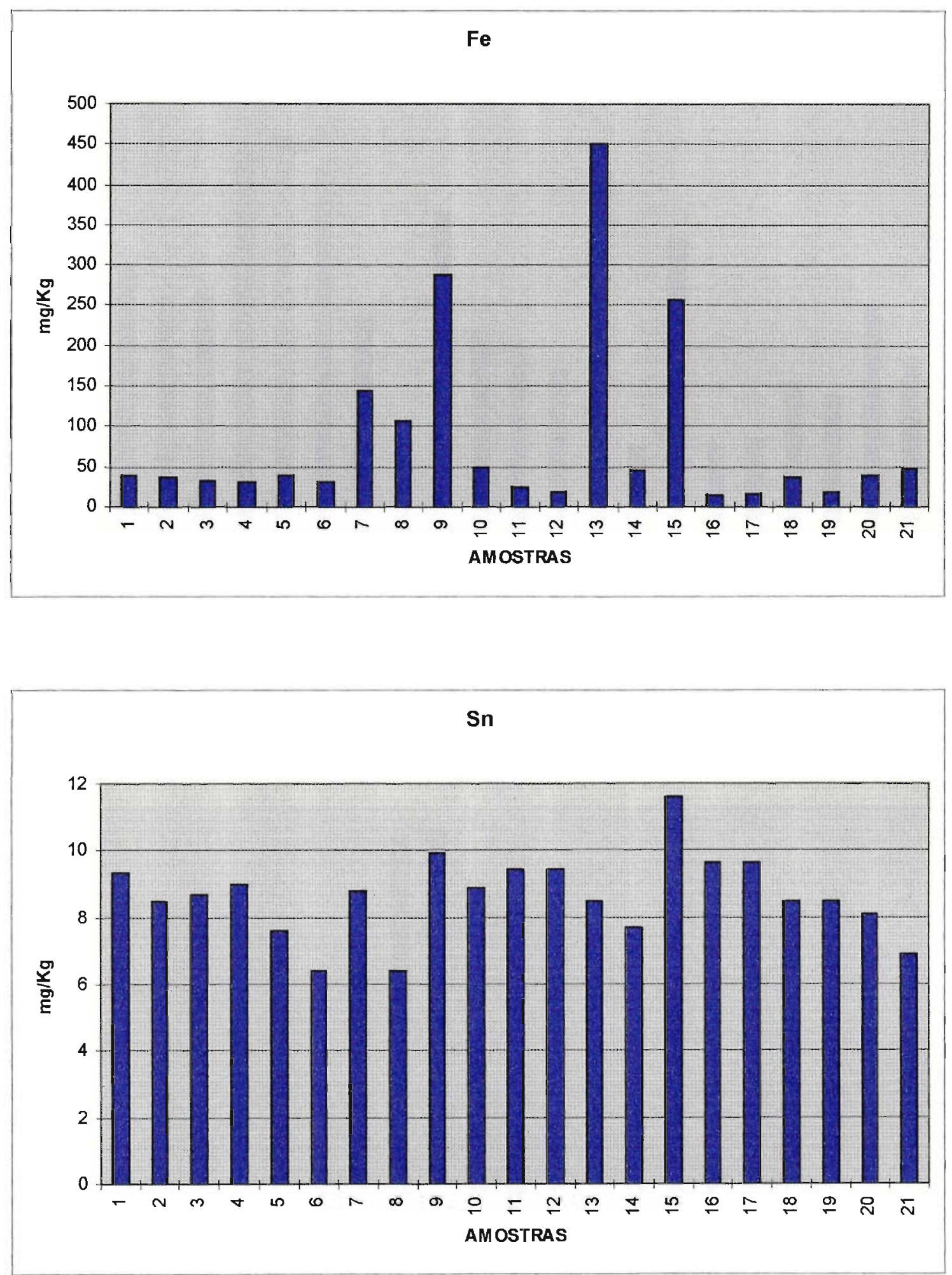

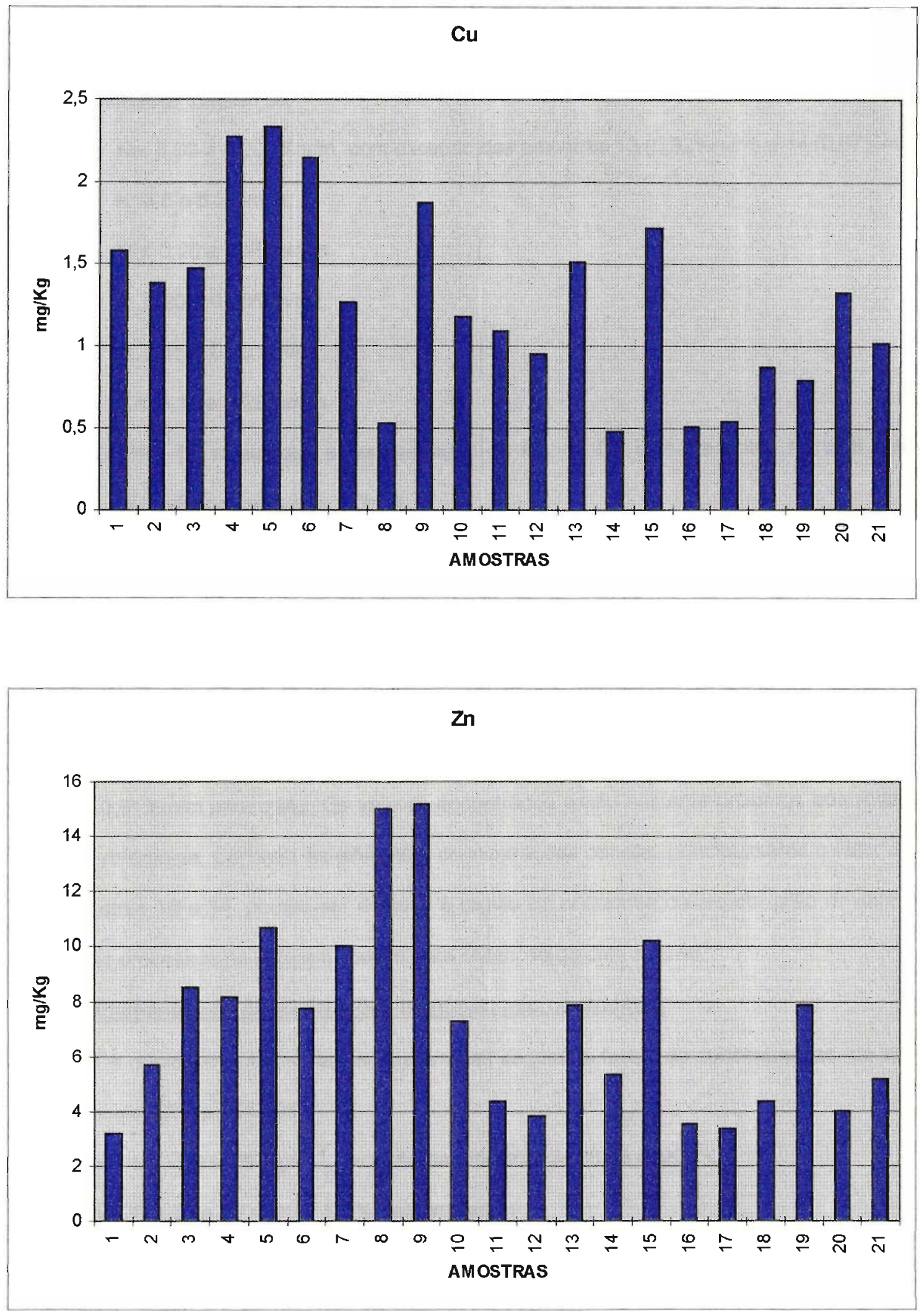


\section{Elementos de concentraç̃es maiores: macronutrientes}

Os macronutrientes se apresentaram nas seguintes faixas de concentrações, de acordo com a tabela XXII, página 95:

- Na: 0,03 a 0,200\%m/m, com exceção das amostras $13(0,32 \% \mathrm{~m} / \mathrm{m})$ e $14(0,67 \% \mathrm{~m} / \mathrm{m})$;

- $\mathrm{K}: 3,5$ a $5,2 \% \mathrm{~m} / \mathrm{m}$;

- Mg: 0,20 a $0,40 \% \mathrm{~m} / \mathrm{m}$;

- P: 0,20 a 0,40\%m/m;

- S: 0,15 a $0,20 \% \mathrm{~m} / \mathrm{m}$;

- Ca: 0,10 a $0,20 \% \mathrm{~m} / \mathrm{m}$.

DEBRY [4] relata que a concentração de $\mathrm{Na}, \mathrm{K}, \mathrm{Ca}$ e $\mathrm{P}$ presentes no café solúvel possuem em média os seguintes valores:

- Na: $0,05 \% \mathrm{~m} / \mathrm{m}$;

- $\mathrm{K}: 4 \% \mathrm{~m} / \mathrm{m}$;

- Ca: $0,15 \% \mathrm{~m} / \mathrm{m}$;

- P: $0,35 \% \mathrm{~m} / \mathrm{m}$.

O teor de $\mathrm{S}$ e $\mathrm{Mg}$ presentes nos grãos de café crú são em média de $0,13 \% \mathrm{~m} / \mathrm{m}$ para o $\mathrm{S}$ e 0,16 a $0,31 \% \mathrm{~m} / \mathrm{m}$ para $\circ \mathrm{Mg}$. Os valores encontrados estão bastante próximos aos relatados por esta referência. Contudo, as diferentes concentrações obtidas, principalmente o valor de $\mathrm{Na}$ nas amostras 13 e 14, podem ser devidos à região de origem do cultivo do grão de café e/ou diferentes processos na industrialização para obtenção do café solúvel.

\section{Elementos de concentracóes menores: micronutrientes}

Os micronutrientes se apresentaram nas seguintes faixas de concentrações, de acordo com a tabela XXII, página 95:

- Mn: 3,6 a $28 \mathrm{mgKg}^{-1}$, exceção da amostra $13\left(38,85 \mathrm{mgKg}^{-1}\right)$;

- Fe: 14 a $49 \mathrm{mgKg}^{-1}$ (76\% das amostras)

107 a $287 \mathrm{mg} \mathrm{Kg}^{-1}$ (4 amostras representando $19 \%$ do total)

$450,8 \mathrm{mg} \mathrm{Kg}^{-1}$ valor apresentado pela amostra 13; 
- Cu: 0,5 a 2,3 $\mathrm{mgKg}^{-1}$;

- Zn: 3 a $15 \mathrm{mgKg}^{-1}$.

No caso dos micronutrientes, DEBRY[4] relata que em média os teores presentes no café solúvel são os seguintes:

- Fe: $45 \mathrm{mgKg}^{-1}$

- Cu: $0,5 \mathrm{mgKg}^{-1}$;

- Zn: $5 \mathrm{mgKg}^{-1}$

SUZUKI et al. [22] relatam que a concentração do Cu é de $2,4 \mathrm{mgKg}^{-1}$. LARA et al.[16] trabalharam com o café bebida a partir da extração com água fervente do pó de café no qual apresentam o teor médio de $\mathrm{Cu}$ igual a $1,2 \mathrm{mg} \mathrm{Kg}^{-1}$. As amostras analisadas são bastante ricas em micronutrientes, com algumas apresentando teores elevados de determinados elementos. Em termos de concentrações presentes a níves de contaminação, a legislação brasileira [3] fixa valores máximos entre os micronutrientes apenas para o $\mathrm{Cu}\left(30 \mathrm{mg} \mathrm{Kg}^{-1}\right)$ e $\mathrm{Zn}\left(50 \mathrm{mg} \mathrm{Kg}^{-1}\right)$, nenhuma das amostras portanto, apresentam valores próximos a estes.

O Fe foi o que apresentou maior variação com teores altos em 5 amostras. Da mesma maneira que o $\mathrm{Na}$, a concentração presente deste elemento deve estar provavelmente relacionada com o tipo de solo onde foi cultivado o café e/ou pelas diferenças de processos industriais de obtenção do produto.

Considerando o consumo diário de 1 copo de café (aproximadamente $200 \mathrm{~mL}$ correspondente a $2 \mathrm{~g}$ de café solúvel) podemos calcular a contribuição dos nutrientes para a Ingestão Diária Recomendada (IDR), definida como a quantidade de vitaminas, minerais e proteínas que deve ser consumida diariamente para atender às necessidades nutricionais da maior parte dos indivíduos e grupos de pessoas de uma população sadia, segundo a Portaria $n^{\circ} 33$ de 13 de janeiro de 1998 da Secretaria de Vigilância Sanitária do Brasil [70].

A tabela XXIII a seguir apresenta esta contribuição dos nutrientes $\mathrm{Ca}, \mathrm{P}, \mathrm{Mg}, \mathrm{Fe}, \mathrm{Zn}, \mathrm{Cu}$, Mn, Na e K. 
Tabela XXIII : contribuição da presença de nutrientes presentes em amostras de café solúvel do mercado brasileiro para a Ingestão Diária Recomendada (IDR) de adultos e crianças.

\begin{tabular}{|c|c|c|c|c|c|}
\hline Nutriente & $\begin{array}{c}\text { IDR-crianças } \\
7-10 \text { anos } \\
\text { (mg) }\end{array}$ & $\begin{array}{l}\text { IDR-Adultos } \\
11-50+\text { anos } \\
\text { (mg) }\end{array}$ & $\begin{array}{l}\text { Am. Café sol. } \\
\text { Nutrientes } \\
\text { (mg) }\end{array}$ & $\begin{array}{c}\text { contribuiçãa } \\
\text { IDR-crianças } \\
\text { (\%) }\end{array}$ & $\begin{array}{c}\text { Contribuição } \\
\text { IDR-adultos } \\
(\%)\end{array}$ \\
\hline${ }^{7} \mathrm{Ca}$ & 800 & 800 & 2,0 a 4,0 & 0,25 a 0,5 & 0,25 a 0,5 \\
\hline${ }^{1} \mathbf{P}$ & 800 & 800 & 4,0 a 8,0 & 0,5 a 1,0 & 0,5 a 1,0 \\
\hline${ }^{1} \mathrm{Mg}$ & 170 & 300 & 4,0 a 8,0 & 2,6 a 4,7 & 1,3 a 2,7 \\
\hline$\sqrt[7]{F e}$ & 10 & 14 & $\begin{array}{c}0,028 \text { a } 0,1 \\
0,21 \text { a } 0,57 \\
0,90 \text { (am13) }\end{array}$ & $\begin{array}{c}0,28 \text { a } 1 \\
2,1 \text { a } 5,7 \\
9,9(\text { am } 13)\end{array}$ & $\begin{array}{c}0,20 \text { a } 0,7 \\
1,5 \text { a } 4,1 \\
6,4 \text { (am 13) }\end{array}$ \\
\hline${ }^{1} \mathrm{Zn}$ & 10 & 15 & $\begin{array}{c}0,0060 \mathrm{a} \\
0,03\end{array}$ & 0,06 a 0,3 & 0,04 a 0,2 \\
\hline${ }^{1} \mathrm{Cu}$ & $\begin{array}{c}\text { Média } 1,5 \\
1,0 \text { a } 2,0\end{array}$ & 3,0 & $\begin{array}{c}0,0010 a \\
0,0046\end{array}$ & 0,07 a 0,31 & 0,03 a 0,15 \\
\hline${ }^{1} \mathrm{Mn}$ & $\begin{array}{c}\text { Média } 2,5 \\
2,0 \text { a } 3,0\end{array}$ & 5 & $\begin{array}{c}0,0072 \mathrm{a} \\
0,056\end{array}$ & 0,28 a 2,24 & 0,14 a 1,12 \\
\hline${ }^{2} \mathrm{Na}$ & 400 & 500 & $\begin{array}{c}0,6 \text { a } 4,0 \\
6,4 \text { (am13) } \\
13,4 \text { (am 14) }\end{array}$ & $\begin{array}{c}0,15 \text { a } 1 \\
1,6(\text { am 13) } \\
3,35 \text { (am 14) }\end{array}$ & $\begin{array}{c}0,12 \text { a } 0,8 \\
1,3 \text { (am 13) } \\
2,70 \text { (am 14) }\end{array}$ \\
\hline${ }^{2} K$ & 1600 & 2000 & 70 a 104 & 4,4 a 6,5 & 3,5 a 5,2 \\
\hline
\end{tabular}

Fonte: Portaria $n^{\circ} 33$, de 13 de janeiro de 1998 [70];

${ }^{2}$ Fonte: Foods \& Nutrition [71].

De uma maneira geral, considerando o consumo diário de 1 copo de café solúvel, a contribuição dos nutrientes $\mathrm{Ca}, \mathrm{P}, \mathrm{Mg}, \mathrm{Fe}, \mathrm{Zn}, \mathrm{Cu}, \mathrm{Mn}, \mathrm{Na}$ e $\mathrm{K}$ para a Ingestão Diária recomendada (IDR) é de 2,1 a $3,4 \%$ para crianças ( 7 a 10 anos) e 1,8 a $2,9 \%$ para adultos (sendo a faixa de idade de 11 a 50+ anos). Contudo, é necessário um estudo complementar da biodisponibilidade destes nutrientes presentes no café solúvel.

\section{Elementos contaminantes}

Os elementos considerados como contaminantes inorgânicos apresentaram-se nas seguintes concentraçōes:

- Al: não detectado ao nível de $5,0 \mathrm{mgKg}^{-1}$ (57\% das amostras);

16 a $38 \mathrm{mgKg}^{-1}$ (5 amostras representando $24 \%$ do total das amostras);

119 a $233 \mathrm{mg} \mathrm{Kg}^{-1}$ (4 amostras representando $19 \%$ do total das amostras).

- Sn: 6 a $12 \mathrm{mgKg}^{-1}$; 
- Ni: não detectado ao nível de $2,50 \mathrm{mgKg}^{-1}$;

- Cd: não detectado ao nível de $0,25 \mathrm{mgKg}^{-1}$;

- Sb: não detectado ao nível de $2,00 \mathrm{mgKg}^{-1}$;

- Cr: não detectado ao nivel de $0,1 \mathrm{mgKg}^{-1}$;

- $\mathrm{Pb}$ : não detectado ao nivel de $0,45 \mathrm{mgKg}^{-1}$;

Apesar de um grupo de amostras apresentar teores variados do $\mathrm{Al}$, o valor definido pela legislação brasileira [3] é de no máximo $2 \% \mathrm{~m} / \mathrm{m}$, portanto bem acima do que aqueles encontrados nas diferentes amostras analisadas. $\mathrm{O}$ trabalho de $\mathrm{KOCH}$ et al. [20] relata a presença de Al em café para infusão na faixa de 20,7 a $30,6 \mathrm{mgKg}^{-1}$, estando próximo à faixa de 16 a $38 \mathrm{mgKg}^{-1}$ encontrados em 5 amostras.

O teor de $\mathrm{Sn}$ (6 a $\left.12 \mathrm{mgkg}^{-1}\right)$ está abaixo do limite especificado pela legislação brasileira [3], com valor máximo de $150 \mathrm{mgKg}^{-1}$.

Os valores definidos pela legislação brasileira [3] para os demais elementos são:

- Ni: $5,00 \mathrm{mgKg}^{-1}$ máximo;

- Sb: $2,00 \mathrm{mgKg}^{-1}$ máximo;

- Cd: $1,00 \mathrm{mgKg}^{-1}$ máximo;

- Cr: $0,10 \mathrm{mgkg}^{-1}$ máximo;

- Pb: $1,00 \mathrm{mgKg}^{-1}$ máximo:

- As: $1,00 \mathrm{mgKg}^{-1}$ máximo;

- Se: $0,30 \mathrm{mgKg}^{-1}$ máximo;

- Hg: 0,01 $\mathrm{mgKg}^{-1}$ máximo.

$\mathrm{Ni}, \mathrm{Sb}, \mathrm{Cd}, \mathrm{Cr}, \mathrm{Pb}, \mathrm{As}$, Se e $\mathrm{Hg}$ não foram detectados aos niveis de concentrações definidos pela legislação brasileira [3] com exceção do $\mathrm{Cr}$ na amostra 13. O valor encontrado deste elemento, $0,52 \pm 0,02 \mathrm{mgKg}^{-1}$, indica contaminação do produto, pois o teor presente é 5 vezes maior que o valor permitido. Grande probabilidade da fonte de contaminação pode ser atribuído a embalagem utilizada pelo fabricante, pois trata-se de recipiente de metal. A figura 74 a seguir apresenta o gráfico de varredura da amostra 13 enriquecida com quantidades 
conhecidas de $\mathrm{Cr}$, sendo: branco, amostra 13 , amostra $13+0,1 \mu \mathrm{gCr} / \mathrm{mL}$, amostra $13+$ $0,5 \mu \mathrm{gCr} / \mathrm{mL}$ e padrão de $1 \mu \mathrm{gCr} / \mathrm{mL}$.

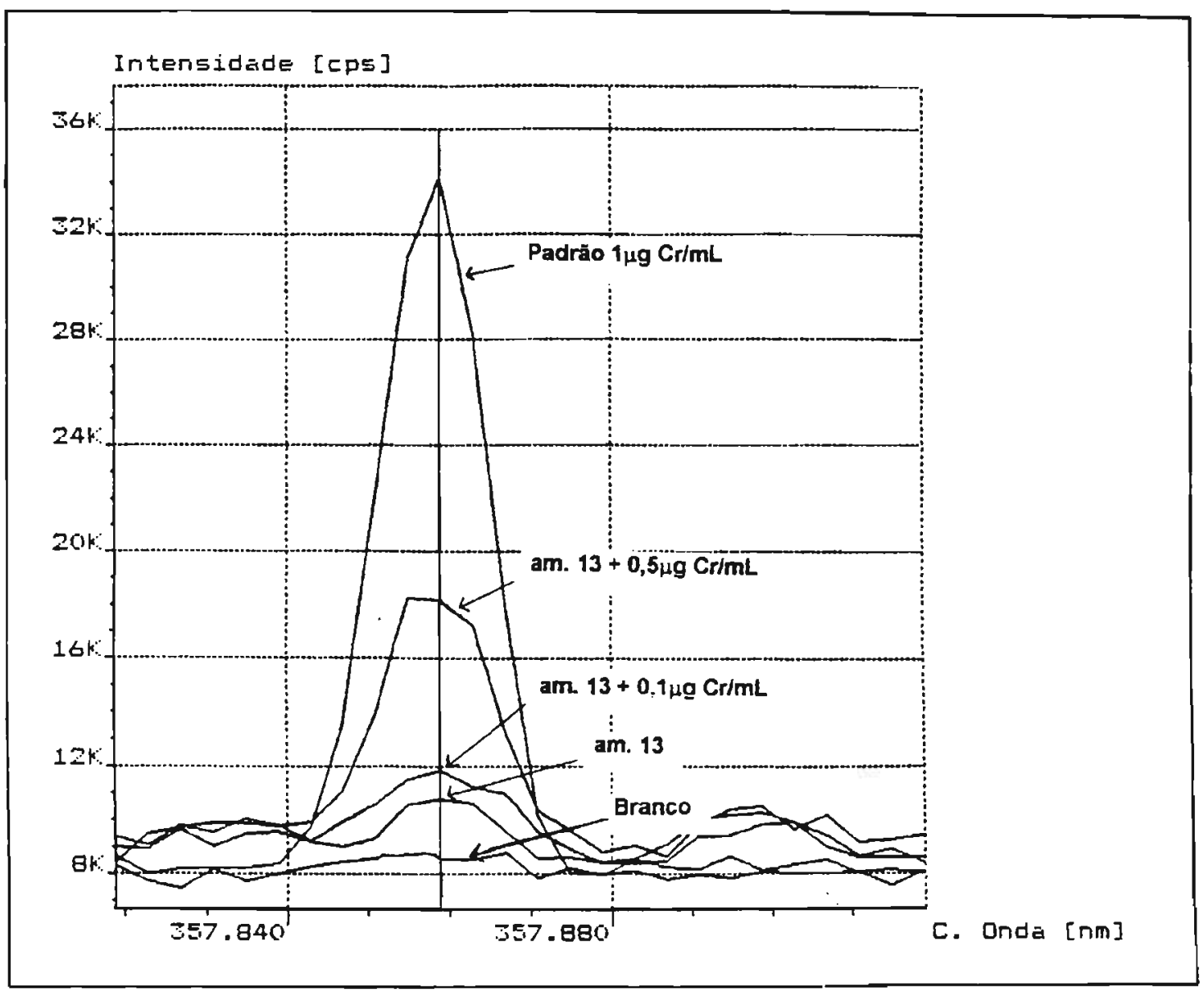

Figura 74 - espectro de varredura do $\mathrm{Cr}$ na amostra 13 (espectrômetro Modula da Spectro).

\subsection{Análise de componentes principais e cluster hierárquicos aos dados de concentrações referentes aos elementos $\mathrm{Na}, \mathrm{K}, \mathrm{Mg}, \mathrm{Al}, \mathrm{P}, \mathrm{S}, \mathrm{Ca}, \mathrm{Mn}, \mathrm{Fe}, \mathrm{Sn}, \mathrm{Cu}$ e Zn}

As ferramentas estatísticas análise de componentes principais e cluster hierárquicos foram aplicados aos dados de concentrações da tabela XXII, página 95, referentes aos elementos $\mathrm{Na}, \mathrm{K}, \mathrm{Mg}, \mathrm{Al}, \mathrm{P}, \mathrm{S}, \mathrm{Ca}, \mathrm{Mn}, \mathrm{Fe}, \mathrm{Sn}, \mathrm{Cu}$ e Zn. Os elementos As, Se, Ni, Cd, Sb, $\mathrm{Cr}$ (exceção amostra 13), $\mathrm{Pb}$ e Hg não foram detectados aos níveis dos limites de determinação e por isto não foram relacionados aos dados para as análises estatísticas. 


\section{Análise de componentes principais}

As tabelas XXIV, XXV e XXVI a seguir apresentam os dados referentes a estatística final após a aplicação do software estatístico SPSS para windows [62]

Tabela XXIV: Estatística final

\begin{tabular}{|l|l|l|l|c|c|c|c|}
\hline Variavel & Comunalidade & variavel & comunalidade & fator $^{{ }^{\top}}$ & Autovalor $^{3}$ & $\begin{array}{c}\% \\
\text { variância }^{4}\end{array}$ & $\begin{array}{c}\text { \% variância } \\
\text { acumulada }^{5}\end{array}$ \\
\hline $\mathrm{Al}$ & 0,88972 & $\mathrm{Mn}$ & 0,85659 & $\mathbf{1}$ & 4,94472 & $\mathbf{4 1 , 2}$ & 41,2 \\
\hline $\mathrm{Ca}$ & 0,85482 & $\mathrm{Na}$ & 0,76652 & $\mathbf{2}$ & 2,55101 & 21,3 & 62,5 \\
\hline $\mathrm{Cu}$ & 0,72296 & $\mathrm{P}$ & 0,83297 & $\mathbf{3}$ & 1,57159 & 13,1 & 75,6 \\
\hline $\mathrm{Fe}$ & 0,93118 & $\mathrm{~S}$ & 0,78528 & $\mathbf{4}$ & 1,02759 & 8,6 & 84,1 \\
\hline $\mathrm{K}$ & 0,86480 & $\mathrm{Sn}$ & 0,83198 & & & & \\
\hline $\mathrm{Mg}$ & 0,88983 & $\mathrm{Zn}$ & 0,86826 & & & & \\
\hline
\end{tabular}

- comunalidade ${ }^{1}$ - refere-se à porcentagem da variância que é explicada (para cada variável) pelos componentes

- Fatores (ou componentes) ${ }^{2}$ - estão sendo interpretados como os possíveis fatores que influenciam a composição das amostras no caso do presente trabalho.

- Autovalor ${ }^{3}$, porcentagem de variância ${ }^{4}$ e porcentagem de variância acumulada ${ }^{5}$ - para escolher o número de componentes necessários para explicar os dados obtidos deve-se observar a porcentagem total da variância que é explicada pelos componentes. Os autovalores representam a variância total explicada em cada componente. Por exemplo o componente 1 possui autovalor igual a 4,94472, o qual representa $41,2 \%$ da variância total (coluna de porcentagem de variância $\left.{ }^{4}\right)$. A última coluna, porcentagem de variância acumulada ${ }^{5}$ indica a porcentagem de variância atribuida ao respectivo componente somada aos seus valores precedentes.

Na tabela XXV, página 108, as matrizes dos fatores (ou matriz dos componentes) são colocadas as variáveis e os valores dos pesos dos componentes que indicam qual é o peso atribuído a cada componente para explicar cada variável. A análise da influência de cada fator ou componente para explicar as variáveis foi realizada observando-se esta tabela com a figura 75 que mostra o gráfico: escores do componente 1 versus escores do componente 2 onde temos a maior porcentagem $(62,5 \%)$ das variâncias explicadas. No presente trabalho foram considerados os valores dos pesos mais significativos iguais a no mínimo 0,7 (positivo ou 
negativo). Assim, no componente 1 encontramos os maiores pesos para os elementos $\mathrm{Fe} \mathrm{e} \mathrm{Al}$ (correlação positiva) e Mg e P (correlação negativa) e no componente $2 \mathrm{Ca}$, Cu e S (correlação positiva). Os escores são apresentados na tabela XXIV e são estes valores que relacionam as amostras com os componentes.

Tabela XXV: matriz dos fatores ou componentes

\begin{tabular}{|l|c|c|}
\hline Variáveis & componente 1 & Componente 2 \\
\hline $\mathrm{Mg}$ & $-0,93592$ & 0,06870 \\
\hline $\mathrm{P}$ & $-0,86713$ & 0,07400 \\
\hline $\mathrm{Fe}$ & 0,81700 & 0,29990 \\
\hline $\mathrm{Al}$ & 0,79190 & 0,16054 \\
\hline $\mathrm{Ca}$ & 0,20632 & 0,88537 \\
\hline $\mathrm{Cu}$ & 0,02729 & 0,77325 \\
\hline $\mathrm{S}$ & $-0,48162$ & 0,73450 \\
\hline $\mathrm{Mn}$ & 0,45678 & 0,55238 \\
\hline $\mathrm{Zn}$ & 0,13529 & 0,15876 \\
\hline $\mathrm{K}$ & 0,36803 & 0,21419 \\
\hline $\mathrm{Na}$ & 0,1764 & 0,01747 \\
\hline $\mathrm{Sn}$ & 0,60340 & $-0,01548$ \\
\hline
\end{tabular}

Tabela XXVI: escores dos componentes relacionados com as amostras

\begin{tabular}{|l|c|c|}
\hline Amostras & escores (componente 1) & Escores (componente 2) \\
\hline 01 & 0,18338 & 0,03925 \\
\hline 02 & 0,11665 & $-0,51596$ \\
\hline 03 & $-0,02394$ & 0,06957 \\
\hline 04 & $-0,60607$ & 1,55175 \\
\hline 05 & $-0,86742$ & 1,62086 \\
\hline 06 & $-1,73767$ & 1,04038 \\
\hline 07 & 1,05924 & $-1,05783$ \\
\hline 08 & $-0,96920$ & $-1,17459$ \\
\hline 09 & 1,03086 & 0,21963 \\
\hline 10 & $-0,57496$ & 0,61732 \\
\hline 11 & $-0,06859$ & $-1,02306$ \\
\hline 12 & 0,03734 & $-0,99347$ \\
\hline 13 & 2,72770 & 1,47715 \\
\hline 14 & 0,28052 & $-1,66244$ \\
\hline 15 & 1,82712 & 0,66130 \\
\hline 16 & $-0,08502$ & $-0,58418$ \\
\hline 17 & 0,06711 & $-0,98180$ \\
\hline 18 & $-0,65050$ & 0,85638 \\
\hline 19 & $-0,48261$ & $-0,79371$ \\
\hline 20 & $-0,51304$ & 0,76177 \\
\hline 21 & $-0,75089$ & $-0,12834$ \\
\hline
\end{tabular}


$\mathrm{Na}$ figura 75 onde temos $62,5 \%$ da variância total do sistema explicado, observa-se que a maioria das amostras possuem composiçōes diferentes umas das outras resultando em uma certa dispersão no plano definido pelos componentes 1 e 2. A amostra 13 é a que se destaca pela separação em relação as demais devido a sua alta correlação positiva com os dois componentes. Esta amostra é rica em minerais, se destacando pelo valor de concentração maior dos elementos $\mathrm{Na}, \mathrm{Al}, \mathrm{Ca}, \mathrm{Mn}$ e $\mathrm{Fe}$ e ao contrário das demais que foram produzidas nos estados do Paraná, São Paulo e Minas Gerais, esta é a única amostra de origem do estado do Espirito Santo, evidenciando condiçōes diferentes do solo onde é cultivado o café elou provavelmente diferenças no processo industrial para a obtenção do café solúvel.

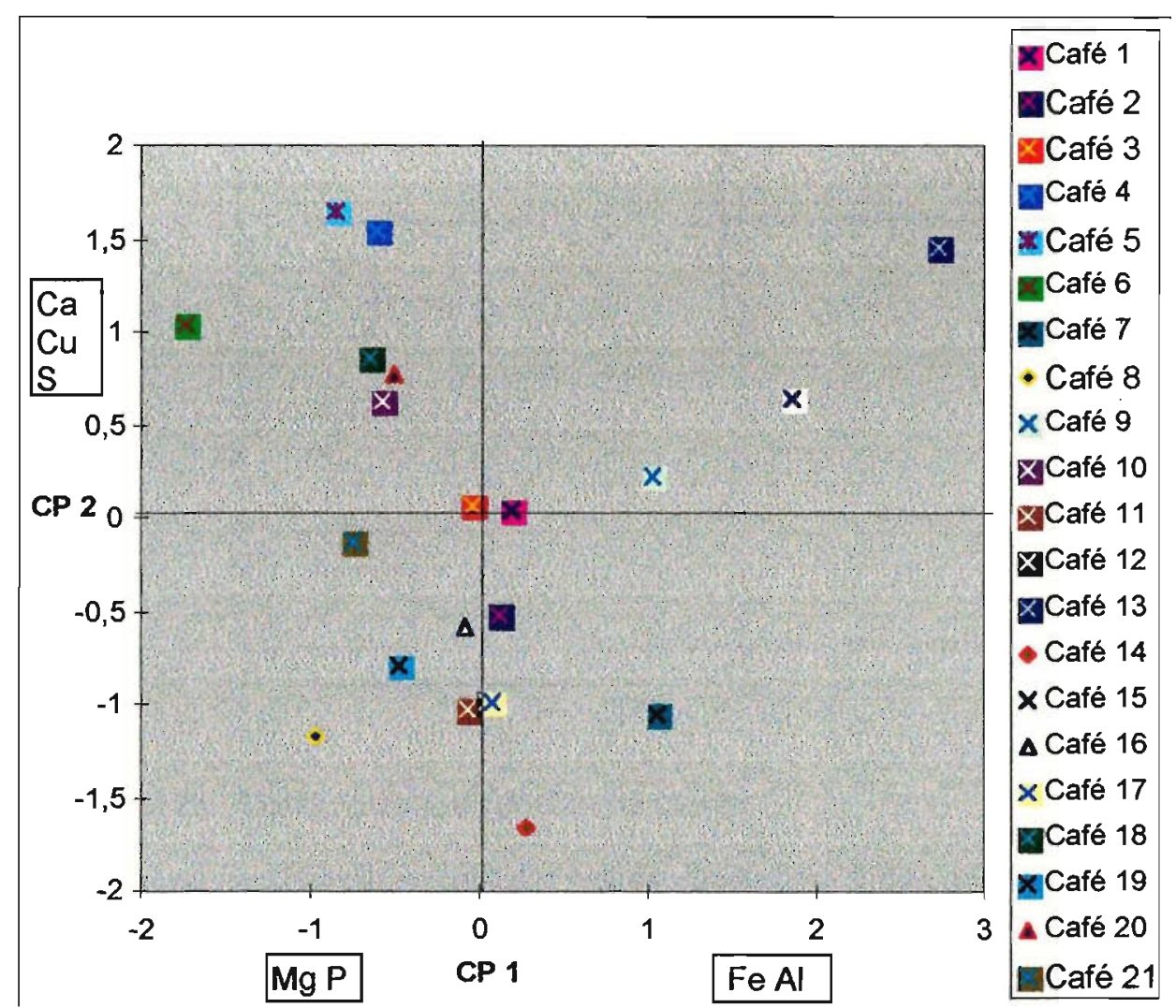

Figura 75: análise de componentes principais - componente 1 versus componente 2. 


\section{Análise de Clusters hierárquicos}

A figura 76 apresenta o dendrograma que mostra como ocorrem os agrupamentos após aplicação do método de Ward através do programa computacional SPSS para windows [62] aos dados de concentração da tabela XXII, página 95. A escala superior do dendrograma vai de 0 a 25 (linha pontilhada) a qual serve para o observador ter uma idéia das distâncias em que ocorrem os agrupamentos.

\section{Distância entre clusters reescalonada}

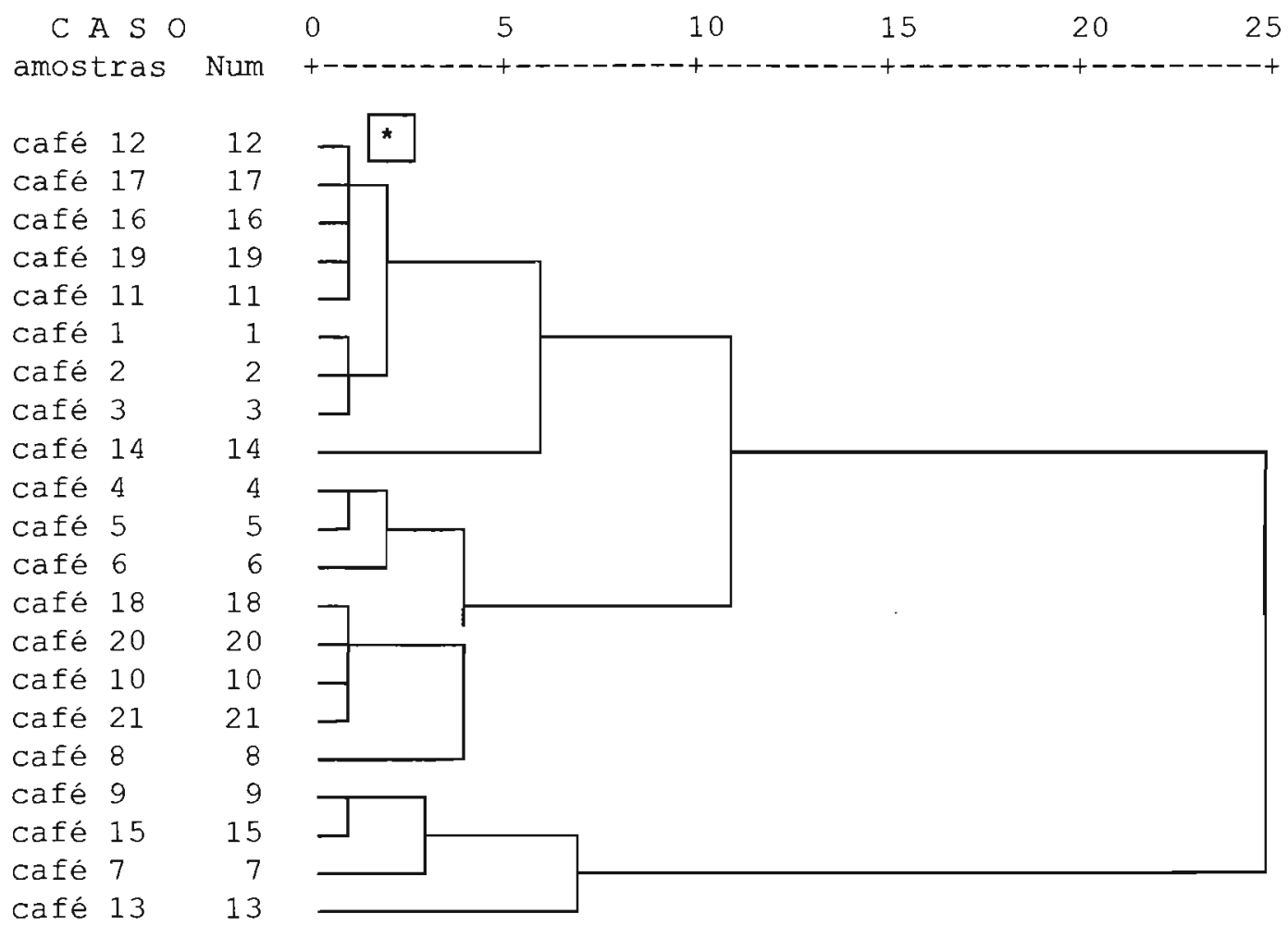

Figura 76 - Dendrograma da análise de cluster

A análise de clusters no estágio representado por (*) nos revela 10 clusters principais cluster 1 agrupando as amostras 12,17,16 19 e 11; cluster 2 com as amostras 1, 2 e 3; cluster 3 a amostra 14; cluster 4 as amostras 4 e 5; cluster 5 a amostra 6; c/uster 6 as amostras 18, 20,10 e 21; cluster 7 a amostra 8; cluster 8 as amostras 9 e 15; cluster 9 a amostra 7 e o cluster 10 a amostra 13. Os clusters 1, 2, 4, 6 (amostras 18 e 20) e 8 possuem amostras que 
estão disponiveis no mercado com nomes elou embalagens diferentes, porém cada cluster com seu respectivo conjunto de amostras são de um mesmo produtor. Assim por exemplo as amostras 12,17, 16, 19 e 11 do cluster 1 , são todas produzidas pelo mesmo produtor, mas disponiveis no mercado em embalagens e/ou nomes diferentes e apresentam portanto uma composição mineral semelhante entre elas porém diferente das amostras de outros produtores. A análise de clusters também nos revela que a amostra 13 é a que apresenta menos semelhança com as demais. A figura 77 apresenta a análise de componentes principais onde temos os escores do componente 1 versus os escores do componente 2 com a identificação dos clusters obtidos do dendrograma na figura 76. Uma boa concordância entre estas duas ferramentas estatisticas é observada considerando que o componente 1 versus o componente 2 explicam $62,5 \%$ da variância total apresentada na análise dos constituintes minerais presentes nas amostras de café solúvel.

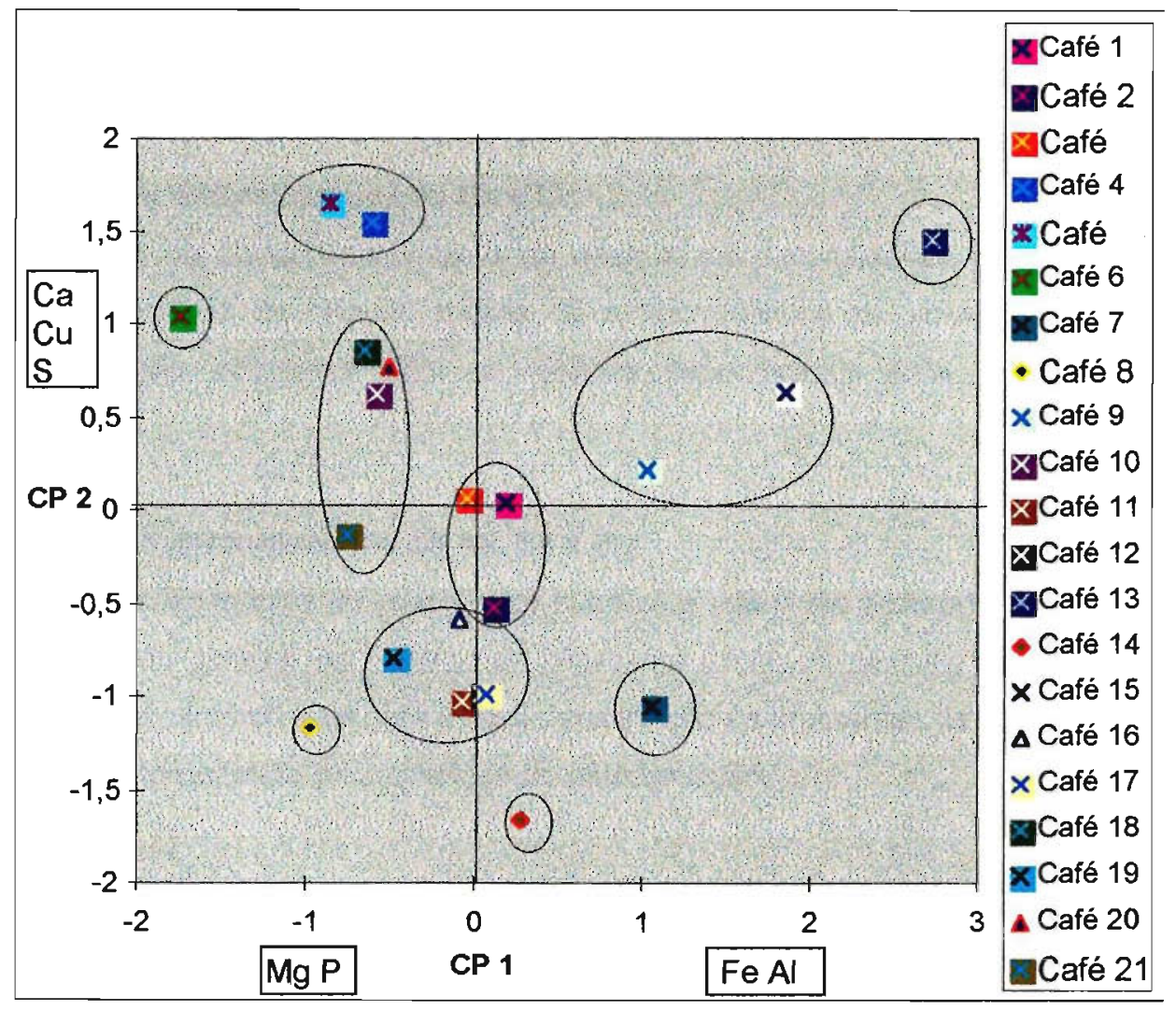

Figura 77 - Análise de componentes principais - componente 1 versus componente 2 com a identificação dos clusters obtidos do dendrograma na figura 18. 


\subsection{CONCLUSÕES}

\section{- Quanto aos métodos de mineralizações}

Nas determinações dos elementos $\mathrm{Na}, \mathrm{K}, \mathrm{Mg}, \mathrm{Al}, \mathrm{P}, \mathrm{S}, \mathrm{Ca}, \mathrm{Mn}, \mathrm{Fe}, \mathrm{Sn}, \mathrm{Ni}, \mathrm{Cu}, \mathrm{Zn}, \mathrm{Cd} \mathbf{S b}$ e no tratamento inicial para análise do As e Se, a utilização do sistema microondas focalizado empregando $\mathrm{HNO}_{3}$ e $\mathrm{H}_{2} \mathrm{O}_{2}$ permitiu uma mineralização rápida e eficiente das amostras utilizando poucas quantidades destes reagentes em um tempo de somente 15 minutos. $\mathrm{O}$ mesmo sistema de microondas focalizado empregando $\mathrm{HNO}_{3}$ e $\mathrm{H}_{2} \mathrm{O}_{2}$, apesar de consumir maior tempo e menor potência, também foi eficiente na mineralização das amostras de café solúvel onde foram determinados os elementos $\mathrm{Pb}, \mathrm{Cr}$ e $\mathrm{Hg}$, o que foi comprovado através dos valores aceitáveis de recuperação em amostras enriquecidas com quantidades conhecidas destes analitos.

- Quanto às determinaçðes de Na, K, Mg, Al, P, S, Ca, Mn, Fe, Ni, Cu, Zn, Cd e Sb

A determinação destes elementos não apresentou problemas de interferências de matriz e/ou espectral sendo que os resultados obtidos apresentaram-se com niveis satisfatórios de precisāo e exatidão.

\section{- Quanto à determinação de Sn}

A correção da radiação de fundo possibilitou a determinação deste analito com segurança.

\section{- Quanto às determinações de $\mathrm{Pb}$ e $\mathrm{Cr}$}

A escolha de comprimentos de onda alternativos possibilitaram as suas determinações e com o aumento da relação massa de amostra/volume de solução atingiu-se limites de determinação coerentes com os valores especificados pela legislação brasileira de alimentos.

\section{- Quanto ás determinaçð̃es de As, Se e Hg}

O emprego da técnica de geração de hidretos e vapor frio acoplado ao ICP-AES através da utilização do gerador de hidretos ou separador de fases, permitiu as determinações de As, Se e $\mathrm{Hg}$ nas amostras de café solúvel, eliminando os problemas de interferências de matriz e espectral, fornecendo baixos limites de determinação.

\section{- Quanto aos resultados gerais obtidos}

A maior parte das amostras de café solúvel do mercado brasileiro se apresentam com composições minerais variadas. A aplicação das ferramentas estatísticas análise de clusters hierárquicos e componentes principais possibilitaram mais facilmente a identificação e 
visualização das amostras com diferentes composições minerais, agrupando as mais similares e relacionando os elementos químicos de maior contribuição para estas diferenças. Estas variações de composições minerais presentes nas amostras de café solúvel, podem ser devidas a diferenças existentes no processo de obtenção industrial do produto e/ou a fatores que influenciam no cultivo da planta do café, como o tipo de solo, o uso de corretivos com diferentes composições químicas e condiçōes ambientais a que estão sujeitas as plantações. Assim, mesmo as amostras onde ocorreram maiores similaridades indicando serem pertencentes a um mesmo produtor, as composições minerais não foram as mesmas apresentando pequenas diferenças. Contudo os valores se apresentaram aceitáveis para o consumo humano, tanto no aspecto nutricional como toxicológico com exceção de uma amostra com teor de $\mathrm{Cr}$ acima do permitido pela legislação brasileira [3], sendo que a fonte de contaminação pode ser atribuída a embalagem de metal desta marca de café solúvel. 


\subsection{SUGESTŐES PARA TRABALHOS FUTUROS}

- Estudo da aplicação da técnica de geração de hidretos na determinação do Sb;

- Ampliação do número de amostras de café solúvel a serem analisadas e dos elementos nutrientes pesquisados, tais como o B, l', $\mathrm{F}^{-}$e Mo:

- Estudo e identificação das principais origens dos nutrientes e/ou possíveis fontes de contaminação por elementos tóxicos iniciando-se a pesquisa desde a plantação e cultivo até o processo de industrialização do café solúvel;

- Estudo da biodisponibilidade dos nutrientes presentes no café solúvel. 


\section{REFERÉNCIAS BIBLIOGRÁFICAS ${ }^{1}$}

[1] - SILVA, Paulo. O Mercado de Café no Brasil. In:REVISTA ALIMENTOS \& TECNOLOGIA, $\mathrm{n}$. 64. São Paulo, p.26-30. 1996.

[2] - OLIVEIRA, Elisabeth. Espectrometria de Emissão Atômica de Plasma de Argônio Induzido. In: I ENCONTRO NACIONAL SOBRE CONTAMINANTES INORGÂNICOS EM ALIMENTOS, 1988 : São Paulo. Anais, São Paulo, SP: Instituto Adolfo Lutz, 1988.

[3] - Compêndio da Legislação de Alimentos - Atos do Ministério da Saúde. In: ADITIVOS INCIDENTAIS, v.1, capítulo 3, resolução nº 4, 1988.

[4] - DEBRY, Gerard. Coffee and Health. Paris: John Libbery Eurotext,1994.

[5]-MASSON, Maria Lúcia; SOCCOL, Carlos Ricardo; VASSÃO, Eloise et al. Tecnologia do Café Solúvel I. Boletim do Centro de Processamento de Alimentos (CEPPA), UFPR, Curitiba, PR, v. 2 (2), p.1-16,1984.

[6]- QUAST, Dietrich G. Tecnologia do Café Solúvel. Boletim do Centro Tropical de Pesquisas e Tecnologia de Alimentos, Campinas, SP, v. 14,p.37-70, 1968.

[7] - JARDINE, José Gilberto; MORETTI, Roberto Hermínio. Tratamento Enzimático de Café para Redução da Viscosidade visando a obtenção de Café Solúvel. Boletim da Sociedade Brasileira de Ciência e Tecnologia de Alimentos, v. 27(1), p. 14-23, 1993.

[8] - MASSON, Maria Lúcia; CARLOS, Ricardo Soccol; VASSÃO, Eloise et al. Tecnologia do Café Solúvel II. Boletim do Centro de Processamento de Alimentos (CEPPA), UFPR, Curitiba, PR, v. 3 (1), p.13-20, 1985.

[9] - ENCICLOPÉDIA Mirador internacional . São Paulo: Encyclopaedia Britannica do Brasil, V.5, 1976.

[10] - OLIVEIRA, Elisabeth.Preparação de Amostras em Absorção Atômica.CG Instrumentos Instrumentos Científicos, Boletim Técnico, São Paulo, SP, 1991.

[11]-ASSOCIATION OF OFFICIAL ANALYTICAL CHEMISTS (AOAC). Official Methods of Analysis, 15th Ed. Arlington, USA, v.1, p.237-242,1990.

[12] - MATUSIEWICZ, H.; STURGEON, R.E.;BERMAN,S.S. Trace Element Analysis of Biological Material Following Pressure Digestion with Nitric Acid-Hydrogen Peroxide and Microwave Heating. Journal of Analytical Atomic Spectrometry, v.4,p.323-327,1989.

[13] - MUNILLA, M.;GOMEZ-PINILLA,I;; RODENAS,S.; LARREA,M.T. Determination of Metals in Seaweeds used as Food by Inductively Coupled Plasma Atomic-Emission Spectrometry. Analusis,v.23,p.463-466, 1995.

[14] - De La GUARDIA, M.; CARBONELLI, V.; MORALES-RUBIO , A.; SALVADOR, A. On-line Microwave - Assisted Digestion of Solid Samples for their Flame Atomic Spectometric Analysis. Talanta, v.40,11,p.1609-1617,1993.

${ }^{1}$ De acordo com a Norma NBR $6023 / 89$ preconizada pela Associação Brasileira de Normas Técnicas - ABNT. 
[15] - HORWITZ, C.; VAN DER LINDEN, S. E. Cadmium and Cobalt in Tea and Coffee and their Relationship to Cardiovascular Disease. S. Afr. Medical Journal, v. 48,p. 230 $233,1974$.

[16] - LARA, H.M.; TOLEDO, M.; TAKAHASHI. Teores de Cobre em Café Torrado e Moído e em Café Bebida. Revista Instituto Adolfo Lutz, v. 35/36, p. 17-22, $1975 / 76$.

[17] - KRIVAN, V.; BARTH, P.; MORALES, A. F. Multielement Analysis of Green Coffee and its Possible Use for the Determination of Origin. Mikrochimica Acta,v.110, p.217-236, 1993.

[18] - ORLIC, I.; MAKJANIC, J.; VALKOVIC, V. Optimization of XRFS for the Analysis of toxic Elements and Heavy Metals in Coffee Products. Journal of Radioanalytical and Nuclear Chemistry, v. 102, p.203-210, 1986.

[19] - KAPUR, J. K.; WEST T. S. Determination of Lead in Instant Coffee and Tea Powders by by Carbon Filament Atomic Absorption Spectrometry. Analytical Chimica Acta, v.73,p.180-184, 1974.

[20] - KOCH, K.R.; POUGNET, M.A.B.; STEPHANIE De VILLIERS. Determination of Aluminium Levels in Tea and Coffee by Inductively Coupled Plasma Emission Spectrometry and Grafite Furnace Atomic Absorption Spectrometry.Analyst, v. 114, p. 911-913, 1989.

[21] - KUENNEN, R. W.; HAHN, M. H.; FRICKE, F. L.; WOLNIK, K. A Hydride Generation and Condensation Flame Atomic Absorption Spectroscopic Determination of Antimony in Raw Coffee Beans and Processed Coffee. Journal of Association of Official Analytical Chemists, v. 65 (5), p.1146 - 1149, 1982.

[22] - SUZUKI, M.; OHTA,K.; KATSUNO,T. Determination of Traces of Lead and Copper in Foods by Electrothermal Atomic Absorption Spectrometry with Metal Atomizer. Mikrochimica Acta, v. II, p.225-230, 1982.

[23] - GILLIES, M. E.; BIRKBECK, J. A. Tea and Coffee as Sources of Some Minerals in the New Zealand Diet. American Journal of Clinical Nutrition, v. 38, p.936 -942, 1983.

[24] - AMERICAN SOCIETY FOR METAL - ACM HANDBOOK. Material Characterization, v.10 p. 31-42, 1986.

[25] - GREENFIELD,S; JONES,I. L; BERRY, CT. High-Pressure Plasmas as Spectroscopic Emission Source. Analyst, v.89, p.713-720,1964.

[26] - FASSEL, V.A.; WENDT, R.H. Induction-Coupled Plasma Spectrometric Excitation Source Analytical Chemistry, v.37, p.920-922,1965.

[27] - OL_IVEIRA, Elisabeth. Espectrometria de Emissão Atómica (ICP-AES).Universidade de São Paulo, USP, Laboratório de Espectrometria de Emissão Atômica (apostila), 1996.

[28] - GINÉ, M.F. Análises Químicas por Espectrometria de Plasma com Detetor de Massa. XXXVI Congresso Brasileiro de Química, ABQ, apostila do curso 02, 1996.

[29] - BOSS, C. B.;FREDEEN, K.J.Concepts, Instrumentation, and Techniques in Inductively Coupled Plasma Atomic Emission Spectrometry. Perkin Elmer Corporation, USA, 1989. 
[30]-THOMPSON, M.; WALSH, J. N. Handbook of Inductively Coupled Plasma Spectrometry. 2nd, New York, 1989.

[31] - KINGSTON, H. M.;JASSIE, L. B.Introduction to Microwave Sample Preparation. ACS, Washington, 1988.

[32]-OLIVEIRA, E. Solubilização de Amostras de Alimentos. In: IV ENCONTRO NACIONAL SOBRE CONTAMINANTES INORGÂNICOS EM ALIMENTOS, 1994: São Paulo. Anais, São Paulo, SP: Instituto Adolfo Lutz, 1994.

[33] - RUSSEL, J. B. Química Geral. McGroaw-Hill, São Paulo, 1982.

[34]-GENERAL GUIDELINES FOR MICROWAVE SAMPLE PREPARATION. CEM Corporation, 1988.

[35] - VOGEL, Arthur I. Química Analítica Qualitativa.Ed. 5. Mestre Jou. São Paulo, SP. p.252$256,1981$.

[36] - FURMAN, N. N. Standard Methods of Chemical Analysis. Ed. 6. v.1: The Elements. USA, 1965.

[37]- Standard Methods for the Examination of Water and Wastewater. 17th Edition. 1989.

[38] - BACCAN, Nivaldo. Técnicas de Geração de Hidretos em Espectrometria Atômica. In: IV ENCONTRO NACIONAL SOBRE CONTAMINANTES INORGÂNICOS EM ALIMENTOS, 1994: São Paulo. Anais, São Paulo, SP : Instituto Adolfo Lutz, 1994.

[39] - KAHN, H. L; SCHALLIS, J. Atomic Absorption Newsletter, 7, (5), 1968.

[40]-HOLAK, W. Gas - Sampling Techinique for Arsenic Determination by Atomic Absorption Spectrophotometry. Analytical Chemistry, v. 41(12), p.1712-1713, 1969.

[41] -CARUSO, J. A.; WOLNIKK.; FRICKE, F. Inductively Coupled Plasma in Analytical Atomic Spectrometry: Injection of Gaseous Samples into Plasmas. VHC, p. 487-525, 1987.

[42] - THOMPSON, M.; PAHLAVANPOUR, B.; WALTON, S. J. Simultaneous Determination of Trace Concentrations of Arsenic, Antimony, Bismuth, Selenium and Tellurium in Aqueous Solution by Introduction of the Gaseous Hydrides into an Inductively Coupled Plasma Source for Emission Spectrometry - Part II:Interference Studies. Analyst,v.103, p. 705-713, 1978.

[43] - LAJUNEN, L. H. Spectrochemical Analysis by Atomic Absorption and Emission. Royal Society of Chemistry. p. 117-125, England, 1992.

[44] - ROBBINS, W. B.; CARUSO,J.A. Development of Hydrides Generation Methods for Atomic Spectroscopic Analysis. Analytical Chemistry, v. 51 (8), p. 889A - 899A, 1979.

[45] - SCHIMIDT, F. J.; ROYER, J. L. Sub Microgram Determination of Arsenic, Selenium, Antimony and Bismuth by Absorption Utilizing Sodium Borohydrides Reduction. Analytical Letters, v.6 (1),p.17-23, 1973. 
[46] - POLLOCK, E. N.; WEST, S.J. The Generation and Determination of Covalent Hydrides by Atomic Absorption. Atomic Absorption Newsletter, v.12 (1),p.6-8, 1973.

[47] - FERNANDEZ, F.J. Atomic Absorption Determination of Gaseous Hydrides Utilizing Sodium Borohydride Reduction. Atomic Absorption Newsletter, v.12 (4),p.93-97, 1973.

[48] - THOMPSON, K. C.; THOMERSON, D.R.Atomic-Absorption Studies on the Determination of Antimony, Arsenic, Bismuth, Germanium, Lead, Selenium, Tellurium and Tin by Utilising the Generation of Covalent Hydrides. Analyst, v. 99,p. 595-601, 1974.

[49] - OLIVEIRA E., MCLAREN J. W., BERMAN S.S. Simultaneous Determination of Arsenic, Antimony, and Selenium in Marine Samples by Inductively Coupled Plasma Atomic Emission Spectrometry. Analytical Chemistry, v. 55 (13),p. 2047-2050, 1983.

[50] - PAHLAVANPOUR B., THOMPSON M., THORNE L. Simultaneous Determination of Trace Concentrations of Arsenic, Antimony and Bismuth in Soils and Sediments by Volatile Hydride Generation and Inductively Coupled Plasma Emission Spectrometry. Analyst, v. 105,p.756-761, 1980.

[51] - NAKAHARA T. Application of Hydride Generation to the Determination of Trace Concentrations of Arsenic by Inductively-Coupled Plasma Atomic Emission Spectrometry. Analytica Chimica Acta, v.131, p.73-82, 1981.

[52] - NYGAARD D. D., LOWRY J. H. Sample Digestion Procedures for Simultaneous Determination of Arsenic, Antimony, and Selenium by Inductively Coupled Argon Plasma Emission Spectrometry with Hydride Generation. Analytical Chemistry, v.54, p.803-807, 1982.

[53] - BRIMMER S.P.,FAWCETT W. R., KULHAVY K. A.Quantitative Reduction of Selenate lon to Selenite in Aqueous Samples. Analytical Chemistry, v. 59, p.1470-1471, 1987.

[54] -THOMPSON, M.; PAHLAVANPOUR, B.; WALTON, S. J. Simultaneous Determination of Trace Concentrations of Arsenic, Antimony, Bismuth, Selenium and Tellurium in Aqueous Solution by Introduction of the Gaseous Hydrides into an Inductively Coupled Plasma Source for Emission Spectrometry - Part I: Preliminary Studies. Analyst, v.103, p.568-579, 1978.

[55] - OZAKI, Elisa Ozaki; OLIVEIRA, Elisabeth.Simultaneous Determination of Arsenic, Bismuth, and antimony in Steels and Nickel Alloys by Inductively Coupled Plasma Atomic Emission Spectrometry with hydride Generation. Journal of Analytical Atomic Spectrometry,v.8, p. 367-370,1993.

[56] - QUIEIROZ, Isa Ramos. Determinação de Metilmercúrio em Peixes de Região de Garimpo, São Paulo, SP, 1985, Dissertação (Mestrado), Faculdade de Ciências Farmacêuticas, Universidade de São Paulo (USP).

[57] - CHRISTIAN, G. D.Analytical Chemistry. John Wiley \& Sons, p. 738,1994.

[58] - TOFFALETTII, J. ; SAVORY, J. Use of Sodium Borohydride for Determination of Total Mercury in Urine by Atomic Absorption spectrometry. Analytical Chemistry,v.47(13), p.2091-2095,1975. 
[59] - ROONEY, R.C. Use of Borohydride for Cold-vapour Atomic-absorption Determination of Inorganic Mercury. Analyst, v. 101 p. 678-682, 1976.

[60] - WELZ,B. Atomic Absorption Spectrometry, VHC, second edition, p.79-81, 1985.

[61] -THOMPSON,M; COLES, B.J.Enhanced Sensitivity in the Determination of Mercury by Inductively Coupled Plasma Atomic-emission Spectrometry. Analyst, v.109, p.529-530, 1984.

[62] -NORUSIS, N. J. SPSS for windows, professional statistics, release 6.0, SPSS-INC, USA, 1993.

[63] - KAUFMANN, A. Multivariate Statistics as a Classification Tool in the Food Laboratory. Journal of AOAC International, v.80 (3), p. 665-675, 1997.

[64] - MARQUEZ, K. S. G. Caracterização dos Componentes lônicos Solúveis do Aerossol Atmosférico da Serra do Navio-Amapá, São Paulo, SP, 1995, Dissertação (Mestrado), Instituto de Quimica, Universidade de São Paulo (USP).

[65] - BRUNS, ROY E.; FAIGLE,J.F.G. Quimiometria. Química Nova, abril, p.84-99, 1985.

[66]-ADAMS, MIKE J. Chemometrics in Analytical Spectroscopy. The Royal Society of Chemistry, p. 105-109,1985.

[67] - THOMPSON, M. Analytical Performance of Inductively Coupled Plasma Atomic Emission Spectrometry. In: MONTASER,A.; GOLIGHTLY, D.W. Inductively Coupled Plasmas in Analytical Atomic Spectrometry. New York: VHC publishers INC, p. 163-199, 1987

[68] - NAKASHIMA, S.;STURGEON, R.E.; WILLIE, S.N.; BERMAN, S.S. Acid Digestion of Marine Samples for Trace Elements Analysis using Microwave Heating. Analyst, v.113, p.159, 1988.

[69] - CARUSO,J.; WOLNIK, K.; FRICKE, F.L. Injection of Gaseous Samples into Plasmas. In: MONTASER,A.; GOLIGHTLY, D.W. Inductively Coupled Plasmas in Analytical Atomic Spectrometry. New York: VHC publishers INC, p.487-526, 1987

[70] - BRASIL. Portaria n³3, de 13 de Janeiro de 1998. Estabelece niveis de Ingestão Diária Recomendada (IDR) para vitaminas, minerais e proteinas, a ser utilizada como parâmetro de ingestão destes nutrientes por indivíduos e diferentes grupos populacionais. Diário Oficial da República Federativa do Brasil, Brasília, n 11-E, p. 5-6, 16 de Janeiro de 1998. Seção 1.

[71] - ENSMINGER, A.H.;ENSMINGER,M. E.;KONLANDE, J.;ROBSON,R.K. Foods \& Nutrition 2nd Edition, vol. 2 , CRC Press, London, 1994. 